\title{
OPOSICIONES A CÁTEDRAS DE DERECHO (1847-1943)
}

\author{
Edición de \\ JAVIER CARLOS DÍAZ RICO
}



OPOSICIONES A CÁTEDRAS DE DERECHO 
The Figuerola Institute

Programme: History of Universities

The Programme "History of Universities" of the Figuerola Institute of Social Science History -a part of the Carlos III University of Madrid- is devoted to improve the overall knowledge on the highlearning academic institutions, since their inception in the Late Middle Ages, until our days. The Programme uses an interdisciplinary approach, and it is open to all branches of related knowledge, such as the history of institutions, of science, and of cultural and social events. A number of experts from several countries have participated in the Programme, bringing in their specialized knowledge and dedication to the subject of their expertise.

To give a better visibility of its activities, the Programme has published in its Book Series a number of monographs on the different aspects of its academic discipline.

Publisher:

Carlos III University of Madrid

Book Series:

History of Universities

Editorial Committee:

Manuel Ángel Bermejo Castrillo, Universidad Carlos III de Madrid

Gianpaolo Brizzi, Alma Mater Studiorum - Università di Bologna

Elena Hernández Sandoica, Universidad Complutense de Madrid

Françoise Hiraux, Université catholique de Louvain

Manuel Martínez Neira, Universidad Carlos III de Madrid

More information at www.uc3m.es/history_universities 
OPOSICIONES A CÁTEDRAS DE DERECHO (1847-1943)

Javier Carlos Díaz Rico (ed.)

DYKINSON

2018 
Historia de las Universidades, 45

ISSN: 1886-0710

(C) 2018 Javier Carlos Díaz Rico

\section{Editorial Dykinson}

c/ Meléndez Valdés, 61 - 28015 Madrid

Tlf. (+34) 915442846

E-mail: info@dykinson.com

http://www.dykinson.com

Preimpresión: TALLERONCE

ISBN - 978-84-9148-852-1

Versión electrónica disponible en e-Archivo

http://hdl.handle.net/10016/27454

\section{(c) $(1)(8) \Theta$}

Licencia Creative Commons Atribución-NoComercial-SinDerivadas 3.o España 


\section{SUMARIO}

\section{Introducción}

25 Inventario documental

475 Índice onomástico

485 Índice de cátedras 



\section{INTRODUCCIÓN}

\section{Planteamiento}

Este trabajo ofrece un inventario documental de expedientes de oposiciones a cátedras de Derecho desde el año 1859 a 1941. La investigación se ha realizado en el marco del proyecto "La memoria del jurista español: génesis y desarrollo de las disciplinas jurídicas" (ref. DER 2014-55035-C2-1-P), financiado por el Ministerio de Economía, Industria y Competitividad (Gobierno de España).

Los autores de la catalogación de una parte de los expedientes son los siguientes: Carlos Petit, Esteban Conde, Aurora María López y Jesús Vallejoํㅜ. El resto de expedientes ha sido catalogado por Javier C. Díaz, ayudante de investigación de la Universidad de Huelva y doctorando de la misma universidad.

La fase inicial de la investigación fue desarrollada en abril y mayo de 2017 por Fernando Hernández Fradejas y Fernando Liendo en el Archivo General de la Administración. Estos investigadores se enfrentaron al catálogo primigenio del archivo, consistente en 1.085 registros. Tras el estudio del sistema de catalogación existente, fueron capaces de detectar las duplicidades y otros fallos del registro primigenio, al tiempo que aseguraban que ninguna información relevante se perdiera. Su labor fue imprescindible para poder proceder a la segunda fase, la inspección material de los expedientes, denominada comúnmente "vaciado", realizada mayormente entre los meses de febrero y agosto de 2018.

Los proyectos pioneros, "Ciencia y Universidad en Andalucía. E-Catálogo de Catedráticos, 1857-1943” y "De la enseñanza a la ciencia del derecho. E-catálogo de catedráticos, 1857-1943", ya pusieron a disposición de la comunidad de investigadores la página electrónica Diccionario de catedráticos españoles de Derecho (1847-1943)², con sus 565 biografías, entre otros materiales. Ahora se añade una nueva sección denominada "oposiciones", que

1 Concretamente con la catalogación de los siguientes legajos: Carlos Petit: 69822, 5337-1, 5337-12, 5337-15, 5337-2, 5337-3, 5337-8, 5337-9, 5336-18, 5336-26, 5336-29, 5337-32, 5337-33, 5337-47, 5337-50, 5337-51, 5337-52, 5338-21, 5338-24, 5338-28, 533829. Esteban Conde: 5339-30; 5342-18; 5342-24; 5342-31; 5342-29; 5345-19; 5346-14; 5349-1. Aurora María López: 5358-7, 5358-6; 5369-8; 5369-9. Jesús Vallejo: 6977-2.

2 http://www.uc3m.es/diccionariodecatedraticos 
alberga una hoja de cálculo con el inventario de los 302 expedientes catalogados. La hoja de cálculo contiene los respectivos hipervínculos a documentos en formato "pdf". Dicha hoja resultará particularmente útil a los investigadores teniendo en cuenta que el inventario consta de un número considerable de expedientes. Aquéllos podrán aprovechar las opciones de búsqueda y filtrado de la hoja de cálculo para seleccionar rápidamente el material de su interés, ya sea un periodo determinado, una universidad concreta o cierta cátedra.

Debido a que este inventario continúa las investigaciones iniciadas por estos proyectos y aprovecha los materiales científicos proporcionados por los mismos, se ha decidido que el título más adecuado para el mismo sea "Oposiciones a cátedras de Derecho (1847-1943)" sin perjuicio de que el inventario arranque en el año 1859, por razones que luego se expondrán.

$\mathrm{El}$ inventario se acompaña de tres índices. Un índice onomástico con los nombres de los catedráticos que ganaron cátedra. Un índice de cátedras, con sus distintas denominaciones según aparecen en los expedientes del archivo, las cuales podrían variar en algún caso respecto de las denominaciones que aparecen en los planes de estudio, debido a las inexactitudes administrativas propias de la época ${ }^{3}$. El tercer índice recoge los nombres de los jueces y adopta la forma de enlace digital a una hoja de cálculo ${ }^{4}$ También se añade un histograma que representa el número de anuncios de oposiciones por año, creciente durante todo el periodo, y con un apreciable aumento en los años 1900-1920.

Este inventario se concibe como un instrumento para el investigador interesado en explorar el surgimiento y evolución de la universidad liberal ${ }^{5}$. Los materiales inventariados resultarán muy útiles para explorar la selección del profesorado y la formación de las disciplinas jurídicas ${ }^{6}$, así como para em-

3 Pueden consultarse los diferentes planes de estudio vigentes en el periodo del inventario en Manuel Martínez Neira, El estudio del Derecho. Libros de texto y planes de estudio en la universidad contemporánea, Madrid, 2001.

4 La hoja de cálculo está depositada en el Consorcio Madroño: https://doi. org/10.21950/6HUTZ1

5 Sobre la concepción subyacente y las ventajas de este instrumento, Sebastián Martín, "De la enseñanza a la ciencia del derecho: biografía colectiva de juristas españoles (1857-1943)", en Cuadernos del Instituto Antonio de Nebrija 12/1 (2009), pp. 33-51.

6 Manuel Martínez Neira, "Hacia la madurez de una disciplina. Las oposiciones a cátedra de Historia del derecho español entre 1898 y 1936”, en Cuadernos del Instituto Antonio de Nebrija 5 (2002), pp. 331-458. 
prender estudios sobre juristas concretos7.

Los expedientes catalogados registran la provisión de cátedras de las siguientes universidades: Barcelona, Central (Madrid), Granada, La Laguna, Murcia, Oviedo, Salamanca, Santiago, Sevilla, Valencia, Valladolid y Zaragoza. Constan dos excepciones: dos provisiones de cátedras de la Escuela del Notariado de Valladolid (1868) y de la Escuela del Notariado de Madrid (1870).

Las cátedras con mayor número de anuncios (en términos relativos) son las de La Laguna y Murcia, cuyas primeras provisiones por oposición datan de 1920 y $1916^{8}$ respectivamente, seguidas de la de Santiago. Ello revela las preferencias de los catedráticos que las dejaban vacantes. Preferencias que en el caso de la Universidad Central, estaban condicionadas por un régimen retributivo especial9.

Además, en el caso de la Universidad de La Laguna, debe tenerse en cuenta que su creación se llevó a cabo en 1927. Antes de esa fecha, La Laguna era una sección de estudios universitarios, y por tanto, su régimen era diferente al de las universidades ${ }^{10}$. Los 17 expedientes del inventario referidos a La Laguna anteriores a 1927 deben por consiguiente tratarse con estas precisiones.

\section{Las fuentes del inventario}

El inventario incluye 302 expedientes custodiados en el Archivo General de la Administración, cuya sede se encuentra en Alcalá de Henares (Madrid).

7 En el reciente trabajo de Carlos Petit puede comprobarse la importancia de estos materiales para situar el texto en el contexto. Cfr. "Democracia y Derecho mercantil: texto y contextos de Joaquín Garrigues, Nuevos hechos, nuevo Derecho de Sociedades Anónimas (1933)", en Revista de derecho mercantil 307 (2018), pp. 187-208.

8 La Gaceta de Madrid de 2 de junio de 1916 anuncia las primeras tres cátedras de la facultad de Derecho de Murcia. La de 18 de septiembre de 1920 hace lo mismo respecto de las 9 primeras de la facultad de Derecho de La Laguna.

9 Otro privilegio de la Universidad Central era que contaba con mayores dotaciones para profesorado auxiliar y supernumerario. Carlos Petit, "La Administración y el Doctorado: centralidad de Madrid”, en Anuario de historia del derecho español 67 (1997), pp. 593-614, 606.

10 Los anuncios de oposiciones de la Gaceta especifican este régimen específico: los catedráticos no figuraban en el escalafón y sus sueldos era mayores. La Universidad de La Laguna fue creada por Real Decreto de 21 de septiembre de 1927 (Gaceta el 23 de septiembre). 
Desde el año 1859 a 1941. Este inventario contiene una descripción de los elementos esenciales del expediente de oposiciones: signatura del archivo, denominación de la cátedra, universidad, fecha del anuncio de la oposición, reglamento aplicable, jueces del tribunal, opositores, votación, propuesta y materiales. Más adelante se efectuarán algunas precisiones sobre estos elementos, que explicarán cómo se han recolectado dichos datos, con qué límites y bajo qué circunstancias.

El material se encuentra en la sección "Educación" del archivo, ordenado bajo la referencia 32. Ésta incluye una amplia variedad de expedientes referentes a distintas facultades universitarias: traslaciones, concursos, oposiciones a auxiliarías, cátedras supernumerarias, convocatorias de la Junta para la Ampliación de Estudios, etc. De todo ello, el presente inventario se limita a las oposiciones a cátedras en sentido estricto, tanto la provisión libre entre doctores como la provisión entre auxiliares. No se han incluido tampoco algunos legajos que, aun refiriéndose a las oposiciones a cátedras, solo conservan unos pocos oficios del negociado, pero no los ejercicios ${ }^{11}$.

Es importante tener presente esta variedad de expedientes del archivo. En ocasiones, materiales que pertenecen a la oposición de una cátedra, se conservan en otro tipo de expedientes, como puede ser el expediente personal del catedrático en cuestión. La consulta de la página electrónica Diccionario de catedráticos españoles de Derecho (1847-1943) es recomendable, ya que puede aportar indicaciones sobre materiales obrantes en los expedientes personales de los catedráticos, en los de expedición del título de licenciado, o en los de expedición del título de doctor, que como se ha dicho, no son fuentes del presente inventario.

No son éstas las únicas oposiciones a cátedras que se conservan en el Archivo General de la Administración. La referencia 31 también conserva oposiciones, tanto anteriores a 1859, ubicadas en los expedientes personales de los catedráticos, como posteriores a 1941. En el futuro esperamos poder continuar la labor de catalogación también respecto de estos expedientes para ofrecer a los investigadores un panorama completo de las oposiciones a cátedras.

Unos pocos expedientes, del año 1920 en adelante, han sido digitalizados. Su soporte digital puede ser solicitado a la unidad competente del Archivo General de la Administración. El inventario recoge este hecho, en su caso.

La catalogación realizada por el Archivo General de la Administración si-

11 La Habana, 32/07305 (5344-46) y Murcia, 32/13671 (9762-2). 
gue una doble numeración. La moderna se refiere al número de caja (v. gr. 32/07305) y la antigua lo hace al legajo (v. gr. 5344-46), ya que dentro de cada caja puede haber varios legajos, en ocasiones más de veinte. Otras veces varios legajos que forman el expediente de cierta oposición se conservan en cajas diferentes, incluso no sucesivas. También es posible que un legajo contenga dos provisiones diferentes. Estos datos dan cuenta de la heterogeneidad de esta sección del archivo ${ }^{12}$.

Tampoco es descartable que aparezcan nuevos expedientes de oposiciones a cátedras conservados en otras secciones del archivo. Conocemos el caso de Fernando de los Ríos. El expediente de oposición de la cátedra Derecho político de Granada por él ganada no ha sido localizado ${ }^{13}$.

El inventario documental que aquí se ofrece está ordenado cronológicamente según la fecha del anuncio de la oposición. En algunos casos (especialmente durante el periodo de expansión de las provisiones de 1900-1920), el expediente no conserva el documento del anuncio de la oposición, por lo cual se han tenido que recurrir a la Gaceta de Madrid para proporcionar el dato exacto. La fecha del anuncio puede conocerse directamente si consta en el expediente la Real Orden del anuncio o el propio edicto (los reglamentos prescribían que los edictos debían de fijarse en los tablones de anuncios de los establecimientos docentes), o indirectamente por menciones en las actas, o en las instancias de los aspirantes. Más adelante se detallará cómo se han tratado las fechas de los anuncios.

La sección de "materiales" del inventario es la que precisa de mayores aclaraciones. Si bien en las primeras décadas su descripción es sencilla, el aumento de materiales aconsejó que a partir de 1900 se catalogasen bajo dos sub-categorías: materiales de tipo administrativo y de tipo académico. Dentro de la primera se hace frecuente referencia a "oficios varios del negociado". Es una etiqueta que pretende incluir cierta variedad de documentos, que no se especifican en el inventario. Los más usuales son los oficios, cartas y telegramas sobre conformación del tribunal, el oficio con el anuncio de la oposición, las comunicaciones entre el ministerio y las universidades (v. gr. elevación por el presidente del tribunal del expediente). Es habitual que los oficios del

12 Otra muestra de esta heterogeneidad de expedientes que forman la referencia 32 son dos cajas con documentación relativa a las Escuelas del Notariado. No se refieren a la provisión de cátedras, sino que son expedientes generales que pueden resultar de interés para investigadores de este campo. Cajas 32/07369 y 32/07370.

13 Nombrado el 14 de marzo de 1911. Anuncio en la Gaceta de Madrid de 19 marzo. 
ministerio aparezcan unidos en un "cuadernillo" redactado en orden cronológico por el negociado, con las firmas correspondientes.

En los casos en que obren documentos más concretos, como dictámenes del Real Consejo de Instrucción Pública, protestas de los opositores, o escritos de recusación, se indica en el inventario. La procedencia y contexto de estos documentos se precisará más adelante, cuando se expongan las fases del procedimiento de provisión de cátedras por oposición.

Aproximadamente a partir de 1925 se aprecia un cambio en el tipo de material más abundante del expediente. Dejan de serlo las comunicaciones sobre conformación del tribunal y lo constituyen las instancias de opositores, que se acompañan por diferentes documentos: hojas de servicios y títulos expedidos por la universidad, protocolos notariales, certificado de antecedentes penales, certificados de estancias en el extranjero, etc.

La mayor parte del periodo la documentación es manuscrita, ya que la introducción de la mecanografía en el procedimiento de provisión de cátedras es lenta. Las primeras actas mecanografías aparecen sobre 1920, pero no se consolidan hasta 1930 aproximadamente.

Se ha optado en general por la transcripción de los apellidos sin la conjunción "y" entre primero y segundo, ya que no se observa una práctica constante en los diferentes documentos. La preposición "de" entre nombre y apellido sí se mantiene (v. gr. Demófilo de Buen). La nomenclatura nobiliaria tampoco se ha mantenido, ya que una persona puede aparecer en un primer momento con su nombre y posteriormente con el título nobiliario (v. gr. Francisco J. Jiménez Pérez de Vargas, marqués de la Merced).

\section{El cuerpo de catedráticos y el procedimiento para su provisión}

Dado que se ofrece un inventario de oposiciones a cátedras de Derecho, debemos referirnos brevemente al elemento lógico anterior: la existencia de un cuerpo que, por razones biológicas o de otra índole, necesita regularmente la reposición de sus miembros.

Tal cuerpo tiene fecha de nacimiento: 1847. Ese año fue publicado el Escalafón definitivo de catedráticos. Esta lista clasificaba según su antigüedad a los catedráticos existentes hasta el momento, provenientes de las más diversas instituciones educativas. A modo de ejemplo, el primer catedrático de la lista fue nombrado en 1797 y provenía de la Universidad de Oviedo. La ges- 
tación del Escalafón fue un proceso complejo abordado en otros estudios ${ }^{14}$. Para nuestra empresa actual será suficiente señalar que con los 276 catedráticos del escalafón fueron ocupadas una parte de las cátedras existentes y se previó que el resto (el 14\% del total) se proveyese por oposición ${ }^{15}$.

Los materiales administrativos conservados en los expedientes atestiguan cómo se desarrollaba este procedimiento de provisión de cátedras. Algunas indicaciones básicas sobre el mismo contribuirán a que el investigador reconozca tales materiales y a que la localización de los documentos relevantes sea más fácil.

La regulación del procedimiento de la provisión varía según el reglamento de cada época, así que únicamente podremos ofrecer una visión general de este procedimiento administrativo, advirtiendo que los órganos que lo impulsaban varían según el reglamento aplicable, así como las condiciones concretas, de gran importancia (requisitos de participación, plazos, posibilidad de recusación de los jueces, y ante todo, modo de nombramiento de los jueces) ${ }^{16}$.

En primer lugar, debía determinarse cuándo procede la oposición, es decir, establecer los turnos. En ciertos periodos, la oposición correspondía alternativamente (una vacante se anunciaba a oposición y la siguiente a concurso), en otros cada tres cátedras vacantes, etc. Era habitual que cierta cátedra hubiese sido anunciada por otro turno (traslación o concurso) pero que tal provisión hubiese quedado desierta. Se anunciaba entonces a oposición.

Después de que la universidad hubiese registrado una vacante, debía remitir al ministerio el parte oficial de ella. Éste verificaba si correspondía al turno de oposición. En caso afirmativo, la anunciaba ("de Real orden lo digo á V. I. para su conocimiento y demás efectos”) y la Real Orden era publicada en la Gaceta de Madrid. Por esta razón, en ocasiones el expediente conserva el ejemplar correspondiente de la Gaceta.

El inventario emplea el término "anuncio" y no el de "convocatoria". Aunque algunos reglamentos de los primeros periodos se refieren a convocatoria y anuncio sin precisar los efectos jurídicos de cada uno y por tanto como sinónimos, a partir del reglamento de 1894 comienza a distinguirse su uso:

14 Manuel Martínez Neira, La creación del cuerpo de catedráticos de universidad (1812-1857). Estudio histórico-jurídico, Madrid, Universidad Carlos III de Madrid, 2014, pp. 35-43.

15 Op. cit., p. 41.

16 Para un estudio particularizado de cada regulación, Manuel Martínez Neira, La regulación de las oposiciones a cátedras universitarias: 1845-1931, Madrid, Universidad Carlos III de Madrid, 2014. 
la convocatoria de oposiciones debía realizarse en el mes de julio, con las vacantes registradas durante el año anterior ${ }^{17}$. No obstante, el reglamento de 1901 y posteriores excluyeron de este régimen, entre otras, a las cátedras de universidad $^{18}$, que pueden anunciarse en cualquier mes.

A pesar de ello, como el reglamento obligaba a hacer una misma "convocatoria" con todas las vacantes de la misma asignatura, se recurrió al expediente de la agregación, término que aparece juridificado por primera vez en el reglamento de $1910^{19}$. El orden del inventario toma en cuenta en estos casos la fecha del primer anuncio, ya que sus efectos son definitivos, es decir, los aspirantes presentados en convocatorias posteriores no tenían opción a las anunciadas anteriormente ${ }^{20}$. En el caso de provisiones suspendidas (por ejemplo durante el Directorio de Primo de Rivera ${ }^{21}$ ) el criterio de catalogación es el inverso: se toma la fecha del segundo anuncio, ya que el primero no desplegó efectos jurídicos.

17 De las diez provisiones inventariadas durante la vigencia de este reglamento, nueve se anuncian en julio y una en agosto.

18 Artículo 4: "Quedan exceptuadas del plazo señalado en el artículo anterior las cátedras que sean únicas en las Universidades, Institutos y Escuelas Normales, de Veterinaria y de Comercio, pudiéndose, en su consecuencia, anunciar la oposición en cualquier época del año".

19 La agregación tenía un límite: que "pueda hacerse sin aplazamiento ni retraso de la fecha en que pudieran comenzar los ejercicios de la oposición anunciada" (artículo 4, Reglamento de 1910).

20 La agitación del periodo 1940-1941 requiere algunas precisiones. La orden de 11 de junio de 1940 (BOE del 25) anuncia 23 oposiciones (17 libres y 5 de auxiliares). Nueve de ellas sufren modificaciones por agregaciones posteriores de cátedras de otras universidades. Además, en ocasiones, la provisión por concurso o traslado genera interferencias en la provisión por oposición. Por ejemplo, la Orden de 25 de septiembre de 1940 (BOE del 29) por la que se declara admitido al opositor a las cátedras de Derecho romano de Murcia y Salamanca indica lo siguiente: "El Tribunal que juzgará las oposiciones, turno libre, a las cátedras de Derecho romano de las Facultades de Derecho de Murcia y Salamanca o las que como consecuencia de los concursos en tramitación resulten vacantes [...] no ha sufrido modificación".

21 Constan provisiones suspendidas en el periodo 1919-1925: 5373-4; 5374-1; 5372-4; 5373-2; 9147. En los años 1923 y 1924 no se anunció ninguna oposición, mientras que en 1925 se anunciaron catorce. La Gaceta del 2 de febrero de 1925 anunció cinco y la del 21 de febrero del mismo año nueve.

En el periodo 1929-1936 constan provisiones tanto suspendidas como no celebradas: 9576-2; 9576-3; 9576-4; 9576-6; 9576-8; 9576-9; 9576-11; 9576-12; 9576-13. El Decreto de 22 de junio de 1936 (Gaceta del 24) anula provisiones anteriores. 
La siguiente fase era la recepción de instancias de los opositores. Éstas se debían acompañar como es obvio de los documentos que acreditasen su capacidad legal y los méritos y servicios que les conviniese justificar. Debían presentarse en el plazo indicado en el reglamento (habitualmente de dos a cuatro meses). Se ha intentado indicar en el inventario los nombres de todos los aspirantes, los que no comparecieron, y los abandonos, ya que su registro posibilita la exploración de trayectorias de individuos concretos. No obstante, en ocasiones la cifra de aspirantes es demasiado elevada, lo que ha obligado a realizar un simple recuento del número de personas que presentaron instancia ${ }^{22}$. Como se ha intentado transmitir en estas páginas, los expedientes son ricos en información, pero su cantidad y extensión impone que este inventario se ciña a los elementos esenciales. El inventario indica, en su caso, si constan reclamaciones de los opositores contra la no admisión.

Posteriormente se procedía a la formación de los tribunales mediante el nombramiento de vocales y sustitutos. El órgano competente del ministerio publicaba en la Gaceta de Madrid los nombres de los jueces y de los aspirantes admitidos. Las instancias de estos últimos eran recibidas por el presidente del tribunal, quien también recibía las renuncias de vocales. A partir del reglamento de 1894 el presidente estaba autorizado para cubrir con los vocales suplentes dichas bajas, competencia importante teniendo en cuenta que las renuncias eran muy habituales. El inventario indica si constan escritos de recusación, para los periodos en los que el reglamento reconocía este derecho.

Por último, el presidente anunciaba el comienzo de los ejercicios en la $\mathrm{Ga}$ ceta de Madrid, con una antelación suficiente en favor de los opositores (habitualmente quince días).

\section{La formación de los tribunales}

El nombramiento de los tribunales es cuestión de gran importancia, ya que su estudio, al cual este inventario pretende ofrecer importantes recursos, permite avanzar en el conocimiento de aspectos como la intervención gubernamental en la selección de catedráticos o los valores predominantes en la comunidad universitaria ${ }^{23}$.

22 Se recomienda la consulta de la Gaceta de Madrid para examinar la lista completa de aspirantes.

23 Como aspecto anecdótico puede señalarse que conocidos políticos o intelectuales de la época formaron parte de diferentes tribunales: Alcalá Galiano, Pi y Margall, Alonso 
El periodo del inventario puede dividirse en seis periodos en función del órgano por el que es nombrado el tribunal. Son los siguientes: por el gobierno (1852 y 1864); por el rector del distrito (1870); por la Dirección General de Instrucción pública (1873 y 1874); por el Ministro (o Ministerio) de Fomento (1875 y 1894); por el Real Consejo de Instrucción Pública (1901 y 1910); por diferentes entidades, con un papel fundamental del Consejo de Instrucción Pública (1931). Más adelante se detallará el papel del Consejo.

Aparte del órgano que nombra al tribunal, también es relevante investigar cuál es el método de elección del presidente, cargo que individualiza importantes atribuciones que no residen en el resto de jueces. Así, tiene potestades de impulso del procedimiento de la provisión y de dirección de los ejercicios. También será conveniente tener en cuenta el método de designación de suplentes, habida cuenta de su gran uso durante el periodo del inventario.

Sin acometer un estudio detallado de las previsiones de los diferentes reglamentos atientes a la formación de los tribunales, se pueden apuntar algunas características generales.

Por un lado, se aprecia una tendencia a detallar con mayor precisión los requisitos que debe cumplir la persona designada juez. Los primeros reglamentos del periodo analizado, de 1852 y 1864 , formulan los requisitos en términos imprecisos: "catedráticos y personas de graduación académica o de notable reputación en la ciencia a que pertenezca la vacante”.

A partir de 1870 se diseña un sistema de categorías, es decir, de "tipos" de jueces, en función del ámbito del que procede. La lista más estable, vigente hasta 1931, la inaugura el reglamento de 1894 y recoge tres categorías: catedráticos, competentes y académicos.

Los competentes son "personas de competencia notoria en la materia, acreditada por la publicación de obras de reconocido mérito o por otros medios dignos de análoga consideración" 24 . Los académicos proceden de la Academia Española, de Historia o de Ciencias Morales y Políticas.

Por último, el reglamento de 1931 diseña el método más complejo, intentando que en los tribunales estuviesen representadas las entidades más relevantes del mundo científico. El Consejo de Instrucción Pública designa al presidente y los cuatro restantes jueces son seleccionados de la siguiente manera: la facultad de la vacante propone un catedrático; los catedráticos de

Martínez, Cánovas, Manuel Silvela, Germán Gamazo, Luis Pidal, Joaquín Costa, Antonio Maura, Menéndez Pelayo, Niceto Alcalá Zamora, etc.

24 Artículo 7, Reglamento de 1894. 
la asignatura proponen a otro catedrático; las facultades o secciones de igual cátedra proponen cada una un especialista y el Consejo escoge; las corporaciones científicas proponen cada una a otro especialista y el Consejo escoge ${ }^{25}$.

Por otro lado, la importancia del Consejo de Instrucción Pública y de su función de "control del profesorado" ${ }^{26}$ va en aumento. No únicamente por la adquisición de la competencia para designar el tribunal, como ya vimos, sino por ocupar su puesto clave, la presidencia. Bajo los reglamentos de 1894 y 1910 el presidente del tribunal debía ser necesariamente un consejero de instrucción pública, mientras que bajo el de 1901, el presidente era el consejero, en el caso de que entre los seleccionados para formar el tribunal hubiese alguno. Precisamente entre las personas que más intervienen en tribunales de oposiciones se cuentan varias que en algún momento ocuparon el cargo de consejero o director general de instrucción pública: Felipe Clemente de Diego, Antonio Royo, Laureano Díez Canseco, Eduardo de Hinojosa, Ismael Calvo, José Gascón, Gumersindo Azcárate, Matías Barrio, Vicente Santamaría ${ }^{27}$.

Como se ha dicho, el inventario incluye un índice digital en forma de hoja de cálculo, que ordena alfabéticamente los nombres de todos los jueces del periodo $^{28}$. Este instrumento resultará particularmente útil para localizar las trayectorias de ciertos personajes con gran presencia en los tribunales de oposiciones $^{29}$, rastrear qué tipos de asignaturas juzgaban los diferentes jueces y a partir de qué momento comienzan a especializarse las mismas, o determinar si la composición de los tribunales era sensible al contexto político y a los cambios de gobierno.

Por lo que hace a esta introducción, son pertinentes cuatro observaciones sobre la formación de los tribunales que han tenido influencia en la confección del inventario.

En primer lugar, el inventario especifica qué persona ocupó el cargo de

25 Artículo 4, Reglamento de 1931.

26 José Luis Peset, "El Real Consejo de Instrucción Pública y la restauración canovista”, en Hispania, XLVIII/170 (1988), pp. 989-1030, 995.

27 La frecuencia de su participación en tribunales es la siguiente: Clemente de Diego, 30; Antonio Royo, 23; Laureano Díez Canseco, 18; Eduardo de Hinojosa, 18; Ismael Calvo, 17; José Gascón, 16; Gumersindo Azcárate, 15; Matías Barrio, 13; Vicente Santamaría, 13.

28 https://doi.org/10.21950/6HUTZ1

29 El índice de jueces muestra que cuatro personajes tienen un número de participaciones en tribunales igual o superior a veintitrés. Felipe Clemente de Diego, el más frecuente, cuenta con treinta participaciones. Los otros tres son Adolfo Posada (25), Rafael de Ureña (23) y Antonio Royo (23). Por el contrario, Giner de los Ríos no aparece ninguna vez. 
secretario del tribunal. La observación panorámica de los expedientes revela que, con muy pocas excepciones, recaía en el catedrático más reciente. Nos encontramos ante una convención o costumbre (que puede incluso conllevar un elemento simbólico de reverencia ${ }^{30}$ ) contraria a los reglamentos, que indican que tal cargo ha de elegirse entre los vocales ${ }^{31}$.

En segundo lugar, también se comprueba fácilmente que la formación del tribunal consume por término medio más tiempo que los propios ejercicios. Incluso consta alguna ocasión en la que el presidente decidió la suspensión de los ejercicios, reanudada meses después. Puede considerarse habitual que la provisión, desde el anuncio de la oposición hasta la formulación de la propuesta, consuma uno o dos años. En ocasiones son tres o cuatro. Cinco o seis años constituye, según la práctica observada, un intervalo anormal, aunque constan ejemplos ${ }^{32}$. El tiempo necesario para la provisión tiende a reducirse debido a algunas modificaciones de los reglamentos, especialmente la reducción del número de miembros del tribunal. El reglamento de 1875 redujo el número de nueve a siete (artículo 6), mientras que el de 1910 lo hizo de siete a cinco (artículo 10). De hecho, la interesante Exposición de este reglamento se centra en el problema del "abandono de la enseñanza" causado por el traslado de catedráticos a Madrid con el objeto de juzgar oposiciones ${ }^{33}$.

En tercer lugar, y en conexión con el punto anterior, hasta aproximadamente 1920, la conformación del tribunal compondrá la mayor parte de la documentación administrativa obrante en los expedientes. El inventario no recoge por regla general los vocales que renunciaron al cargo o los que abandonaron el tribunal, sino solo los que participaron en la votación final.

Por el contrario, se indica el sentido del voto de cada uno, ya que este dato

30 Otro elemento relacionado con el concepto de honor eran las Reales Órdenes que anunciaban que "S. M. el Rey (Q. D. G.) ha tenido á bien resolver que en su nombre se den las gracias por el importante y gratuito servicio que han prestado como Jueces...”. Por ejemplo, en la Gaceta de 18 de mayo de 1883.

31 Bajo los reglamentos de 1845, 1847 y 1852 el cargo de secretario lo desempeñaba el juez más joven.

32 La provisión más larga del inventario es la relativa a la cátedra de Procedimientos judiciales de Salamanca, anunciada el 30 de julio de 1905 y con fin de los ejercicios el 20 de noviembre de 16. Expediente 5363-4.

33 El Reglamento de 1873 fue el único del periodo del inventario que diseñó un sistema de oposiciones descentralizado, con ejercicios en la universidad de la capital del distrito universitario (artículo 13.5). Recordemos que durante el periodo del inventario, con escasas excepciones, la Universidad Central tuvo el monopolio de expedición del título de doctor. 
puede aportar información sobre la vida interna de la disciplina ${ }^{34}$. Debe señalarse que la publicidad de la votación fue cuestión muy discutida del sistema de examinación. Los primeros reglamentos establecen votaciones secretas. El reglamento de 1870 introduce la votación pública, el de 1894 retorna a la secreta y a partir del de 1901 se consolida la pública.

La sección "votación" del inventario, al igual que la de "tribunal”, seguirá una tendencia a la simplificación por dos razones. La primera, la introducción del carácter eliminatorio de cada vez más ejercicios, que provocará que menos aspirantes alcancen la votación final. La segunda, la eliminación del antiguo sistema de votación del orden relativo de los opositores. Este método, tedioso en algunas ocasiones, hace que la sección "votación" sea a menudo la más extensa del inventario durante los primeros periodos.

Tras el desarrollo de los ejercicios y las votaciones, el tribunal formulaba la propuesta de nombramiento. El único periodo en el que el tribunal proclamaba directamente al catedrático fue el Sexenio (reglamentos de 1870, 1873 y 1874$)^{35}$. En las primeras épocas la propuesta se concretaba en una terna, mientras que los últimos reglamentos prescriben que la propuesta debía ser respecto de una única persona. El inventario indica, en su caso, si constan protestas de los aspirantes, para las que los reglamentos otorgaban un cortísimo plazo de presentación (normalmente 24 horas) ${ }^{36}$.

El inventario recoge tres casos peculiares relacionados con las propuestas. El primero es el de Fernando Mellado Leguez. Fue nombrado catedrático en 1876 pese a quedar en el lugar tercero de la terna propuesta por el tribunal ${ }^{37}$. Algo parecido ocurrió con Leopoldo García-Alas, que pese a obtener el primer puesto de la terna para la cátedra de Elementos de Economía política y Estadística de Salamanca, fue nombrado para la cátedra de Zaragoza ${ }^{38}$. El tercer caso es el de Juan Sala Bonán, fallecido antes de ser nombrado. Fue nombra-

34 Petit, Democracia y Derecho mercantil, cit. p. 189.

35 Martínez Neira, La regulación de las oposiciones a cátedras universitarias, cit. p. 16.

36 Constan incluso protestas por supuesto plagio. Expediente 32/07281 (5338-38).

37 La terna tenía en su primer lugar a José María Piernas y en su segundo a Francisco Javier Jiménez. Expediente 32/o7285 (5339-31)

38 Para Salamanca fue nombrado Teodoro Peña Fernández, segundo en la terna. Expediente 32/07287 (5340-4).

El Real Decreto de 17 de marzo de 1882 (Gaceta del 18) atribuyó a las personas clasificadas en primeros lugares en ternas que no hubiesen sido nombradas un derecho de nombramiento para vacantes de igual asignatura. 
do en 1895 en su lugar la segunda persona en la votación del mérito relativo: Antonio Royo Villanova ${ }^{39}$.

\section{Los ejercicios}

Los ejercicios son el núcleo básico que define un expediente de oposiciones. Su conocimiento es primordial para determinar qué materiales pueden encontrarse en los mismos ${ }^{40}$. El periodo analizado acoge 10 reglamentos de oposiciones (1852, 1864, 1870, 1873, 1874, 1875, 1894, 1901, 1910, 1931), aunque algunos de ellos tienen una vigencia muy limitada en lo que afecta a este inventario. Por ejemplo, los tres reglamentos del periodo 1870-1874, únicamente se aplican a nueve expedientes del inventario. A su vez, se debe tener en cuenta que estos reglamentos sufrieron numerosas modificaciones ${ }^{41}$.

El número de ejercicios es creciente: de los tres ejercicios de 1852 se llega a los seis de 1931. En total, el periodo del inventario acogió en uno u otro momento, los siguientes ejercicios: discurso, preguntas orales, preguntas escritas, lección del programa, ejercicio práctico, exposición del trabajo de investigación (labor personal a partir de 1931), defensa del programa.

El profesor Manuel Martínez Neira nos ofrece un estudio de la evolución de los ejercicios a través de los diferentes reglamentos y el propio texto oficial de éstos ${ }^{42}$.

La introducción de este inventario se limitará a hacer algunas referencias, teniendo en cuenta el estudio citado, a la influencia que ha tenido la evolución de los ejercicios en la propia catalogación que ahora se ofrece y al origen de los materiales catalogados, con el objetivo de que el investigador pueda percibir qué lugar ocupan en la provisión de cátedras por oposiciones y pueda dirigirse fácilmente al resto de información del expediente que por motivos de extensión no se incluye en el inventario.

Es obvio que las lecciones orales de los aspirantes no dejaron más rastro en los expedientes que sus enunciados, que aparecen en las actas. El discurso

39 Expediente 32/07304 (5344-36).

40 Merece la pena consultar el artículo de Torres Campos, testigo de oposiciones, aunque solo se refiera a la etapa anterior a 1880. Manuel Torres Campos, "La reforma de los estudios jurídicos”, en Revista de los Tribunales, 3 (1880), pp. 186-208. Dicho artículo me fue sugerido por Fernando Liendo.

41 El Reglamento de 1931 obtuvo fuerza de ley debido a su ratificación por ley de las Cortes Constituyentes de 4 de noviembre de 1931 (Gaceta del 6).

42 Martínez Neira, La regulación de las oposiciones, cit. 
en cambio, aunque era leído por el opositor, se conserva (antes de su eliminación de los ejercicios en 1870) en algún expediente en su forma escrita.

No obstante, aunque la respuesta oral no se transcribiese, consta en los expedientes, a partir de 1875, una fuente indirecta del ejercicio: la lista de los libros consultados por los opositores. Debido a su amplitud (es habitual encontrar listas con un rango de diez a treinta obras, por cada uno de los opositores) no se ha incluido en la descripción que ofrece este inventario, pero se indica su presencia en el expediente.

Los ejercicios escritos se conservan en casi todos los expedientes. El inventario trascribe los enunciados de éstos. Además las actas suelen incluir un cuestionario aprobado por el tribunal, que en los primeros periodos es simplemente una colección de papeletas con el enunciado de la pregunta, del que se extraía a la suerte el tema. Los escritos prácticos también constan en la mayoría de expedientes, pero su enunciado no se incluye en el inventario por regla general, ya que usualmente es muy amplio.

Para el resto de ejercicios la descripción contenida en la sección "materiales” del inventario es suficiente. La aparición en 1870 de los ejercicios consistentes en el programa y la memoria (artículo 26 del reglamento de 1870) y del trabajo de investigación (artículo 6 del reglamento de 1901) provocará un aumento del volumen de los expedientes, aunque los más grandes, que pueden ocupar tres o a cuatro cajas, deberán su tamaño sobre todo a las numerosas revistas y libros publicados por los aspirantes y presentados como méritos ${ }^{43}$.

Decíamos que la descripción del inventario es suficiente porque no existe rastro del impacto de estos documentos en el examen, es decir, no se especifica su valoración por parte del tribunal. Con una excepción: el reglamento de 1931, concretamente su artículo 26. Este precepto establece la obligación de los jueces de redactar un informe firmado acerca de los ejercicios y los trabajos presentados, que se une al expediente. Esta diferencia produce un salto cualitativo en los expedientes de este periodo. El valor de esta fuente para realizar la reconstrucción de una disciplina, determinar las "reglas estructurales que componen el milieu" 44 en el que se mueve el profesorado, o incluso estudiar la imagen de los juristas percibida por especialistas de otras

43 La Revista General de Legislación y Jurisprudencia y la Revista de Derecho Privado son las más repetidas. Su presencia es masiva a partir de 1900 y 1915 respectivamente. Los puestos tercero y cuarto los ocupan la Revista de Cultura y Vida Universitaria y la Revista de Ciencias Jurídicas y Sociales ya en los años veinte.

44 Martín, "De la enseñanza a la ciencia del derecho", cit. p. 34. 
disciplinas (constan informes de personalidades como Unamuno, Ortega o Sánchez Albornoz) es altísimo.

Agradezco la posibilidad de haber podido realizar esta investigación a Carlos Petit, director del proyecto y coautor, y a Manuel Martínez Neira, que me ha prestado todo tipo de asistencia y consejos, y cuyo estudio sobre los reglamentos ha impedido que esta investigación fuese interminable. A Fernando Liendo y Fernando Hernández Fradejas por ser los pioneros del inventario. A Esteban Conde, Aurora María López y Jesús Vallejo, coatuores de la catalogación.

Espero que haya quedado claro en estas páginas el entusiasmo con que he realizado la confección del inventario y la prolijidad de valiosas particularidades que pueden conocerse con la consulta de estos expedientes.

También quería agradecer la labor del personal facultativo del Archivo General de la Administración, así como la simpatía y enseñanzas de los investigadores que he tenido la fortuna de conocer en el mismo. 
INVENTARIO DOCUMENTAL 



\section{Signatura}

AGA 32/o7275. Legajo 5337-1.

\section{Cátedra}

Instituciones de Hacienda pública de España (sección de Administración).

\section{Universidad}

Barcelona.

\section{Anuncio}

1859, 19 de octubre. Gaceta del 25 de octubre.

\section{Reglamento aplicable}

10 de septiembre, 1852.

\section{Fechas de la oposición}

Constitución del tribunal: 27 de marzo, 1860.

Presentación de los opositores: (para el primer ejercicio) 24 de abril, 1860.

Votación y propuesta: 8 de mayo, 1860.

\section{Tribunal}

Presidente: Pedro Gómez de la Serna.

Vocales: Buenaventura Carlos Aribau, Luis Pastor, V. León y Medina, José Gener, Juan Bautista Trúpita, Laureano Figuerola.

Secretario: Manuel Colmeiro.

\section{Opositores}

José Domenech y Coll.

Eustaquio Toledano y Hernansaiz.

\section{Votación y propuesta}

1860, 8 de mayo. Primer lugar: seis votos para Toledano y dos para Domenech en votación secreta. Segundo lugar: unanimidad de votos para Domenech.

Propuesto en primer lugar, Toledano es nombrado por R.O. de 10 de julio, 1860.

\section{Materiales}

Actas de la oposición; oficios del negociado; anuncio de la oposición; oficios varios sobre conformación del tribunal. 


\section{Signatura}

AGA 32/07275. Legajo 5337-2.

\section{Cátedra}

Disciplina general de la Iglesia y particular de la de España.

\section{Universidad}

Oviedo.

\section{Anuncio}

1859, 19 de octubre. Gaceta del 26.

\section{Reglamento aplicable}

10 de septiembre, 1852.

\section{Fechas de la oposición}

Constitución: 30 de enero, 1860.

Presentación de los opositores: (para el primer ejercicio) 9 de febrero, 1860.

Votación y propuesta: 30 de abril, 1860.

\section{Tribunal}

Presidente: Francisco Escudero y Azara.

Vocales: Joaquín Aguirre, Pedro Benito Golmayo, Fidel Garrido, Alejandro Morales, Pedro Sabau, Juan Antonio Andonaegui, Carlos M. ${ }^{\text {a }}$ Coronado.

Secretario: Vicente de la Fuente.

Tras el segundo ejercicio se ausentó Golmayo, "a causa del mal estado de su salud” (17 de marzo, 1860). Provocó así un número par de miembros que se tradujo en un resultado de empate al formular la propuesta.

\section{Opositores}

Nicolás Malo y Jordana.

Miguel Fco. Eleyzegui.

Dionisio de la Peña.

Guillermo Estrada y Villaverde.

Ramón Vinader y Nubaco.

Pedro Barta.

José Aguilera Meléndez.

Eugenio Montero Ríos.

Pedro López Sánchez.

Manuel Blasco y Metre.

Desistieron de participar otros tres firmantes. 


\section{Votación y propuesta}

La votación, que según reglamento se efectuaba por papeletas secretas, arrojo un empate para el primer lugar: Guillermo Estrada obtuvo cuatro votos, lo mismo que Eugenio Monterio Ríos. Reiterada la votación arrojó el mismo resultado. "No habiendo medio en el Reglamento para dirimir el empate se acordó por unanimidad se elevase la propuesta al Gobierno de S. M. en la forma que designaban ambas votaciones". El Consejo de Instrucción Pública, considerando otros méritos de los dos opositores, "en un caso tan singular como el presente, que no es fácil ni apenas posible se repita con todas sus circunstancias", propuso al gobierno que concediera cátedra a los dos, lo que se aprobó (R.O. de 26 de junio, 1860). A su vez, los opositores solicitaron al día siguiente la permuta de las cátedras para las que fueron nombrados y pasaron, finalmente, Estrada a la cátedra de Oviedo y Montero Ríos a la de Santiago.

Para el segundo lugar fue votado Eugenio Montero Ríos (6 votos), Guillermo Estrada (dos votos). Se propone al primero.

Para el tercero, Ramón Vinader (4 votos), Pedro López Sánchez (3 votos), Miguel F. Eleyzegui (1 voto). Se propone al primero.

\section{Materiales}

Contiene sólo documentación de naturaleza administrativa, sin temarios ni materiales producidos por los opositores.

\section{Signatura}

AGA 32/07275. Legajo 5337-2.

\section{Cátedra}

Historia y examen crítico de los principales tratados de España con otras potencias.

\section{Universidad}

Central (sección de Administración).

\section{Anuncio}

14 de agosto, 186o, Gaceta del 16.

\section{Reglamento aplicable}

10 de septiembre, 1852. 


\section{Fechas de la oposición}

Constitución: 7 de noviembre, 1860.

Presentación: 12 de noviembre, 1860.

Votación y propuesta: 24 de noviembre, 1860.

\section{Tribunal}

Presidente: Francisco Martínez de la Rosa.

Vocales: Claudio Antón de Luzuriaga, Antonio González, Juan Manuel Montalbán, Pedro Gómez de la Serna, Carlos María Coronado, Laureano Figuerola.

Secretario: Manuel Colmeiro.

\section{Opositores}

José Moreno Nieto.

El firmante José Cancio y Mena envió telegrama eléctrico alegando una indisposición, con la consiguiente renuncia a participar.

\section{Votación y propuesta}

1860, 24 de noviembre. Se propone unánimemente para la cátedra al único opositor, José Moreno Nieto.

Fue nombrado catedrático por R.O. de 14 de enero, 1861.

\section{Materiales}

Actas de la oposición; oficios del negociado; anuncio de la oposición; oficios varios sobre conformación del tribunal.

Obra también un "Discurso del opositor D. José Moreno Nieto" (tema del tercer ejercicio) sobre "Principio del equilibrio europeo; engrandecimiento de la Rusia y de la Prusia en el siglo 18; su intervención en las cuestiones europeas; potencias de $1 .{ }^{\text {er }}$ orden".

\section{Signatura}

AGA 32/07275. Legajo 5337-13.

\section{Cátedra}

Elementos de Economía política y Estadística.

\section{Universidad}

Oviedo.

\section{Anuncio}

R.O. de 21 de marzo, 1861, Gaceta del 30. 


\section{Reglamento aplicable}

10 de septiembre, 1852.

\section{Fechas de la oposición}

Constitución: 1 de julio, 1861 (con suspensión de los ejercicios por vacaciones).

Presentación: 23 de diciembre, 1861.

Votación y propuesta: 20 de enero, 1862.

\section{Tribunal}

Presidente: Pedro Gómez de la Serna.

Vocales: Antonio Alcalá-Galiano, Buenaventura Carlos Aribau, Santiago Diego Madrazo, Carlos M. ${ }^{a}$ Coronado, Manuel Colmeiro, José Moreno Nieto, Manuel García Barzanallana.

Secretario: Benito Gutiérrez.

Todavía en la sesión de 18 de diciembre, 1861, se tratan renuncias y nuevos nombramientos.

\section{Opositores}

Manuel Blanco y Matres.

Luis Serra y Clausell.

Eusebio Alonso Pesqueras.

José Aguilera y Meléndez.

Diego Álvarez de los Corrales.

Nicolás García Vázquez.

Miguel Aragón y García.

Manuel Tarrasa y Romanz.

Ramón Lorente y Mora.

\section{Votación y propuesta}

Primer lugar: Miguel Aragón y García (5 votos), Diego Álvarez de los Corrales (4 votos).

Segundo lugar: Diego Álvarez de los Corrales (9 votos).

Tercer lugar: José Aguilera y Meléndez (6 votos), Luis Serra y Clausell (3 votos). En consecuencia, la terna elevada fue así: Miguel Aragón, Diego Álvarez de los Corrales, José Aguilera.

Fue nombrado el primero por R.O. de 8 de febrero, 1862.

\section{Materiales}

Actas de la oposición; oficios del negociado; anuncio de la oposición; oficios varios sobre conformación del tribunal, ejemplar de la Gaceta correspondiente al 30 de marzo, 1861. 


\section{Signatura}

AGA 32/07275. Legajo 5337-9.

\section{Cátedra}

Elementos de Derecho mercantil y penal.

\section{Universidad}

Barcelona, Santiago y Valencia.

\section{Anuncio}

11 de enero, 1862. Gaceta del 26.

\section{Reglamento aplicable}

10 de septiembre, 1852.

\section{Fechas de la oposición}

Constitución: 15 de abril, 1862.

Presentación: 23 de abril, 1862.

Votación y propuesta: 30 de mayo, 1862.

\section{Tribunal}

Presidente: Manuel Ortiz de Zúñiga.

Vocales: Laureano Arrieta, Teodoro Moreno, Juan Gómez Acebedo, Francisco de Paula Novar, Carlos María Coronado, Pedro de la Puente Apecechea, Manuel Silvela. Secretario: Benito Gutiérrez.

\section{Opositores}

Venancio Moreno Pablos.

Manuel Durán y Bas.

Ventura Gutiérrez.

José María Llopis Domínguez.

Ángel Crehuet y Guillén.

Cayetano Población Fernández.

Antonio Canals y Llinas.

Ignacio Martín Casado.

Tomás Álvarez Martínez.

José López Romero.

Bienvenido Oliver y Esteller.

Joaquín Vellando. 
Eduardo Serrano Fatigati.

Luis Serra y Clausell.

Francisco Vilantra y Sabble.

Antonio Cosín y Martín.

Augusto Comas.

José Laso y Medina.

Manuel Pérez Santa Marina.

Manuel Tarrasa.

Manuel Blasco Matres.

Hubo varios opositores que no comparecieron o que el tribunal estimó no reunían los requisitos previstos.

\section{Votación y propuesta}

Primer lugar: Manuel Durán y Bas (9 votos), Augusto Comas (7 votos), Cayetano Población (7 votos), José Laso y Medina (3 votos), Bienvenido Oliver (1 voto). Se elevó la terna formada por Manuel Durán, Augusto Comas, Cayetano Población. Segundo lugar: José Llopis (7 votos), Venancio Moreno (4 votos), José Laso y Medina (4 votos), José López Romero (2 votos), Manuel Pérez Santa Marina (1 voto), Manuel Tarrasa (3 votos); el empate entre Moreno y Laso se deshizo en una segunda votación: Laso (6 votos), Moreno (3 votos). Se elevó la terna formada por José Llopis Domínguez, Bienvenido Oliver, José Laso.

Tercer lugar: José López Romero (8 votos), Venancio Moreno (8 votos), Manuel Blasco (4 votos), Manuel Tarrasa (3 votos), Manuel Pérez Santa Marina (2 votos), Ángel Crehuet (2 votos); se repitió la votación entre Blasco y Tarrasa, con el resultado de Tarrasa (5 votos) y Blasco (4 votos). Se elevó la terna formada por José López Romero, Venancio Moreno Pablos, Manuel Tarrasa.

Por R.O. de 14 de junio fueron nombrados Manuel Durán para Barcelona, Augusto Comas para Valencia, José Llopis para Santiago.

\section{Materiales}

Actas de la oposición; oficios del negociado; anuncio de la oposición; oficios varios sobre conformación del tribunal y lista de opositores, ejemplares de la Gaceta.

\section{Signatura}

AGA 32/o7275. Legajo 5337-15.

\section{Cátedra}

Disciplina general de la Iglesia y particular de España.

\section{Universidad}

Salamanca. 


\section{Anuncio}

R.O. del 11 de enero de 1862, Gaceta de 26.

\section{Reglamento aplicable}

10 de septiembre, 1852.

\section{Fechas de la oposición}

Constitución: 20 de mayo, 1862.

Presentación: 24 de mayo, 1862.

Votación y propuesta: 9 de junio, 1862.

\section{Tribunal}

Presidente: Francisco Escudero y Azara.

Vocales: Juan Antonio de Andonegui, Eustoquio Laso, Saturnino Gómez Escribano, José Vallés, Francisco de Paula Lobo, Manuel León de Berriozábal.

Secretario: Vicente de la Fuente.

\section{Opositores}

Félix López San Martín.

Miguel Eleizegui e Iturrate.

Pedro López Sánchez.

José Correa Torrejón.

Otros ocho firmantes no se presentaron al primer ejercicio.

\section{Votación y propuesta}

Primer lugar: Pedro López Sánchez (7 votos), Félix López San Martín (1 voto). Segundo lugar: Félix López San Martín (5 votos), Miguel Eleizegui (2 votos), José Correa (1 voto).

Tercer lugar: José Correa (4 votos), Miguel Eleizegui (4 votos). Tres votaciones sucesivas no alteraron este resultado.

La terna elevada fue esta: Pedro López Sánchez, Félix López San Martín, José Correa Torrejón.

Nombrado Pedro López Sánchez, primero de la terna, por R.O. de 18 de junio, 1862.

\section{Materiales}

Actas de la oposición; oficios del negociado; anuncio de la oposición; oficios varios sobre conformación del tribunal, ejemplares de la Gaceta y del Diario oficial de Avisos de Madrid. 


\section{Signatura}

AGA 32/07276. Legajo 5337-18.

\section{Cátedra}

Derecho político de los principales Estados y Derecho mercantil y legislación de aduanas de los pueblos con quienes España tiene más frecuentes relaciones comerciales.

\section{Universidad}

Valladolid.

\section{Anuncio}

Gaceta del 26 de enero, 1862.

\section{Reglamento aplicable}

10 de septiembre, 1852.

\section{Fechas de la oposición}

Constitución: 25 de abril, 1862.

Presentación: 28 de abril, 1862.

Votación y propuesta: 9 de mayo, 1862.

\section{Tribunal}

Presidente: José Castro y Orozco, marqués de Gerona.

Vocales: Laureano Figuerola, Fernando Calderón Collantes, Manuel Colmeiro, Santiago Diego Madrazo.

Secretario: José Moreno Nieto.

\section{Opositores}

José Flaquer.

Miguel Pérez Alonso.

Dos firmantes no pudieron acreditar su doctorado en la sección de Administración; otros dos no se presentaron.

\section{Votación y propuesta}

Primer lugar: José Flaquer (unanimidad).

Segundo lugar: Miguel Pérez Alonso (4 votos).

Por R.O. de 14 de junio, 1862, fue nombrado José Flaquer. 


\section{Materiales}

Actas de la oposición; oficios del negociado; anuncio de la oposición; oficios varios sobre conformación del tribunal.

\section{Signatura}

AGA 32/o7276. Legajo 5337-28.

\section{Cátedra}

Derecho romano.

\section{Universidad}

Salamanca, Barcelona y Sevilla.

\section{Anuncio}

14 de julio, 1862.

Los oficios refieren una convocatoria anterior, de 7 de enero de 1862. Para la cátedra de Sevilla de Introducción al Estudio del Derecho, Principios de Derecho Natural, Historia y Elementos del Derecho romano; y para la de Derecho romano de Barcelona.

\section{Reglamento aplicable}

10 de septiembre, 1852.

\section{Fechas de la oposición}

Constitución del tribunal: 18 de noviembre, 1862.

Presentación de los opositores: 18 de noviembre, 1862.

Votación y propuesta: 19 de enero, 1863.

\section{Tribunal}

Presidente: Juan Martín Carramolino.

Vocales: José María de Álava, Carlos María Coronado, Francisco de Novar, Antonio Ubach Serrano, Manuel León de Berriozábal.

Secretario: Eugenio Montero Ríos.

\section{Opositores}

José Canals Llanas.

Ángel Crehuet Guillén. 
Antonio García Vázquez.

Manuel Herreros Sánchez.

Félix López S. Martín.

Tomás Álvarez.

Manuel Anglasell Serra.

Diego Álvarez de los Corrales.

Miguel Hue.

José Samsó.

Manuel Bartolomé Tarrasa Román.

Miguel Eloycegui Ituarte.

No comparecieron: Santiago Alfaro, Antonio Laguardia, Ramón Vinader, Julián Arribas Baraya, Bienvenido Oliver, José Correa Torrejón, Demetrio Gutiérrez Cañas, Manuel Blasco Matres.

\section{Votación y Propuesta}

Primeros Lugares:

1. ${ }^{\circ}$ Samsó: seis votos.

2. ${ }^{\circ}$ Eloycegui: cinco votos.

Segunda votación:

1. ${ }^{\circ}$ Tarrasa: cinco votos.

2. ${ }^{\circ}$ Álvarez de los Corrales: cuatro votos.

Segundos lugares:

$1 .^{\circ}$ Anglarell: siete votos.

2. ${ }^{\circ}$ Álvarez de los Corrales: seis votos.

$3 .{ }^{\circ}$ García Vázquez: seis votos.

Segunda votación:

1. ${ }^{\circ}$ Álvarez de los Corrales: seis votos.

2. ${ }^{\circ}$ García Vázquez: tres votos.

Últimos lugares:

1. ${ }^{\circ}$ Herreros: nueve votos.

$2 .{ }^{\circ}$ Canals: seis votos.

$3 .{ }^{\circ}$ López Martín: seis votos.

Segunda votación:

2. ${ }^{\circ}$ Canals: seis votos.

$3 \cdot{ }^{\circ}$ López Martín: tres votos.

Propuestas:

1. ${ }^{a}$ Terna. Barcelona. Samsó, Anglacell, Herreros.

2. ${ }^{\text {a }}$ Terna. Sevilla. Eloycegui, Álvarez de los Corrales, Canals.

$3{ }^{a}$ Terna: Salamanca. Tarrasa, García Vázquez, López Martín. 


\section{Materiales}

- Documentación de naturaleza administrativa del negociado. Oficios sobre conformación del tribunal. Se incluyen las actas.

- Anuncio de la oposición.

- Ejemplares de la Gaceta: 3 de diciembre, 1862; 10 de diciembre, 1862; 29 de diciembre, 1862.

\section{Signatura}

AGA 32/07277. Legajo 5337-32.

\section{Cátedra}

Derecho Político de los principales Estados de Europa, Derecho mercantil y Legislación de Aduanas de los pueblos con quienes España tiene más frecuentes relaciones comerciales.

\section{Universidad}

Sevilla.

\section{Anuncio}

R.O. de 17 de diciembre, 1862; Gaceta del 21.

\section{Reglamento aplicable}

10 de septiembre, 1852.

\section{Fechas de la oposición}

Constitución: 27 de marzo, 1863.

Presentación: 30 de marzo, 1863.

Votación y propuesta: 4 de abril, 1863.

\section{Tribunal}

Presidente: Pedro Gómez de la Serna.

Vocales: Fernando Calderón Collantes, Manuel García Barzanallana, Antonio M. ${ }^{a}$ Segovia, Francisco de Cárdenas, Manuel Colmeiro, Santiago Diego Madrazo, Laureano Figuerola.

Secretario: José Moreno Nieto.

\section{Opositores}

Diego Álvarez de los Corrales.

Los otros dos firmantes no comparecieron. 


\section{Votación y propuesta}

Fue votado unánimemente Diego Álvarez de los Corrales.

Por R.O. de 9 de mayo, 1863, fue nombrado para la plaza en oposición.

\section{Materiales}

Actas de la oposición; oficios del negociado; anuncio de la oposición; oficios varios sobre conformación del tribunal.

\section{Signatura}

AGA 32/07277. Legajo 5337-33.

\section{Cátedra}

Instituciones de Hacienda pública de España.

\section{Universidad}

Sevilla (Sección Administración).

\section{Reglamento aplicable}

10 de septiembre, 1852.

\section{Anuncio}

R.O. de 11 de febrero, 1863; Gaceta del 14.

\section{Fechas de la oposición}

Constitución: 26 de mayo, 1863.

Presentación: 30 de mayo, 1863.

Votación y propuesta: 9 de junio, 1863.

\section{Tribunal}

Presidente: Juan Martín Carramolino.

Vocales: Santiago Diego Madrazo, José García Barzanallana, José Magaz, Francisco de Cárdenas.

Secretario: José Moreno Nieto.

Comenzaron su ejercicio, además de los mencionados, Manuel de Sierra y Moya y Fernando Calderón Collantes, que renunciaron antes de comenzar las pruebas y fueron sustituidos por Luis M. ${ }^{a}$ Pastor y José Magaz y Jaime. No consta la participación de Pastor. 


\section{Opositores}

José Díez de Tejada.

Luis García García.

\section{Votación y propuesta}

Primer lugar: Luis García y García, por unanimidad.

Segundo lugar: José Díez de Tejada.

Por R.O. de 27 de junio, 1863, fue nombrado el primero.

\section{Materiales}

Actas de la oposición; oficios del negociado; anuncio de la oposición; oficios varios sobre conformación del tribunal, Gaceta del 14 de febrero, 1863.

\section{Signatura}

AGA 32/o7277. Legajo 5337-34.

\section{Cátedra}

Derecho político de los principales Estados de Europa, Derecho mercantil y Legislación de aduanas de los pueblos con quienes España tiene más frecuentes relaciones comerciales.

\section{Universidad}

Valladolid (Derecho administrativo).

\section{Anuncio}

R.O. 21 de febrero, 1863. Gaceta del 25.

\section{Reglamento aplicable}

10 de septiembre, 1862.

\section{Fechas de la oposición}

Constitución: 11 de mayo, 1863.

Presentación: 18 de mayo, 1863.

Votación y propuesta: 30 de mayo, 1863.

\section{Tribunal}

Presidente: Domingo Álvarez Arenas.

Vocales: Fernando Álvarez, Manuel Colmeiro, Antonio de Mena y Zorrilla, Matías Rodríguez Sobrino, Laureano Figuerola.

Secretario: Benito Gutiérrez. 


\section{Opositores}

Eusebio Monzó Pesquera.

Miguel Pérez Monzó.

Ángel Bas y Amigó.

\section{Votación y propuesta}

Por cinco votos contra dos se decidió la no provisión.

\section{Materiales}

Actas de la oposición; oficios del negociado; anuncio de la oposición; oficios varios sobre conformación del tribunal, ejemplares de la Gaceta y del Diario de Avisos.

\section{Signatura}

AGA 32/07277. Legajo 5337-45.

\section{Cátedra}

Economía política y Estadística.

\section{Universidad}

Oviedo.

\section{Anuncio}

Gaceta del 22 de febrero, 1864.

\section{Reglamento aplicable}

10 de septiembre, 1852.

\section{Fechas de la oposición}

Constitución: 15 de mayo, 1864 . Presentación: 23 de mayo, 1864.

Votación y propuesta: 4 de junio, 1864.

\section{Tribunal}

Presidente: Alejandro Oliván.

Vocales: Laureano Figuerola, Manuel Colmeiro, Lorenzo Nicolás Quintana, José Lorenzo Figueroa, Francisco de Paula Canalejas, José Magaz, Santiago Diego Madrazo. Secretario: Segismundo Moret.

\section{Opositores}

Rafael Coronel Ortiz. 
Ignacio Ferrán.

Nicolás Malo.

Francisco Vilanova.

No comparecieron: José Laso, Ángel Crehuet.

\section{Votación y propuesta}

Votación del primer lugar:

- Rafael Coronel: un voto.

- Ignacio Ferrán: cuatro votos.

- Francisco Vilanova: un voto.

- Dos votos en blanco.

Segunda votación del primer lugar:

- Rafael Coronel: un voto.

- Ignacio Ferrán: cinco votos.

- Francisco Vilanova: dos votos.

Votación del segundo lugar:

- Rafael Coronel: cinco votos.

- Francisco Vilanova: tres votos.

Votación del tercer lugar: Vilanova por unanimidad.

Propuesta de terna: Ferrán, Coronel, Vilanova.

\section{Materiales}

Únicamente se conservan las actas.

Trascriben los enunciados de las preguntas contestadas por los opositores en los diferentes ejercicios.

\section{Signatura}

32/07276. Legajo 5336-26.

\section{Cátedra}

Historia y elementos de Derecho civil español, común y foral.

\section{Universidad}

Barcelona (sección Civil y canónico).

\section{Anuncio}

R.O. de 25 de febrero, 1863. Gaceta de 4 de marzo.

\section{Reglamento aplicable}

10 de septiembre, 1852. 


\section{Fechas de la oposición}

Constitución: 1 de junio, 1863.

Presentación: 12 de junio, 1863.

Votación y propuesta: 27 de junio, 1863.

\section{Tribunal}

Presidente: Francisco Tames Hevia.

Vocales: Manuel de Urbina, Pedro López Clarós, Luis de Trelles, Francisco de Paula Novar, Vicente de la Fuente, Manuel Álvarez de Linera, Benigno Cafranga. Secretario: Manuel Silvela.

\section{Opositores}

Luis Serra y Clausell.

Julián Arribas Baraya.

Bienvenido Oliver y Estaller.

José Laso y Medina.

Joaquín Vellando.

Dos opositores no comparecieron a los ejercicios.

\section{Votación y propuesta}

Primer lugar: Julián Arribas (8 votos), José Laso (1 voto).

Segundo lugar: José Laso (4 votos), Serra Clausel (1 voto), Bienvenido Oliver (1 voto), en blanco 3 votos; se repitió la votación con el resultado de Laso (4 votos), Oliver (1 voto), 4 en blanco.

Tercer lugar: Bienvenido Oliver (6 votos), José Laso (1 voto).

Se elevó esta terna: Arribas, Laso, Bienvenido Oliver.

Por R.O. de 18 de julio, 1863 fue nombrado Julián Arribas Baraya.

\section{Materiales}

Actas de la oposición; oficios del negociado; anuncio de la oposición; oficios varios sobre conformación del tribunal.

\section{Signatura}

AGA 32/07276. Legajo 5336-29.

\section{Cátedra}

Instituciones de Hacienda pública de España.

\section{Universidad}

Madrid (sección Derecho administrativo). 


\section{Anuncio}

R.O. de 25 de febrero, 1863, Gaceta de 8 de abril.

En realidad, se acordó convocar la oposición el 11 de enero de 1862, pero el director general ordenó verbalmente en varios momentos la suspensión del expediente.

\section{Reglamento aplicable}

10 de septiembre, 1852.

\section{Fechas de la oposición}

Constitución: 8 de octubre, 1863 .

Presentación: 13 de octubre, 1863.

Votación y propuesta: 21 de octubre, 1863.

\section{Tribunal}

Presidente: José de Castro y Orozco, marqués de Gerona.

Vocales: Luis M. ${ }^{a}$ Pastor, Laureano Figuerola, Francisco de Cárdenas, Santiago Diego Madrazo.

Secretario: Manuel Colmeiro.

\section{Opositores}

Segismundo Moret.

José Higinio Arriaga.

Un firmante no se presentó.

\section{Votación y propuesta}

Fueron propuestos por unanimidad:

$\left.{ }^{\circ}{ }^{\circ}\right)$ Segismundo Moret;

2. $\left.{ }^{\circ}\right)$ José Higinio Arriaga.

Por R.O. de 10 de noviembre, 1863, es nombrado Segismundo Moret y Prendergast.

\section{Materiales}

Actas de la oposición (recoge los enunciados de las preguntas a los opositores); oficios del negociado; anuncios de la oposición; oficios varios sobre conformación del tribunal; oficios y comunicaciones sobre la demora de la convocatoria. 


\section{Signatura}

AGA 32/07277. Legajo 5337-47.

\section{Cátedra}

Derecho mercantil y penal.

\section{Universidad}

Salamanca.

\section{Anuncio}

R.O. de 26 de enero, 1864; Gaceta de 22 de febrero.

\section{Reglamento aplicable}

10 de septiembre, 1852.

\section{Fechas de la oposición}

Constitución: 12 de mayo, 1864.

Presentación: 18 de mayo, 1864.

Votación y propuesta: 3 de junio, 1864.

\section{Tribunal}

Presidente: Domingo Álvarez Arenas.

Vocales: Pedro de la Puente Apecechea, Amalio Marichalar (marqués de Montesa), Vicente Manuel de la Rúa, Manuel Durán y Bas, Carlos Espinosa, Pedro López Sánchez.

Secretario: José Moreno Nieto.

\section{Opositores}

Nicolás Malo Jordana.

José Laso Medina.

Joaquín Vallando.

José Hinojosa.

Luis Gómez de Terán.

Ángel Crehuet y Guillén.

Tres firmantes no se presentaron.

\section{Votación y propuesta}

Primer lugar: José Laso Medina (6 votos), Ángel Crehuet (2 votos).

Segundo lugar: Crehuet (5 votos), Goméz de Terán (3 votos).

Tercer lugar: Gómez de Terán (5 votos), Hinojosa (3 votos).

Por R.O. de 15 de junio, 1864, fue nombrado José Laso. 


\section{Materiales}

Actas de la oposición; oficios del negociado; anuncio de la oposición; oficios varios sobre conformación del tribunal.

\section{Signatura}

AGA 32/07278. Legajo 5337-50.

\section{Cátedra}

Instituciones de Hacienda pública de España.

\section{Universidad}

Sevilla.

\section{Anuncio}

R.O. de 29 de abril, 1864; Gaceta de 7 de julio.

Tras la reforma reglamentaria, se instó al Consejo de Instrucción Pública la fijación de un tema para los discursos de los opositores. Fue aprobado "Condiciones que deben procurarse en los impuestos públicos”, sesión de 19 de mayo, 1864.

\section{Reglamento aplicable}

1 de mayo, 1864.

\section{Fechas de la oposición}

Constitución: 12 de octubre, 1864 .

Presentación: 4 de noviembre, 1864.

Votación y propuesta: 13 de noviembre, 1864.

\section{Tribunal}

Presidente: Francisco Tames Hevia.

Vocales: Francisco de Cárdenas, José Magaz, Melchor Salvá, Francisco de Paula Canalejas, Santiago Diego Madrazo, Julián Manuel de Sabando.

Secretario: Segismundo Moret.

\section{Opositores}

José Díez de Tejada.

José María Millet Alhambra.

Se retiró un firmante antes de comenzar los ejercicios. 


\section{Votación y propuesta}

Aprobados los ejercicios de Millet por 7 bolas blancas contra 1 negra, fue propuesto para la cátedra.

Por R.O. de 13 de diciembre, 1863 se nombró a José María Millet.

\section{Materiales}

Actas de la oposición; oficios del negociado; anuncio de la oposición; oficios varios sobre conformación del tribunal, ejemplares de la Gaceta.

\section{Signatura}

AGA 32/07278. Legajo 5337-51.

\section{Cátedra}

Derecho político de los principales Estados de Europa, Derecho mercantil y Legislación de aduanas de los pueblos con quienes España tiene más frecuentes relaciones comerciales.

\section{Universidad}

Valladolid (Derecho administrativo).

\section{Anuncio}

R.O. de 14 de mayo, 1864; Gaceta del 7 de julio.

El tema que fijó el Consejo de Instrucción Pública para el trabajo de los opositores (10 de mayo, 1864) fue: "Juicio sobre las Instituciones políticas de Inglaterra".

\section{Reglamento aplicable}

1 de mayo, 1864 .

\section{Fechas de la oposición}

Constitución: 4 de octubre, 1864.

Presentación: 20 de octubre, 1864.

Votación y propuesta: 28 de octubre, 1864 .

\section{Tribunal}

Presidente: Manuel Ortiz de Zúñiga.

Vocales: José G. Barzanallana, Matías Rodríguez Sobrino, Laureano Figuerola, Pedro de la Puente Apecechea, José Moreno Nieto.

Secretario: Benito Gutiérrez. 


\section{Opositores}

Andrés Blas y Meléndez.

Miguel Pérez Alonso.

\section{Votación y propuesta}

Primer lugar: Miguel Pérez Alonso (4 votos, 3 en blanco).

Segundo lugar: Andrés Blas (4 votos, 3 en blanco).

Fueron propuestos por ese mismo orden.

Por R.O. de 17 de noviembre, 1864, fue nombrado Miguel Pérez Alonso.

\section{Materiales}

Actas de la oposición; oficios del negociado; anuncio de la oposición; oficios varios sobre conformación del tribunal, ejemplares de la Gaceta.

\section{Signatura}

AGA 32/07368. Legajo 5375-1.

\section{Cátedra}

Nociones de Derecho civil, mercantil y penal de España.

\section{Universidad}

Escuela del Notariado de Valladolid.

\section{Anuncio}

Gaceta del 18 de febrero, 1865.

\section{Reglamento aplicable}

1 de mayo, 1864.

\section{Fechas de la oposición}

Constitución del tribunal: 20 de mayo, 1865.

Presentación de los opositores: 9 de junio, 1865.

Votación y propuesta: 21 de junio, 1865.

\section{Tribunal}

Presidente: Domingo Álvarez Arenas.

Vocales: Fermín de la Puente, León Galindo y Vera, Mariano Soler, Matías Rodríguez Sobrino, Carlos María Coronado, Benigno Cafranga.

Secretario: Benito Gutiérrez. 
No participaron en la votación: Rodríguez Sobrino, Coronado.

\section{Opositores}

Trinca:

- Rafael Coronel Ortiz.

- José Hinojosa Menjoulet.

- José Pazos Brandín.

1. ${ }^{\text {a Binca: }}$

- Eusebio María Chapado García.

- Andrés Blas y Melendo.

2. ${ }^{\text {a }}$ Binca:

- Venancio de Antestiarte.

- José Correa Torrejón.

\section{Votación}

1. ${ }^{\circ}$ lugar: José Correa Torrejón. Por cuatro votos contra dos de Hinojosa.

2. ${ }^{\circ}$ lugar: José Hinojosa Menjoulet. Por cuatro votos contra dos de Pazos.

$3 .^{\circ}$ lugar: José Pazos Brandín. Por cuatro votos contra dos de Antestiarte.

José Correa fue nombrado por R.O. de 8 de julio de 1865.

\section{Materiales}

- Actas

- Oficios varios del negociado, oficios sobre conformación del tribunal, etc.

- Memoria de los méritos de Eusebio María Chapado.

- Anuncio de la oposición de la Dirección General de Universidades.

- Ejemplar de la Gaceta de Madrid del 18 de febrero de 1865.

\section{Signatura}

AGA 32/07280. Legajo 5338-21.

\section{Cátedra}

Filosofía del Derecho y Derecho internacional.

\section{Universidad}

Central (Doctorado).

\section{Anuncio}

R.O. de 7 de marzo, 1865; Gaceta de 13 de abril.

El tema propuesto por el Consejo de Instrucción (23 de marzo, 1865) fue "Dife- 
rencias entre la propiedad colectiva y la individual, consideradas filosóficamente".

\section{Reglamento aplicable}

1 de mayo, 1864.

\section{Fechas de la oposición}

Constitución: 20 de febrero, 1866.

Presentación: 5 de mayo, 1866.

Votación y propuesta: 27 de octubre, 1866 (nueva propuesta, tras rechazarse la primitiva, adoptada el 18 de mayo, 1866).

\section{Tribunal}

Presidente: Cirilo Álvarez.

Vocales: Juan Antonio de Andonaegui, Francisco de Cárdenas (sustituido por Guillermo Estrada), Víctor Arnau, Francisco de Paula Lobo, Benito Gutiérrez, Manuel de la Fuente Andrés.

Secretario: Luis García García.

\section{Opositores}

Francisco de León y Olarrieta.

Melchor Salvá.

Clemente Fernández Elías.

Manuel Bartolomé Tarrasa.

Francisco Giner de los Ríos.

Antes de los ejercicios falleció el firmante Manuel Aragón; no se presentó Estanislao Reynals.

\section{Votación y propuesta}

Primer lugar: Francisco Giner de los Ríos (4 votos, 4 en blanco).

Segundo lugar: Francisco Giner de los Ríos (6 votos, 2 en blanco).

Tercer lugar: Melchor Salvá (5 votos), Clemente Fernández Elías (3 votos); este fue el resultado de una segunda votación, tras obtener en la primera Salvá (4 votos), Manuel Bartolomé Tarrasa (2 votos), Clemente Fernández (2 votos).

El dictamen del Consejo de Instrucción Pública (9 de junio, 1866) advirtió sobre "irregularidades y vacilaciones que denotan un criterio poco seguro en el tribunal, estraviado desde el principio á causa de una viciosa interpretación del reglamento". Se propuesto finalmente dar por válidos los ejercicios pero devolver el expediente para nueva votación, al tiempo que se lamentaba que una cátedra de Doctorado se cubriese por oposición ("no es ilegal, pero tampoco es prudente"). 
Comunicada por R.O. de 6 de julio la devolución del expediente para nueva votación, el resultado fue:

Primer lugar: Francisco Giner de los Ríos (4 votos, 1 en blanco).

Segundo lugar: Melchor Salvá (3 votos), Clemente Fernández Elías (2 votos).

Tercer lugar: Clemente Fernández Elías (3 votos), Manuel B. Tarrasa (2 votos).

El Consejo (19 de enero, 1867) reparó en la reducción del tribunal de los ocho primitivos a cinco miembros, por fallecimiento entretanto de Manuel de la Fuente y de Luis García, más la ausencia autorizada de Guillermo Estrada; pero los inconvenientes se salvaron por aplicación analógica de lo previsto para el voto de sentencias en el reglamento provisional para la Administración de Justicia.

Por R.O. de 20 de julio, 1867, fue nombrado Francisco Giner de los Ríos.

\section{Materiales}

Actas de la oposición, con mención de las preguntas formuladas; oficios del negociado; anuncio de la oposición; oficios varios sobre conformación del tribunal; Gaceta de Madrid.

\section{Signatura}

AGA 32/o728o. Legajo 5338-28.

\section{Cátedra}

Derecho civil español, común y foral.

\section{Universidad}

Zaragoza.

\section{Anuncio}

R.O. de 11 de abril, 1865, Gaceta del 25 de mayo.

El Consejo de Instrucción propuso como tema para el discurso de los opositores (22 de abril, 1865) "Sobre la legitimación por el subsiguiente matrimonio de los hijos habidos entre parientes".

\section{Reglamento aplicable}

1 de mayo, 1864 .

\section{Fechas de la oposición}

Constitución: 6 de marzo, 1868.

Presentación: 18 de abril, 1868.

Votación y propuesta: 7 de mayo, 1868. 


\section{Tribunal}

Presidente: Domingo Moreno.

Vocales: Cristóbal Martín de Herrera, Benito Gutiérrez, Santos de Ysasa, Carlos Espinosa, Benigno de Cafranga, Alejandro Ramírez de Villaurrutia; no participó en la votación Antonio Rivero y Cidraque (ausente del primer ejercicio por fallecimiento de su suegro).

Secretario: Augusto Comas.

\section{Opositores}

Salvador Gavila y García.

Cruz Ochoa y Zavalegui.

José Hinojosa y Menjoulet.

No se presentaron quince firmantes; otros dos presentaron renuncia por escrito.

\section{Votación y propuesta}

Primer lugar: José Hinojosa (8 votos).

Segundo lugar: Salvador Gavila (4 votos), Cruz Ochoa (3 votos), 1 en blanco; en segunda votación Gavila obtuvo 5 votos, por 3 Ochoa.

Tercer lugar: Cruz Ochoa (5 votos), 3 en blanco.

La terna fue Hinojosa, Gavila, Ochoa. Por R.O. de 13 de julio, 1868, fue nombrado el primero.

\section{Materiales}

Actas de la oposición; oficios del negociado; anuncio de la oposición; oficios varios sobre conformación del tribunal.

\section{Signatura}

32/07280. Legajo 5338-24.

\section{Cátedra}

Elementos de Derecho mercantil y penal.

\section{Universidad}

Santiago.

\section{Anuncio}

R.O. de 27 de enero, 1866. Gaceta de 3 de abril.

El Consejo de Instrucción Pública (17 de febrero, 1866) acordó como tema para el discurso reglamentario que debían entregar los firmantes, lo siguiente: "Examen 
general de las circunstancias atenuantes. ¿Deberá contarse entre ellas la confesión del delito por el reo?”.

\section{Reglamento aplicable}

1 de mayo, 1864 .

\section{Fechas de la oposición}

Constitución: 14 de octubre, 1867.

Presentación: 28 de noviembre, 1867.

Votación y propuesta: 14 de diciembre, 1867.

\section{Tribunal}

Presidente: Manuel Silvela.

Vocales: Laureano Figuerola, Segismundo Moret, Pablo Zamora, José María Ruiz López, Juan Francisco Mambrilla, Pedro Calderón, Francisco de la Pisa Pajares.

Secretario: Augusto Comas.

\section{Opositores}

José Hinojosa y Menjoulet.

Ramón Ramiro Rueda y Neira.

Demetrio Gutiérrez Cañas.

Manuel Buitrón Ruiz.

Francisco Hernández Vidal.

Otros nueve firmantes no se presentaron.

\section{Votación y propuesta}

Primer lugar: Ramiro Rueda (7 votos), Gutiérrez Cañas (1 voto), 1 en blanco.

Segundo lugar: Gutiérrez Cañas (5 votos), Hinojosa (2 votos), 2 en blanco.

Tercer lugar: Hinojosa (3 votos), Gutiérrez Cañas (2 votos), 4 en blanco; repetida la votación obtuvieron Hinojosa (4 votos), Gutiérrez Cañas (1 voto), 4 en blanco. La terna propuesta fue: Ramiro Rueda y Neira, Demetrio Gutiérrez Cañas, José Hinojosa Moujoulet.

Por R.O. de 21 de enero, 1868, fue nombrado Ramiro Rueda.

\section{Materiales}

Actas de la oposición; oficios del negociado; anuncio de la oposición; oficios varios sobre conformación del tribunal. 


\section{Signatura}

AGA 32/07281. Legajo 5338-41.

\section{Cátedra}

Ampliación del Derecho civil y Códigos españoles.

\section{Universidad}

Salamanca, Granada, Santiago.

\section{Anuncio}

29 de noviembre, 1867.

\section{Reglamento aplicable}

1 de mayo, 1864.

\section{Fechas de la oposición}

No constan.

El Real Consejo de I.P. acuerda el 13 de febrero de 1868 el tema para los discursos de los opositores: "Ventajas en inconvenientes de la codificación en cuanto al Derecho civil".

El presidente del tribunal Laureano Figuerola es nombrado el 21 de agosto de 1871.

El presidente del tribunal remite las actas de los ejercicios el 22 de febrero de 1872.

\section{Tribunal}

Presidente: Laureano Figuerola.

Vocales: Francisco Salmerón Alonso. No consta la identidad del resto.

Secretario: Luis Silvela.

\section{Opositores}

Modesto Falcón, Julián Sáenz Torres, Juan Puig, Nicolás Serrano, Gayo López, Vicente Oliva, Vicente Gadea, Antonio García Vázquez, Demetrio Gutiérrez, Rafael Llamas, Enrique Zamora, Roberto Casajús, Luis Miralles.Nicolás Canales, Vicente Olivares, Pedro Bais, Francisco Hernández, Joaquín Vellando, José Hinojosa, Salvador Gavilá, Jose Font, Mariano Ripollés, Eduardo Oradea, Francisco Vilanova, Manuel Sicilia, Enrique Muñoz, Marcial de la Campa, Luis Escribano, Luciano Buga, Melquíades González, José Aguilera. 


\section{Votación y Propuesta}

Primeros Lugares:

1. ${ }^{\circ}$ Nicolás Canales Ibañez (Granada).

2. ${ }^{\circ}$ Roberto Casajús Gómez (Salamanca).

3. ${ }^{\circ}$ Demetrio Gutiérrez (Santiago).

Segundos lugares:

$10^{\circ}$ Ripollés.

2. ${ }^{\circ}$ García Vázquez.

$3 \cdot{ }^{\circ}$ Miralles.

Terceros lugares:

$1 .^{\circ}$ Falcón.

$2 .{ }^{\circ}$ Oliva.

$3 \cdot{ }^{\circ}$ Vellando.

\section{Materiales}

Documentación de naturaleza administrativa del negociado.

No se conservan las actas.

En el cuadernillo del negociado aparece una resolución de la Junta Consultiva de I.P. de 8 de abril de 1872. Se refiere al procedimiento para dirimir desempates. El acuerdo del tribunal de 25 de mayo de 1872 se opone a la instrucción de la Junta. Indica que "cuando los individuos que formaron aquel tribunal se convenzan de que han cometido un error, y que es necesario subsanarlo, no opondrán ninguna dificultad a confesarlo y corregirlo, mientras tanto no reconocen en V.E. ni en nadie Autoridad suficiente para hacerles cambiar sus votos".

\section{Signatura}

AGA 32/07281. Legajo 5338-32.

\section{Cátedra}

Introducción al estudio del Derecho, Principios de Derecho natural, Historia y elementos del Derecho romano.

\section{Universidad}

Central.

\section{Anuncio}

27 de marzo, 1869.

El 23 de marzo de 1869 el Consejo Universitario designa tema para el discurso de los opositores: "Estudio filosófico del Derecho de familia: desarrollo de esta institución jurídica en la historia del pueblo romano". 


\section{Reglamento aplicable}

1 de mayo, 1864.

\section{Fechas de la oposición}

Constitución: 28 de junio, 1869.

Presentación de los opositores: 4 de enero, 1870.

Votación y propuesta: 10 de febrero, 1870.

\section{Tribunal}

Presidente: Juan Antonio Andonaegui.

Vocales: Víctor Arnau, Miguel Zorrilla, Manuel Ruiz de Quevedo, Rafael Prieto de Canles.

Secretario: Francisco de la Pisa Pajares.

\section{Opositores}

1. ${ }^{\text {a }}$ Trinca:

- Antonio José Pou Urdinas.

- Luis Miralles.

- José María Maranges.

2. ${ }^{\mathrm{a}}$ Trinca:

- Pedro Moreno Villena.

- José Manuel Prieto.

- Diego Bahamonde.

3. ${ }^{\mathrm{a}}$ Trinca:

- Matías Barrio Mier.

- José Otero Carracedo.

- Pedro López Sánchez.

\section{Votación y Propuesta}

- Primer Lugar: Maranges por cuatro votos contra uno de López Sánchez y uno de Barrio.

- Segundo lugar: en primera votación dos votos para Barrio, dos para López Sánchez, uno para Miralles, y uno para Prieto. En segunda votación cuatro para Barrio y dos para López Sánchez.

- Tercer lugar: cuatro para López Sánchez, uno para Miralles y uno para Prieto. Se formuló la propuesta en concordancia.

\section{Materiales}

- Documentación de naturaleza administrativa del negociado. Se incluyen las actas. 
- Protesta de los opositores Miralles, Moreno, Prieto, Bahamonde, Barrio y López Sánchez, de 12 de febrero de 1870 . Se solicita la nulidad de la propuesta por irregularidades en los ejercicios de Maranges.

- Informe del tribunal. 15 de marzo, 1870.

- Propuesta de la Comisión de Ponentes. 17 de mayo, 1870.

- Informe del Consejo de Estado. 13 de julio, 1870.

\section{Signatura}

AGA 32/07281. Legajo 5338-29.

\section{Cátedra}

Economía política y Estadística.

\section{Universidad}

Valladolid y Oviedo.

\section{Anuncio}

R.O. 11 de junio, 1869.

El Consejo Universitario fijó como tema para los firmantes: "Estado actual de los Estudios económicos. Fundamentos que hasta ahora se han [sic] dado a la Economía Política. Sus relaciones con la ciencia del Derecho".

\section{Reglamento aplicable}

1 de mayo, 1864 .

\section{Fechas de la oposición}

Constitución: 12 de octubre, 1869.

Presentación: 10 de diciembre, 1869.

Votación y propuesta: 14 de enero, 1870.

\section{Tribunal}

Presidente: Luis M. ${ }^{\text {a }}$ Pastor.

Vocales: Félix de Bona, Francisco Pi y Margall, Leandro Rubio, Francisco de la Pisa Pajares, Joaquín María Sanromá.

Secretario: Luis Silvela.

\section{Opositores}

José Huelves Templado.

Gumersindo de Azcárate. 
Tomás Lezcano y Hernández.

Eduardo Orodea e Ibarra.

José Piernas Hurtado.

Eduardo Coll y Masadas.

Eladio García Amado.

Se presentaron dos renuncias escritas y otros dos firmantes no comparecieron.

\section{Votación y propuesta}

Primer lugar, primera vacante: Orodea (3 votos), Azcárate (2 votos), Piernas (2 votos). En segunda votación: Orodea (4 votos), Azcárate (2 votos), Piernas (1 voto).

Primer lugar, segunda vacante: Piernas (4 votos), Azcárate (3 votos).

Segundo lugar, primera vacante: Huelves (4 votos), Azcárate (3 votos).

Segundo lugar, segunda vacante: Azcárate (7 votos).

Tercer lugar, primera vacante: Coll (5 votos), G. ${ }^{a}$ Amado (2 votos).

Terce lugar, segunda vacante: G. ${ }^{a}$ Amado (7 votos).

Propuesta:

Primeros lugares: Orodea, Piernas.

Segundos lugares: Huelves, Azcárate.

Terceros lugares: Coll, Garcia Amado.

Fueron nombrados Orodea para Valladolid y Piernas para Oviedo. R.O. de 26 de marzo, 1870 .

\section{Materiales}

Actas de la oposición; oficios del negociado; anuncio de la oposición; oficios varios sobre conformación del tribunal.

\section{Signatura}

AGA 32/o7368. Legajo 5375-2.

\section{Cátedra}

Redacción de instrumentos públicos y actuaciones judiciales.

\section{Universidad}

Escuela del Notariado de Madrid.

\section{Anuncio}

28 de julio, 1870. Gaceta del 11 de agosto. 


\section{Reglamento aplicable}

15 de enero, 1870.

\section{Fechas de la oposición}

Constitución del tribunal: 18 de octubre, 1871.

Presentación de los opositores: 23 de octubre, 1871.

Votación y propuesta: 15 de diciembre, 1871.

\section{Tribunal}

Presidente: Juan Antonio Andonaegui.

Vocales: Félix María Falguera, José María de la Barrera, Francisco Morcillo y León, José Gonzalo de las Casas, Benigno Cafranga, Estanislao Reynals.

Secretario: Pablo de la Lastra.

\section{Opositores}

Trinca:

- José Manuel Prieto González.

- Ricardo Ruiz Benitúa.

- Salvador Torres Aguilar.

Binca:

- Miguel la Guardia Corencia.

- Antonio Boada Janer.

\section{Votación}

- Salvador Torres Aguilar: cinco votos (Reynals, Barrera, Morcillo, de las Casas, de Lastra).

- Miguel la Guardia: tres votos (Andonaegui, Gutiérrez, Cafranga).

El presidente proclamó catedrático a Salvador Torres Aguilar.

\section{Materiales}

- Actas.

- Oficios varios del negociado, oficios sobre conformación del tribunal, etc.

- Ejemplares de la Gaceta de Madrid del 11 de agosto y 12 de agosto de 1870, y de 7 de octubre de 1871.

- R.O. de la Dirección General de I.P. de diciembre de 1871 (el día no se puede leer con exactitud) que resuelve una consulta planteada sobre el artículo 31 del Reglamento. Se resuelve que "todo juez firme su papeleta, [...]”. 


\section{Signatura}

AGA 32/o7283. Legajo 5339-3.

\section{Cátedra}

Legislación comparada.

\section{Universidad}

Central.

\section{Anuncio}

1871, 2 de junio. Gaceta del 11.

\section{Reglamento aplicable}

15 de enero, 1870.

\section{Fechas de la oposición}

Constitución: 20 de octubre, 1871.

Presentación de los opositores: 16 de noviembre, 1872.

Votación y propuesta: 19 de febrero, 1873.

\section{Tribunal}

Presidente: Antonio Cánovas del Castillo.

Vocales: José Moreno Prieto, Juan Antonio Andonaegui, Víctor Arnau.

Secretario: Benito Gutiérrez.

Cánovas fue nombrado presidente tras conocerse que Cirilo Álvarez, el anterior presidente, había dejado de formar parte del tribunal. En sesión posterior se conoció la renuncia de los vocales Reynals y González Acevedo.

\section{Opositores}

José López Romero.

Jorge María de Ledesma.

Gumersindo de Azcárate.

Los opositores Salvador Torres de Aguilar y Francisco de la Concha Alcalde manifestaron su renuncia a tomar parte en los ejercicios, con anterioridad al comienzo de éstos.

\section{Votación y Propuesta}

Los cinco miembros del tribunal votan a Gumersindo de Azcárate. 


\section{Materiales}

Contiene solo documentación de naturaleza administrativa, sin temarios ni materiales producidos por los opositores.

\section{Signatura}

AGA 32/o7281. Legajo 5338-38.

\section{Cátedra}

Teoría y práctica de los Procedimientos judiciales y práctica forense.

\section{Universidad}

Valencia.

\section{Anuncio}

R.O. de 28 de noviembre, 1871.

\section{Reglamento aplicable}

15 de enero, 1870 .

\section{Fechas de la oposición}

Constitución: 4 de abril, 1872.

Presentación de los opositores: 11 de abril, 1872.

Votación y propuesta: 11 de mayo, 1872.

\section{Tribunal}

Presidente: Antonio Rodríguez de Cepeda.

Vocales: Juan Inocencio Conde, Fernando de León Olarieta, José María Llopis, Mariano Amigó, Vicente Tormo, Simón Cirujeda, Hiliberto García.

Secretario: Manuel Tarrasa.

\section{Opositores}

1. ${ }^{\mathrm{a}}$ trinca:

- Víctor Navarro.

- Vicente Gadea.

- Pablo Buil Bayod.

2. ${ }^{\mathrm{a}}$ pareja:

- Andrés Blas y Melendo.

- Ángel María Álvarez Cabeza de Vaca. 
3. ${ }^{\mathrm{a}}$ pareja:

- Manuel Torres Campos.

- José Salvador Gamboa.

\section{Votación y proclamación}

Vicente Gadea obtuvo todos los votos.

El presidente hizo la proclamación de catedrático a su favor.

\section{Materiales}

- Documentación de naturaleza administrativa, sin temarios ni materiales producidos por los opositores. Incluye las actas.

- Anuncio de la convocatoria.

- Escrito de apelación de 18 de mayo de 1872 firmado por Blas, Gamboa y Buil. Se adjunta una "demostración de algunos de los plagios" de la memoria de Gadea.

- Escrito de apelación de Navarro. 4 de junio, 1872.

- Escrito de alegaciones de Gadea. 18 de mayo, 1872.

- Ejemplar de Las Provincias. Diario de Valencia, de 16 de mayo de 1872.

\section{Signatura}

AGA 32/o7282. Legajo 5338-44.

\section{Cátedra}

Teoría y práctica de los Procedimientos judiciales y práctica forense.

\section{Universidad}

Oviedo.

\section{Anuncio}

R.O. de 11 de enero, 1872. Gaceta del 19.

Fue anunciada a traslación (14 de mayo de 1870) y concurso (26 de julio de 1870).

\section{Reglamento aplicable}

15 de enero, 1870.

\section{Fechas de la oposición}

Constitución: 16 de diciembre, 1872.

Presentación de los opositores: 21 de diciembre, 1872.

Votación y propuesta: 28 de marzo, 1874. 


\section{Tribunal}

Presidente: Francisco de la Pisa.

Vocales: Juan Inocencio Conde, Felipe González Vallarino, Luis Silvela, Rafael Conde Luque.

Secretario: José Manuel Piernas.

\section{Opositores}

1. ${ }^{\mathrm{a}}$ trinca:

- Eduardo Soler Pérez.

- José Ramón Melendrera.

- Andrés Blas y Melendo.

2. ${ }^{\mathrm{a}}$ trinca:

- Ángel María Álvarez Cabeza de Vaca.

- Mariano Laspra.

- Antonio Ochils Font del Sol.

$3 .^{\text {a }}$ trinca:

- Manuel Torres Campos.

- Pablo Buil Bayod.

- José Salvador Gamboa.

\section{Votación y proclamación}

Eduardo Soler obtuvo todos los votos menos el de Vallarino, quien votó por la no provisión.

El presidente hizo la proclamación de catedrático a su favor.

\section{Materiales}

- Documentación de naturaleza administrativa, sin temarios ni materiales producidos por los opositores.

- Anuncio de la convocatoria. Se indica que los ejercicios se verificarían en Oviedo.

- Escrito de los opositores Soler, Torres Campos y Gamboa por el que se solicita que los ejercicios se verifiquen en Madrid. 28 de febrero, 1872.

- Escrito del opositor Lastra por el que se solicita que los ejercicios se verifiquen en Oviedo. 12 de diciembre, 1872.

- Escrito de recusación de Eduardo Soler contra Benito Gutiérrez y Benigno Cafranga. Datado el 5 de agosto de 1872. 


\section{Signatura}

AGA 32/o7284. Legajo 5339-28.

\section{Cátedra}

Historia y elementos de Derecho romano.

\section{Universidad}

Sevilla, Granada, Salamanca, Santiago, Zaragoza.

\section{Anuncio}

R.O. de 18 de noviembre, 1872; Gaceta del 25.

\section{Reglamento aplicable}

15 de enero, 1870.

\section{Fechas de la oposición}

Constitución: 6 de noviembre, 1875.

Presentación: 10 de noviembre, 1875.

Votación y propuesta: 19 de enero, 1876.

\section{Tribunal}

Presidente: José Moreno Nieto.

Vocales: Fernando Álvarez, Carlos María Coronado, Luis Pidal y Mon (Marqués de Pidal), Julián Pastor Alvira, Félix López San Martín.

Secretario: Fabio de la Rada Delgado.

\section{Opositores}

Modesto Falcón Ozcoidi.

Pablo Buil Bayod.

José Otero Carracedo.

Benito Núñez Forcelledo.

Manuel Pérez Santamarina.

Luis Miralles Salabert.

Eladio García Amado.

Eusebio María Chapado y García.

Miguel Silva González.

Santiago Muñiz López.

Manuel Poley Poley.

Pablo de Peña Entrala.

Manuel Torres Campos. 


\section{Votación y propuesta}

En la primera votación el tribunal consideró con aptitud suficiente a los siguientes opositores: José Otero Carracedo, por cinco votos contra uno; Benito Núñez Forcelledo por unanimidad; Luis Miralles Salabert por unanimidad; Eladio García Amado por unanimidad; Pablo de Peña Entrala por unanimidad; Manuel Torres Campos por cuatro votos contra dos.

En la segunda votación el tribunal calificó el mérito relativo de los opositores considerados aptos. El resultado fue el siguiente:

- Para el primer lugar, Peña Entrala por cuatro votos contra dos obtenidos por Núñez Forcelledo.

- Para el segundo lugar, Núñez Forcelledo por cinco votos contra uno obtenido por García Amado.

- Para el tercer lugar, Miralles Salabert obtuvo dos votos frente a otros dos votos de García Amado. El tribunal decidió el empate a favor de Miralles Salabert, por haber sido propuesto éste en terna en segundo lugar en una oposición anterior.

- Para el cuarto lugar, García Amado por tres votos contra dos de Torres Campos.

- Para el quinto lugar, Otero Carracedo por cuatro votos frente a dos de Torres Campos.

- Para el sexto lugar, Torres Campos.

En consecuencia fueron nombrados los siguientes catedráticos: José Otero Carracedo para Sevilla, Benito Núñez Forcelledo para Santiago; Luis Miralles Salabert para Zaragoza; Eladio García Amado para Salamanca; Pablo de Peña Entrala para Granada.

\section{Materiales}

Actas de la oposición; oficios del negociado; oficios varios sobre conformación del tribunal. Las actas recogen el listado de libros solicitados por los opositores.

\section{Signatura}

AGA 32/07283. Legajo 5339-1.

\section{Cátedra}

Ampliación del Derecho civil y Códigos españoles.

\section{Universidad}

Barcelona y Oviedo.

\section{Anuncio}

R.O. de 18 de abril, 1873. Gaceta del 28. 


\section{Reglamento aplicable}

15 de enero, 1870.

\section{Fechas de la oposición}

Constitución: 5 de enero, 1874 .

Presentación de los opositores: 24 de enero, 1874.

Votación y propuesta: 30 de mayo, 1874.

Acto de proclamación de la cátedra de Oviedo: 16 de junio, 1874.

\section{Tribunal}

Presidente: Domingo Ramón Domingo.

Vocales: Benito Gutiérrez, Augusto Comas, Gumersindo Azcárate, Benigno Cafranga Pando, Salvador Torres Aguilar, Francisco Sales Jaumar.

Secretario: José Manuel Piernas.

\section{Opositores}

Mariano Ripollés Baranda.

Jorge María Ledesma y Palacios.

Modesto Falcón y Ozcoide.

Miguel de la Guardia y Corencia.

Florentino Humberti Sala.

José María Planas Casals.

Andrés Blas y Melendo.

Félix Aramburu y Zuloaga.

\section{Votación y Propuesta}

Para la cátedra de Barcelona cada uno de los ocho jueces votaron a José María Planas Casals.

Para la cátedra de Oviedo se obtuvo el resultado siguiente: tres votos de "no ha lugar a la provisión de la cátedra, otros tres votos a favor de Mariano Ripollés y Baranda, y otros dos votos a favor de Félix Aramburu Zuloaga.

A falta de mayoría absoluta, se procedió a una segunda votación, que arrojó el mismo resultado. Por consiguiente, se decidió que no había lugar a proveer la cátedra vacante de Oviedo.

En sesión de 16 de junio de 1874, tras apelación interpuesta por el opositor Mariano Ripollés Baranda, declarada procedente por el Consejo Universitario, se proclama catedrático a tal opositor.

El anterior presidente del tribunal, Domingo Ramón Domingo, no concurre a la sesión. Se nombra por tanto nuevo presidente a Benito Gutiérrez. 


\section{Materiales}

Contiene documentación de naturaleza administrativa, sin temarios ni materiales producidos por los opositores.

\section{Signatura}

AGA 32/07285. Legajo 5339-30.

\section{Cátedra}

Filosofía del Derecho y Derecho internacional (vacante por separación de Giner de los Ríos).

\section{Universidad}

Central.

\section{Anuncio}

R.O. de 10 de agosto, 1873; Gaceta del 19.

\section{Reglamento aplicable}

1 de junio, 1873 .

\section{Fechas de la oposición}

Constitución: 4 de abril, 1876.

Presentación: 26 de abril, 1876.

Votación y propuesta: 10 de mayo, 1876.

\section{Tribunal}

Presidente: Antonio Benavides.

Vocales: José María Manresa, Amalio Marichalar, José María Antequera, José Pantoja, Melchor Salvá.

Secretario: Fernando Mellado.

(Los vocales inicialmente propuestos que renuncian son Manuel Laraña, Nicolás de Paso Delgado, Benito Gutiérrez y Julián Pastor Alvira, padre de uno de los opositores).

\section{Opositores}

Julián Pastor y Rodríguez.

Pedro López Sánchez.

Nicolás María Serrano. Se retira "por causas imprevistas y agenas a mi voluntad". 


\section{Votación y propuesta}

El tribunal propuso para el primer lugar de la terna a Pedro López Sánchez, con seis votos contra uno a favor de Julián Pastor Rodríguez, propuesto para el segundo lugar.

López Sánchez fue nombrado el 5 de julio de 1876.

\section{Materiales}

Actas de la oposición; oficios del negociado; oficios varios sobre conformación del tribunal, ejemplar de la Gaceta de 12 de abril de 1876. Las actas recogen el listado de libros solicitados utilizados por los opositores, tanto los que pertenecían a la biblioteca de la universidad, como los que eran propiedad de éstos.

Hay larga nota del negociado (3 de agosto de 1875) sobre la falta de equidad y justicia que se deriva del Decreto de 11 de Julio de 1871 (y del de 15 de enero de 1870), conforme al cual las vacantes se cubren por concurso y las oposiciones se aplazan indefinidamente "con notable perjuicio de la enseñanza". Es una "anomalía" aún más "chocante", dicen, cuando se trata de la Facultad de Derecho.

\section{Signatura}

AGA 32/07285. Legajo 5339-29.

\section{Cátedra}

Elementos de Derecho político y administrativo español.

\section{Universidad}

Granada, Valencia y Oviedo.

\section{Anuncio}

R.O. de 16 de marzo, 1874; Gaceta del 22.

\section{Reglamento aplicable}

1 de junio, 1873 .

\section{Fechas de la oposición}

Constitución: 9 de marzo, 1876.

Presentación: 10 de marzo, 1876.

Votación y propuesta: 11 de abril, 1876.

\section{Tribunal}

Presidente: Manuel Colmeiro. 
Vocales: Juan Morales, Salvador Albacete, Mariano Carreras, Ignacio Ferrán, Nicolás Canales.

Secretario: Salvador Parga.

\section{Opositores}

Juan Santiago Portero.

Salvador Cuesta Martín.

Joaquín Costa Martínez.

Rafael Ureña.

Ramón Andreu Serra.

Vicente Santamaría y Paredes.

Juan de Dios Vico Bravo.

Salvador Dávila García.

\section{Votación y propuesta}

En la primera votación el tribunal consideró, por unanimidad, con aptitud suficiente a los siguientes opositores: Juan Santiago Portero, Salvador Cuesta Martín, Joaquín Costa Martínez, Rafael Ureña, Vicente Santamaría y Juan de Dios Vico Bravo.

En la segunda votación el tribunal calificó el mérito relativo de los opositores considerados aptos. El resultado fue el siguiente:

- Para el primer lugar, Vico Bravo por cinco votos contra dos obtenidos por Santamaría.

- Para el segundo lugar, Santamaría por unanimidad.

- Para el tercer lugar, Santiago Portero por cinco votos frente a dos de Costa.

- Para el cuarto lugar, Costa por unanimidad.

- Para el quinto lugar, Ureña por unanimidad.

El tribunal realizó la siguiente propuesta de terna:

Para la primera, Vico Bravo primero y Costa segundo.

Para la segunda, Santamaría primero y Ureña segundo.

Para la tercera, en único lugar Portero.

\section{Materiales}

Actas de la oposición; oficios del negociado; oficios varios sobre conformación del tribunal, anuncio de vacantes. Las actas recogen el listado de libros solicitados por los opositores. 


\section{Signatura}

AGA 32/07283. Legajo 5339-9.

\section{Cátedra}

Disciplina general de la Iglesia y particular de España.

\section{Universidad}

Oviedo y Salamanca.

\section{Anuncio}

1874, 16 de marzo. Gaceta del 22.

\section{Reglamento aplicable}

1 de junio, 1873.

\section{Fechas de la oposición}

Constitución: 10 de noviembre, 1875.

Presentación de los opositores: misma fecha que la anterior.

Votación y propuesta: 10 de diciembre, 1875.

\section{Tribunal}

Presidente: José Lorenzo Aragonés.

Vocales: Juan Antonio Andonaegui, Eduardo Palou y Flores, Casto Ramón Fort, Rafael Conde Luque, Manuel García Menéndez.

Secretario: Pedro López Sánchez.

\section{Opositores}

Pío José Sánchez.

Víctor Díaz Ordoñez.

Modesto Falcón.

\section{Votación y Propuesta}

Para el primer lugar fue elegido por unanimidad Víctor Díaz Ordoñez. Para el segundo lugar Pío José Sánchez obtuvo tres votos, Modesto Falcón otros tres votos y hubo un voto en blanco.

El tribunal declaró a Modesto Falcón en segundo lugar debido a que había sido propuesto en terna en anteriores oposiciones. Por ello, el tribunal votó para el tercer lugar a Pío José Sánchez.

En virtud de lo anterior el tribunal formula la siguiente propuesta. Para la cátedra de Oviedo Víctor Díaz Ordoñez primero, Modesto Falcón segundo, y Pío José 
Sánchez tercero. Para la cátedra de Salamanca, Modesto Falcón primero y Pío José Sánchez segundo.

\section{Materiales}

Aparte de documentación de naturaleza administrativa habitual, el expediente recoge un ejemplar de la Gaceta de Madrid de 22 de octubre de 1875 y tres listados de libros que se solicitan al tribunal, correspondientes a los tres opositores.

\section{Signatura}

AGA 32/07286. Legajo 5339-44.

\section{Cátedra}

Elementos de Derecho mercantil y penal.

\section{Universidad}

Sevilla.

\section{Anuncio}

R.O. de 2 de abril, 1875; Gaceta del 22.

\section{Reglamento aplicable}

2 de abril, 1875 .

\section{Fechas de la oposición}

Constitución: 15 de noviembre, 1877.

Presentación de los opositores: 16 de noviembre, 1877.

Votación y propuesta: 17 de diciembre, 1877.

\section{Tribunal}

Presidente: Alejandro Groizard.

Vocales: Fernando Vida, Felipe González Vallarino, Luis Silvela, Francisco de Borja Palomo, Francisco Lastres.

Secretario: Melchor Salvá.

\section{Opositores}

Rafael Ureña.

Manuel Laraña Ramírez.

Ignacio Alonso Martínez.

Manuel Torres Campos. 
Faustino Álvarez de Manzano.

Antonio Cidad y Olmos.

No comparecieron: Luis Macías, Jacinto Moutells, José María Rojas.

Se retiraron de los ejercicios: Eusebio María Chapado García, Vicente Santiago Mansilla y Enrique de Sierra Valenzuela.

\section{Votación y propuesta}

En la primera votación el tribunal consideró con aptitud suficiente a los siguientes opositores por unanimidad: Rafael Ureña; Manuel Laraña; Manuel Torres, Faustino Álvarez de Manzano.

Antonio Cidad y Vicente Santiago no manifestaron "capacidad científica" por cuatro votos contra tres, y cinco votos contra dos respectivamente.

En la segunda votación el tribunal calificó el mérito relativo de los opositores considerados aptos. El resultado fue el siguiente:

- Para el primer lugar, Manuel Laraña por unanimidad.

- Para el segundo lugar, Faustino Álvarez de Manzano por unanimidad.

- Para el tercer lugar Ureña, por cuatro votos frente a dos de Torres.

- Para el cuarto lugar Torres por unanimidad.

El tribunal elevó a la superioridad la siguiente terna: para el primer lugar Laraña, para el segundo Álvarez de Manzano; para el tercero Ureña.

\section{Materiales}

Actas de la oposición; oficios del negociado; oficios varios sobre conformación del tribunal.

\section{Signatura}

AGA 32/07284. Legajo 5339-21.

\section{Cátedra}

Elementos de Derecho político y administrativo español.

\section{Universidad}

Salamanca.

\section{Anuncio}

1875, 21 de abril. Gaceta del 29.

\section{Reglamento aplicable}

2 de abril, 1875 . 


\section{Fechas de la oposición}

Constitución: 29 de octubre, 1875.

Presentación de los opositores: misma fecha que la anterior.

Votación y propuesta: 15 de noviembre, 1875 .

\section{Tribunal}

Presidente: Víctor Arnau.

Vocales: Salvador Albacete, Manuel Campos, José María Trías, José Millet, Antonio Alcántara.

Secretario: Germán Gamazo.

\section{Opositores}

Modesto Falcón Ozcaidi.

Juan Santiago Portero.

Enrique Gil Robles.

No comparecen: Francisco de Paula Villareal, Salvador Cuesta y Joaquín Costa.

\section{Votación y Propuesta}

Votos para el primer lugar: Enrique Gil Robles, cuatro; Juan Santiago Portero, tres.

Votos para el segundo lugar: Juan Santiago Portero, siete.

Votos para el tercer lugar: Modesto Falcón Ozcaidi: siete.

Propuesta en orden descendiente: Enrique Gil Robles; Juan Santiago Portero; Modesto Falcón Ozcaidi.

\section{Materiales}

Aparte de documentación de naturaleza administrativa habitual, un ejemplar del Boletín Oficial del 16 de octubre de 1875. El expediente recoge un listado con 103 preguntas aprobadas por el tribunal.

\section{Signatura}

AGA 32/07285. Legajo 5339-31.

\section{Cátedra}

Instituciones de Hacienda pública de España.

\section{Universidad}

Central. 


\section{Anuncio}

R.O. de 26 de mayo, 1875; Gaceta del 4 de julio.

\section{Reglamento aplicable}

2 de abril, 1875 .

\section{Fechas de la oposición}

Constitución: 17 de enero, 1876.

Presentación de los opositores: misma fecha, en la sesión de las tres de la tarde. Votación y propuesta: 11 de febrero, 1876.

\section{Tribunal}

Presidente: Manuel Silvela.

Vocales: Manuel Alonso Martínez, Fernando Ruiz Gómez, José García Barzanallana, Justo Pelayo Cuesta, Juan Antonio Andonaegui.

Secretario: José Doménech Coll.

\section{Opositores}

Modesto Fernández González.

José María Piernas Hurtado.

Juan Araúz de la Hidalga.

Francisco Javier Jiménez Pérez de Vargas.

Fernando Mellado Leguez.

\section{Votación y propuesta}

En la primera votación el tribunal consideró, por unanimidad, con aptitud suficiente a los todos los opositores.

En la segunda votación el tribunal calificó el mérito relativo de los opositores considerados aptos. El resultado fue el siguiente:

- Para el primer lugar, José María Piernas por cuatro votos.

- Para el segundo lugar, Francisco Javier Jiménez cuatro votos.

- Para el tercer lugar, Fernando Mellado por seis votos.

- Para el cuarto lugar, Juan Araúz por cuatro votos.

- Para el quinto lugar, Modesto Fernández por seis votos.

El tribunal propuso por consiguiente para el primer lugar de la terna a José María Piernas; para el segundo lugar a Francisco Javier Jiménez; para el tercero a Fernando Mellado Leguez.

A pesar de esta propuesta del tribunal, en 17 de marzo de 1876 fue nombrado Fernando Mellado Leguez . 


\section{Materiales}

Actas de la oposición; oficios del negociado; oficios varios sobre conformación del tribunal. Las actas recogen el listado de libros solicitados por los opositores. En algún caso el opositor menciona los que fueron efectivamente consultados, ya que otros no estuvieron a su disposición.

El expediente recoge un amplio informe fechado el primero de marzo de 1876 encargado por la Sección Segunda del Consejo de Instrucción Pública al Marqués de Zafra. En su conclusión segunda expresa que el Gobierno debe hacer entre la terna propuesta por el tribunal "su libre elección". El cuerpo de dicho informe se refiere en diversas ocasiones a la afiliación de los otros opositores en las "escuelas krausistas y revolucionarias".

\section{Signatura}

AGA 32/07284. Legajo 5339-20.

\section{Cátedra}

Historia y elementos de Derecho romano.

\section{Universidad}

Oviedo.

\section{Anuncio}

28 de julio, 1875. Gaceta del 7 de agosto.

No habiéndose presentado aspirantes al concurso, se declara desierto y se acuerda que dicha cátedra se provea por oposición. A su vez, dicho concurso fue anunciado por no haber habido ninguna solicitud por traslación.

\section{Reglamento aplicable}

2 de abril, 1875 .

\section{Fechas de la oposición}

Constitución: 11 de mayo, 1876.

Presentación de los opositores: 11 de mayo, 1876.

Votación y propuesta: 26 de mayo, 1876.

\section{Tribunal}

Presidente: Víctor Arnau.

Vocales: Francisco de la Pisa, Luis Silvela, José Prieto Álvarez, Manuel Tarrasa, Francisco Gómez Salazar.

Secretario: Santos Alfaro Lafuente. 


\section{Opositores}

Cleto Troncoso Pequeño.

\section{Votación y Propuesta}

Lo miembros del tribunal deciden por unanimidad que el opositor tiene la aptitud suficiente para ser nombrado catedrático.

\section{Materiales}

Aparte de documentación de naturaleza administrativa habitual, el expediente recoge un ejemplar de la Gaceta de Madrid de 30 de abril de 1876.

\section{Signatura}

AGA 32/07284. Legajo 5339-27.

\section{Cátedra}

Ampliación del Derecho civil y Códigos españoles.

\section{Universidad}

Granada, Santiago y Oviedo.

\section{Anuncio}

1875, 11 de octubre. Gaceta del 16.

\section{Reglamento aplicable}

2 de abril, 1875 .

\section{Fechas de la oposición}

Constitución: 8 de abril, 1876.

Presentación de los opositores: 10 de abril, 1876.

Votación y propuesta: 24 de mayo, 1876.

\section{Tribunal}

Presidente: Vicente Lafuente.

Vocales: Antonio Rodríguez Cepeda, Augusto Comas, Domingo Alcalde, Felipe González Vallarcino, Vicente Olivares.

Secretario: Mariano Ripollés Baranda. 


\section{Opositores}

Felipe Sánchez Román.

Lorenzo de Prada Fernández.

Fermín Canella Secadez.

Federico Brusi Crespo.

Félix Pío Aramburu Zuloaga.

José Sánchez de Molina.

No comparecen: Fernando Muñoz Rosa, Ramón Andreu Serra, Eusebio Sánchez Reina.

\section{Votación y Propuesta}

Votos para el primer lugar: Felipe Sánchez Román por seis votos.

Votos para el segundo lugar: Félix Pío Aramburu Zuloaga por seis votos.

Votos para el tercer lugar: Lorenzo de Prada Fernández por seis votos.

Votos para el cuarto lugar: en blanco por seis votos.

Votos para el quinto lugar: en blanco por seis votos.

Votos para el sexto lugar: Fermín Canella Secadez por seis votos.

Propuesta: para Granada Felipe Sánchez Román; para Oviedo Félix Pío Aramburu Zuloaga; y para Santiago Lorenzo de Prada Fernández en primer lugar y Fermín Canella Secadez en segundo lugar.

\section{Materiales}

Aparte de la documentación de naturaleza administrativa habitual, el expediente recoge un ejemplar de la Gaceta de 26 de marzo de 1876. Asimismo se enumeran los libros solicitados por los actuantes.

\section{Signatura}

AGA 32/07286. Legajo 5339-42.

\section{Cátedra}

Teoría y práctica de los Procedimientos judiciales y práctica forense.

\section{Universidad}

Oviedo.

\section{Anuncio}

R.O. de 21 de abril, 1875; Gaceta del 30.

En 7 de enero de 1876 la cátedra se anuncia a traslación.

El 19 de febrero de 1876 se convoca de nuevo la oposición. Gaceta del 27. 


\section{Reglamento aplicable}

2 de abril, 1875 .

\section{Fechas de la oposición}

Constitución del primer tribunal: 12 de noviembre, 1875 .

Votación y propuesta: 17 de diciembre, 1975. Se declaró no haber lugar a la provisión de la cátedra. Los opositores examinados fueron los siguientes: Víctor Polledo, Antonio Cidad, José Salvador Gamboa.

Constitución del segundo tribunal: 4 de diciembre, 1876 .

Presentación de los opositores: 11 de diciembre, 1876.

Votación y propuesta: 7 de enero, 1877.

\section{Tribunal}

Presidente: Manuel Colmeiro.

Vocales: Juan Inocencio Conde, Ramón Segovia Solanas, Saturnino Arenillas, Francisco Pareja de Alarcón, Manuel Danvila.

Secretario: Salvador Torres Aguilar.

\section{Opositores}

Antonio Cidad Olmos.

Manuel Brualla Alicar.

Eusebio María Chapado García.

No comparecieron: Francisco de Paula Villareal, Rafael Giménez, José Ramón Melendreras, Mariano Laspra, Antonio Andrade, Santiago Prieto, Pedro Mirasol, Enrique de Sierra, Francisco de Paula Blanco.

\section{Votación y propuesta}

En la primera votación el tribunal consideró con aptitud suficiente a los todos los opositores. Eusebio María Chapado García por seis votos contra uno; Antonio Cidad y Olmos por cuatro votos contra tres, Manuel Brualla por cinco votos contra tres.

En la segunda votación el tribunal calificó el mérito relativo de los opositores considerados aptos. El resultado fue el siguiente:

- Para el primer lugar, Brualla cuatro votos; Chapado tres votos.

- Para el segundo lugar, Chapado cinco votos; Brualla un voto y Cidad un voto.

- Para el tercer lugar Cidad tres votos y cuatro votos en blanco.

El tribunal elevó al Gobierno la propuesta siguiente: para el primer lugar de la terna a Brualla; para el segundo lugar a Chapado; para el tercero a Cidad. 


\section{Materiales}

Actas de la oposición; oficios del negociado; oficios varios sobre conformación del tribunal. Las actas recogen el listado de libros utilizados por los opositores.

\section{Signatura}

AGA 32/07286. Legajo 5339-43.

\section{Cátedra}

Historia y elementos del Derecho civil español, común y foral.

\section{Universidad}

Oviedo.

\section{Anuncio}

R.O. de 11 de agosto, 1875; Gaceta del 24.

En 9 de marzo de 1876 se anuncia a traslación, pero en 22 de abril de 1876 se vuelve a anunciar la oposición. Gaceta del 7.

\section{Reglamento aplicable}

2 de abril, 1875 .

\section{Fechas de la oposición}

Constitución del primer tribunal: 20 de febrero, 1876.

Votación y propuesta: de febrero, 1876. Se acordó "no haber lugar a declarar si procede la provisión de la cátedra”. El único opositor fue Federico Brusi y Crespo, quién obtuvo tres votos a favor y tres en contra en la votación sobre su aptitud. Constitución del segundo tribunal: 24 de enero, 1877.

Presentación de los opositores: 29 de enero, 1877.

Votación y propuesta: 21 de febrero, 1877.

\section{Tribunal}

Presidente: Víctor Arnau.

Vocales: Benito Gutiérrez, Plácido Jove-Hevia, Diego Suárez, Julián Pastor, Melchor Salva.

Secretario: Felipe Sánchez Román.

\section{Opositores}

Luis Muñiz Miranda Valdés.

Juan Noguera Vilalta. 
Lorenzo de Prada Fernández.

No comparecieron: Eusebio Chapado, Ramón Guixi, Agustín Hidalgo, Manuel Torres, José Sánchez de Molina.

\section{Votación y propuesta}

En la primera votación el tribunal consideró con aptitud suficiente a los todos los opositores. Luis Muñiz Miranda por unanimidad; Juan Noguera por cuatro votos y dos en blanco; Lorenzo de Prada por unanimidad.

En la segunda votación el tribunal calificó el mérito relativo de los opositores considerados aptos. El resultado fue el siguiente:

- Para el primer lugar, Lorenzo de Prada por cinco votos contra uno de Luis Muñiz Miranda.

- Para el segundo lugar, Luis Muñiz Miranda por unanimidad.

- Para el tercer lugar Juan Noguera cuatro votos y dos en blanco.

El tribunal elevó al Gobierno la propuesta de la terna siguiente: para el primer lugar Lorenzo de Prada; para el segundo lugar Luis Muñiz Miranda; para el tercero Juan Noguera.

\section{Materiales}

Actas de la oposición; oficios del negociado; oficios varios sobre conformación del tribunal. Las actas recogen el listado de libros utilizados por los opositores.

El expediente instruye también la provisión de la cátedra de Salamanca, anunciada a traslación, para la cual fue nombrado Mariano Ripollés. Consta su hoja de estudios.

\section{Signatura}

AGA 32/07286. Legajo 5339-45.

\section{Cátedra}

Elementos de Economía política y Estadística.

\section{Universidad}

Valladolid.

\section{Anuncio}

R.O. de 31 de octubre, 1876; Gaceta del 14 de noviembre.

\section{Reglamento aplicable}

2 de abril, 1875 . 


\section{Fechas de la oposición}

Constitución: 3 de mayo, 1877.

Presentación de los opositores: 5 de mayo, 1877.

Votación y propuesta: 26 de mayo, 1877.

\section{Tribunal}

Presidente: Manuel Colmeiro.

Vocales: Lope Gisbert, Francisco Millán Caro, Carlos María Perier, Narciso Guillén Tomás, José Piernas y Hurtado.

Secretario: Modesto Fernández y González.

\section{Opositores}

Rafael Ureña.

Ramón Guixé.

Adolfo Álvarez Buylla González.

Ángel María Álvarez Cabeza de Vaca.

No compareció Luis Pazos López.

\section{Votación y propuesta}

En la primera votación el tribunal consideró con aptitud suficiente a los cuatro opositores. Guixé por cuatro votos contra tres, Adolfo Álvarez Buylla González por seis contra uno, Rafael Ureña por cinco contra dos, Ángel María Álvarez Cabeza de Vaca por cuatro contra tres.

En la segunda votación el tribunal calificó el mérito relativo de los opositores considerados aptos. El resultado fue el siguiente:

- Para el primer lugar, Álvarez Buylla por seis votos contra uno de Álvarez Cabeza de Vaca.

- Para el segundo lugar, Ureña por cuatro votos contra dos de Guixé y uno de Buylla.

- Para el tercer lugar Álvarez Cabeza de Vaca por cuatro votos frente a dos de Ureña y uno de Guixé.

El tribunal formuló la siguiente terna: para el primer lugar Álvarez Buylla, para el segundo Ureña; para el tercero Álvarez Cabeza de Vaca.

\section{Materiales}

Actas de la oposición; oficios del negociado; oficios varios sobre conformación del tribunal. Las actas enumeran los libros utilizados por los opositores. 


\section{Signatura}

AGA 32/o7287. Legajo 5340-3.

\section{Cátedra}

Elementos de Derecho político y administrativo español.

\section{Universidad}

Oviedo.

\section{Anuncio}

R.O. de 24 de mayo, 1877; Gaceta del 30.

\section{Reglamento aplicable}

2 de abril, 1875 .

\section{Fechas de la oposición}

Constitución: 16 de febrero, 1878.

Presentación de los opositores: 18 de febrero, 1878

Votación: 31 de marzo, 1878.

\section{Tribunal}

Presidente: Manuel Colmeiro.

Vocales: Mariano Carreras y González, Fernando Mellado, Fermín Canella, Vicente Santamaría, José Nieto Álvarez. Éste último no votó, por no haber asistido a las últimas sesiones.

Secretario: Ricardo Ruiz Benitua.

\section{Opositores}

Alberto Laberón Vasconi.

Rafael Ureña.

Salvador Cuesta Sánchez.

Rogelio Jove Bravo.

No comparecieron: Francisco Villareal Valdivia, Eduardo Gómez Moreno y Puchol. Eusebio Sánchez Reina se retiró.

\section{Votación y propuesta}

El tribunal aprobó los ejercicios de todos los opositores. El de Alberto Laberón por cuatro votos contra dos, el de Rafael Ureña por cinco votos contra uno, el de Salvador Cuesta por cinco votos contra uno, y el de Rogelio Jove por cuatro votos contra dos. 
En la segunda votación el tribunal calificó el mérito relativo de los opositores considerados aptos. El resultado fue el siguiente:

- Para el primer lugar, Ureña por cinco votos contra uno de Cuesta.

- Para el segundo lugar, Cuesta por unanimidad.

- Para el tercer lugar, Jove por cinco votos contra uno de Laberón.

La propuesta queda formulada como sigue: Ureña para el primer lugar; Cuesta para el segundo; Jove para el tercero.

\section{Materiales}

Actas de la oposición; oficios del negociado; oficios varios sobre conformación del tribunal. Las actas recogen las solicitudes de libros de cada opositor.

\section{Signatura}

AGA 32/07287. Legajo 5340-8.

\section{Cátedra}

Ampliación del Derecho civil y Códigos españoles.

\section{Universidad}

Sevilla.

\section{Anuncio}

R.O. de 23 de julio, 1877; Gaceta del 1 de agosto.

La cátedra fue anunciada a traslación y a concurso con anterioridad al anuncio de la oposición.

\section{Reglamento aplicable}

2 de abril, 1875 .

\section{Fechas de la oposición}

Constitución: 13 de marzo, 1878.

Presentación de los opositores: 15 de marzo, 1878.

Votación: 28 de marzo, 1878.

Nombramiento del catedrático: 15 de abril, 1878.

\section{Tribunal}

Presidente: Víctor Arnau.

Vocales: Vicente de la Fuente, Benito Gutiérrez, Manuel Laraña, Pedro López Sánchez, Juan de Dios de la Rada.

Secretario: Jorge María Ledesma. 


\section{Opositores}

Manuel Bedmar Escudero.

Antonio Andrade Navarrete.

No comparecieron: Eusebio Chapado, Luis Muñoz, Rafael Ureña, Federico Brusi, Ángel Sánchez, Enrique Zalavar, Antonio Cidad, Eusebio Sánchez.

\section{Votación y propuesta}

El tribunal declaró la aptitud de ambos opositores.

Acordó el primer lugar a Manuel Bedmar Escudero y el segundo a Antonio Andrade.

Por lo que formuló propuesta en dicho orden. Todo ello por unanimidad.

\section{Materiales}

Actas de la oposición; oficios del negociado; oficios varios sobre conformación del tribunal; ejemplar del Boletín Oficial de 5 de marzo de 1878. Las actas mencionan libros solicitados por cada opositor.

\section{Signatura}

AGA 32/07287. Legajo 5340-2.

\section{Cátedra}

Elementos de Economía política y Estadística.

\section{Universidad}

Granada.

\section{Anuncio}

R.O. de 6 de octubre, 1877; Gaceta del 10.

\section{Reglamento aplicable}

2 de abril, 1875 .

\section{Fechas de la oposición}

Constitución: 5 de febrero, 1878 .

Presentación de los opositores: 8 de febrero, 1878 .

Votación: 10 de marzo, 1878. El tribunal eleva consulta a la Superioridad.

Propuesta: 23 de marzo, 1878. 


\section{Tribunal}

Presidente: José Moreno Nieto.

Vocales: Francisco Millán Caro, Juan Morales y Serrano, Rafael Conde Luque, José María Piernas Hurtado, Carlos María Perier.

Secretario: Modesto González Fernández.

\section{Opositores}

Ramón Guixé Mexía.

Rafael Giménez Baena.

Rafael Ureña.

José España Lledó.

No compareció Ángel María Álvarez Cabeza de Vaca.

\section{Votación y propuesta}

El tribunal consideró por unanimidad con aptitud suficiente a todos los opositores.

En la segunda votación el tribunal calificó el mérito relativo de los opositores considerados aptos.

La votación para el primer puesto dio el resultado siguiente:

- Rafael Giménez Baena, dos votos.

- Rafael Ureña, dos votos.

- José España y Lledó, dos votos.

El mismo resultado se repitió en segunda votación. Ante las dudas interpretativas acerca de lo dispuesto para el caso de desempate por el Reglamento de 2 de abril de 1875, el tribunal acuerda elevar consulta a la Superioridad.

Después de recibida y leída la respuesta, el tribunal declaró que correspondía el primer lugar de la terna a Giménez Baena, Catedrático de Economía política y Estadística Comercial del Instituto de segunda enseñanza de Málaga desde el 27 de octubre de 1876, ya que España Lledó era Catedrático de Geografía e Historia del Instituto de Castellón únicamente desde el 8 de septiembre de 1877.

- Para el segundo lugar España y Lledó obtiene cuatro votos frente a dos de Ureña.

- Para el tercer lugar Ureña obtiene seis votos.

- Para el cuarto lugar Guixé obtiene seis votos.

La propuesta queda formulada como sigue: Rafael Giménez Baena para el primer lugar; José España Lledó para el segundo; Rafael Ureña para el tercero; Ramón Guixé Mexía para el cuarto.

\section{Materiales}

Actas de la oposición; oficios del negociado; oficios varios sobre conformación del 
tribunal. Unidas a las actas se conservan las papeletas con las diez preguntas que extrajo cada opositor de la urna en el primer ejercicio. También se unen las hojas con las solicitudes de libros de cada opositor.

La consulta a la Superioridad está firmada por el presidente del tribunal el 10 de marzo de 1978. Una carta de protesta del opositor Lledó esta fechada en 21 de marzo.

\section{Signatura}

AGA 32/07287. Legajo 5340-1.

\section{Cátedra}

Disciplina general de la Iglesia y particular de España.

\section{Universidad}

Granada.

\section{Anuncio}

R.O. de 13 de marzo, 1878; Gaceta del 24.

\section{Reglamento aplicable}

2 de abril, 1875 .

\section{Fechas de la oposición}

Constitución: 19 de octubre, 1878.

Presentación de los opositores: 22 de octubre, 1878.

Votación y propuesta: 20 de noviembre, 1878.

\section{Tribunal}

Presidente: Eduardo Palou Flores.

Vocales: Pedro de la Casa, José Mateos Gago, Manuel Chacón, Justo Barbajero, Pedro López Sánchez.

Secretario: Víctor Díaz Ordóñez Escandón.

\section{Opositores}

Ignacio Alonso Martínez.

Ángel Rodríguez Méndez.

Francisco de Paula Leal de Ibarra.

Ángel Sánchez Rubio.

Juan Pedro Morales Alonso. 
Andrés Manjón Manjón.

Álvaro López de Mora.

No comparecieron Eduardo Gómez, José Hospital, Alberto Laberrón.

\section{Votación y propuesta}

El tribunal consideró por unanimidad con aptitud suficiente a todos los opositores. En la segunda votación el tribunal calificó el mérito relativo de los opositores considerados aptos. El resultado fue el siguiente:

- Para el primer lugar, obtuvieron tres votos respectivamente Juan Pedro Morales y Álvaro López de Mora. El empate fue resuelto a favor de Morales por la mayor antigüedad de su título de Doctor.

- Para el segundo lugar, López de Mora por cuatro votos contra dos de Manjón y Manjón.

- Para el tercer lugar, Manjón y Manjón por cuatro votos frente a uno de Ignacio Alonso Martínez y uno de Francisco de Paula Leal de Ibarra.

- Para el cuarto lugar, Alonso Martínez tres votos, Leal de Ibarra dos votos y Sánchez Rubio un voto. En segunda votación Alonso Martínez obtuvo cuatro votos.

- Para el quinto lugar, Sánchez Rubio cuatro votos, Leal de Ibarra un voto y Rodríguez Méndez un voto.

- Para el sexto lugar, tres votos para Leal de Ibarra y Rodríguez Méndez respectivamente. El empate fue resuelto a favor de Rodríguez Méndez por la mayor antigüedad del título.

- Para el séptimo lugar Leal de Ibarra por unanimidad.

El tribunal formuló la siguiente terna: para el primer lugar Juan Pedro Morales, para el segundo Álvaro López de Mora; para el tercero Andrés Manjón Manjón.

\section{Materiales}

Actas de la oposición; oficios del negociado; oficios varios sobre conformación del tribunal. Unidas a las actas se conservan las papeletas con las diez preguntas que extrajo cada opositor de la urna en el primer ejercicio.

\section{Signatura}

AGA 32/07287. Legajo 5340-4.

\section{Cátedra}

Elementos de Economía política y Estadística.

\section{Universidad}

Salamanca. 


\section{Anuncio}

R.O. de 4 de mayo, 1878; Gaceta del 12.

\section{Reglamento aplicable}

2 de abril, 1875 .

\section{Fechas de la oposición}

Constitución: 21 de octubre, 1878.

Presentación de los opositores: misma fecha que la anterior.

Votación y propuesta: 15 de noviembre, 1878.

\section{Tribunal}

Presidente: José Moreno Nieto.

Vocales: Melchor Salvá, Félix Pío de Aramburu, Carlos María Perier, Francisco Millán Caro, Vicente Olivares.

Secretario: Felipe Sánchez Román.

Carlos María Perier no asiste a las últimas sesiones ni a la votación.

\section{Opositores}

Ángel Rico Valarmino.

Ramiro Fernández de la Mora.

Ramón Guixé Mexía.

Teodoro Peña Fernández.

Leopoldo García Alas Ureña.

Víctor Ozcariz Laraga.

No comparecieron: Ángel Álvarez Cabeza de Vaca, Salvador Cuesta.

Se retiraron: Juan Poveda García y Francisco de Paula Blanco Constans.

\section{Votación y propuesta}

El tribunal declaró la aptitud de todos los opositores. La de Ángel Rico Valarmino, Ramiro Fernández de la Mora, Teodoro Peña Fernández y Leopoldo García Alas Ureña, por unanimidad. La de Ramón Guixé y Mexía por cinco votos contra uno. La de Víctor Ozcariz Laraga por cuatro votos contra dos.

En la segunda votación el tribunal calificó el mérito relativo de los opositores considerados aptos. El resultado fue el siguiente:

- Para el primer lugar, García Alas por cuatro votos contra uno de Rico y uno de Peña.

- Para el segundo lugar, Peña Fernández por tres votos contra dos de Rico y uno de Fernández de la Mora.

- Para el tercer lugar, Rico por tres votos contra dos de Fernández de la Mora y uno de Guixé. 
- Para el cuarto lugar, Fernández de la Mora por cinco votos contra uno de Guixé. - Para el quinto lugar, Guixé por cinco votos y uno en blanco.

La propuesta de terna queda formulada como sigue: García Alas para el primer lugar; Peña y Fernández para el segundo; Rico y Valarmino para el tercero.

\section{Materiales}

Actas de la oposición; oficios del negociado; oficios varios sobre conformación del tribunal. Las actas recogen las solicitudes de libros de cada opositor.

\section{Signatura}

AGA 32/07287. Legajo 5340-6.

\section{Cátedra}

Disciplina general de la Iglesia y particular de España.

\section{Universidad}

Santiago.

\section{Anuncio}

R.O. de 26 de julio, 1878; Gaceta del 7 de agosto.

\section{Reglamento aplicable}

2 de abril, 1875 .

\section{Fechas de la oposición}

Constitución: 21 de febrero, 1879.

Presentación de los opositores: 22 de febrero, 1879.

Votación: 17 de marzo, 1879.

\section{Tribunal}

Presidente: Alejandro Groizard.

Vocales: Juan Inocencio Conde, Francisco Germán Salazar, Manuel García Menéndez de Navas, Didio González Ibarra, Benigno Cafranga.

Secretario: Juan de Dios Vico Bravo.

\section{Opositores}

Andrés Manjón Manjón.

Álvaro López de Mora.

Antonio Toledo Quintela. 
Antonio García Vázquez Queipo.

Ignacio Alonso Martínez.

No comparecieron: Francisco Leal, Eduardo Gómez, Ángel Sánchez, Enrique Ferreyro, Juan Puig, Alberto Laverón.

\section{Votación y propuesta}

El tribunal declaró por unanimidad la aptitud de todos los opositores.

En la segunda votación el tribunal calificó el mérito relativo de los opositores considerados aptos. El resultado fue el siguiente:

- Para el primer lugar, Manjón Manjón por cuatro votos contra tres de López de Mora.

- Para el segundo lugar, López de Mora por cuatro votos contra uno de García Vázquez Queipo, uno de Alonso Martínez y uno de Toledo Quintela.

- Para el tercer lugar, García Vázquez Queipo por tres votos contra dos de Alonso Martínez y dos de Toledo Quintela.

- Para el cuarto lugar, Toledo Quintela por cuatro votos contra dos Alonso Martínez y uno de García Vázquez Queipo.

- Para el quinto lugar, Alonso Martínez por unanimidad.

La propuesta de terna queda formulada como sigue: Manjón Manjón para el primer lugar; López de Mora para el segundo, García Vázquez Queipo para el tercero.

\section{Materiales}

Actas de la oposición; oficios del negociado; oficios varios sobre conformación del tribunal. Unidas a las actas se conservan las papeletas con las diez preguntas que extrajo cada opositor de la urna en el primer ejercicio. También se unen las hojas con las solicitudes de libros de cada opositor.

\section{Signatura}

AGA 32/07288. Legajo 5340-13.

\section{Cátedra}

Historia y elementos del Derecho civil español, común y foral.

\section{Universidad}

Oviedo.

\section{Anuncio}

R.O. de 27 de marzo, 1879; Gaceta del 5 de abril. 


\section{Reglamento aplicable}

2 de abril, 1875 .

\section{Fechas de la oposición}

Constitución: 3 de noviembre, 1879.

Presentación de los opositores: 6 de noviembre, 1879.

Votación y propuesta: 15 de diciembre, 1879.

\section{Tribunal}

Presidente: Luis Pidal y Mon (Marqués de Pidal).

Vocales: Vicente de la Fuente, Augusto Comas, Felipe Sánchez Román, José García Barzanallana, Plácido Jove Hevia.

Secretario: Manuel Benagas Portocarrero.

\section{Opositores}

Vicente Calabuig Larra.

Manuel Puig Torán.

Faustino Álvarez del Manzano Álvarez de Rivera.

Gerardo Berjano Escobar.

Cándido Blanco Velasco.

Arturo Corbella Pascual.

Gregorio Pérez Aoiz.

Jaime Torné Alerany.

Manuel Garijo Isasa.

No comparecieron: Manuel Garijo, Antonio Andrade, Ángel Rico, Álvaro López de Mora, José Núñez, Eduardo Gómez, Vicente Sancho, Luis Muñiz.

\section{Votación y propuesta}

El tribunal declaro la aptitud de todos los opositores. La de Calabuig Larra y la de Álvarez del Manzano por unanimidad. Las de Puig Torán, Pérez Aoiz, Torné y Alerany por seis votos contra uno. Las de Berjano Escobar, y Garijo Isasa por cinco votos contra dos.

En la segunda votación el tribunal calificó el mérito relativo de los opositores considerados aptos. El resultado fue el siguiente:

- Para el primer lugar, Calabuig con tres votos contra dos de Álvarez del Manzano, uno de Puig, y uno de Berjano.

- Para el segundo lugar, Berjano por tres votos contra dos de Puig, y dos de Álvarez del Manzano.

- Para el tercer lugar, Puig por cinco votos contra uno de Torné y una papeleta en blanco. 
- Para el cuarto lugar, Torné por tres votos contra uno de Álvarez del Manzano, uno de Pérez Aoiz, uno de Berjano, y una papeleta en blanco.

- Para el quinto lugar, Álvarez del Manzano por tres votos contra dos de Pérez Aoiz, uno de Garijo, y una papeleta en blanco.

- Para el sexto lugar, Garijo por tres votos contra uno de Pérez Aoiz, uno de Garijo e Isasa y dos papeletas en blanco.

- Para el séptimo lugar, Pérez Aoiz por cuatro votos contra uno de Garijo y dos papeletas en blanco.

La propuesta de terna queda formulada como sigue: Calabuig para el primer lugar; Berjano para el segundo; Puig para el tercero.

\section{Materiales}

Actas de la oposición; oficios del negociado; oficios varios sobre conformación del tribunal. Las actas indican qué libros solicitó de cada opositor.

\section{Signatura}

AGA 32/07288. Legajo 5340-16.

\section{Cátedra}

Historia y elementos de Derecho romano.

\section{Universidad}

Valencia.

\section{Anuncio}

R.O. de 23 de julio, 1879; Gaceta del 1 de agosto.

\section{Reglamento aplicable}

2 de abril, 1875 .

\section{Fechas de la oposición}

Constitución: 23 de diciembre, 1879.

Presentación de los opositores: 9 de enero, 1880.

Votación y propuesta: 30 de enero, 1880.

\section{Tribunal}

Presidente: Víctor Arnau.

Vocales: Julián Pastor, Benito Gutiérrez, Francisco Gómez Salazar, Rafael Conde Luque, Javier González Castejón.

Secretario: José de Isasa. 


\section{Opositores}

Eduardo Gadea y Alera.

Rafael Comenge Dalmau.

Matías Barrio Mier.

Rafael Rodríguez de Cepeda Márquez.

Arturo Corbella Pascual.

\section{Votación y propuesta}

El tribunal declaró por unanimidad la aptitud de todos los opositores.

En la segunda votación el tribunal calificó el mérito relativo de los opositores considerados aptos. El resultado fue el siguiente:

- Para el primer lugar, Matías Barrio Mier por unanimidad.

- Para el segundo lugar, Eduardo Gadea Alera por seis votos contra uno de Rodríguez de Cepeda Márquez.

- Para el tercer lugar, Rodríguez de Cepeda Márquez por seis votos contra uno de Comenge Dalmau.

- Para el cuarto lugar, Corbella Pascual por cuatro votos contra tres de Comenge Dalmau.

- Para el quinto lugar, Comenge Dalmau por unanimidad.

La propuesta de terna queda formulada como sigue: Matías Barrio Mier para el primer lugar; Eduardo Gadea Alera para el segundo, Rodríguez de Cepeda Márquez para el tercero.

\section{Materiales}

Actas de la oposición; oficios del negociado; oficios varios sobre conformación del tribunal. Las actas indican qué libros solicitó cada opositor.

\section{Signatura}

AGA 32/o7288. Legajo 5340-20.

\section{Cátedra}

Historia y elementos de Derecho romano.

\section{Universidad}

Zaragoza.

\section{Anuncio}

R.O. de 23 de diciembre, 1879; Gaceta del 8 de enero de 1880. 


\section{Reglamento aplicable}

2 de abril, 1875 .

\section{Fechas de la oposición}

Constitución: 17 de diciembre, 1881.

Presentación de los opositores: 21 de diciembre, 1881.

Votación y propuesta: 12 de enero, 1882.

\section{Tribunal}

Presidente: José de Cárdenas.

Vocales: Julián Pastor, Domingo Alcalde, Juan de la Concha Castañeda, José María Antequera, José María Pantoja.

Secretario: Eduardo Hinojosa.

\section{Opositores}

Celestino María Herrero y Calvo.

Rafael Rodríguez de Cepeda.

Ilirio Guimerá Álvarez.

Ricardo Lasera Samsón.

No comparecieron: Faustino Álvarez del Manzano Álvarez de Rivera, Gerardo Berjano Escobar, Arturo Corbella Pascual, Paulino Cubells Feixeró, Fernando Ros Andrés, Antonio Toledo Quintela, Antonio María de Soria Brú, Manuel Puig Ferrán, Manuel Zabala, Matías Barrio Mier.

Pedro Antonio Ibarra Loire se retiró antes del primer ejercicio.

\section{Votación y propuesta}

El tribunal declaró por unanimidad la aptitud de Ricardo Lasera Samsón, y por cinco votos contra dos la de Celestino María Herrero Calvo, Rafael Rodríguez de Cepeda y la de Ilirio Guimerá Álvarez.

En la segunda votación el tribunal calificó el mérito relativo de los opositores considerados aptos. El resultado fue el siguiente:

- Para el primer lugar, Ricardo Lasera por unanimidad.

- Para el segundo lugar, Rafael Rodríguez de Cepeda con cinco votos y dos en blanco.

- Para el tercer lugar, Celestino María Herrero con tres votos contra uno de Ilirio Guimerá y dos en blanco.

La propuesta de terna queda formulada como sigue: Ricardo Lasera Samsón para el primer lugar; Rafael Rodríguez de Cepeda para el segundo; Celestino María Herrero para el tercero. 


\section{Materiales}

Actas de la oposición; oficios del negociado; oficios varios sobre conformación del tribunal. Las actas indican qué libros solicitó cada opositor.

\section{Signatura}

AGA 32/07289. Legajo 5340-27.

\section{Cátedra}

Elementos de Derecho mercantil y penal.

\section{Universidad}

Granada.

\section{Anuncio}

R.O. de 24 de abril, 1880; Gaceta del 10 de mayo.

\section{Reglamento aplicable}

2 de abril, 1875 .

\section{Fechas de la oposición}

Constitución: 19 de abril, 1882.

Presentación de los opositores: 20 de abril, 1882.

Votación y propuesta: 12 de mayo, 1882.

\section{Tribunal}

Presidente: Víctor Arnau.

Vocales: Luis Silvela, Melchor Salvá, José Hinojosa, Pablo Peña Entrala, Enrique Gil Robles.

Secretario: Félix de Aramburu.

\section{Opositores}

Faustino Álvarez del Manzano Álvarez de Rivera.

Leopoldo González Revilla.

Francisco Blanco Constans.

Gerardo Berjano.

No comparecieron: Cándido Emperador, Ignacio Alonso Martínez, Enrique Delgado, Manuel de Rueda, Francisco González Barrera, José Valdés, Antonio Marín.

Paulino Cubells se retiró. 


\section{Votación y propuesta}

En la primera votación el tribunal consideró por unanimidad "aptos para el profesorado" a los cuatro opositores.

En la segunda votación el tribunal calificó el mérito relativo de los opositores considerados aptos.

El resultado fue el siguiente:

- Para el primer lugar, Faustino Álvarez del Manzano por unanimidad.

- Para el segundo lugar, Leopoldo González Revilla por cuatro votos contra dos de Gerardo Berjano y uno de Francisco Blanco Constans.

- Para el tercer lugar, Gerardo Berjano por cuatro votos contra tres de Francisco Blanco Constans.

El orden de clasificación de los opositores vino a ser: para el primer lugar Álvarez del Manzano, para el segundo González Revilla; para el tercero Berjano, y para el cuarto Blanco Constans.

\section{Materiales}

Actas de la oposición; oficios del negociado; oficios varios sobre conformación del tribunal. Las actas indican qué libros solicitó cada opositor.

\section{Signatura}

AGA 32/07289. Legajo 5340-30.

\section{Cátedra}

Teoría y práctica de los Procedimientos judiciales y práctica forense.

\section{Universidad}

Central.

\section{Anuncio}

R.O. de 31 de mayo, 1880; Gaceta del 11 de junio.

\section{Reglamento aplicable}

2 de abril, 1875 .

\section{Fechas de la oposición}

Constitución: 4 de febrero, 1882.

Presentación de los opositores: 10 de febrero, 1882.

Votación y propuesta: 1 de abril, 1882. 


\section{Tribunal}

Presidente: José Luis Retortillo.

Vocales: José Rens García, Augusto Comas, Cristóbal Colón de la Cerda, Gumersindo Azcárate, Antonio Fernández Durán.

Secretario: Luis Moreno Gil de Borja.

\section{Opositores}

Florentino Humbert Sala.

Ángel Allende Salazar.

Francisco Javier González Castejón.

Paulino Cubells Feixeró.

Tomás Montejo Rica.

No comparecieron: Guillermo de Brocá, José de Isasa, Antonio Toledo.

Salvador Torres Aguilar se retiró.

\section{Votación y propuesta}

El tribunal declaró por unanimidad la aptitud de los cinco opositores.

En la segunda votación calificó el mérito relativo de los opositores considerados aptos. El resultado fue el siguiente:

- Para el primer lugar, Tomás Montejo Rica.

- Para el segundo lugar, Ángel Allende Salazar.

- Para el tercer lugar, Francisco Javier González Castejón.

- Para el cuarto lugar, Paulino Cubells Teixeró.

- Para el quinto lugar, Florentino Humbert Sala.

Todas las votaciones lograron la unanimidad. El tribunal acordó proponer para la provisión de la cátedra a Tomás Montejo Rica.

\section{Materiales}

Actas de la oposición; oficios del negociado; oficios varios sobre conformación del tribunal. Las actas indican qué libros solicitó de cada opositor.

\section{Signatura}

AGA 32/07290. Legajo 5341-2.

\section{Cátedra}

Disciplina general de la Iglesia y particular de España.

\section{Universidad}

Barcelona. 


\section{Anuncio}

R.O. de 18 de febrero, 1881; Gaceta del 26.

\section{Reglamento aplicable}

2 de abril, 1875 .

\section{Fechas de la oposición}

Constitución: 26 de enero, 1882.

Presentación de los opositores: 14 de febrero, 1882.

Votación y propuesta: 29 de marzo, 1882.

\section{Tribunal}

Presidente: Ciriaco Saudía, Obispo auxiliar.

Vocales: Eugenio Montero Ríos, Vicente de Lafuente, Rafael Conde Luque, Enrique Ucelay, José Cristóbal Sorní.

Secretario: Eduardo Soler.

\section{Opositores}

Manuel María de Soria Bru.

Ignacio Bermúdez Sela.

Eulogio Romero del Castillo.

Álvaro López de Mora.

José Estanyol Colón.

Eduardo Gómez Moreno.

No comparecieron: Ignacio Alonso Martínez, Antonio Toledo Quintela, Jesús Firmat y Cabrero.

Se excluye por falta de asistencia a Ángel Sánchez Rubio Ibáñez.

\section{Votación y propuesta}

El tribunal declaró por unanimidad la aptitud de los opositores López de Mora y Estanyol; la de Ignacio Bermúdez Sela por cuatro votos contra tres.

En la segunda votación calificó el mérito relativo de los opositores considerados aptos. El resultado fue el siguiente:

- Para el primer lugar, Estanyol por cuatro votos contra tres de López de Mora.

- Para el segundo lugar, López de Mora por unanimidad.

- Para el tercer lugar, Ignacio Bermúdez Sela por cuatro votos.

El orden de clasificación de los opositores vino a ser: en el primer lugar Estanyol, en el segundo López de Mora; en el tercero Ignacio Bermúdez Sela. A lo anterior se añade: "Pero si la Superioridad estimare hallarse derogado [el artículo 25 del Reglamento de 2 de abril, 1875] por el decreto de diecinueve del corriente, que 
establece la propuesta unipersonal, el Tribunal para este caso propondrá a Don José Estanyol y Colón, [...]”.

\section{Materiales}

Actas de la oposición; oficios del negociado; oficios varios sobre conformación del tribunal. Las actas indican qué libros solicitó de cada opositor.

El expediente recoge un dictamen del Consejo de Instrucción Pública con fecha 21 de abril de 1882 que resuelve una protesta presentada por el opositor Ángel Sánchez Rubio Ibáñez contra su exclusión, así como los escritos de protesta presentados por éste.

\section{Signatura}

AGA 32/07291. Legajo 5341-5.

\section{Cátedra}

Historia y elementos de Derecho romano.

\section{Universidad}

Oviedo.

\section{Anuncio}

R.O. de 19 de noviembre, 1881; Gaceta del 27.

\section{Reglamento aplicable}

2 de abril, 1875 .

\section{Fechas de la oposición}

Constitución: 28 de octubre, 1882.

Presentación de los opositores: misma fecha que la anterior, en segunda sesión. Votación y propuesta: 28 de octubre, 1882.

\section{Tribunal}

Presidente: Francisco de la Pisa Pajares.

Vocales: Demetrio Gutiérrez Cañas, José Manuel Piernas Hurtado, Jorge María Ledesma, José Laso Medina.

Secretario: Ramón Martínez Agulló.

\section{Opositores}

Celestino María Herrero y Calvo. 
Hilario Beato Méndez.

Fernando Ros Andrés.

Ángel Rico Valarino.

Antonio Orio Dalier.

Gerardo Berjano Escobar.

Pedro Antonio Ibarra Loyre.

Ilirio Guimerá Álvarez.

No comparecieron: Manuel María de Soria Bru, Ignacio Bermúdez Sela, Rafael Rodríguez, Emilio Jimeno, Faustino Álvarez del Manzano, Áureo Alonso, Leopoldo García Alas, Paulino Cubells.

\section{Votación y propuesta}

El tribunal declaró la aptitud de los siguientes opositores: por cinco bolas blancas y una negra la de Herrero, Beato y Rico; por cuatro blancas y dos negras la de Orio, Ibarra y Guimerá.

En la segunda votación calificó el mérito relativo de los opositores considerados aptos. El resultado fue el siguiente:

- Para el primer lugar, Herrero por cinco votos contra uno de Rico.

- Para el segundo lugar, Beato por cinco votos contra uno de Rico.

- Para el tercer lugar, tres votos de Rico contra tres de Ibarra. El empate se resolvió a favor de Rico por haber sido incluido en terna en una oposición anterior.

- Para el cuarto lugar, Ibarra por unanimidad.

- Para el quinto lugar, Orio por cinco votos contra uno de Guimerá.

- Para el sexto lugar, Guimerá por cuatro votos y dos papeletas en blanco.

La propuesta de terna quedó formulada como sigue: Celestino María Herrero Calvo para el primer lugar; Hilario Beato Méndez para el segundo; Ángel Rico Valarino para el tercero.

Se menciona que para el caso de propuesta unipersonal era Celestino María Herrero el propuesto.

\section{Materiales}

Actas de la oposición; oficios del negociado; oficios varios sobre conformación del tribunal, ejemplar del Boletín general de ventas de bienes nacionales de fecha 3 de octubre de 1882. Las actas indican qué libros solicitó de cada opositor.

Consta escrito de protesta del opositor Pedro Antonio Ibarra Loyre contra la resolución del empate. 


\section{Signatura}

AGA 32/07292. Legajo 5341-24.

\section{Cátedra}

Historia y elementos de Derecho romano.

\section{Universidad}

\section{Salamanca.}

\section{Anuncio}

R.O. de 26 de mayo, 1882; Gaceta del 5 de junio.

\section{Reglamento aplicable}

2 de abril, 1875 .

El Real Decreto de 17 de marzo de 1882 se aplica a ciertos extremos de la votación y propuesta.

\section{Fechas de la oposición}

Constitución: 12 de marzo, 1883.

Presentación de los opositores: misma fecha que la anterior, en segunda sesión. Votación y propuesta: 11 de abril, 1883.

\section{Tribunal}

Presidente: Augusto Comas.

Vocales: José María Pantoja, José Fernández Iturralde, Julián Pastor, Vicente Santamaría, Francisco Javier González Castejón.

Secretario: José Isasa.

\section{Opositores}

Hilario Beato Méndez.

Luis Mendizábal.

Florentino Humbert.

Jerónimo Vida Vilches.

Pedro Antonio Ibarra Loyre.

Ángel Rico Valarino.

Antonio Orio y Dalier.

Ignacio Bermúdez Sela.

Juan de Dios Trías Jiró.

Jesús Firmat.

Gregorio Burón.

Moisés Carballo. 


\section{Votación y propuesta}

El tribunal declaró la aptitud de los siguientes opositores: Luis Mendizábal por unanimidad; Hilario Beato Méndez por cuatro votos contra dos; Antonio Orio y Dalier por unanimidad; Juan de Dios Trías Jiró por unanimidad.

En la segunda votación calificó el mérito relativo de los opositores considerados aptos.

El resultado fue el siguiente:

- Para el primer lugar, Trías por unanimidad.

- Para el segundo lugar, Orio por cinco votos contra uno de Mendizábal.

- Para el tercer lugar, Mendizábal por cinco votos contra uno de Orio.

- Para el cuarto lugar, Beato por cuatro votos y dos papeletas en Blanco.

El tribunal propuso a Juan de Dios Trías Jiró.

\section{Materiales}

Actas de la oposición; oficios del negociado; oficios varios sobre conformación del tribunal. Las actas indican qué libros solicitó de cada opositor.

\section{Signatura}

AGA 32/07292. Legajo 5341-22.

\section{Cátedra}

Elementos de Derecho político y administrativo español.

\section{Universidad}

Oviedo.

\section{Anuncio}

R.O. de 3 de enero, 1883; Gaceta del 11.

\section{Reglamento aplicable}

2 de abril, 1875 .

El Real Decreto de 17 de marzo de 1882 se aplica a ciertos extremos de la votación y propuesta.

\section{Fechas de la oposición}

Constitución: 12 de mayo, 1883.

Presentación de los opositores: 14 de mayo, 1883.

Votación y propuesta: 12 de junio, 1883. 


\section{Tribunal}

Presidente: Juan Uña.

Vocales: Laureano Figuerola, Gumersindo Azcárate, Juan Hinojosa, Francisco Concha Alcalde, Leopoldo García Alas.

Secretario: Adolfo Álvarez Buylla.

\section{Opositores}

José María Rogelio y Jove.

Mario Blanco.

Luis Morote.

Antonio Díaz Domínguez.

Enrique Crespo Aparicio.

Adolfo González Posada.

José Valdés Rubio.

Jacinto Montells.

No comparecieron: Marcelino San Román, Luis López Moreno, Constantino Garrán, Ángel Salcedo.

\section{Votación y propuesta}

El tribunal declaró por unanimidad la aptitud de los siguientes opositores: José María Rogelio y Jove, Luis Morote, Enrique Crespo Aparicio, Adolfo González Posada, José Valdés Rubio.

En la segunda votación calificó el mérito relativo de los opositores considerados aptos. El resultado fue el siguiente:

- Para el primer lugar, González Posada por unanimidad.

- Para el segundo lugar, Morote por tres votos contra dos de Jove y uno de Valdés.

- Para el tercer lugar, tres votos para Valdés y tres para Jove. El empate se resolvió a favor de Jove por haber sido propuesto en ternas anteriores.

- Para el cuarto lugar, Valdés por unanimidad.

- Para el quinto lugar, Crespo por unanimidad.

El tribunal acordó proponer a Adolfo González Posada.

\section{Materiales}

Actas de la oposición; oficios del negociado; oficios varios sobre conformación del tribunal. Las actas indican qué libros solicitó de cada opositor. 


\section{Signatura}

AGA 32/o7293. Legajo 5341-38.

\section{Cátedra}

Elementos de Economía política y de Estadística.

\section{Universidad}

Zaragoza.

\section{Anuncio}

R.O. de 29 de julio, 1883; Gaceta del 3 de agosto.

\section{Reglamento aplicable}

2 de abril, 1875 .

El Real Decreto de 17 de marzo de 1882 se aplica a ciertos extremos de la votación y propuesta.

\section{Fechas de la oposición}

Constitución: 2 de febrero, 1884 .

Presentación de los opositores: 4 de febrero, 1884.

Votación y propuesta: 11 de marzo, 1884.

\section{Tribunal}

Presidente: Víctor Arnau.

Vocales: Santos Alfaro, Jorge María Ledesma, Teodoro Peña, Tomás Lezcano.

Secretario: Celestino Herrero.

Fernando Mellado abandona el tribunal a causa de su salud quebrantada el 28 de enero de 1884.

\section{Opositores}

Rafael de Gracia.

Álvaro López de Mora.

Vicente Frornés Sallart.

Lorenzo Benito.

Ángel Sánchez Rubio.

Raimundo de Abadal.

Pedro Antonio Ibarra.

Constantino Garrán.

Se retiraron: Antonio Díaz Domínguez, Antonio Toledo Quintela, Lino Torres García, Ángel Rico Valarino.

No comparecieron: Fernando Ros, José de Liñán. 


\section{Votación y propuesta}

El tribunal declaró por unanimidad la aptitud de los siguientes opositores: Rafael de Gracia, Álvaro López de Mora, Vicente Frornés Sallart, Lorenzo Benito, Ángel Sánchez Rubio, Raimundo de Abadal, Pedro Antonio Ibarra.

En la segunda votación calificó el mérito relativo de los opositores considerados aptos.

El resultado fue el siguiente:

- Para el primer lugar, Sánchez Rubio por cuatro votos contra dos de Frornés.

- Para el segundo lugar, Frornés por tres votos contra dos de Rafael de Gracia y uno de Benito.

- Para el tercer lugar, Rafael de Gracia por cuatro votos contra dos de Benito.

- Para el cuarto lugar, Benito por cinco votos contra uno de Abadal.

- Para el quinto lugar, Abadal por cuatro votos contra dos de Ibarra.

- Para el sexto lugar, López de Mora por cuatro votos contra dos de Ibarra.

- Para el séptimo lugar, Ibarra por unanimidad.

El tribunal acordó proponer a Ángel Sánchez Rubio.

\section{Materiales}

Actas de la oposición; oficios del negociado; oficios varios sobre conformación del tribunal. Las actas indican qué libros solicitó de cada opositor.

Constan escritos del opositor Antonio Toledo Quintela contra su exclusión, así como certificados sobre su salud, firmados por un doctor en medicina. Tal particular fue mencionado en el expediente, en cuyo margen aparece la siguiente anotación: "La Dirección no quiso resolver".

\section{Signatura}

AGA 32/07297. Legajo 5342-29.

\section{Cátedra}

Principios de Derecho natural.

Cátedra creada por Decreto de 2 de septiembre de 1883, en substitución de la Cátedra de Historia y elementos de Derecho romano, que había salido a oposición por R.O. de 13 de febrero de 1883 , Gaceta de 22 de febrero.

\section{Universidad}

Valencia.

\section{Anuncio}

R.O. de 9 de octubre, 1883. Gaceta del 15. 


\section{Reglamento aplicable}

2 de abril, 1875 .

Se aplican también otras normas que modifican el anterior reglamento: Real Decreto de 17 de marzo de 1882; Real Decreto de 15 de mayo de 1884.

\section{Fechas de la oposición}

Constitución: 23 de enero, 1886.

Presentación de los opositores: misma fecha que la anterior, en segunda sesión.

Votación y propuesta: 18 de febrero, 1886.

\section{Tribunal}

Presidente: Víctor Arnau (propuesto por el Consejo de Instrucción pública). Vocales: Melchor Salvá y José María de Antequera (propuestos por la Academia de Ciencias morales y políticas), Eduardo Soler Pérez (propuesto por el Claustro de la Universidad de Valencia), Vicente Romero Girón (propuesto por el Consejo de Instrucción pública), Francisco de Sales Jaumar.

Secretario: Pablo Peña Entrala.

\section{Opositores}

Jerónimo Vida.

Antonio Orio.

Luis Mendizábal.

José Ferraz.

Rafael Rodríguez de Cepeda.

No comparecieron: Moisés Carballo, Luis María de Sáez, Ilirio Guimera, Ignacio Bermúdez Sela, Agustín Vida, Francisco Blanco.

\section{Votación y propuesta}

La votación fue ganada por Rodríguez de Cepeda por cuatro votos contra tres de Vida y fue por tanto propuesto. Nombrado el 26 de abril de 1886.

La votación del mérito relativo dio el siguiente resultado:

- Para el segundo lugar, Vida por cinco votos contra dos de Mendizábal.

- Para el tercer lugar, Orio por cinco votos contra dos de Mendizábal.

- Para el cuarto lugar, Mendizábal por unanimidad.

\section{Materiales}

Oficios del negociado; anuncio de la oposición; oficios varios sobre conformación del tribunal; actas de la oposición (con los enunciados de las preguntas a los opositores) y anuncio. 


\section{Signatura}

AGA 32/07295. Legajo 5342-7.

\section{Cátedra}

Derecho mercantil de España y de las principales naciones de Europa y América.

\section{Universidad}

Central, Zaragoza y Salamanca.

\section{Anuncio}

R.O. de 6 de noviembre, 1884. Gaceta del 7.

\section{Reglamento aplicable}

2 de abril, 1875 .

Se aplican también otras normas que modifican el anterior reglamento: Real Decreto de 17 de marzo de 1882; Real Decreto de 15 de mayo de 1884; Real Decreto de 13 de septiembre de 1886 .

\section{Fechas de la oposición}

Constitución: 15 de febrero, 1887.

Presentación de los opositores: 15 de febrero, 1887, sesión de tarde.

Votación y propuesta: 25 de marzo, 1887.

\section{Tribunal}

Presidente: Joaquín María Sanromá.

Vocales: Plácido Jove, Manuel Durán Bas (abandonó antes de la votación), Juan de Morales, Faustino Rodríguez de San Pedro.

Secretario: José Lasso (tras el abandono de Félix Aramburu).

\section{Opositores}

Leopoldo González Revilla.

Lorenzo Benito.

Rafael de Gracia.

José Casabó.

Nicasio Sánchez Mata.

Salvador Gamboa.

Antonio Turón.

Joaquín de Reina.

Marcelino Isabal. 
Ricardo de Checa.

Nicolás López Rodríguez.

Francisco de Casso.

Francisco Blanco.

Faustino Álvarez del Manzano.

Leopoldo García Alas.

Cándido Emperador.

\section{Votación y propuesta}

El tribunal votó y propuso por unanimidad a Faustino Álvarez del Manzano para la cátedra de Madrid y a Ricardo de Checa para la de Zaragoza. Para la de Salamanca fue propuesto Lorenzo Benito por tres votos contra dos de Nicasio Sánchez. La votación del mérito relativo del resto de opositores dio el siguiente resultado: para el primer lugar, Nicasio Sánchez por unanimidad; para el segundo lugar, Gamboa por cuatro votos; para el tercer lugar, Casabó por cuatro votos; para el cuarto lugar, Nicolás López por tres votos.

\section{Materiales}

Actas de la oposición (recogen los enunciados de las preguntas a los opositores); oficios del negociado; oficios varios sobre conformación del tribunal, anuncio de la oposición; escritos de opositores de renuncia y de petición de suspensión por enfermedad.

Unidos a las actas están los escritos de solicitudes de libros de cada opositor y las diez papeletas con las preguntas de cada uno.

\section{Signatura}

AGA 32/07295. Legajo 5342-12.

\section{Cátedra}

Derecho político y administrativo.

\section{Universidad}

Valladolid.

\section{Anuncio}

R.O. de 6 de noviembre, 1884. Gaceta del 7.

\section{Reglamento aplicable}

2 de abril, 1875 . 
Se aplican también otras normas que modifican el anterior reglamento: Real Decreto de 17 de marzo de 1882; Real Decreto de 15 de mayo de 1884; Real Decreto de 13 de septiembre de 1886 .

\section{Fechas de la oposición}

Constitución: 4 de mayo, 1886.

Presentación de los opositores: misma fecha que la anterior, segunda sesión.

Votación y propuesta: 27 de mayo, 1886.

\section{Tribunal}

Presidente: José Luis Retortillo.

Vocales: Emilio Alcalá Galiano, Ángel María Dacarrete, José Flaquer, Benigno de Cafranga.

Secretario: José Nieto Álvarez (tras el abandono de Ramón María de Dalmau, marqués de Olivart).

\section{Opositores}

Benigno Martín.

Luis Morote.

Ángel Rico Valarino.

José María Rogelio Jove.

José de Liñán.

Hilario Beato.

Federico Brizuela.

No comparecieron: José María Álvarez Taladriz, Teodoro Peña.

\section{Votación y propuesta}

Ángel Rico Valarino ganó la votación por cuatro votos contra uno de Liñán, y fue por consiguiente propuesto para la cátedra.

La votación del mérito relativo del resto de opositores dio el siguiente resultado: para el primer lugar, Beato por tres votos contra dos de Liñán; para el segundo lugar, Liñán por tres votos contra dos de Jove; para el tercer lugar, Rogelio Jove por tres votos contra dos de Brizuela; para el cuarto lugar, Brizuela por unanimidad; para el quinto lugar, Martín por tres votos y dos en blanco.

\section{Materiales}

Actas de la oposición (recogen los enunciados de las preguntas a los opositores); oficios del negociado; oficios varios sobre conformación del tribunal. Unidos a las actas están los escritos de solicitudes de libros de cada opositor. 


\section{Signatura}

AGA 32/07294. Legajo sin numerar.

\section{Cátedra}

Derecho civil español, común y foral.

\section{Universidad}

Granada.

\section{Anuncio}

R.O. de 6 de noviembre, 1884 . Gaceta del 7.

\section{Reglamento aplicable}

2 de abril, 1875 .

Se aplican también otras normas que modifican el anterior reglamento: Real Decreto de 17 de marzo de 1882; Real Decreto de 15 de mayo de 1884.

\section{Fechas de la oposición}

Constitución: 4 de noviembre, 1886.

Presentación de los opositores: 5 de noviembre, 1886.

Votación y propuesta: 24 de noviembre, 1886.

\section{Tribunal}

Presidente: Augusto Comas.

Vocales: Vicente de la Fuente, Manuel Laraña, Domingo Ramón Domingo, José María Antequera, Antonio Maura.

Secretario: Rafael de Ureña.

\section{Opositores}

Miguel de la Guardia.

Juan José Crespo.

Gregorio Burón.

José Sánchez Vilches.

Hilario Beato Méndez.

No comparecieron: José Sabas, Ramón Tojo, Francisco Blanco.

\section{Votación y propuesta}

El tribunal vota y propone por unanimidad a Hilario Beato Méndez. 
El orden de clasificación del resto de opositores quedó como sigue:

- Para el segundo lugar, Burón por cuatro votos.

- Para el tercer lugar, Crespo por unanimidad.

\section{Materiales}

Actas de la oposición; oficios del negociado; oficios varios sobre conformación del tribunal. Las actas indican qué libros solicitó de cada opositor.

\section{Signatura}

AGA 32/07295. Legajo 5342-4.

AGA 32/o7297. Legajo 5342-30.

\section{Cátedra}

Derecho internacional público y Derecho internacional privado.

\section{Universidad}

Granada, Santiago y Sevilla.

\section{Anuncio}

R.O. de 6 de noviembre, 1884. Gaceta del 7.

\section{Reglamento aplicable}

2 de abril, 1875.

Se aplican también otras normas que modifican el anterior reglamento: Real Decreto de 17 de marzo de 1882; Real Decreto de 15 de mayo de 1884; Real Decreto de 13 de septiembre de 1886 .

\section{Fechas de la oposición}

Constitución: 4 de mayo, 1886.

Presentación de los opositores: 6 de mayo, 1886.

Votación y propuesta: 19 de junio, 1886.

\section{Tribunal}

Presidente: Felipe Sánchez Román (por el Consejo de Instrucción Pública, en sustitución de Groizard).

Vocales: Castor María Perier (por la Academia), Rafael Conde Luque, Guillermo Estrada Villaverde, José Díez de Tejada (por Sevilla, en sustitución de Laraña), Vicente Olivares Biec (por la Academia, en sustitución del Marqués de Valmar, Leopoldo Augusto de Cueto).

Secretario: Rafael María de Labra (por el Consejo). 


\section{Opositores}

Manuel Torres Campos.

Joaquín Fernández Prida.

Manuel Tobía.

Ángel Pintos.

Luis Gestoso.

Adolfo Moris.

Antonio de la Figuera.

Federico Hernández.

Ricardo Guzmán.

Ramón Estalella.

Raimundo Abadal.

Aniceto Sela.

Manuel Alonso.

No comparecieron: Florencio Díez Aguasal, Clemente Fernández, Julio Pimentel, Manuel Jiménez, José Puig, Luis Molero, Vicente Vidal, Joaquín Camuñas, Antonio Vázquez y López, Aniceto de Rezola, Ángel Rico, Ecequiel Gómez.

Se retiraron: Ramón María Dalmau, Fernando de Checa, Luis Mendizábal, José Joaquín Camuñas.

\section{Votación y propuesta}

Por unanimidad se propone a Manuel Torres Campos y a Joaquín Fernández Prida para Granada y Sevilla respectivamente. Para Santiago se propone a Adolfo Moris por cuatro votos contra tres de Estalella.

La votación del mérito relativo del resto de opositores dio el siguiente resultado: para el primer lugar, Estalella por unanimidad; para el segundo lugar, Sela por cinco votos contra uno de Abadal y uno de Guzmán; para el tercer lugar, Gestoso por cuatro votos contra dos de Guzmán y uno de Abadal; para el cuarto lugar, Guzmán por seis votos contra uno de Abadal; para el quinto lugar, Abadal por cuatro votos contra tres de Alonso; para el sexto lugar, Alonso por seis votos y uno en blanco; para el séptimo lugar, Figuera por cinco votos y dos en blanco; para el octavo, Pintos por cinco votos y dos en blanco; para el noveno, Hernández por cinco votos y dos en blanco; para el décimo Tobía por cuatro votos y tres en blanco.

\section{Materiales}

Actas de la oposición (recogen los enunciados de las preguntas a los opositores); oficios del negociado; oficios varios sobre conformación del tribunal, anuncio de la oposición. Unidos a las actas están los escritos de solicitudes de libros de cada opositor. 


\section{Signatura}

AGA 32/07296. Legajo 5342-18.

\section{Cátedra}

Elementos de Derecho natural.

\section{Universidad}

Salamanca.

\section{Anuncio}

R.O. de 27 de febrero, 1885. Gaceta del 8 de marzo.

\section{Reglamento aplicable}

2 de abril, 1875.

Se aplican también otras normas que modifican el anterior reglamento: Real Decreto de 17 de marzo de 1882; Real Decreto de 15 de mayo de 1884.

\section{Fechas de la oposición}

Constitución: 18 de noviembre, 1886.

Presentación de los opositores: 19 de noviembre, 1886.

Votación y propuesta: 17 de diciembre, 1886.

\section{Tribunal}

Presidente: Francisco de la Pisa Pajares (en sustitución de Víctor Arnau, inicialmente propuesto por el Consejo de IP).

Vocales: Ricardo Díaz de Rueda (a propuesta del Consejo de IP), Plácido Jove y Hevia (Vizconde de Campo Grande) y José María Llorente (ambos propuestos por la Academia de Ciencias Morales y Políticas), Vicente Santamaría de Paredes (en substitución de Eladio García Amado) y Benito Núñez Forcelledo.

Secretario: Salvador Cuesta y Martín (propuesto por el claustro salmantino).

\section{Opositores}

Manuel Sánchez de Castro.

Jacobo Guerreira.

Gonzalo María Jaumar.

Alfredo Calderón.

Gerónimo Vida.

Antonio Orio.

Luis Mendizábal. 
No comparecieron: Hilario Guimera, Miguel Crespo, Juan María Romero, Moisés Carballo.

\section{Votación y propuesta}

Fueron declarados aptos los siguientes opositores: por unanimidad, Sánchez de Castro, Mendizábal y Vida, por seis bolas blancas y una negra Calderón y Orio; por cuatro blancas contra tres negras Jaumar.

Guerreira fue declarado no apto por cuatro negras contra tres blancas.

La votación de lugares dio el siguiente resultado:

- Para el primer lugar, Mendizábal por cuatro votos contra tres de Vida.

- Para el segundo lugar, Vida por cuatro votos contra tres de Sánchez de Castro.

- Para el tercer lugar, Sánchez de Castro por cinco votos contra dos de Calderón.

- Para el cuarto lugar, Calderón por seis votos contra uno de Orio.

- Para el quinto lugar, Orio por cinco votos contra dos de Jaumar.

- Para el sexto lugar, Jaumar por cuatro votos y dos en blanco.

Luis Mendizábal Martín fue nombrado el 31 de enero de 1887 ("por más que en la propuesta se observa una ligera falta en la forma”).

\section{Materiales}

Oficios del negociado; anuncio de la oposición; oficios varios sobre conformación del tribunal; actas de la oposición (con los enunciados de las preguntas a los opositores). Unidos a las actas están los escritos de solicitudes de libros de cada opositor y las papeletas con las preguntas sacadas por éstos de la urna.

\section{Signatura}

AGA 32/07296. Legajo 5342-20.

AGA 32/07297. Legajo 5342-32.

\section{Cátedra}

Derecho civil español, común y foral.

\section{Universidad}

Valencia.

\section{Anuncio}

R.O. de 27 de febrero, 1885. Gaceta del 8 de marzo.

\section{Reglamento aplicable}

2 de abril, 1875 . 
Se aplican también otras normas que modifican el anterior reglamento: Real Decreto de 17 de marzo de 1882; Real Decreto de 15 de mayo de 1884; Real Decreto de 13 de septiembre de 1886 .

\section{Fechas de la oposición}

Constitución: 3 de marzo, 1887.

Presentación de los opositores: misma fecha que la anterior, segunda sesión.

Votación y propuesta: 23 de abril, 1887.

\section{Tribunal}

Presidente: Juan Uña.

Vocales: Julián Arribas, Domingo Alcalde, José Hinojosa, Jacobo Gil Villanueva, Cleto Troncoso.

Secretario: Fermín Canella.

\section{Opositores}

Juan Antonio Bernabé.

Miguel de la Guardia.

Antonio de la Figuera.

Juan Crespo.

Gregorio Burón.

Ramón Tojo.

No comparecieron o se retiraron: José Sánchez Vilches, Vicente Rodríguez Encina, Agustín Muñoz Trujeda, Carlos Blanco Pérez, Nicolás López Rodríguez, Francisco Blanco, Vicente Sancho-Tello.

\section{Votación y propuesta}

Miguel de la Guardia Corencia ganó la votación por cuatro votos contra dos de Tojo y uno de Burón.

La votación del mérito relativo del resto de opositores dio el siguiente resultado: para el primer lugar, Burón por cuatro votos contra dos de Tojo y uno de Crespo; para el segundo lugar, Crespo cinco votos contra dos de Tojo; para el tercer lugar, Tojo por cinco votos contra dos de Figuera; para el cuarto lugar, Figuera por cinco votos contra dos de Bernabé; para el quinto lugar, Bernabé por unanimidad.

Miguel de la Guardia fue nombrado por R.O. de 1 de junio, 1887.

\section{Materiales}

Oficios del negociado; anuncio de la oposición; oficios varios sobre conformación del tribunal; solicitudes de renuncia de algunos vocales y certificados médicos correspondientes. 
Actas de la oposición (recogen los enunciados de las preguntas a los opositores). Unidos a las actas están los escritos de solicitudes de libros de cada opositor.

\section{Signatura}

AGA 32/07302. Legajo 5344-1.

\section{Cátedra}

Historia general del Derecho español.

\section{Universidad}

Central.

\section{Anuncio}

R.O. de 12 de enero, 1886. Gaceta del 19.

\section{Reglamento aplicable}

2 de abril, 1875 .

Se aplican también otras normas que modifican el anterior reglamento: Real Decreto de 17 de marzo de 1882; Real Decreto de 15 de mayo de 1884; Real Decreto de 13 de septiembre de 1886 .

\section{Fechas de la oposición}

Constitución: 4 de noviembre, 1891.

Presentación de los opositores: 5 de noviembre, 1891.

Votación y propuesta: 25 de noviembre, 1891.

\section{Tribunal}

Presidente: José de Cárdenas.

Vocales: Fernando Mellado, Benigno de Cafranga, Lorenzo de Prada, Juan Permanyer.

Secretario: Federico Brusi.

Gerardo Berjano abandona el tribunal el 17 de noviembre.

\section{Opositores}

Matías Barrio Mier.

Marcelo Cervino.

Francisco J. Jiménez.

No comparecieron: José de Liñan, Luis Coll, Pedro Domingo, José Sánchez Vilches, Agustín Ondovilla, Ignacio M. ${ }^{a}$ Pintado, Luis Molero, José Lameyer, Enri- 
que Gil Robles, Leopoldo García Alas, Gerardo Berjano Escobar, Daniel Berjano Escobar, Eduardo Hinojosa.

Adolfo Moris se retiró el 14 de noviembre.

\section{Votación y propuesta}

Matías Barrio ganó la votación por cuatro votos contra uno de Cervino y uno de Jiménez.

Fue por consiguiente propuesto para la cátedra.

La votación del mérito relativo de los opositores no propuestos fue ganada por Cervino por cuatro votos contra dos de Jiménez.

Por tanto ocuparon el lugar primero y segundo respectivamente.

\section{Materiales}

Actas de la oposición (recogen los enunciados de las preguntas a los opositores); oficios del negociado; oficios varios sobre conformación del tribunal; anuncio de la oposición. Unidos a las actas están los escritos de solicitudes de libros de cada opositor.

\section{Signatura}

AGA 32/07296. Legajo 5342-24.

AGA 32/07297. Legajo 5342-31.

\section{Cátedra}

Elementos de Derecho natural.

\section{Universidad}

Oviedo.

\section{Anuncio}

R.O. de 25 de septiembre, 1886. Gaceta del 26 de marzo.

\section{Reglamento aplicable}

2 de abril, 1875 .

Se aplican también otras normas que modifican el anterior reglamento: Real Decreto de 17 de marzo de 1882; Real Decreto de 15 de mayo de 1884, Real Decreto de 13 de septiembre de 1886 .

\section{Fechas de la oposición}

Constitución: 7 de marzo, 1887. 
Presentación de los opositores: misma fecha que la anterior, segunda sesión.

Votación y propuesta: 13 de abril, 1887.

\section{Tribunal}

Presidente: Víctor Arnau.

Vocales: Pablo Peña, Eladio García Amado, Juan Pedro Morales, Francisco J. González Castejón, Benito Núñez Forcelledo.

Secretario: Rafael Rodríguez de Cepeda.

\section{Opositores}

Alfredo Brañas.

Gonzalo Pintos Reino.

José de Liñán.

Manuel Sánchez de Castro.

Miles Bea y López.

Francisco Cueva Palacio.

Jacobo Guerreira.

Gonzalo María Jaumar.

Alfredo Calderón.

Jerónimo Vida.

No comparecieron: José Rico Fuensalida, Emilio Moreno Nieto, Lorenzo Sáenz Fernández.

\section{Votación y propuesta}

La votación fue ganada por Alfredo Brañas por cuatro votos contra dos de Jerónimo Vida, por lo que fue propuesto.

La votación del mérito relativo dio el siguiente resultado:

- Para el primer lugar, Sánchez de Castro por cuatro votos contra dos de Vida.

- Para el segundo lugar, Melquiades Álvarez por cuatro votos contra dos de Vida.

- Para el tercer lugar, Vida por cuatro votos contra dos de Liñán.

- Para el cuarto lugar, Liñán por unanimidad.

- Para el quinto lugar, Cueva por cinco votos y uno en blanco.

- Para el sexto lugar, Guerreira por cuatro votos y dos en blanco.

Bea y Pintos no fueron aprobados.

Alfredo Brañas fue nombrado por R.O. de 1 de junio, 1887.

\section{Materiales}

Oficios del negociado; anuncio de la oposición; oficios varios sobre conformación del tribunal; actas de la oposición (recogen los enunciados de las preguntas a los opositores). Unidos a las actas están los escritos de solicitudes de libros de cada 
opositor y las papeletas con las preguntas sacadas por éstos de la urna.

El expediente recoge un dictamen del Consejo de Instrucción Pública de fecha 6 de mayo de 1887 referido a las protestas suscritas por Jerónimo Vida, Alfredo Calderón y Gonzalo Pintos.

El manuscrito con la protesta de Alfredo Calderón, de fecha 17 de marzo de 1887, impugna las preguntas porque están "redactadas en el sentido de imponer una determinada doctrina". Las protestas de los otros dos opositores también están unidas a las actas.

\section{Signatura}

AGA 32/07295. Legajo 5342-11.

\section{Cátedra}

Derecho internacional público y Derecho internacional privado.

\section{Universidad}

Valencia.

\section{Anuncio}

R.O. de 19 de enero, 1887. Gaceta del 7.

Fue anunciada a traslación por R.O. de 6 de noviembre, 1884 (Gaceta del 7), y a concurso en 24 de enero, 1885 (Gaceta del 4 de febrero).

\section{Reglamento aplicable}

2 de abril, 1875 .

Se aplican también otras normas que modifican el anterior reglamento: Real Decreto de 17 de marzo de 1882; Real Decreto de 15 de mayo de 1884; Real Decreto de 13 de septiembre de 1886 .

\section{Fechas de la oposición}

Constitución: 17 de noviembre, 1887.

Presentación de los opositores: 19 de noviembre, 1887.

Votación y propuesta: 11 de diciembre, 1887.

\section{Tribunal}

Presidente: Augusto Comas.

Vocales: Rafael Conde Luque, Guillermo Estrada, Manuel Torres Campos, Adolfo Moris, Juan de Dios Trías.

Secretario: Emilio de la Peña. 


\section{Opositores}

Mariano Avelló.

Luis Morote.

Luis Gestoso.

Aniceto Sela.

Ramón Estalella.

No comparecieron: Antonio de la Figuera, Isidro Pérez, Ramón María Dalmau.

\section{Votación y propuesta}

La primera votación dio el siguiente resultado: tres votos para Aniceto Sela; tres votos para Estalella, un voto para Morote.

En segunda votación Sela obtuvo cuatro votos, por lo que se acordó su propuesta.

La votación del mérito relativo del resto de opositores dio el siguiente resultado: para el primer lugar, cinco votos para Estalella contra dos de Morote; para el segundo lugar, Gestoso por cuatro votos contra tres de Morote; para el tercer lugar, Morote por seis votos y uno en blanco; para el cuarto lugar, Avellón por seis votos y uno en blanco.

\section{Materiales}

Actas de la oposición (recogen los enunciados de las preguntas a los opositores); oficios del negociado; oficios varios sobre conformación del tribunal. Unidos a las actas están los escritos de solicitudes de libros de cada opositor.

\section{Signatura}

AGA 32/0730o. Legajo 5343-41.

\section{Cátedra}

Derecho mercantil de España y de las principales naciones de Europa y América.

\section{Universidad}

Granada y Santiago.

\section{Anuncio}

R.O. de 16 de junio, 1887. Gaceta del 25.

\section{Reglamento aplicable}

2 de abril, 1875 .

Se aplican también otras normas que modifican el anterior reglamento: Real De- 
creto de 17 de marzo de 1882; Real Decreto de 15 de mayo de 1884; Real Decreto de 13 de septiembre de 1886 .

\section{Fechas de la oposición}

Constitución: 7 de mayo, 1888.

Presentación de los opositores: 10 de mayo, 1888.

Votación y propuesta: 29 de mayo, 1888.

\section{Tribunal}

Presidente: Joaquín María Sanromá.

Vocales: Matías Barrio, Faustino Álvarez del Manzano, Salvador Salom Puig, Lorenzo Benito, Gerardo Berjano.

Secretario: Ricardo Checa.

\section{Opositores}

José Casabó.

Francisco Blanco Constans.

Gregorio Burón.

Antonio Mejías.

Santiago de la Escalera.

No comparecieron: Gerónimo Vida, Nicolás López Rodríguez.

\section{Votación y propuesta}

En primer lugar se efectuó la votación para la catedra de Granada, ganada por José Casabó por cuatro votos contra uno de Francisco Blanco, uno de Gregorio Burón y uno de Antonio Mejías. Fue propuesto Casabó.

En segundo lugar, la votación de la de Santiago, en la que Gregorio Burón obtuvo tres votos, dos Francisco Blanco, uno de Antonio Mejías y un voto en blanco. Sin mayoría absoluta, se llevó a cabo segunda votación, con el siguiente resultado: cuatro votos para Blanco y tres para Burón. Fue propuesto el primero.

Por último se calificó el mérito de los opositores no propuestos. En primer lugar Burón por seis votos contra uno de Mejías. En segundo lugar Mejías por unanimidad.

\section{Materiales}

Actas de la oposición (recogen los enunciados de las preguntas a los opositores); oficios del negociado; oficios varios sobre conformación del tribunal. Unidos a las actas están los escritos de solicitudes de libros de cada opositor y las papeletas extraídas por éstos con sus preguntas. 
También se conserva el manuscrito del programa aportado por el opositor Nicolás López Rodríguez. Se compone de un "Razonamiento sobre el método y plan adaptado en el siguiente programa" y del propio programa compuesto por 79 lecciones.

\section{Signatura}

AGA 32/07294. Legajo 5342-1.

\section{Cátedra}

Derecho procesal civil, penal, canónico, administrativo y Teoría y Práctica de redacción de instrumentos públicos.

\section{Universidad}

Barcelona, Oviedo, Santiago y Valencia.

\section{Anuncio}

R.O. de 6 de noviembre, 1884 . Gaceta del 7.

La oposición se volvió a anunciar el 9 de julio, 1887. Gaceta del 30.

\section{Reglamento aplicable}

2 de abril, 1875 .

Se aplican también otras normas que modifican el anterior reglamento: Real Decreto de 17 de marzo de 1882; Real Decreto de 15 de mayo de 1884; Real Decreto de 13 de septiembre de 1886 .

\section{Fechas de la oposición}

Constitución: 12 de octubre, 1888.

Presentación de los opositores: 15 de octubre, 1888.

Votación: 14 de diciembre, 1888.

Propuesta: 15 de diciembre, 1888 .

En fecha 19 de enero de 1887 se constituyó un primer tribunal para juzgar idénticas cátedras, presidido por Felipe Sánchez Román, con Tomás Montejo como secretario y con los siguientes vocales: Salvá, Gutiérrez Cañas, Enríquez, Paso y Delgado, y Pantoja.

Tal tribunal acordó que no había lugar a la provisión de ninguna de las cátedras.

\section{Tribunal}

Presidente: Francisco de la Pisa.

Vocales: Salvador Torres Aguilar, José López Romero, José Gonzalo de las Casas, 
Nicolás del Paso Delgado, Ramón Segovia.

Secretario: Juan María Rodríguez Arango.

\section{Opositores}

Tomás de Barinaga.

Arsenio Misol.

José María Casas.

Santos Lubias.

Gil Gil Gil.

Magín Fábregas.

Félix Contreras.

José María Gadea.

Jaime Torné.

Eduardo Serrano.

Carlos María Bru.

No comparecieron: Lucio Eduardo Sloker, Tomás Pelayo, Jeclenco Fravé, Florentino Humbert, Secundino de la Torre, Ángel Pintos, Emilio Gimeno, Felipe José Guillén, Ramón Rojo Pérez, Juan Iboms.

\section{Votación y propuesta}

El tribunal votó el orden de clasificación y obtuvo el siguiente resultado:

- Para el primer lugar, Magín Fábrega por cinco votos contra uno de Gadea y uno de Torné.

- Para el segundo lugar, Gadea por seis votos contra uno de Torné.

- Para el tercer lugar, Serrano por cinco votos contra dos de Torné.

- Para el cuarto lugar, Torné y Misol obtuvieron tres votos y Contreras uno.

En segunda votación Misol obtuvo cuatro votos contra tres de Torné.

A continuación se valora el mérito relativo de los restantes opositores.

El resultado es el siguiente:

- Número uno: Torné por siete votos.

- Número dos: Contreras por siete votos.

- Número tres: Gil Gil por siete votos.

- Número cuatro: Barinaga por cuatro votos y tres papeletas en blanco.

En la siguiente sesión se produjo la designación de las cátedras. Fábrega optó por la de Barcelona, Gadea por la de Valencia, Serrano por la de Oviedo y Misol por la de Santiago. El tribunal acuerda realizar la propuesta de conformidad con tales manifestaciones.

\section{Materiales}

Actas de la oposición (recoge los enunciados de las preguntas a los opositores); 
oficios del negociado; oficios varios sobre conformación del tribunal. Las actas indican qué libros solicitó de cada opositor. También se unen los manuscritos de los opositores correspondientes al caso práctico.

En relación con la primera de las oposiciones que tuvo lugar, además de su habitual documentación administrativa, constan los siguientes documentos:

- Escrito de protesta de los opositores Magín, Brú, Gadea y Fabrega de 14 de marzo de 1887.

- Informe del presidente del tribunal de 23 de marzo de 1887 dirigido al Ministro de Fomento, por el cuál eleva el expediente.

- Dictamen del Consejo de Instrucción Pública de 5 de julio de 1887.

\section{Signatura}

AGA 32/07298. Legajo 5343-4.

\section{Cátedra}

Elementos de Derecho natural.

\section{Universidad}

Sevilla.

\section{Anuncio}

R.O. de 14 de noviembre, 1887. Gaceta del 8 de diciembre.

\section{Reglamento aplicable}

2 de abril, 1875 .

Se aplican también otras normas que modifican el anterior reglamento: Real Decreto de 17 de marzo de 1882; Real Decreto de 15 de mayo de 1884; Real Decreto de 13 de septiembre de 1886 .

\section{Fechas de la oposición}

Constitución: 5 de noviembre, 1889 .

Presentación de los opositores: misma fecha que la anterior, segunda sesión.

Votación y propuesta: 5 de diciembre, 1889 .

\section{Tribunal}

Presidente: Augusto Comas.

Vocales: José Otero, Francisco J. González Castejón, Joaquín Costa, Julián Pastor, Laureano Figuerola.

Secretario: Luis Mendizábal. 


\section{Opositores}

Manuel Sánchez de Castro.

Clemente Fernández.

Alfredo Calderón.

Jerónimo Vida.

Pedro Domingo de Rute.

Ángel Salcedo Ruiz.

No comparecieron: José Ferraz, Antonio Anglada, José Liñán, Emilio Moreno, Jacobo Guerreira, Luis Gestoso, Francisco González, Antonio Valbuena, Melquíades Álvarez.

Clemente Fernández se retiró durante los ejercicios.

\section{Votación y propuesta}

Fue declarada la aptitud de todos los opositores. Por seis votos contra uno, la de Sánchez de Castro, Salcedo y Vida; por cinco votos contra dos la de Domingo de Rute; por cuatro votos contra tres la de Calderón.

La votación fue ganada por Sánchez de Castro por cuatro votos contra dos de Vida y uno de Calderón, por lo que fue propuesto.

Acto seguido el vocal Joaquín Costa abandonó el tribunal "alegando al efecto algunas razones".

La votación del mérito relativo dio el siguiente resultado:

- Para el primer lugar, Vida por cinco votos contra uno.

- Para el segundo lugar, hubo empate entre Calderón y Salcedo, que se mantuvo en segunda votación. Se declara no haber lugar a la designación de tercero u ulteriores puestos.

\section{Materiales}

Oficios del negociado; anuncio de la oposición; oficios varios sobre conformación del tribunal; actas de la oposición (con los enunciados de las preguntas a los opositores). Unidos a las actas están los escritos de solicitudes de libros de cada opositor.

Consta manuscrito de protesta de los opositores Vida y Calderón en el que se expone, entre otros extremos, que el opositor propuesto "no contestó sino ocho de las diez preguntas". El expediente recoge el dictamen del Consejo de Instrucción Pública que deniega tales protestas. 


\section{Signatura}

AGA 32/07298. Legajo 5343-7.

\section{Cátedra}

Derecho penal.

\section{Universidad}

Salamanca.

\section{Anuncio}

R.O. de 14 de noviembre, 1887. Gaceta del 29.

\section{Reglamento aplicable}

2 de abril, 1875 .

Se aplican también otras normas que modifican el anterior reglamento: Real Decreto de 17 de marzo de 1882; Real Decreto de 15 de mayo de 1884; Real Decreto de 13 de septiembre de 1886 .

\section{Fechas de la oposición}

Constitución: 11 de octubre, 1890.

Presentación de los opositores: 13 de octubre, 1890.

Votación y propuesta: 25 de octubre, 1890.

\section{Tribunal}

Presidente: Felipe Sánchez Román.

Vocales: Vicente Romero, Félix Pío Aramburu, José Valdés, Manuel José Rodríguez, Julián Pastor.

Secretario: Rafael Salillas.

\section{Opositores}

Jerónimo Vida.

No comparecieron: Felipe Clemente de Diego, Manuel Catalina, Jacobo Guerreira, Pedro Domingo de Rute, Gonzalo Pintos, José María Rico, Luis Maldonado, Lorenzo Velasco, Melquíades Álvarez, Enrique Martín, Carlos Blanco.

\section{Votación y propuesta}

El único opositor, Jerónimo Vida, es propuesto por unanimidad.

\section{Materiales}

Actas de la oposición (recogen los enunciados de las preguntas a los opositores); 
oficios del negociado; oficios varios sobre conformación del tribunal, anuncio de la oposición.

Unidos a las actas están los escritos de solicitudes de libros de cada opositor.

Consta escrito de recusación de Jerónimo Vida contra Julián Pastor. La Dirección del negociado desestimó la recusación en fecha 15 de febrero de 1890.

\section{Signatura}

AGA 32/07299. Legajo 5343-22.

\section{Cátedra}

Derecho internacional público y Derecho internacional privado.

\section{Universidad}

Oviedo.

\section{Anuncio}

R.O. de 20 de mayo, 1888. Gaceta del 23.

\section{Reglamento aplicable}

2 de abril, 1875 .

Se aplican también otras normas que modifican el anterior reglamento: Real Decreto de 17 de marzo de 1882; Real Decreto de 15 de mayo de 1884; Real Decreto de 13 de septiembre de 1886 .

\section{Fechas de la oposición}

Constitución: 28 de marzo, 1891.

Presentación de los opositores: 3 de abril, 1891.

Votación y propuesta: 25 de abril, 1891.

\section{Tribunal}

Presidente: Eduardo Palou Flores.

Vocales: Manuel Torres Campos, Salvador Bermúdez, Rafael Ureña, Adolfo González Posada, Francisco Javier Jiménez Pérez de Vargas.

Secretario: Adolfo Moris.

\section{Opositores}

Luis Gestoso Alarcón.

Jesús Sánchez Dierma.

No comparecieron: Mariano Avellón, Antonio de la Figuera, Eduardo Ibarra, Pío 
Blanco, Aureliano Escotet, Antonio Mejías, Fernando de Checa, Luis Morote, Isidro Pérez.

\section{Votación y propuesta}

Luis Gestoso Alarcón ganó la votación por cinco votos y dos papeletas en blanco. Fue por consiguiente propuesto para la cátedra.

Jesús Sánchez Dierma ocupó el lugar inmediato al de la propuesta por cinco votos y dos papeletas en blanco.

\section{Materiales}

Actas de la oposición (recogen los enunciados de las preguntas a los opositores); oficios del negociado; oficios varios sobre conformación del tribunal, anuncio de la oposición.

Unidos a las actas están los escritos de solicitudes de libros de cada opositor.

\section{Signatura}

AGA 32/07302. Legajo 5344-2.

\section{Cátedra}

Instituciones de Derecho romano.

\section{Universidad}

Barcelona.

\section{Anuncio}

R.O. de 23 de agosto, 1888. Gaceta del 26.

\section{Reglamento aplicable}

2 de abril, 1875 .

Se aplican también otras normas que modifican el anterior reglamento: Real Decreto de 17 de marzo de 1882; Real Decreto de 15 de mayo de 1884; Real Decreto de 13 de septiembre de 1886 .

\section{Fechas de la oposición}

Constitución: 26 de marzo, 1892.

Presentación de los opositores: 31 de marzo, 1892.

Votación y propuesta: 4 de mayo, 1892. 


\section{Tribunal}

Presidente: Joaquín María Sanromá.

Vocales: Bienvenido Oliver, Francisco Javier Jiménez, Melchor Salvá, Julián Pastor, Francisco de Casso.

Secretario: Agustín Retortillo.

\section{Opositores}

Delfín Fuentes.

Víctor Sampere.

Fernando Ferreiro.

Esteban Jiménez.

No comparecieron: Emilio Saquer, Guillermo de Brocá, Felipe Clemente de Diego, Ramón María Cata, Enrique de Larratea, Santiago de la Escalera, Jaime Carner, José Pasés, Ramón Cantó.

\section{Votación y propuesta}

La primera votación dio el siguiente resultado: tres votos para Esteban Jiménez, dos votos para Víctor Sampere, dos papeletas en blanco. En la segunda votación el resultado fue el mismo.

No habiendo mayoría absoluta, el tribunal declara no haber lugar a la provisión de la cátedra.

\section{Materiales}

Actas de la oposición (recogen los enunciados de las preguntas a los opositores); oficios del negociado; oficios varios sobre conformación del tribunal. Unidos a las actas están los escritos de solicitudes de libros de cada opositor.

\section{Signatura}

AGA 32/07310. Legajo 5346-13.

\section{Cátedra}

Instituciones de Derecho romano.

\section{Universidad}

Oviedo.

\section{Anuncio}

R.O. de 7 de enero, 1889. Gaceta del 13. 
La cátedra se había anunciado a traslación (R.O. de 16 de octubre, 1888) y a concurso (R.O. de 20 de noviembre, 1888).

\section{Reglamento aplicable}

2 de abril, 1875 .

Se aplican también otras normas que modifican el anterior reglamento: Real Decreto de 17 de marzo de 1882; Real Decreto de 15 de mayo de 1884; Real Decreto de 13 de septiembre de 1886 .

\section{Fechas de la oposición}

Constitución: 23 de octubre, 1899.

Presentación de los opositores: 27 de octubre, 1899.

Votación y propuesta: 7 de noviembre, 1899.

\section{Tribunal}

Presidente: Eduardo Palou.

Vocales: Gumersindo Azcárate, José María Gadea, Rafael Rodríguez de Cepeda, Damián Isern, Cipriano Herce.

Secretario: Marcelo Cervino.

\section{Opositores}

Melquíades Álvarez González.

No comparecieron: Emilio Saquer, Cipriano Álvarez, Nicolás San Román, Esteban Jiménez, José Herráiz, Tomás Barreda, Aurelio Ballesteros, Santiago de la Escalera, Ángel Pintos, Felipe de Diego, Delfín Fuentes, Fernando Ferreiro, Leopoldo de Michelena, Ramón Menéndez, Hipólito González.

\section{Votación y propuesta}

Los ejercicios del único opositor fueron aprobados por cuatro votos y tres en blanco. Fue propuesto para la cátedra.

\section{Materiales}

Actas de la oposición (indican las preguntas sacadas de la urna), oficios del negociado, oficios varios sobre conformación del tribunal, anuncio de la oposición. Se une el listado de libros consultados. 


\section{Signatura}

AGA 32/07307. Legajo 5345-7.

\section{Cátedra}

Derecho mercantil de España y de las principales naciones de Europa y América.

\section{Universidad}

Zaragoza.

\section{Anuncio}

R.O. de 25 de enero, 1889.

\section{Reglamento aplicable}

2 de abril, 1875 .

Se aplican también otras normas que modifican el anterior reglamento: Real Decreto de 17 de marzo de 1882; Real Decreto de 15 de mayo de 1884; Real Decreto de 13 de septiembre de 1886 .

\section{Fechas de la oposición}

Constitución: 14 de mayo, 1897.

Presentación de los opositores: 17 de mayo, 1897.

Votación y propuesta: 21 de mayo, 1897.

\section{Tribunal}

Presidente: Faustino Álvarez del Manzano.

Vocales: José Valdés, Damián Isern, Mariano Sabas, Prudencio Requejo.

Secretario: Lorenzo Benito.

Lorenzo Benito abandonó el tribunal el día 28 de mayo.

\section{Opositores}

Manuel Cabrera Warleta.

Antonio de la Figuera Lezcano.

No comparecieron otros 18 opositores.

\section{Votación y propuesta}

Se declara por unanimidad la aptitud de ambos opositores.

La votación fue ganada por Antonio de la Figuera Lezcano por cinco votos contra uno de Manuel Cabrera Warleta, por lo que fue propuesto.

\section{Materiales}

De tipo administrativo: actas de la oposición (indican las preguntas del segundo 
ejercicio); oficios del negociado; oficios varios sobre conformación del tribunal, anuncio de la oposición.

De tipo académico o referentes a los ejercicios:

- Papeletas con las 10 preguntas sacadas de la urna por cada opositor.

- Escritos de solicitudes de libros de cada opositor.

\section{Signatura}

AGA 32/07299. Legajo 5343-18.

\section{Cátedra}

Derecho civil español, común y foral.

\section{Universidad}

Valladolid.

\section{Anuncio}

R.O. de 22 de febrero, 1889. Gaceta del 3 de marzo.

\section{Reglamento aplicable}

2 de abril, 1875 .

Se aplican también otras normas que modifican el anterior reglamento: Real Decreto de 17 de marzo de 1882; Real Decreto de 15 de mayo de 1884; Real Decreto de 13 de septiembre de 1886 .

\section{Fechas de la oposición}

Constitución: 11 de abril, 1891.

Presentación de los opositores: 13 de abril, 1891.

Votación y propuesta: 14 de mayo, 1891.

\section{Tribunal}

Presidente: Felipe Sánchez Román.

Vocales: Julián Arribas, Domingo Alcalde, Juan Hinojosa, José Gonzalo de las Casas, Ignacio Suárez.

Secretario: José Muro Carvajal.

\section{Opositores}

Gregorio Burón García.

Hipólito González Rebollar.

Alfonso Ortiz de la Torre. 
Emilio Moreno Nieto.

Matías Medina Rosales.

Juan Antonio Bernabé y Herrero.

Juan José Crespo y Herrero.

Nicolás López Rodríguez.

No comparecieron: Segura y Fernández, García Paredes, Caro Riaño, Esteban García, Santugini Romero, Figuera y Lezcano, Madrazo Villar, Valdés, Gestoso, San Román y Rodríguez, Bermúdez, Marín del Campo, Casso Fernández, Rañada Barros.

\section{Votación y propuesta}

Gregorio Burón García ganó la votación por cinco votos contra uno de Juan Antonio Bernabé y uno de Juan José Crespo. Fue por consiguiente propuesto para la cátedra.

La votación del mérito relativo del resto de opositores dio el siguiente resultado: para el primer lugar, Bernabé por cuatro votos contra tres de Crespo; para el segundo lugar, Crespo por cinco votos contra uno de López Rodríguez y uno de Rebollar; para el tercer lugar, López Rodríguez por cinco votos contra uno de Bernabé y uno de Burón; para el cuarto lugar, Ortiz por cuatro votos contra tres de Rebollar en segunda votación; para el quinto lugar, Rebollar por seis votos contra uno de Ortiz; para el sexto lugar, Medina por cinco votos contra uno de Ortiz y uno en blanco.

\section{Materiales}

Actas de la oposición (recogen los enunciados de las preguntas a los opositores); oficios del negociado; oficios varios sobre conformación del tribunal, anuncio de la oposición. Unidos a las actas están los escritos de solicitudes de libros de cada opositor.

\section{Signatura}

AGA 32/07302. Legajo 5344-4.

\section{Cátedra}

Derecho político y administrativo.

\section{Universidad}

Granada.

\section{Anuncio}

R.O. de 3 de febrero, 1890. Gaceta del 14. 


\section{Reglamento aplicable}

2 de abril, 1875 .

Se aplican también otras normas que modifican el anterior reglamento: Real Decreto de 17 de marzo de 1882; Real Decreto de 15 de mayo de 1884; Real Decreto de 13 de septiembre de 1886 .

\section{Fechas de la oposición}

Constitución: 31 de marzo, 1892.

Presentación de los opositores: 2 de abril, 1892.

Votación y propuesta: 29 de mayo, 1892.

\section{Tribunal}

Presidente: Felipe Sánchez Román.

Vocales: Fernando Mellado, Adolfo Moris, Adolfo González Posada, Pedro Moreno Villena, Francisco de Paula Blanco Constans.

Secretario: Jerónimo Vida.

\section{Opositores}

Pedro García Dorado.

Jesús Sánchez Diezma

Juan Sala Bonán.

José de Liñán.

Agustín Rodríguez Aguilera.

Carlos Arévalo.

No comparecieron: Francisco Cuervo, Vicente Ruiz Caruana, Alfonso Retortillo, Alfonso Castells, Luis Obreu, José García Valenzuela, Ignacio María Pintado, Jerónimo Vida, Fernando Ferreiro, Jaime Torné, Luis Gestoso, Manuel Segura.

\section{Votación y propuesta}

La votación fue ganada por Pedro García Dorado por cuatro votos contra dos de Jesús Sánchez Diezma y uno de Juan Sala Bonán.

La votación del mérito relativo fue la siguiente:

- Para el primer lugar, Sala Bonán por cuatro votos contra tres de Sánchez Diezma.

- Para el segundo lugar, Arévalo por cuatro votos contra uno de Rodríguez Aguilera y dos en blanco.

- Para el tercer lugar, Rodríguez Aguilera por cinco votos y dos en blanco.

\section{Materiales}

Actas de la oposición (recogen los enunciados de las preguntas a los opositores); 
oficios del negociado; oficios varios sobre conformación del tribunal, anuncio de la oposición. Unidos a las actas están los escritos de solicitudes de libros de cada opositor.

\section{Signatura}

AGA 32/o7306. Legajo 5345-1.

\section{Cátedra}

Instituciones de Derecho romano.

\section{Universidad}

Santiago.

\section{Anuncio}

R.O. de 20 de febrero, 1890. Gaceta del 28.

\section{Reglamento aplicable}

2 de abril, 1875.

Se aplican también otras normas que modifican el anterior reglamento: Real Decreto de 17 de marzo de 1882; Real Decreto de 15 de mayo de 1884; Real Decreto de 13 de septiembre de 1886 .

\section{Fechas de la oposición}

Constitución: 27 de enero, 1897.

Presentación de los opositores: 1 de febrero, 1897.

Votación y propuesta: 15 de febrero, 1897.

\section{Tribunal}

Presidente: Ismael Calvo.

Vocales: Damián Isern, Enrique de Larratea, Eladio García Amado, Francisco de Casso, Javier Jiménez de Vargas.

Secretario: Nicasio Sánchez.

\section{Opositores}

Felipe Clemente de Diego.

Esteban Jiménez García.

No comparecieron otros 15 opositores. 


\section{Votación y propuesta}

La votación fue ganada por Felipe Clemente de Diego por cuatro votos contra tres de Esteban Jiménez García, por lo que fue propuesto.

Jiménez García fue considerado por unanimidad en el primer lugar del mérito relativo.

\section{Materiales}

Actas de la oposición (recogen los enunciados de las preguntas a los opositores); oficios del negociado; oficios varios sobre conformación del tribunal, anuncio de la oposición. Unidos a las actas están los escritos de solicitudes de libros de cada opositor y las papeletas con las preguntas sacadas por éstos de la urna.

\section{Signatura}

AGA 32/07302. Legajo 5344-3 y 5 .

\section{Cátedra}

Derecho civil español, común y foral.

\section{Universidad}

Granada.

\section{Anuncio}

Para la primera oposición, R.O. de 4 de junio, 1888. Gaceta del 23. Para la segunda, R.O. de 31 de mayo, 1890. Gaceta del 16 de junio.

\section{Reglamento aplicable}

2 de abril, 1875 .

Se aplican también otras normas que modifican el anterior reglamento: Real Decreto de 17 de marzo de 1882; Real Decreto de 15 de mayo de 1884; Real Decreto de 13 de septiembre de 1886.

\section{Fechas de la oposición}

Constitución: 20 de enero, 1892.

Presentación de los opositores: 29 de enero, 1892.

Votación y propuesta: 30 de marzo, 1892.

Un primer tribunal, presidido por Sánchez Román, se constituyó el 30 de marzo de 1890 para juzgar, respecto de la misma cátedra, la aptitud de los opositores Crespo y Herrero, Bernabé, Moreno Nieto, y Burón. Ante la falta de mayoría absoluta en las dos votaciones, se acordó no haber lugar a la provisión de la cátedra. 


\section{Tribunal}

Presidente: Augusto Comas.

Vocales: Cleto Troncoso, Rafael de Ureña, Ricardo Díaz de Ruedo, José García de la Lastra, Francisco de Paula Blanco Constans.

Secretario: Jerónimo Vida.

\section{Opositores}

Juan Antonio Bernabé Herrero.

Emilio Moreno Nieto.

José María Segura Fernández.

Nicolás López Rodríguez.

Hipólito González Rebollar.

Isidro Iglesias García.

Ramón Rodríguez Díaz.

Felipe Campos de los Reyes.

Antonio Reñada.

No comparecieron: Francisco Esteban, Matías Medina, Rodrigo Valdés, Cesar Antonio de Arruche, Ángel Conejo, Secundino Amigo, Antonio de la Figuera, Gregorio Burón, Agustín Muñoz, Alfonso Ortiz, Pedro Garriga, José España, Rafael Altamira, Juan José Crespo, Nicolás Nicasio.

\section{Votación y propuesta}

La votación fue ganada por Juan Antonio Bernabé Herrero por cinco votos contra uno de Emilio Moreno Nieto y uno de José María Segura.

La votación del mérito relativo fue la siguiente:

- Para el primer lugar, Emilio Moreno por cuatro votos contra tres de José María Segura.

- Para el segundo lugar, José María Segura por unanimidad.

- Para el tercer lugar, López Rodríguez por unanimidad.

- Para el cuarto lugar, Rebollar por unanimidad.

- Para el sexto lugar, Iglesias por cinco votos y dos en blanco.

\section{Materiales}

Actas de la oposición (recogen los enunciados de las preguntas a los opositores); oficios del negociado; oficios varios sobre conformación del tribunal, anuncio de la oposición. Unidos a las actas están los escritos de solicitudes de libros de cada opositor.

Los mismos materiales se conservan respecto de la primera oposición. 


\section{Signatura}

AGA 32/07304. Legajo 5344-35.

\section{Cátedra}

Derecho político y administrativo.

\section{Universidad}

Barcelona.

\section{Anuncio}

R.O. de 11 de diciembre, 1891. Gaceta del 15.

\section{Reglamento aplicable}

2 de abril, 1875 .

Se aplican también otras normas que modifican el anterior reglamento: Real Decreto de 17 de marzo de 1882; Real Decreto de 15 de mayo de 1884; Real Decreto de 13 de septiembre de 1886 .

\section{Fechas de la oposición}

Constitución: 17 de septiembre, 1894.

Presentación de los opositores: 20 de septiembre, 1894.

Votación y propuesta: 3 de diciembre, 1894.

\section{Tribunal}

Presidente: Juan de Dios de la Rada.

Vocales: Nicolás de Paso, Ángel Bas Amigó, Melchor Salvá, Francisco Javier Jiménez.

Secretario: José María de Olózaga.

\section{Opositores}

Jesús Sánchez Diezma.

Cesar Antonio Arruche.

Pedro Larrinoa.

Juan Arana de la Hidalga.

Narciso Plá Deniel.

Juan Sala Bonán.

Jaime Torné Alerany.

Antonio Royo Villanova.

Carlos Arévalo Ibañez.

Sandalio Díaz Tendero. 
No comparecieron otros 12 opositores.

Elías Tormo se retiró durante la realización de los ejercicios.

\section{Votación y propuesta}

La votación fue ganada por Jesús Sánchez Diezma por cinco votos contra uno de Juan Arana, por lo que fue propuesto para la cátedra.

La votación del mérito relativo fue la siguiente:

- Para el primer lugar, Sala Bonán por cuatro votos contra dos de Juan Arana.

- Para el segundo lugar, Arruche por cuatro votos contra uno de Arana y uno de

Díaz.

- Para el tercer lugar, Arana por cinco votos contra uno de Díaz.

- Para el cuarto lugar, Díaz por cinco votos contra uno de Plá.

- Para el quinto lugar, Plá por unanimidad.

- Para el sexto lugar, Royo Villanova por unanimidad.

- Para el séptimo lugar, Larrinoa por cuatro votos y dos en blanco.

\section{Materiales}

Actas de la oposición (recogen los enunciados de las preguntas a los opositores); oficios del negociado; oficios varios sobre conformación del tribunal, anuncio de la oposición. Unidos a las actas están los escritos de solicitudes de libros de cada opositor y las diez papeletas con las preguntas sacadas de la urna por éstos.

\section{Signatura}

AGA 32/07306. Legajo 5345-3.

\section{Cátedra}

Derecho civil español, común y foral.

\section{Universidad}

Salamanca.

\section{Anuncio}

R.O. de 29 de agosto, 1893. Gaceta del 8 de septiembre.

\section{Reglamento aplicable}

\section{2 de abril, 1875.}

Se aplican también otras normas que modifican el anterior reglamento: Real Decreto de 17 de marzo de 1882; Real Decreto de 15 de mayo de 1884; Real Decreto de 13 de septiembre de 1886 . 


\section{Fechas de la oposición}

Constitución: 18 de marzo, 1897.

Presentación de los opositores: 22 de marzo, 1897.

Votación y propuesta: 29 de abril, 1897.

\section{Tribunal}

Presidente: Matías Barrio.

Vocales: Salvador Torres, Cleto Troncoso, Manuel Puig, Luis Silvela, José Manuel Segura Fernández.

Secretario: Ramón Sánchez de Ocaña.

\section{Opositores}

Emilio Moreno Nieto.

Matías de Medina Rosales.

Calixto Valverde y Valverde.

Pedro Garriga Folch.

Braulio Álvarez Gómez Salazar.

Antonio Serra Morant.

Guillermo García Valdecasas.

Constantino Menéndez Argumosa.

Luis Maldonado Fernández.

Nicolás López Rodríguez.

Mariano Aramburu y Machado.

No comparecieron: José María Soto, Juan Crespo, Isidoro Iglesias, Luis Planas, Pedro Cristóbal, Vicente Ferrer, Isidro Beato, Eduardo Gómez de Vaquero, Enrique Horstman, Alberto López Selva, Clemente González Alonso, Vicente Brochín, Vicente de Mendoza, José María Ventura, Antonio de la Bañada, César Antonio de Arruche, Rufino Amusátegui, Gregorio Galindo, José María Segura, Antonio Royo, Antonio de la Figuera, Hipólito González, Francisco Zarandona.

\section{Votación y propuesta}

La primera votación fue ganada sin mayoría absoluta por Guillermo García Valdecasas por tres votos contra dos de Valverde y dos en blanco. Se volvió a imponer en la segunda votación por cuatro votos contra tres de Valverde, por lo que fue propuesto.

La votación del mérito relativo dio el siguiente resultado:

- Para el primer lugar, Valverde por unanimidad.

- Para el segundo lugar, Garriga por cuatro votos contra tres López Rodríguez.

- Para el tercer lugar, López Rodríguez por unanimidad.

- Para el cuarto lugar, Medina por seis votos y uno en blanco. 
- Para el quinto lugar, Álvarez Gómez por cinco votos y dos en blanco.

- Para el sexto lugar, Serra por cuatro votos y tres en blanco.

\section{Materiales}

Actas de la oposición (recogen los enunciados de las preguntas a los opositores); oficios del negociado; oficios varios sobre conformación del tribunal, anuncio de la oposición. Unidos a las actas están los escritos de solicitudes de libros de cada opositor y las papeletas con las preguntas sacadas por éstos de la urna.

\section{Signatura}

AGA 32/07303. Legajo 5344-33.

\section{Cátedra}

Derecho mercantil de España y de las principales naciones de Europa y América.

\section{Universidad}

Santiago.

\section{Anuncio}

R.O. de 29 de agosto, 1893. Gaceta del 9 de septiembre.

\section{Reglamento aplicable}

2 de abril, 1875 .

Se aplican también otras normas que modifican el anterior reglamento: Real Decreto de 17 de marzo de 1882; Real Decreto de 15 de mayo de 1884; Real Decreto de 13 de septiembre de 1886 .

\section{Fechas de la oposición}

Constitución: 22 de enero, 1895.

Presentación de los opositores: 29 de enero, 1895.

Votación y propuesta: 22 de marzo, 1895.

\section{Tribunal}

Presidente: José Manuel Piernas Hurtado.

Vocales: Cleto Troncoso, Rafael de Ureña, Manuel Torres Campos, Leopoldo González Revilla.

Secretario: Francisco Blanco Constans. 


\section{Opositores}

Lino Torre Sánchez.

Miguel Garriga.

Francisco Bernad.

Salvador Cabeza.

Prudencio Requejo.

Manuel Cabrera Warleta.

Antonio de la Figuera.

Benito Zurita Nieto.

Sandalio Díaz Tendero.

Isidro Beato.

Antonio Serra.

No comparecieron otros 22 opositores.

\section{Votación y propuesta}

La primera votación dio el siguiente resultado: dos votos para Requejo, uno para Figuera, uno para Torre, uno para Cabrera y uno para Blanco.

La segunda votación fue ganada por Requejo por cuatro votos contra uno de Torre y uno de Blanco. Por consiguiente se propone a Requejo.

La votación del mérito relativo fue la siguiente:

- Para el primer lugar, Cabrera obtuvo dos votos, Torre también dos y uno Figuera. La segunda votación fue ganada por Torre por cuatro votos contra dos de Cabrera.

- Para el segundo lugar, Cabrera por cuatro votos contra uno de Figuera y uno de Bernad.

- Para el tercer lugar, Figuera por cinco votos contra uno de Bernad.

- Para el cuarto lugar, Díaz Tendero por cuatro votos contra dos de Bernad.

- Para el quinto lugar, Bernad por cuatro votos contra dos de Zurita.

- Para el sexto lugar, Zurita por cuatro votos contra dos de Cabeza.

- Para el séptimo lugar, Cabeza por cuatro votos y dos en blanco.

- Para el octavo lugar, Garriga por cuatro votos y dos en blanco.

- Para el noveno lugar, Serra por cuatro votos y dos en blanco.

\section{Materiales}

Actas de la oposición (recogen los enunciados de las preguntas a los opositores); oficios del negociado; oficios varios sobre conformación del tribunal, anuncio de la oposición. Unidos a las actas están los escritos de solicitudes de libros de cada opositor. 


\section{Signatura}

AGA 32/07304. Legajo 5344-34.

\section{Cátedra}

Instituciones de Derecho romano.

\section{Universidad}

Central.

\section{Anuncio}

R.O. de 14 de octubre, 1893. Gaceta del 27.

\section{Reglamento aplicable}

2 de abril, 1875 .

Se aplican también otras normas que modifican el anterior reglamento: Real Decreto de 17 de marzo de 1882; Real Decreto de 15 de mayo de 1884; Real Decreto de 13 de septiembre de 1886 .

\section{Fechas de la oposición}

Constitución: 25 de febrero, 1895.

Presentación de los opositores: 26 de febrero, 1895.

Votación y propuesta: 1 de abril, 1895.

\section{Tribunal}

Presidente: Juan de Dios de la Rada.

Vocales: José Muro, Florencio Álvarez Ossorio, Cipriano Herce, Matías Barrio, Eladio García.

Secretario: José Valdés.

\section{Opositores}

Leopoldo de Michelena.

Melquíades Álvarez.

Sandalio Díaz Tendero.

Ismael Calvo Madroño.

Esteban Jiménez.

Manuel Pastor Rodríguez.

Lorenzo Moret.

No comparecieron otros 14 opositores. 


\section{Votación y propuesta}

La primera votación dio el siguiente resultado: tres votos para Calvo, dos para Melquíades Álvarez, uno para Felipe Clemente y un voto en blanco. La segunda votación fue ganada por Calvo por cinco votos contra dos de Melquíades Álvarez. Por consiguiente se propone a Ismael Calvo.

La votación del mérito relativo fue la siguiente:

- Para el primer lugar, Melquíades Álvarez por unanimidad.

- Para el segundo lugar, Clemente por seis votos contra uno de Pastor.

- Para el tercer lugar, Michelena obtuvo tres votos, Pastor dos, Moret uno y Díaz uno. Pastor ganó la segunda votación por cuatro votos contra tres de Michelena.

- Para el cuarto lugar, Michelena por unanimidad.

- Para el quinto lugar, Moret por cuatro votos contra tres de Díaz.

- Para el sexto lugar, Díaz por unanimidad.

\section{Materiales}

Actas de la oposición (recogen los enunciados de las preguntas a los opositores); oficios del negociado; oficios varios sobre conformación del tribunal, anuncio de la oposición. Unidos a las actas están los escritos de solicitudes de libros de cada opositor y las papeletas con las preguntas sacadas por éstos de la urna.

\section{Signatura}

AGA 32/07304. Legajo 5344-36.

\section{Cátedra}

Derecho político y administrativo.

\section{Universidad}

Valladolid.

\section{Anuncio}

R.O. de 25 de febrero, 1894. Gaceta del 6 de marzo.

\section{Reglamento aplicable}

2 de abril, 1875 .

Se aplican también otras normas que modifican el anterior reglamento: Real Decreto de 17 de marzo de 1882; Real Decreto de 15 de mayo de 1884; Real Decreto de 13 de septiembre de 1886 . 


\section{Fechas de la oposición}

Constitución: 12 de febrero, 1895.

Presentación de los opositores: 15 de febrero, 1895.

Votación y propuesta: 3 de mayo, 1895 .

\section{Tribunal}

Presidente: Antonio Ruiz (en sustitución del fallecido Antonio Mena).

Vocales: Vicente Santamaría, Eduardo Sanz, Joaquín Fernández Prida, Adolfo Moris.

Secretario: Mario Navarro.

\section{Opositores}

Elías Tormo.

Francisco Gómez del Campillo.

Juan Sala Bonán.

Cesar Antonio Arruche.

Pedro Bao Pita.

Francisco Zarandona.

Calixto Valverde.

Alfonso Retortillo.

Gonzalo Castillo Alonso.

Jesús Sánchez Diezma.

Policarpo Peña López.

Jesús Arias de Velasco.

Antonio Royo Villanova.

Carlos Arévalo Ibañez.

Sandalio Díaz Tendero.

No comparecieron: Isidro Beato, Eusebio Romeo, Miguel Paole, Pero de Larrinoa, Clemente González, Benigno Martín, Esteban Jiménez, Laureano Díez.

\section{Votación y propuesta}

La votación fue ganada por Juan Sala Bonán por cuatro votos contra uno de Moya y uno de Arruche, por lo que fue propuesto para la cátedra.

La votación del mérito relativo fue la siguiente:

- Para el primer lugar, Royo por cinco votos contra uno de Arruche.

- Para el segundo lugar, Tormo por cinco votos contra uno de Arruche.

- Para el tercer lugar, Arruche por unanimidad.

- Para el cuarto lugar, Zarandona por unanimidad.

- Para el quinto lugar, Valverde por cinco votos contra uno de Gonzalo del Castillo. 
- Para el sexto lugar, Gómez por cuatro votos contra uno de Gonzalo del Castillo y uno de Bao Pita.

- Para el séptimo lugar, Bao Pita obtuvo tres votos, Castillo dos votos y Peña un voto. La segunda votación fue ganada por Bao por cuatro votos contra dos de Castillo.

- Para el octavo lugar, Castillo por cuatro votos contra dos de Peña.

- Para el noveno lugar, Peña por unanimidad.

\section{Materiales}

Actas de la oposición (recogen los enunciados de las preguntas a los opositores); oficios del negociado; oficios varios sobre conformación del tribunal, anuncio de la oposición. Unidos a las actas están los escritos de solicitudes de libros de cada opositor.

\section{Signatura}

AGA 32/07308. Legajo 5345-25.

\section{Cátedra}

Derecho mercantil de España y de las principales naciones de Europa y América.

\section{Universidad}

Salamanca.

\section{Anuncio}

R.O. de 19 de marzo, 1894. Gaceta del 31.

La cátedra había sido anunciada a traslación (R.O. de 29 de agosto, 1893) y a concurso (R.O. de 14 de noviembre, 1893).

\section{Reglamento aplicable}

2 de abril, 1875 .

Se aplica también el Real Decreto de 9 marzo de 1888.

\section{Fechas de la oposición}

Constitución: 14 de noviembre, 1898.

Presentación de los opositores y formación de las trincas: 15 de noviembre, 1898. Votación y propuesta: 14 de diciembre, 1898.

\section{Tribunal}

Presidente: José Manuel Piernas y Hurtado. 
Vocales: Francisco Blanco Constans, Melchor Salvá, Cándido Emperador, Francisco Javier Jiménez, Lorenzo Benito.

Secretario: Gregorio Burón García.

\section{Opositores}

Francisco Esteban García.

Francisco Bernard Partagás.

Benito Zurita Nieto.

Pedro Garriga y Folch.

Lino Torres Sánchez.

Isidoro Iglesias.

No comparecieron otros 17 opositores.

\section{Votación y propuesta}

La votación fue ganada por Lino Torres por cuatro votos contra dos de Zurita y uno de Bernad, por lo que fue propuesto.

La votación del mérito relativo dio el siguiente resultado:

1. ${ }^{\circ}$ Zurita por cuatro votos contra tres de Bernad.

$2 .^{\circ}$ Bernad por unanimidad.

$3 .{ }^{\circ}$ Iglesias por cuatro votos contra tres de Garriga.

$4 .{ }^{\circ}$ Garriga por unanimidad.

\section{Materiales}

Actas de la oposición (indican las 10 preguntas del primer ejercicio y recogen los escritos de solicitudes de libros de cada opositor); oficios del negociado; oficios varios sobre conformación del tribunal, anuncio de la oposición, recorte de la Gaceta con el anuncio.

\section{Signatura}

AGA 32/07306. Legajo 5345-6.

\section{Cátedra}

Procedimientos judiciales y práctica forense.

\section{Universidad}

Zaragoza.

\section{Anuncio}

R.O. de 18 de julio, 1895 . 


\section{Reglamento aplicable}

27 de julio, 1894 .

\section{Fechas de la oposición}

Constitución: 15 de febrero, 1897.

Presentación de los opositores: 16 de febrero, 1897.

Votación y propuesta: 20 de abril, 1897.

\section{Tribunal}

Presidente: Vicente Gadea Orozco.

Vocales: Salvador Torres Aguilar-Amat, Tomás Montejo y Rica, Vicente Romero Girón, Francisco Javier Castejón, Julián Pastor y Rodríguez.

Secretario: Arsenio Misol.

\section{Opositores}

Juan Barriovero.

Francisco Bernad.

Francisco Comín Moya.

Gil Gil Gil.

Antonio Serra y Morant.

No comparecieron otros 17 opositores.

\section{Votación y propuesta}

La votación fue ganada por Francisco Comín Moya por seis votos y uno en blanco, por lo que fue propuesto.

\section{Materiales}

De tipo administrativo: actas de la oposición; oficios del negociado; oficios varios sobre conformación del tribunal, anuncio de la oposición.

De tipo académico o referentes a los ejercicios:

- Escritos de solicitudes de libros de cada opositor.

- Papeletas con las preguntas sacadas de la urna.

- Trabajos escritos correspondientes al primer ejercicio. Dos temas: "Procedimiento especial en los casos de delito flagrante de pena correccional; Organización del jurado con arreglo a las disposiciones vigentes".

- Casos prácticos correspondientes al quinto ejercicio. 


\section{Signatura}

AGA 32/07306. Legajo 5345-8.

\section{Cátedra}

Historia general del Derecho español.

\section{Universidad}

Oviedo.

\section{Anuncio}

R.O. de 18 de julio, 1895 .

\section{Reglamento aplicable}

27 de julio, 1894.

\section{Fechas de la oposición}

Constitución: 21 de enero, 1897.

Presentación de los opositores: 25 de enero, 1897.

Formación de las trincas: 19 de febrero, 1897.

Votación y propuesta: 23 de marzo, 1897.

\section{Tribunal}

Presidente: Matías Barrio Mier (por el Consejo).

Vocales: Marcelino Menéndez Pelayo (por la Academia), Gumersindo de Azcárate (por la Central), Federico Brusi (por la de Salamanca), Enrique Ferreiro (por la de Santiago), Antonio Balbín.

Secretario: Esteban Jiménez.

\section{Opositores}

Joaquín de Palacios.

Matías de Medina Rosales.

Rafael Altamira Crevea.

Eduardo Casuso de la Hera Quintana.

José García Revillo.

César A. Arruche.

José de Liñán Eguizábal.

No comparecieron: Santiago Baselga, Antonio Serra, José María Calatayud, Ricardo González García, Mariano de la Cámara, Clemente González Alonso, Elías Tormo, Juan Manuel Bel, Julio Pujol, Anselmo de Aramburu.

Díaz Tendero y González Rebollar abandonaron en 25 de enero, Villalonga Ale- 
many el 6 de febrero, Blanco de Ardines el 15 de febrero, Díez Canseco el 16 y Boo Pita el 5 de marzo.

\section{Votación y propuesta}

Tras los ejercicios primero y segundo, fueron aprobados por unanimidad Altamira, Arruche, Casuso y Liñán; por seis votos contra uno Palacios; por cinco votos contra dos Boo, Medina y Revillo.

Tras el resto de ejercicios se declaró aptos a todos los opositores.

La votación final dio el siguiente resultado: tres votos para Altamira, dos para Liñán y dos para Casuso.

En la segundo votación Altamira obtuvo cuatro votos contra tres de Casuso, por lo que fue propuesto.

\section{Materiales}

De tipo administrativo: actas de la oposición (indican las preguntas del cuarto ejercicio); oficios del negociado; oficios varios sobre conformación del tribunal, anuncio de la oposición, anuncio de la oposición.

De tipo académico o referentes a los ejercicios:

- Escritos de solicitudes de libros de cada opositor.

- Papeletas con las preguntas sacadas de la urna.

- Trabajos escritos correspondientes al primer ejercicio. Dos temas: "Fuero de León. Su historia y su análisis; El regalismo en España desde Macanaz hasta Campomanes y Martínez Marina”.

\section{Signatura}

AGA 32/07308. Legajo 5345-19.

\section{Cátedra}

Elementos de Derecho natural.

\section{Universidad}

Santiago.

\section{Anuncio}

R.O. de 18 de julio, 1895 .

\section{Reglamento aplicable}

27 de julio, 1894. 


\section{Fechas de la oposición}

Constitución: 5 de noviembre, 1897.

Presentación de los opositores: 6 de noviembre, 1897.

Votación y propuesta: 24 de noviembre, 1897.

\section{Tribunal}

Presidente: Vicente Gadea Orozco (tras la renuncia de Antonio Ruiz Ruiz).

Vocales: Francisco González Castejón, Leopoldo García Alas, Manuel Sánchez de Castro, Melchor Salvá, Benigno Cafranga.

Secretario: Luis Mendizábal Martín.

\section{Opositores}

Jesús Arias de Velasco.

Eduardo Velariño.

Elías Tormo Monzó.

Jesús Rubio. Excluido al no presentarse al primer ejercicio.

No comparecieron: Laureano Díez, Nicolás Sanromán.

\section{Votación y propuesta}

Fueron aprobados por unanimidad todos los opositores.

La votación fue ganada por Elías Tormo y Monzó por seis votos contra uno de Arias de Velasco.

La votación del mérito relativo del resto de opositores dio el siguiente resultado:

- Para el primer lugar, Vilariño por seis votos contra uno de Arias.

- Para el segundo lugar, Arias por unanimidad.

Elías Tormo Monzó fue nombrado el 9 de abril de 1898. Se admite su renuncia el 9 de diciembre de 1898 y se nombre a Eduardo Vilariño Magdalena.

\section{Materiales}

De tipo administrativo: actas de la oposición (indican las preguntas del cuarto ejercicio); oficios del negociado; oficios varios sobre conformación del tribunal, anuncio de la oposición, anuncio de la oposición.

Protesta del opositor Arias de Velasco y dictamen sobre la misma del tribunal de oposiciones. 


\section{Signatura}

AGA 32/07311. Legajo 5346-19.

\section{Cátedra}

Instituciones de Derecho canónico.

\section{Universidad}

Santiago.

\section{Anuncio}

R.O. de 18 de julio, 1895.

La cátedra se había anunciado a traslación (R.O. de 12 de junio, 1893) y a concurso (R.O. de 29 de agosto, 1893).

\section{Reglamento aplicable}

27 de julio, 1894 .

\section{Fechas de la oposición}

Constitución: 23 de noviembre, 1899.

Presentación de los opositores: 27 noviembre, 1899.

Votación y propuesta: 19 diciembre, 1899.

\section{Tribunal}

Presidente: Eduardo Palou.

Vocales: Melchor Salvá, Juan Morales, Nicolás Varela, Alfredo Brañas, Gregorio Burón.

Secretario: Francisco Cueva.

\section{Opositores}

Juan Bonnín Aguiló.

Joaquín Girón Areas.

Francisco Gómez del Campillo.

Armando Álvarez y Rodríguez.

Vicente López Vigo.

Juan Moneva Pujol.

No comparecieron otros 24 aspirantes.

\section{Votación y propuesta}

Primera votación: Lopéz de Vigo, tres votos; Moneva y Pujol, dos; Girón y Areas dos. 
Segunda votación: Lopéz de Vigo, tres votos; Moneva y Pujol, tres; Girón y Areas, uno. Ante la ausencia de mayoría absoluta se declaró no haber lugar a la provisión de la cátedra.

\section{Materiales}

Oficios del negociado, oficios varios sobre conformación del tribunal, anuncio de la oposición, actas (indican las preguntas).

- Escritos del primer ejercicio. Dos temas: "Párrocos: historia de su institución"; "Del anatema, deposición y degradación".

- Libros consultados por los opositores.

\section{Signatura}

AGA 32/o7306. Legajos 5345-5. Hay tres legajos con esta misma numeración.

\section{Cátedra}

Instituciones de Derecho romano.

\section{Universidad}

Salamanca.

\section{Anuncio}

R.O. de 18 de julio, 1895 .

\section{Reglamento aplicable}

27 de julio, 1894 .

También se aplica la Resolución de la Dirección General de Instrucción Pública de 11 de marzo de 1897.

\section{Fechas de la oposición}

Constitución: 20 de abril, 1897.

Presentación de los opositores: 3 de mayo, 1897.

Votación y propuesta: 20 de abril, 1897.

\section{Tribunal}

Presidente: Ismael Calvo.

Vocales: Francisco J. González Castejón, Gumersindo Azcárate, Vicente Olivares, Manuel Gómez Marín, Felipe Clemente de Diego.

Secretario: Juan Perigallo. 


\section{Opositores}

Sandalio Díaz Tendero.

Esteban Jiménez de la Flor.

Maro de Aguinaga, Manuel Pastor y Rodríguez, Tomás Barreda y Gonzalo Jaumar fueron excluidos en la sesión de 4 de mayo de 1897.

Melquíades Álvarez e Hipólito González fueron excluidos por la superioridad.

No comparecieron: Felipe Campo de los Reyes, Felipe Clemente de Diego, Mariano

Escalada, Guillermo García Valdecasas, Ángel Garjón, Clemente González Alonso, Francisco González Bautista, Rafael Marsá, Alberto Martín Costea, José María Rico.

\section{Votación y propuesta}

La votación fue ganada por Esteban Jiménez de la Flor por tres votos contra dos Sandalio Díaz Tendero, por lo que fue propuesto.

\section{Materiales}

Actas de la oposición; oficios del negociado; oficios varios sobre conformación del tribunal, anuncio de la oposición.

Unidos a las actas están los escritos de solicitudes de libros de cada opositor, las papeletas con las preguntas sacadas por éstos de la urna y los trabajos escritos (dos temas) correspondientes al primer ejercicio.

Constan protestas de Melquíades y de Maro de Aguinaga contra su exclusión.

\section{Signatura}

AGA 32/o7312. Legajos 5347-1. Hay dos legajos con la misma numeración.

\section{Cátedra}

Derecho político y administrativo.

\section{Universidad}

Sevilla.

\section{Anuncio}

R.O. de 8 de julio, 1896. Gaceta del 12.

\section{Reglamento aplicable}

27 de julio, 1894.

\section{Fechas de la oposición}

Constitución: 17 de febrero, 1902.

Presentación de los opositores: misma fecha que la anterior, segunda sesión.

Votación y propuesta: 16 de marzo, 1902. 


\section{Tribunal}

Presidente: Gumersindo Azcárate.

Vocales: Vicente Santamaría, Fernando Mellado, Enrique Gil Robles, Jerónimo Vida, Adolfo González Posada.

Secretario: Antonio Royo Villanova.

\section{Opositores}

Amando Ricardo Castroviejo.

José Gascón Marín.

Joaquín de Palacios Cárdenas.

Gonzalo del Castillo Alonso.

No comparecieron otros 23 aspirantes.

\section{Votación y propuesta}

José Gascón Marín obtuvo seis votos frente a uno a favor de Castroviejo (de Gil Robles). Fue por tanto propuesto.

La votación del mérito relativo del resto de opositores dio el siguiente resultado:

$1 .^{\circ}$ Amando Ricardo Castroviejo; $2 .^{\circ}$ Gonzalo del Castillo Alonso; $3{ }^{\circ}$ Joaquín de Palacios Cárdenas.

En una nota al margen se indica que el acuerdo derivado de la votación del mérito relativo fue anulado por R.O. de 7 de abril de 1902.

\section{Materiales}

Oficios del negociado, oficios varios sobre conformación del tribunal, anuncio de la oposición, actas (indican las preguntas).

- Cuestionario preparado por el tribunal (147 temas).

- Escritos del primer ejercicio. Dos temas: "Fines jurídicos del Estado"; "Facultades de las Cortes aragonesas".

- Papeletas del segundo ejercicio.

- Escritos del cuarto ejercicio.

- Libros consultados por los opositores.

\section{Signatura}

AGA 32/07309. Legajos 5346-1. Hay dos legajos con la misma numeración.

\section{Cátedra}

Derecho internacional público y privado.

\section{Universidad}

Santiago. 


\section{Anuncio}

R.O. de 7 de julio, 1897. Gaceta del 15.

La cátedra había sido anunciada a traslación (R.O. de 27 de diciembre, 1895) y a concurso (R.O. de 22 febrero de 1896).

\section{Reglamento aplicable}

27 de julio, 1894.

\section{Fechas de la oposición}

Constitución: 8 de enero, 1903.

Presentación de los opositores: 20 de enero, 1903.

Votación y propuesta: 31 de enero, 1903.

\section{Tribunal}

Presidente: Rafael Conde Luque.

Vocales: Eduardo Sanz y Escartín, Juan de Dios Trías, Joaquín Fernández Prida, Manuel Torres Campos.

Secretario: Alfonso Retortillo.

\section{Opositores}

Juan de Reza Estévez.

Salvador Cabeza León.

No comparecieron: Felipe García Ontiveros, Manuel Xucla, Adoración Martínez, José Gascón Marín, Vicente de Piniés, Juan Andrés Palomar, Emilio Miñana Villagrasa, Jesús Sánchez y Sánchez, Pío Blanco de Andrés, Francisco Albó Martí, Juan Manuel Bel Serrano, Ramón Ferreiro Lago, Amando Ricardo Castroviejo, Julio Casín y González, Antonio Goicoechea Cosculluela, Francisco Rico Pérez.

\section{Votación y propuesta}

Cabeza fue propuesto por seis votos. Torres Campos votó contra la provisión de la cátedra.

\section{Materiales}

De tipo administrativo: actas de la oposición, oficios del negociado, oficios varios sobre conformación del tribunal, anuncio de la oposición, anuncio de la oposición.

De tipo académico o referentes a los ejercicios:

- Cuestionario elaborado por el tribunal para los ejercicios primero y segundo (124 preguntas).

- Escritos de solicitudes de libros de cada opositor. 
- Trabajos escritos correspondientes al primer ejercicio. Dos temas: "Clasificación de los derechos internacionales de los Estados; Cómo puede dividirse la guerra".

- Trabajos escritos correspondientes al ejercicio práctico.

- Programa aportado por el opositor Salvador Cabeza (86 lecciones).

- Programa y Memoria sobre el método de enseñanza y fuentes de conocimiento aportado por el opositor Salvador Cabeza.

- Trabajo de investigación aportado por el opositor Salvador Cabeza correspondiente al ejercicio quinto (La teoría de la personalidad del derecho).

Consta escrito de recusación de Ramón Ferreiro contra Nicolás López.

\section{Signatura}

32/07310. Legajo 5346-14.

\section{Cátedra}

Elementos de Derecho natural.

\section{Universidad}

Valladolid.

\section{Anuncio}

Gaceta de 6 de agosto de 1897 (R. O. de 2 de agosto de 1897).

\section{Reglamento aplicable}

Reglamento de 27 de julio de 1894 .

\section{Fechas de la oposición}

10 de marzo de 1900: constitución del tribunal.

12 de marzo de 1900: presentación de los opositores.

8 de abril de 1900: votación y propuesta.

\section{Tribunal}

Presidente: Juan Uña.

Vocales: Francisco González Castejón, Nicasio Sánchez Mata, Gumersindo Azcárate, Rafael Ureña, Cándido Emperador (renuncia a mitad de los ejercicios).

Secretario: Joaquín Fernández Prida.

\section{Opositores}

Isidro Beato Sala. 
Roque Bellido.

Adolfo Bonilla San Martín.

Laureano Díez Canseco.

Gonzalo Jaumar de la Carrera.

José Liñan y Eguizabal.

Benigno Martín Martín. Desiste tras el primer ejercicio.

Julio Puyol Alonso.

Fernando Romero González.

Ángel Sánchez Vera.

Calixto Valverde.

\section{Votación y propuesta}

Laureano Díez Canseco, 4 votos frente a 2 a favor de Bonilla.

Lista de mérito relativo:

$1 .^{\circ}$ Bonilla.

$2 .^{\circ}$ Liñan.

$3 \cdot{ }^{\circ}$ Valverde.

$4 .^{\circ}$ Puyol.

$5{ }^{\circ}$ Romero.

6. ${ }^{\circ}$ Jaumar.

7. ${ }^{\circ}$ Sánchez Vera.

30 de mayo de 1900: nombramiento de Laureano Díez Canseco.

\section{Materiales}

Consta el expediente completo (37 actas), así como Programa y Memoria de Canseco.

\section{Signatura}

AGA 32/07309. Legajo 5346-4.

\section{Cátedra}

Derecho civil español, común y foral.

\section{Universidad}

Granada.

\section{Anuncio}

R.O. de 24 de julio, 1899. Gaceta del 30. 


\section{Reglamento aplicable}

27 de julio, 1894 .

\section{Fechas de la oposición}

Constitución: 6 de febrero, 1903.

Presentación de los opositores: 12 de febrero, 1903.

Votación y propuesta: 4 de abril, 1903.

\section{Tribunal}

Presidente: Felipe Sánchez Román.

Vocales: Gumersindo Azcárate, Eduardo de Hinojosa, Cleto Troncoso, José Martos de la Fuente, Gregorio Burón.

Secretario: Guillermo García Valdecasas.

\section{Opositores}

Manuel Bedmar Ferraz.

Joaquín Dualde Gómez.

Felipe Gil Casares.

Calixto Valverde Valverde.

No comparecieron otros 29 aspirantes.

\section{Votación y propuesta}

Calixto Valverde obtuvo seis votos contra uno a favor de Joaquín Dualde (de Azcárate). Fue propuesto para la cátedra.

\section{Materiales}

Actas de la oposición (indican las preguntas sacadas de la urna), oficios del negociado, oficios varios sobre conformación del tribunal, anuncio de la oposición.

\section{Signatura}

AGA 32/07309. Legajo 5346-3.

\section{Cátedra}

Economía política y Hacienda pública.

\section{Universidad}

Santiago. 


\section{Anuncio}

R.O. de 28 de julio, 1900. Gaceta del 30.

\section{Reglamento aplicable}

27 de julio, 1894.

\section{Fechas de la oposición}

Constitución: 5 de marzo, 1903.

Presentación de los opositores: 16 de marzo, 1903.

Votación y propuesta: 31 de enero, 1903.

\section{Tribunal}

Presidente: José Manuel Piernas.

Vocales: Eduardo Sanz Escartín, Manuel de Bedmar Escudero, Teodoro Peña Fernández, Francisco J. Jiménez, Joaquín Fernández Prida.

Secretario: Elías Tormo y Monzó.

\section{Opositores}

Francisco García de Cáceres.

José María Zumalacárregui Prat.

Luis del Valle Pascual y Manuel Rey García se retiraron.

No comparecieron otros 24 opositores.

\section{Votación y propuesta}

José María Zumalacárregui fue propuesto por seis votos contra uno a favor de García de Cáceres (de Teodoro Peña).

\section{Materiales}

De tipo administrativo: actas de la oposición, oficios del negociado, oficios varios sobre conformación del tribunal, anuncio de la oposición.

De tipo académico o referentes a los ejercicios:

- Cuestionario elaborado por el tribunal para los ejercicios primero y segundo (138 preguntas).

- Escritos de libros consultados por cada opositor.

- Trabajos escritos correspondientes al primer ejercicio. Dos temas: "Teoría del cambio; El producto económico".

- Trabajos escritos correspondientes al cuarto ejercicio. Un tema: "Nuestro régimen arancelario". 
Referencia de archivo

AGA 32/07313. Legajo 5347-6.

AGA 32/07310. Legajo 5346-5.

\section{Materia}

Instituciones de Derecho canónico.

\section{Universidad}

Zaragoza y Santiago.

\section{Convocatoria}

R.O. de 25 de agosto, 1900.

La cátedra se había anunciado a traslación (R.O. de 29 de junio, 1898) y a concurso (R.O. de 18 de agosto, 1898).

\section{Reglamento aplicable}

27 de julio, 1894.

\section{Fechas de la oposición}

Constitución: 28 de octubre, 1902.

Presentación de los opositores: 18 de noviembre, 1902.

El presidente Juan de la Concha Castañeda abandona el tribunal el 2 de diciembre. Eduardo Palou ejerce la presidencia interina.

Por R.O. de la Subsecretaria del Ministerio de I.P. de 18 de diciembre se ordena que Eduardo Soler ocupe la presidencia.

En 17 de enero de 1903 se aprueban los ejercicios primero y segundo de todos los opositores.

Votación: 11 de marzo, 1903. La propuesta el día siguiente.

\section{Tribunal}

Presidente: Eduardo Soler.

Vocales: Eduardo Palou, Cipriano Herce, Salvador Torres Aguilar, Juan Pedro Morales.

Secretario: Felipe Clemente de Diego.

\section{Opositores}

Manuel Cabrera Warleta.

Francisco Gómez del Campillo.

Juan Estrada Acebal.

Joaquín Girón Arcas. 
Armando Álvarez Rodríguez.

Vicente López Vigo.

Juan Moneva Pujol.

Juan Bonnín Aguiló se retiró.

No comparecieron otros 18 opositores.

\section{Votación y propuesta}

La votación para el primer lugar fue ganada por Juan Moneva con los votos de todos los miembros del tribunal menos el de Soler, que no propuso opositor.

La votación para el segundo lugar dio el siguiente resultado: tres votos para López Vigo (de Diego, Herce y Palou) y dos votos para Girón (Morales y Torres Aguilar). Soler no propuso opositor. En las votaciones segunda y tercera ningún opositor obtuvo mayoría absoluta, por lo cual se acordó que no procedía la designación del segundo lugar.

Juan Moneva optó por la cátedra de Zaragoza y fue propuesto.

\section{Materiales}

De tipo administrativo: actas de la oposición (se unen las papeletas de las preguntas), oficios del negociado, oficios varios sobre conformación del tribunal, anuncio de la oposición, escrito de protesta del opositor Joaquín Girón, escrito del vocal Soler solicitando la suspensión de las sesiones. El expediente recoge un dictamen del Consejo de I.P. de 23 de noviembre de 1898, al que se añade un voto particular.

De tipo académico o referentes a los ejercicios:

-Cuestionario elaborado por el tribunal (133 temas).

-Escritos del primer ejercicio. Dos temas: "Actos de la potestad de jurisdicción...”; "De los auxiliares del Tribunal del Obispo".

-Trabajos escritos correspondientes al cuarto ejercicio.

-Escritos de libros consultados por cada opositor.

-Programa elaborado por Manuel Cabrera Warleta.

-Trabajo de investigación de Manuel Cabrera Warleta: "Las comunidades de beneficiados de la Corona de Aragón".

\section{Signatura}

AGA 32/07312. Legajo 5347-4.

\section{Cátedra}

Derecho mercantil de España y de las principales naciones de Europa y América. 


\section{Universidad}

Valencia.

\section{Anuncio}

R.O. de 25 de agosto, 1900. Gaceta del 1 de septiembre.

\section{Reglamento aplicable}

27 de julio, 1894.

\section{Fechas de la oposición}

Constitución: 30 de enero, 1903.

Presentación de los opositores: 12 de febrero, 1903.

Votación y propuesta: 19 de marzo, 1903.

\section{Tribunal}

Presidente: Faustino Álvarez del Manzano.

Vocales: Prudencio Requejo, Eduardo Sanz y Escartín, Eduardo Soler, Tomás Montejo, José María Olózaga.

Secretario: Antonio de la Figuera.

\section{Opositores}

Benito Zurita Nieto.

Casto Barahona Holgado.

Rafael Marín Lázaro.

Joaquín Ros Gómez.

Adolfo Bonilla San Martín.

Antonio Nin Devesa.

No comparecieron otros 20 opositores.

\section{Votación y propuesta}

Adolfo Bonilla San Martín ganó la votación por cinco votos (Álvarez del Manzano, Requejo, Montejo, Olózaga, de la Figuera) contra dos a favor de Rafael Marín Lázaro (de Sanz Escartín y Soler). Fue por tanto propuesto.

\section{Materiales}

De tipo administrativo: actas de la oposición, oficios del negociado, oficios varios sobre conformación del tribunal, anuncio de la oposición.

De tipo académico o referentes a los ejercicios:

- Cuestionario elaborado por el tribunal (141 preguntas).

- Escritos del primer ejercicio. Dos temas: "Legislación mercantil de las Repúbli- 
cas Hispano-americanas"; "Sociedades bancarias de emisión y descuento según derecho español".

- Trabajos escritos correspondientes al cuarto ejercicio.

- Escritos de libros consultados por cada opositor.

De tipo procesal:

- Escrito de protesta del opositor Rafael Marín Lázaro.

- Sentencia del Tribunal Supremo (sala de lo contencioso-administrativo) de 29 de junio de 1904, que desestima el recurso interpuesto por Rafael Marín Lázaro.

\section{Signatura}

AGA 32/07314. Legajos 5347-8.

\section{Cátedra}

Derecho civil español, común y foral.

\section{Universidad}

Zaragoza.

\section{Anuncio}

R.O. de 29 de diciembre, 1900. Gaceta del 30.

\section{Reglamento aplicable}

27 de julio, 1894 .

\section{Fechas de la oposición}

Constitución: 3 de noviembre, 1904.

Presentación de los opositores: 7 de noviembre, 1904.

Votación y propuesta: 13 de diciembre, 1904.

\section{Tribunal}

Presidente: Matías Barrio.

Vocales: Felipe Sánchez Román, Cleto Troncoso, Eduardo Hinojosa, Teodoro Gómez, Tomás Montejo.

Secretario: Ismael Calvo.

\section{Opositores}

Gil Gil Gil.

No comparecieron: Cirilo Palomo, Leopoldo Michelena, Gregorio Galindo, Isidro Beato, Pedro Garriga, Gonzalo Jaumar, Antonio Mejías, José Gascón, Roberto Gómez, Calixto Valverde, Hipólito González. 


\section{Votación y propuesta}

Por unanimidad se votó y propuso a Gil Gil Gil.

\section{Materiales}

De tipo administrativo: actas de la oposición (se unen las papeletas de las preguntas), oficios del negociado, oficios varios sobre conformación del tribunal, anuncio de la oposición.

De tipo académico o referentes a los ejercicios:

- Cuestionario elaborado por el tribunal (180 temas).

- Escritos del primer ejercicio. Dos temas: "Conceptos de propiedad, del derecho de propiedad y del dominio"; "Contrato de préstamo".

- Trabajo escrito correspondiente al ejercicio práctico: ¿Puede la mujer casada ser fiadora de su marido?

- Escrito de libros consultados por el opositor.

\section{Signatura}

AGA 32/07312. Legajo 5347-5.

\section{Cátedra}

Derecho civil español, común y foral.

\section{Universidad}

Sevilla.

La R.O. indica las universidades de Sevilla y Barcelona. Sin embargo, se anuló la convocatoria para Barcelona debido a la reintegración del catedrático jubilado Modesto Falcón.

\section{Anuncio}

R.O. de 29 de diciembre, 1900. Gaceta del 30.

\section{Reglamento aplicable}

27 de julio, 1894.

\section{Fechas de la oposición}

Constitución: 15 de abril, 1903.

En 6 de mayo de 1903 se suspenden las sesiones por enfermedad del vocal José Martos.

Presentación de los opositores: 8 de noviembre, 1904.

Votación y propuesta: 14 de diciembre, 1904. 


\section{Tribunal}

Presidente: Felipe Sánchez Román.

Vocales: José Maluquer (en sustitución de Azcárate), Eduardo Hinojosa, Cleto Troncoso, Tomás Montejo (en sustitución de Gregorio Burón), José Martos de la Fuente.

Secretario: Guillermo García Valdecasas.

\section{Opositores}

Manuel de Bedmar Larraz.

Joaquín Dualde Gómez.

Antonio Mejías Asensio.

Juan Antonio Velasco Lacasa se retiró durante los ejercicios.

No comparecieron otros 20 opositores.

\section{Votación y propuesta}

- Joaquín Dualde y Gómez: cinco votos (Maluquer, Valdecasas, Troncoso, Sánchez Román y Montejo).

- Manuel de Bedmar y Larraz: un voto (Martos).

- Antonio Mejías y Asensio: un voto (Hinojosa).

Se propone a Joaquín Dualde.

\section{Materiales}

De tipo administrativo: actas de la oposición, oficios del negociado, oficios varios sobre conformación del tribunal, anuncio de la oposición.

De tipo académico o referentes a los ejercicios:

- Cuestionario elaborado por el tribunal (197 preguntas).

- Trabajos escritos correspondientes al primer ejercicio. Dos temas: "Ligera idea del Registro Civil..."; "Anotaciones preventivas..."

- Trabajos escritos correspondientes al cuarto ejercicio.

- Escritos de libros consultados por cada opositor.

\section{Signatura}

AGA 32/07313. Legajo 5347-6.

\section{Cátedra}

Instituciones de Derecho canónico.

\section{Universidad}

Salamanca y Sevilla. 


\section{Anuncio}

R.O. de 29 de diciembre, 1900.

\section{Reglamento aplicable}

27 de julio, 1894.

\section{Fechas de la oposición}

Constitución: 14 de abril, 1903.

Presentación de los opositores: 16 de abril, 1903.

Votación: 29 de mayo, 1903.

Propuesta: 30 de mayo, 1903 .

\section{Tribunal}

Presidente: Eduardo Soler.

Vocales: Eduardo Palou, Cipriano Herce, Salvador Torres Aguilar, Matías Barrio, Eduardo Hinojosa.

Secretario: Felipe Clemente de Diego.

\section{Opositores}

Isidro Beato Sala.

Isidoro Iglesias García.

Francisco Cueva Palacio.

Manuel Cabrera Warleta.

Vicente López Vigo.

Juan Moneva Pujol se retiró.

No comparecieron otros 20 opositores.

\section{Votación y propuesta}

$1 .^{\circ}$ Francisco Cueva por unanimidad.

2. ${ }^{\circ}$ Manuel Cabrera por cuatro votos (Barrio, Herce, Palou y Soler) contra tres de López Vigo (de Diego, Torres Aguilar e Hinojosa).

Francisco Cueva optó por la cátedra de Salamanca; Manuel Cabrera aceptó la de Sevilla. Fueron propuestos.

\section{Materiales}

De tipo administrativo: actas de la oposición, oficios del negociado, oficios varios sobre conformación del tribunal, anuncio de la oposición.

De tipo académico o referentes a los ejercicios:

- Cuestionario elaborado por el tribunal (155 temas).

- Escritos del primer ejercicio. Dos temas: "Celibato eclesiástico"; "Proclamas". 
- Trabajos escritos correspondientes al cuarto ejercicio.

- Escritos de libros consultados por cada opositor.

- Programa elaborado por Manuel Cabrera Warleta.

- Trabajo de investigación de Manuel Cabrera Warleta: "Las comunidades de beneficiados de la Corona de Aragón".

\section{Signatura}

AGA 32/07312. Legajo 5347-3.

\section{Cátedra}

Instituciones de Derecho romano.

\section{Universidad}

Barcelona.

\section{Anuncio}

R.O. de 29 de diciembre de 1900 (Gaceta del 30).

\section{Reglamento aplicable}

27 de julio, 1894 .

\section{Fechas de la oposición}

Constitución: 12 de abril, 1902.

Presentación de los opositores: 22 de abril, 1902.

Votación y propuesta: 21 de mayo, 1902.

\section{Tribunal}

Presidente: Matías Barrio Mier.

Vocales: Eduardo de Hinojosa, Salvador Torres Aguilar, Gregorio Burón, Ismael Calvo, Eladio García Amado.

Secretario: Felipe Clemente de Diego.

\section{Opositores}

José María Jaumar.

Pedro Garriga Folch.

José Moneva Pujol.

Juan Perigallo Amorós.

No comparecieron: José Rivero Aguilar, Leopoldo Michelena, Cirilo Palomo, Isidro Beato, José Gascón Marín. 


\section{Votación y propuesta}

En la primera votación hubo tres votos a favor de la no provisión de la cátedra (de Diego, Calvo y Torres Aguilar) y tres votos a favor del opositor Garriga (Burón, Hinojosa, y Barrio).

En la segunda votación Garriga obtuvo cinco votos (Calvo, Burón, Torres Aguilar, Hinojosa y Barrio) y Moneva uno (de Diego).

Fue por tanto propuesto Pedro Garriga Folch.

\section{Materiales}

Solo constan las actas, con los siguientes documentos unidos:

- Cuestionario elaborado por el tribunal (135 preguntas).

- Escritos del primer ejercicio. Dos temas: "Capacidad para ser testigo en un testamento romano"; "Modos de extinguirse las obligaciones".

- Papeletas del segundo ejercicio (contestación oral) y del tercero (lección).

- Trabajos escritos correspondientes al cuarto ejercicio.

- Escritos de libros consultados por cada opositor.

\section{Signatura}

AGA 32/o7312. Legajos 5347-2. Hay dos legajos con la misma numeración.

\section{Cátedra}

Derecho administrativo.

\section{Universidad}

Santiago.

\section{Anuncio}

R.O. de 22 de julio, 1901.

\section{Reglamento aplicable}

27 de julio, 1894 .

\section{Fechas de la oposición}

Constitución: 3 de abril, 1902.

Presentación de los opositores: 8 de abril, 1902.

Votación y propuesta: 23 de abril, 1902. 


\section{Tribunal}

Presidente: Vicente Santamaría.

Vocales: Melchor Salvá, Eduardo Hinojosa, Fernando Mellado, Francisco J. Jiménez, José Olózaga.

Secretario: Antonio Goicoechea.

\section{Opositores}

Leopoldo de Michelena García de Paredes.

No comparecieron: José Gascón Marín, Isidro Beato Sala, Ángel Pintos Pintos.

\section{Votación y propuesta}

Michelena obtuvo los votos de todos los jueces y fue propuesto para la cátedra.

\section{Materiales}

Oficios del negociado, oficios varios sobre conformación del tribunal, anuncio de la oposición, actas (indican las preguntas).

- Cuestionario preparado por el tribunal (10o temas).

- Escritos del primer ejercicio. Dos temas: "Policía sanitaria"; "Montes".

- Papeletas del segundo ejercicio.

- Escritos del ejercicio práctico.

- Libros consultados por el opositor.

\section{Signatura}

AGA 32/07318. Legajo 5349-2.

\section{Cátedra}

Economía política y Hacienda pública.

\section{Universidad}

Barcelona.

\section{Anuncio}

R.O. de 22 de julio, 1901.

\section{Reglamento aplicable}

27 de julio, 1894 .

\section{Fechas de la oposición}

Constitución: 25 de enero, 1904. 
Presentación de los opositores: 27 de enero, 1904.

Votación y propuesta: 16 de marzo, 1904.

\section{Tribunal}

Presidente: José Piernas y Hurtado.

Vocales: Ismael Calvo Madroño, Francisco J. Jiménez de Vargas, Eduardo Sanz Escartín, Manuel de Bedmar.

Secretario: José María de Olózaga.

Teodoro Peña Fernández abandonó el tribunal y no participó en la votación.

\section{Opositores}

Juan Fernández Loaysa.

José Santaló Rodríguez.

Antonio Flores de Lemus.

Francisco García de Cáceres.

Ángel Sánchez Vera.

Francisco Juan Benlloch se retira durante los ejercicios.

No comparecieron otros 25 opositores.

\section{Votación y propuesta}

La votación final fue ganada por Antonio Flores por cinco votos (Olózaga, Jiménez, Bedmar, Sanz y Piernas) contra uno de Ángel Sánchez Vera (Calvo). Antonio Flores fue propuesto.

\section{Materiales}

De tipo administrativo: actas, oficios del negociado, oficios varios sobre conformación del tribunal, anuncio de la oposición, ejemplar de la Gaceta de 24 de marzo de 1903.

De tipo académico o referentes a los ejercicios:

- Cuestionario elaborado por el tribunal (138 temas).

- Escritos del primer ejercicio. Dos temas: "El consumo público. Sus límites racionales"; "Ventajas e inconvenientes de la fácil movilización de la propiedad".

- Trabajos escritos correspondientes al ejercicio práctico: "Modos por los cuales podría nuestro país alcanzar la normalidad monetaria".

- Escritos de libros consultados por cada opositor. 


\section{Signatura}

AGA 32/07309. Legajo 5346-3.

\section{Cátedra}

Economía política y Hacienda pública.

\section{Universidad}

Valladolid y Sevilla.

\section{Anuncio}

R. O. de 14 de junio de 1902, Gaceta del 25.

\section{Reglamento aplicable}

11 de agosto, 1901.

\section{Fechas de la oposición}

Constitución: 6 de febrero, 1903.

Presentación de los opositores: 16 de febrero, 1903.

Votación: 12 de marzo, 1903.

Propuesta: 12 de marzo, 1903.

\section{Tribunal}

Presidente: José Manuel Piernas.

Vocales: Eduardo Sanz Escartín, Manuel de Bedmar Escudero, Teodoro Peña Fernández, Francisco J. Jiménez, Joaquín Fernández Prida.

Secretario: José María de Olózaga.

\section{Opositores}

Manuel Fernández Mourillo.

Manuel de Losada Llanos.

Amando Castroviejo.

Luis del Valle Pascual.

Manuel Oller Belda se retiró el 19 de febrero.

No comparecieron otros 13 opositores.

\section{Votación y propuesta}

1. ${ }^{\circ}$ Amando Castroviejo por unanimidad.

Por unanimidad se declaró que no procedía la designación del segundo lugar.

Castroviejo optó por la cátedra de Sevilla. 


\section{Materiales}

No consta el expediente administrativo, pero sí las actas.

De tipo académico o referentes a los ejercicios:

- Trabajos escritos correspondientes al primer ejercicio. Dos temas: Las doctrinas financieras de Francisco Quesnay y Adam Smith; La propiedad del Estado.

- Trabajos escritos correspondientes al cuarto ejercicio. Un tema: La deuda exterior de España.

- Escritos de libros consultados por cada opositor.

\section{Signatura}

32/07318. Legajo 5349-1.

\section{Cátedra}

Elementos de Derecho natural.

\section{Universidad}

Oviedo.

\section{Anuncio}

Gaceta de 1 de agosto de 1902 (R. O. de 29 de julio de 1902).

\section{Reglamento aplicable}

Reglamento de 11 de agosto de 1901.

\section{Fechas de la oposición}

10 de octubre de 1903: constitución del tribunal.

23 de octubre de 1903: presentación de los opositores.

17 de diciembre de 1903: votación y propuesta.

\section{Tribunal}

Presidente: Gumersindo Azcárate.

Vocales: Francisco González Castejón Elio, Rafael Ureña, Joaquín Fernández Prida (en substitución de Francisco Giner de los Ríos), Juan de Arana, José de Cárdenas (en substitución de Joaquín Costa).

Secretario: Laureano Díez Canseco.

\section{Opositores}

Jesús Arias de Velasco.

Tomás Carreras Artau. 
Fernando Pérez Bueno.

Francisco Rivera Pastor.

\section{Votación y propuesta}

En primera votación: Pérez Bueno, 3 votos (Arana, Ureña y Cárdenas); Arias de Velasco, 2 (Fernández Prida y González Castejón); Rivera Pastor, 2 (Azcárate y Díez Canseco).

A falta de mayoría absoluta, se procede a segunda votación:

Pérez Bueno, 4 votos (Arana, Castejón, Ureña y Cárdenas) frente a 2 votos para Rivera (Díez Canseco y Azcárate) y 1 voto en favor de Arias Velasco (Fernández Prida).

28 de diciembre de 1903: nombramiento de Fernando Pérez Bueno.

\section{Materiales}

Consta el expediente completo.

La cátedra de Derecho Natural de Oviedo, vacante por fallecimiento de Leopoldo García Alas, es inicialmente provista por turno de traslación: el único aspirante, Eduardo Vilariño Magdalena, es nombrado para ocuparla por R.O. de 25 de septiembre de 1901, pero renuncia el 18 de octubre y sale entonces a oposición.

\section{Signatura}

AGA 32/07322. Legajo 5350-4.

\section{Cátedra}

Derecho civil español, común y foral.

\section{Universidad}

Central.

\section{Anuncio}

R.O. de 23 de mayo, 1903. Gaceta del 1 de junio.

La cátedra había sido anunciada a oposición por R.O. de 29 de diciembre de 1900 (Gaceta del 30). Tal Orden fue impugnada por el catedrático Gregorio Burón.

\section{Reglamento aplicable}

11 de agosto, 1901.

\section{Fechas de la oposición}

Constitución del tribunal: 15 de febrero, 1906. 
Presentación de los opositores: 20 de febrero, 1906.

Votación y propuesta: 10 de marzo, 1906.

\section{Tribunal}

Presidente: Gumersindo de Azcárate.

Vocales: Felipe Sánchez Román, Francisco J. Castejón, Francisco Lastras, Ismael Calvo, Matías Barrio.

Secretario: José Manuel de la Fuente Quijano.

\section{Opositores}

Felipe Clemente de Diego.

No comparecieron: Francisco de Casso, Cleto Troncoso, Juan Perigallo, Antonio Mejías, Ángel Sánchez, Cirilo Palomo.

\section{Votación y propuesta}

Felipe Clemente de Diego fue votado por unanimidad y fue propuesto.

\section{Materiales}

De tipo administrativo: actas, oficios del negociado, oficios varios sobre conformación del tribunal, anuncio de la oposición.

De tipo jurisdiccional: sentencia del tribunal de lo contencioso-administrativo de 23 de diciembre de 1901; sentencia del Tribunal Supremo (sala de lo contenciosoadministrativo) de 22 de octubre de 1904.

De tipo académico o referentes a los ejercicios:

- Cuestionario elaborado por el tribunal (143 temas).

- Ejercicio escritos correspondientes al primer ejercicio. Dos temas: "Elementos que han intervenido en la formación del Derecho civil español"; "Sistema de contratación del Código Civil español”.

- Trabajo escrito correspondiente al ejercicio práctico (cuarto ejercicio).

- Escrito de libros consultados por el opositor.

\section{Signatura}

AGA 32/o7321. Legajo 5350-1.

\section{Cátedra}

Derecho administrativo.

\section{Universidad}

Santiago. 


\section{Anuncio}

R.O. de 27 de julio, 1903. Gaceta del 31.

\section{Reglamento aplicable}

11 de agosto, 1901.

\section{Fechas de la oposición}

Constitución del tribunal: 1 de marzo, 1905.

Presentación de los opositores: 14 de marzo, 1905.

Votación y propuesta: 10 de abril, 1905.

\section{Tribunal}

Presidente: Eduardo de Hinojosa.

Vocales: Eduardo Soler, Vicente Santamaría, Rafael Ureña, Ismael Calvo, Francisco J. Jiménez Pérez de Vargas.

Secretario: José Gascón Marín.

\section{Opositores}

Antonio Mesa Moles.

Gonzalo del Castillo.

Cándido Cerdeira.

No comparecieron otros 26 opositores.

\section{Votación y propuesta}

Gonzalo del Castillo recibió los votos de todos los jueces menos el de Soler, quien voto en el sentido de no designar opositor. Fue propuesto.

\section{Materiales}

De tipo administrativo: actas, oficios del negociado, oficios varios sobre conformación del tribunal, anuncio de la oposición.

De tipo académico o referentes a los ejercicios:

- Cuestionario elaborado por el tribunal (114 temas).

- Ejercicio escritos correspondientes al primer ejercicio. Dos temas: "Instituciones administrativas actuales que se refieren a la llamada cuestión obrera"; "De la enseñanza en general".

- Trabajos escritos correspondientes al ejercicio práctico (cuarto ejercicio).

- Escritos de libros consultados por cada opositor. 


\section{Signatura}

AGA 32/o7314. Legajos 5347-7. Hay dos legajos con la misma numeración.

\section{Cátedra}

Instituciones de Derecho canónico.

\section{Universidad}

Santiago.

\section{Anuncio}

R.O. de 27 de julio, 1903.

\section{Reglamento aplicable}

11 de agosto, 1901.

\section{Fechas de la oposición}

Constitución: 5 de febrero, 1904.

Presentación de los opositores: 18 de febrero, 1904.

Votación y propuesta: 28 de abril, 1904.

\section{Tribunal}

Presidente: Victoriano Guisasola (Obispo de Madrid-Alcalá).

Vocales: Eduardo Palou, Salvador Torres Aguilar, Matías Barrio, Tomás Montejo, Francisco Cueva.

Secretario: Juan Moneva Pujol.

\section{Opositores}

Juan Estrada Acebal.

Carlos de Castro Rodríguez.

Joaquín Girón Arcas.

Juan Bonnín Aguiló.

Isidoro Iglesias García.

Ángel Vázquez de Parga.

Eduardo Ugarte Albizu.

Amado Salas Medina.

No comparecieron otros 24 opositores.

\section{Votación y propuesta}

Se declaró la aptitud para pasar al tercer ejercicio de todos los opositores menos la de Carlos de Castro Rodríguez. 
La votación final fue ganada por Joaquín Girón por cuatro votos (Moneva, Montejo, Palou y Guisasola) contra uno de Iglesias (Cueva), uno de Estrada (Barrio), y uno de Salas (Torres Aguilar).

Joaquín Girón fue propuesto.

\section{Materiales}

De tipo administrativo: actas de la oposición (se unen las papeletas de las preguntas), oficios del negociado, oficios varios sobre conformación del tribunal, anuncio de la oposición.

Consta sentencia del tribunal de lo contencioso-administrativo de 22 de abril de 1904, sobre protesta del opositor Joaquín Girón en la oposición a las cátedras de Zaragoza y Santiago de 1902.

De tipo académico o referentes a los ejercicios:

- Cuestionario elaborado por el tribunal (200 temas).

- Escritos del primer ejercicio. Dos temas: "Carácter y contenido de la Bula Unam Sanctum"; "Autoridades que pueden imponer censuras".

- Trabajos escritos correspondientes al ejercicio práctico.

- Escritos de libros consultados por cada opositor.

\section{Signatura}

AGA 32/o7320. Legajos 5349-7. Hay dos legajos con la misma numeración.

\section{Cátedra}

Economía política y Estadística y Hacienda pública.

\section{Universidad}

Valladolid.

\section{Anuncio}

R.O. de 27 de julio, 1903.

La provisión de la misma cátedra anunciada por R.O. de 24 de julio de 1899 había quedado desierta.

\section{Reglamento aplicable}

11 de agosto, 1901.

\section{Fechas de la oposición}

Constitución del tribunal: 26 de enero, 1905.

Presentación de los opositores: 30 de enero, 1905. 
Votación y propuesta: 10 de abril, 1905.

\section{Tribunal}

Presidente: José Piernas Hurtado.

Vocales: Eduardo Sanz Escartín, Francisco J. Jiménez Pérez de Vargas, Adolfo Álvarez Buylla, José Maluquer, José María Olózaga.

Secretario: Amando Castroviejo.

\section{Opositores}

Francisco Bernis.

Vicente Gay.

Rafael Gallego Díaz.

Francisco Benlloch.

Juan Fernández Loayse.

José Santaló Rodríguez.

Francisco García de Cáceres.

Inocencio Jiménez.

José Monge.

Quintín Palacios.

Manuel Rey García.

Ángel Sánchez Vera.

No comparecieron otros 23 opositores.

\section{Votación y propuesta}

La primera votación dio el siguiente resultado:

- Rafael Gallego: dos votos (Castroviejo, Peña).

- Vicente Gay: tres votos (Olózaga, Maluquer, Buylla).

- Francisco Bernis: dos votos (Jiménez, Piernas).

La segunda votación dio el siguiente resultado:

- Rafael Gallego: un voto (Castroviejo).

- Vicente Gay: cuatro votos (Olózaga, Maluquer, Buylla, Peña).

- Francisco Bernis: dos votos (Jiménez, Piernas).

Fue propuesto Vicente Gay.

\section{Materiales}

De tipo administrativo: actas, oficios del negociado, oficios varios sobre conformación del tribunal, anuncio de la oposición.

De tipo académico o referentes a los ejercicios:

- Cuestionario elaborado por el tribunal (148 temas).

- Ejercicio escritos correspondientes al primer ejercicio. Dos temas: “Concepto y 
contenido de la economía política"; "Intervención y funciones del ser humano en la producción económica".

- Trabajos escritos correspondientes al ejercicio práctico: "Medidas necesarias para normalizar la situación del Banco de España”.

- Escritos de libros consultados por cada opositor.

\section{Signatura}

AGA 32/07321. Legajo 5350-3.

\section{Cátedra}

Instituciones de Derecho romano.

\section{Universidad}

Sevilla.

\section{Anuncio}

R.O. de 28 de julio, 1904. Gaceta del 29.

La cátedra se había anunciado a traslación por R.O. de 28 de marzo, 1904.

\section{Reglamento aplicable}

11 de agosto, 1901.

\section{Fechas de la oposición}

Constitución del tribunal: 20 de enero, 1905.

Presentación de los opositores: 21 de enero, 1905.

Votación y propuesta: 16 de febrero, 1905.

\section{Tribunal}

Presidente: Matías Barrio.

Vocales: Eladio García Amado, Francisco Cueva, Esteban Jiménez de la Flor, Ismael Calvo, Eduardo de Hinojosa.

Secretario: Lorenzo Galindo.

\section{Opositores}

José Castillejo Duarte.

Gonzalo María Jaumar.

Joaquín Girón Arcas.

Juan Perigallo Amargós. 
No comparecieron: Sandalio Díaz, Eusebio Díaz, Isidro Beato, José Rivero, Joaquín Ros, León Carlos Riba, José María Pujo.

\section{Votación y propuesta}

Primera votación:

- Castillejo: tres votos (Calvo, Hinojosa y Barrio).

- Jaumar: dos votos (García Amado y Galindo).

- Girón: un voto (Cueva).

- Perigallo: un voto (Jiménez).

Segunda votación:

- Castillejo: cinco votos (Cueva, Jiménez, Calvo, Hinojosa y Barrio).

- Jaumar: dos votos (García Amado y Galindo).

José Castillejo fue propuesto.

\section{Materiales}

De tipo administrativo: actas, oficios del negociado, oficios varios sobre conformación del tribunal, anuncio de la oposición. Consta escrito de elevación por el presidente de una protesta presentada por los opositores Jaumar, Girón y Perigallo contra Castillejo.

De tipo académico o referentes a los ejercicios:

- Cuestionario elaborado por el tribunal (154 temas).

- Ejercicio escritos correspondientes al primer ejercicio. Dos temas: "El derecho real de enfiteusis"; "Institución de heredero".

- Trabajos escritos correspondientes al ejercicio práctico (cuarto ejercicio).

- Escritos de libros consultados por cada opositor.

\section{Signatura}

AGA 32/07317. Legajo 5348-12.

\section{Cátedra}

Instituciones de Derecho canónico.

\section{Universidad}

Salamanca.

\section{Anuncio}

R.O. de 28 de julio, 1904. Gaceta del 29. 


\section{Reglamento aplicable}

11 de agosto, 1901.

\section{Fechas de la oposición}

Constitución: 16 de enero, 1905.

Presentación de los opositores: 19 de enero, 1905.

Votación y propuesta: 21 de febrero, 1905.

\section{Tribunal}

Presidente: Victoriano Guisasola (Obispo de Madrid-Alcalá).

Vocales: Bernardo Barbajero, Donato Jiménez, Salvador Torres Aguilar, Matías Barrio, Francisco Cueva.

Secretario: Juan Moneva Pujol.

\section{Opositores}

Isidro Beato Sala.

Isidoro Iglesias García.

Vicente López Vigo.

Juan Perigallo Amargós.

No comparecieron: León Carlos Riba, Joaquín Ros.

\section{Votación y propuesta}

La votación final fue ganada por Vicente López por cinco votos (Moneva, Barrio, Torres, Jiménez y Guisasola) contra uno de Iglesias (Cueva) y uno de Beato (Berbajero). Vicente López fue propuesto.

\section{Materiales}

De tipo administrativo: pieza de actas, pieza de edictos, oficios del negociado, oficios varios sobre conformación del tribunal, anuncio de la oposición.

De tipo académico o referentes a los ejercicios:

- Escritos del primer ejercicio. Dos temas: "La tradición y la costumbre como fuentes de Derecho canónico"; “Concordatos españoles del siglo XVIII”.

- Trabajos escritos correspondientes al ejercicio práctico.

- Escritos de libros consultados por cada opositor.

- La pieza de ejercicios contiene las papeletas con los temas que conformaban el programa. 


\section{Signatura}

AGA 32/07320. Legajo 5349-6.

\section{Cátedra}

Derecho penal.

\section{Universidad}

Santiago.

\section{Anuncio}

R.O. de 28 de julio, 1904. Gaceta del 29.

Fue anunciada antes a traslación (R.O. de 10 de octubre, 1903).

\section{Reglamento aplicable}

11 de agosto, 1901.

\section{Fechas de la oposición}

Constitución: 27 de febrero, 1905.

Reconstitución: 6 de noviembre, 1905.

Presentación de los opositores: 10 de noviembre, 1905.

Votación y propuesta: 4 de diciembre, 1905.

\section{Tribunal}

Presidente: Faustino Álvarez del Manzano.

Vocales: José María Valdés, Francisco Leal de Ibarra (en sustitución de Pedro García Dorado), Melchor Salvá, Rafael Ureña, Francisco J. Jiménez Pérez de Vargas. Secretario: Fernando Cadalso.

\section{Opositores}

Pedro Isaac Rovira.

Vicente de Mendoza.

Enrique de Benito de la Llave.

No comparecieron: Isidro Beato, Juan Perigallo, León Carlos Riba.

\section{Votación y propuesta}

La votación fue ganada por unanimidad por Enrique de Benito. Fue propuesto.

\section{Materiales}

De tipo administrativo: actas, oficios del negociado, oficios varios sobre conformación del tribunal, anuncio de la oposición, ejemplar de la Gaceta de 24 de octubre de 1905 . 
De tipo académico o referentes a los ejercicios:

- Cuestionario elaborado por el tribunal (145 temas).

- Ejercicio escritos correspondientes al primer ejercicio. Dos temas: "Concepto, naturaleza y efectos respectivos de las causas de justificación, de las de inimputabilidad y de las absolutorias"; "El trabajo en las prisiones como parte integrante de la ejecución de la pena".

- Ejercicios escritos correspondientes al ejercicio práctico.

- Escritos de libros consultados por cada opositor.

\section{Signatura}

AGA 32/07321. Legajo 5350-2.

\section{Cátedra}

Procedimientos judiciales y práctica forense.

\section{Universidad}

Salamanca.

\section{Anuncio}

R.O. de 28 de julio, 1904. Gaceta del 29.

\section{Reglamento aplicable}

11 de agosto, 1901.

\section{Fechas de la oposición}

Constitución del tribunal: 15 de febrero, 1905.

Presentación de los opositores: 20 de febrero, 1905.

Votación y propuesta: 28 de marzo, 1905.

\section{Tribunal}

Presidente: Matías Barrio.

Vocales: Vicente Olivares Biec, José María Gadea, Tomás Montejo Rica, Salvador Torres Aguilar, Demetrio Gutiérrez Cañas.

Secretario: José María Valdés.

\section{Opositores}

Luis Agapito Piernavieja.

Francisco Bernad Partagás.

Mauro Miguel y Romero. 
No comparecieron otros 33 opositores.

Adoración Martínez Durán se retiró.

\section{Votación y propuesta}

Primera votación:

- Piernavieja: dos votos (Valdés y Gutiérrez).

- Bernad: dos votos (Olivares y Gadea).

- Tres votos por la no provisión (Montejo, Torres y Barrio).

Segunda votación:

- Piernavieja: tres votos (Valdés, Barrio y Gutiérrez).

- Bernad: dos votos (Olivares y Gadea).

- Dos votos por la no provisión (Montejo y Torres).

La tercera votación dio el mismo resultado que la primera. Por tanto, se acordó no haber lugar a la provisión de la cátedra.

\section{Materiales}

No constan documentos de tipo administrativo, a excepción de las actas. Junto a éstas están los habituales documentos referentes a los ejercicios:

- Cuestionario elaborado por el tribunal (246 temas).

- Ejercicio escritos correspondientes al primer ejercicio. Dos temas: "Partes en el juicio. Los terceros opositores"; "Personas que pueden comparecer en las escrituras de capitulaciones matrimoniales".

- Trabajos escritos correspondientes al ejercicio práctico (cuarto ejercicio).

- Escritos de libros consultados por cada opositor.

\section{Signatura}

AGA 32/o7319. Legajos 5349-4. Hay dos legajos con la misma numeración.

\section{Cátedra}

Economía política y Hacienda pública.

\section{Universidad}

Santiago.

\section{Anuncio}

R.O. de 30 de julio, 1905. Gaceta del 31.

\section{Reglamento aplicable}

11 de agosto, 1901. 


\section{Fechas de la oposición}

Constitución: 21 de febrero, 1906.

Presentación de los opositores: 23 de febrero, 1906.

Votación y propuesta: 31 de marzo, 1906.

\section{Tribunal}

Presidente: José Piernas Hurtado.

Vocales: Fernando Mellado, Adolfo Álvarez Buylla, Francisco J. Castejón, Francisco J. Jiménez Pérez de Vargas, Juan Moneva Pujol.

Secretario: Amando Castroviejo.

\section{Opositores}

Francisco Bernis.

Rafael Gallego Díaz.

José Santaló Rodríguez.

Francisco García de Cáceres.

Ángel Sánchez Vera.

No comparecieron otros 24 opositores.

\section{Votación y propuesta}

La votación fue ganada por Francisco Bernis por cuatro votos (Jiménez, Mellado Buylla y Piernas) contra dos de Rafael Gallego (Castroviejo, Castejón) y uno de Sánchez Vera (Moneva). Fue propuesto Francisco Bernis.

\section{Materiales}

De tipo administrativo: actas, oficios del negociado, oficios varios sobre conformación del tribunal.

De tipo académico o referentes a los ejercicios:

- Cuestionario elaborado por el tribunal (126 temas).

- Ejercicio escritos correspondientes al primer ejercicio. Dos temas: "Condiciones económicas de la naturaleza"; "Municipalización de los servicios públicos".

- Trabajos escritos correspondientes al ejercicio práctico: "Aplicación de los principios científicos a la reforma del sistema tributario español".

- Escritos de libros consultados por cada opositor.

- Memoria razonada aportada por el opositor Francisco Bernis.

- Memoria aportada por el opositor Francisco Bernis (con dos apéndices).

- Programa de Economía y Hacienda aportado por el opositor Francisco Bernis. 


\section{Signatura}

AGA 32/o7324. Legajo 5351-6.

\section{Cátedra}

Derecho internacional público y privado.

\section{Universidad}

Salamanca.

\section{Anuncio}

R.O. de 30 de julio, 1905. Gaceta del 31.

La cátedra había sido anunciada a traslación (R.O. de 10 de marzo, 1905).

\section{Reglamento aplicable}

11 de agosto, 1901.

\section{Fechas de la oposición}

Constitución del tribunal: 25 de enero, 1907.

Presentación de los opositores: 4 de febrero, 1907.

Votación y propuesta: 27 de febrero, 1907.

\section{Tribunal}

Presidente: Gumersindo Azcárate.

Vocales: Francisco J. Jiménez Pérez de Vargas, Antonio Royo Villanova, Joaquín Fernández Prida, Rafael de Ureña, Luis Gestoso Acosta.

Secretario: José Gascón Marín.

\section{Opositores}

Ernesto Amador Carrandi.

Gonzalo Fernández de Córdoba Morales.

Ángel Sánchez Vera.

Emilio Alfredo Serrano Jover.

Juan Ruiz Obregón Retortillo.

No comparecieron otros 29 aspirantes.

\section{Votación y propuesta}

Gonzalo Fernández de Córdoba ganó la votación por cinco votos (Royo, Gestoso, Jiménez de Vargas, Fernández Prida y Azcárate) contra dos votos de Alfredo Serrano (Ureña y Gascón). 


\section{Materiales}

De tipo administrativo: actas, oficios del negociado, oficios varios sobre conformación del tribunal, anuncio de la oposición. Gaceta de 20 de enero de 1907. De tipo académico o referentes a los ejercicios:

- Cuestionario elaborado por el tribunal (193 temas).

- Ejercicio escritos correspondientes al primer ejercicio. Dos temas: "Los cónsules en los países cristianos"; "El reconocimiento de los hijos ilegítimos según el derecho internacional privado".

- Trabajos escritos correspondientes al ejercicio práctico (cuarto ejercicio).

- Escritos de libros consultados por cada opositor.

- Programas aportados por Gonzalo Fernández de Córdoba. Dos: de Derecho internacional público y de Derecho internacional privado.

- Memoria aportada por Gonzalo Fernández de Córdoba: El Ius Gentium de los romanos y el Derecho internacional privado.

- Obras impresas aportadas por Gonzalo Fernández de Córdoba: La solución jurídica de los conflictos internacionales (publicado por la Revista general de Legislación y Jurisprudencia); El Derecho interregional (publicado por la Revista general de Legislación y Jurisprudencia).

\section{Signatura}

AGA 32/07325. Legajo 5352-1.

\section{Cátedra}

Derecho mercantil de España y de las principales naciones de Europa y América.

\section{Universidad}

Granada.

\section{Anuncio}

R.O. de 30 de julio, 1905. Gaceta del 9 de agosto.

La cátedra había sido anunciada a traslación (R.O. de 17 de junio, 1905).

\section{Reglamento aplicable}

11 de agosto, 1901.

\section{Fechas de la oposición}

Constitución del tribunal: 14 de marzo, 1907.

Presentación de los opositores: 18 de marzo, 1907.

Votación y propuesta: 29 de abril, 1907. 


\section{Tribunal}

Presidente: Faustino Álvarez del Manzano.

Vocales: Rafael Ureña, Ismael Calvo, Melchor Salvá, Antonio de la Figuera, Francisco J. Jiménez Pérez de Vargas.

Secretario: Adolfo Bonilla San Martín.

\section{Opositores}

Felipe Gil Casares.

José María Campos Pulido.

Manuel Miguel Traviesas.

Antonio Díaz Domínguez.

No comparecieron: Eusebio Díaz, Joaquín Ros, Joaquín Dualde, Isidro Beato, Rafael Marín, César Mantilla, José María Pujó.

José María González se retiró durante los ejercicios.

\section{Votación y propuesta}

Primera votación:

- Antonio Díaz: tres votos (Bonilla, Ureña, Álvarez del Manzano).

- Manuel Miguel Traviesas: un voto (La Figuera).

- Felipe Gil: dos votos (Jiménez Pérez de Vargas y Salvá).

- Calvo votó la no provisión.

La segunda votación fue ganada por Antonio Díaz por cuatro votos (Bonilla, Ureña, La Figuera y Álvarez del Manzano) contra dos votos de Gil (Jiménez Pérez de Vargas y Salvá) y un voto por la no provisión (Calvo).

Antonio Díaz fue propuesto. El resto de opositores fueron aprobados.

\section{Materiales}

De tipo administrativo: actas, oficios del negociado, oficios varios sobre conformación del tribunal, anuncio de la oposición.

De tipo académico o referentes a los ejercicios:

- Cuestionario elaborado por el tribunal (132 temas).

- Ejercicio escritos correspondientes al primer ejercicio. Dos temas: "Determinación de los derechos y de las obligaciones inherentes al estado del comerciante"; "Compraventa de buques".

- Trabajos escritos correspondientes al ejercicio práctico (cuarto ejercicio).

- Escritos de libros consultados por cada opositor.

- Programa presentado por Antonio Díaz.

- Trabajo de investigación presentado por Antonio Díaz: Apuntes para un ensayo crítico acerca del vigente Código de Comercio. 


\section{Signatura}

AGA 32/o7347. Legajo 5363-4.

\section{Cátedra}

Procedimientos judiciales y práctica forense.

\section{Universidad}

Salamanca.

\section{Anuncio}

Hubo una primera oposición convocada por R.O. de 28 de julio de 1904 (Gaceta del 29). Se acordó no haber lugar a la provisión de la cátedra (presidente Matías Barrio).

Se volvió a anunciar por R.O. de 30 de julio de 1905 (Gaceta del 31). La primera propuesta del Consejo de I.P. de conformación del tribunal es de 18 de noviembre de 1905. Se nombraba presidente a José de Cárdenas.

\section{Reglamento aplicable}

11 agosto, 1901.

\section{Fechas de la oposición}

Constitución del tribunal: 28 de octubre, 1916.

Presentación de los opositores: 10 de noviembre, 1916.

Calificación de los ejercicios primero y segundo y fin de los ejercicios: 20 de noviembre, 1916.

\section{Tribunal}

Presidente: Joaquín Fernández Prida.

Vocales: Tomás Montejo, Salvador Torres Aguilar, José María Gadea Orozco.

Secretario: Francisco de Paula Rives Martí.

\section{Opositores}

Cándido Cerdeira Fernández.

José García Revilla.

No comparecieron otros 34 aspirantes.

\section{Votación}

Ningún opositor superó los ejercicios primero y segundo.

Se acordó el fin de los ejercicios. 


\section{Materiales}

De tipo administrativo: actas, oficios del negociado, anuncio de la oposición. Se conservan numerosos oficios sobre la conformación del tribunal, dado el anómalo lapso temporal que necesitó la misma.

De tipo académico o referentes a los ejercicios:

- Cuestionario elaborado por el tribunal (148 temas).

- Escritos del primer ejercicio. Dos temas: "Juicio penal canónico y modo de comenzar"; "Procedimiento ante el Consejo Supremo de Guerra y Marina".

\section{Signatura}

AGA 32/07318. Legajo 5349-3.

\section{Cátedra}

Derecho penal.

\section{Universidad}

Valladolid y Zaragoza.

\section{Anuncio}

R.O. de 30 de julio, 1905. Gaceta del 9 de agosto.

Fueron anunciadas a traslación: la de Zaragoza por R.O. de 28 de julio, 1904; la de Valladolid por R.O. de 6 de junio, 1905.

\section{Reglamento aplicable}

11 de agosto, 1901.

\section{Fechas de la oposición}

Constitución: 1 de marzo, 1906.

Presentación de los opositores: 5 de marzo, 1906.

Votación y propuesta: 29 de abril, 1906.

\section{Tribunal}

Presidente: Faustino Álvarez del Manzano.

Vocales: José Valdés Rubio, Joaquín Fernández Prida, Félix Pío de Aramburu, Francisco J. González de Castejón, Fernando Mellado.

Secretario: Francisco Cueva Palacio.

\section{Opositores}

César Mantilla Ortiz. 
Pedro Isaac Rovira.

Inocencio Jiménez Vicente.

Vicente de Mendoza.

No comparecieron: Eusebio Díaz, Eugenio Cuello, Enrique de Benito, Isidro Beato, José Gascón, Manuel Miguel Traviesas, José María González, Ricardo Mur, Federico Santander, Leopoldo Palacios.

\section{Votación y propuesta}

Fue designado por unanimidad para el número primero Inocencio Jiménez.

La votación del número dos fue ganada por Vicente de Mendoza por cuatro votos (Cueva, González de Castejón, Aramburu, Álvarez del Manzano) contra tres de César Mantilla (Fernández Prida, Valdés, Mellado).

Inocencio Jiménez optó por la cátedra de Zaragoza y Vicente de Mendoza por la de Valladolid. Fueron propuestos en consecuencia.

\section{Materiales}

De tipo administrativo: actas, oficios del negociado, oficios varios sobre conformación del tribunal, anuncio de la oposición.

De tipo académico o referentes a los ejercicios:

- Cuestionario elaborado por el tribunal (183 temas).

- Escritos del primer ejercicio. Dos temas: “¿Es delito el pacto Cuota litis?”; “¿Es necesario que los códigos penales establezcan los principios fundamentales del sistema penitenciario...?”

- Trabajos escritos correspondientes al ejercicio práctico.

- Escritos de libros consultados por cada opositor.

\section{Signatura}

AGA 32/07319. Legajo 5349-5.

\section{Cátedra}

Instituciones de Derecho romano.

\section{Universidad}

Santiago y Valencia.

\section{Anuncio}

R.O. de 30 de julio, 1905. Gaceta del 9 de agosto.

Fueron anunciadas antes a traslación: la de Santiago por R.O. de 24 de abril, 1905; la de Valencia por R.O. de 23 de septiembre, 1904. 


\section{Reglamento aplicable}

11 de agosto, 1901.

\section{Fechas de la oposición}

Constitución: 24 de febrero, 1906.

Presentación de los opositores: 1 de marzo, 1906.

Votación: 6 de abril, 1906.

Propuesta: 7 de abril, 1906.

\section{Tribunal}

Presidente: Matías Barrio.

Vocales: José María Gadea, Ismael Calvo, Esteban Jiménez, Manuel Bofarull.

Secretario: Francisco Cueva Palacio.

Gumersindo Azacárate abandonó el tribunal y no participó en la votación.

\section{Opositores}

Juan Perigallo.

Eusebio Díaz.

Joaquín Ros.

Gonzalo María Jaumar.

Manuel Miguel Traviesas.

No comparecieron: Rafael Atard, Joaquín Dualde, José Rivero de Aguilar, Inocencio Jiménez Vicente, Isidro Beato, José María Ventura, José María Pujó, Ricardo Mur.

\section{Votación y propuesta}

La votación del número uno fue ganada por Joaquín Ros por cuatro votos (Bofarull, Calvo, Gadea y Barrio) contra dos de Díaz (Jiménez y Cueva).

La votación del número dos fue ganada por Eusebio Díaz por cuatro votos (Cueva, Jiménez, Calvo y Barrio) contra uno de Perigallo (Gadea) y uno de Jaumar (Bofarull).

Joaquín Ros optó por la cátedra de Valencia y Eusebio Díaz por la de Santiago. Fueron propuestos en consecuencia.

\section{Materiales}

De tipo administrativo: actas, oficios del negociado, oficios varios sobre conformación del tribunal, anuncio de la oposición.

De tipo académico o referentes a los ejercicios:

- Cuestionario elaborado por el tribunal (173 temas).

- Ejercicio escritos correspondientes al primer ejercicio. Dos temas: "Adquisi- 
ción de la propiedad por los hijos de familia"; "Del ejercicio de los derechos y tiempo legal para ello".

- Trabajos escritos correspondientes al ejercicio práctico.

\section{Signatura}

AGA 32/o7325. Legajo 5352-2.

\section{Cátedra}

Derecho penal.

\section{Universidad}

Santiago.

\section{Anuncio}

R.O. de 18 de julio, 1906. Gaceta del 2 de agosto.

Fue anunciada antes a traslación (R.O. de 11 de abril, 1906).

\section{Reglamento aplicable}

11 de agosto, 1901.

\section{Fechas de la oposición}

Constitución: 3 de noviembre, 1907.

Presentación de los opositores: 4 de noviembre, 1907.

Votación y propuesta: 11 de febrero, 1908.

\section{Tribunal}

Presidente: Eduardo Hinojosa.

Vocales: José María Valdés, Francisco Cueva, Antonio Goicoechea (en sustitución de Félix Pío de Aramburu), Faustino Álvarez del Manzano, Ismael Calvo. Secretario: Antonio Mejías Asensio.

\section{Opositores}

Rafael Monzón Rodríguez.

Quintiliano Saldaña.

Eugenio Cuello.

Carlos García Oviedo.

Constante Amor.

Pedro Isaac Rovira.

Antonio Bellver. 
No comparecieron otros 22 opositores.

\section{Votación y propuesta}

La votación fue ganada por Quintiliano Saldaña por cuatro votos (Cueva, Valdés, Álvarez del Manzano e Hinojosa) contra dos de Eugenio Cuello (Goicoechea y Calvo) y uno de Carlos García (Mejías). Fue propuesto.

\section{Materiales}

De tipo administrativo: actas, oficios del negociado, oficios varios sobre conformación del tribunal, anuncio de la oposición, ejemplares de la Gaceta de 8 de octubre y de 13 de noviembre de 1907.

De tipo académico o referentes a los ejercicios:

- Cuestionario elaborado por el tribunal (200 temas).

- Ejercicios escritos correspondientes al primer ejercicio.

- Ejercicios escritos correspondientes al ejercicio práctico.

- Escritos de libros consultados por cada opositor.

\section{Signatura}

AGA 32/o7328. Legajo 5354-2.

\section{Cátedra}

Derecho civil español, común y foral.

\section{Universidad}

Sevilla.

\section{Anuncio}

R.O. de 27 de julio, 1907. Gaceta del 2 de agosto.

\section{Reglamento aplicable}

11 de agosto, 1901.

\section{Fechas de la oposición}

Constitución: no consta. El último oficio sobre conformación del tribunal es de 25 de agosto, 1910.

Presentación de los opositores: no consta. El cuestionario elaborado por el tribunal (sesión normalmente anterior a la de presentación) es de 7 de abril, 1911. Votación y propuesta: no consta.

El oficio de elevación del expediente terminado es de 3 de julio, 1911. 


\section{Tribunal}

Presidente: Joaquín Fernández Prida.

Vocales: Vicente Calabuig, Carlos María del Brú, Julián García San Miguel.

Secretario: Felipe Clemente de Diego.

\section{Opositores}

Ignacio Casso Romero.

Francisco Monedero Ruiz.

José Monge Bernal.

Alberto Rodríguez Pelaéz.

No comparecieron otros 19 aspirantes.

\section{Votación y propuesta}

No consta la votación. Fue propuesto Ignacio Casso.

\section{Materiales}

No constan las actas, pero sí documentación administrativa: oficios del negociado, oficios varios sobre conformación del tribunal, etc.

En cuanto a materiales referentes a los ejercicios, constan los siguientes:

- Cuestionario elaborado por el tribunal (164 temas).

- Escritos del primer ejercicio. Dos temas: "Teoría y valor de la costumbre como fuente del Derecho civil en general y con relación a las leyes españolas"; "Servidumbre de medianería y de luces y vistas".

- Ejercicios prácticos.

- Escritos de libros consultados por los opositores.

- Programa aportado por Ignacio de Casso (148 lecciones).

- Memoria aportada por Ignacio de Casso: El problema de la persona social en el derecho privado, 16 de abril, 1911.

- Certificados académicos y personales de Ignacio de Casso.

\section{Signatura}

AGA 32/07330. Legajo 5355-1.

\section{Cátedra}

Historia general de Derecho español.

\section{Universidad}

Zaragoza. 


\section{Anuncio}

27 de julio, 1907. Gaceta del 2 de agosto.

\section{Reglamento aplicable}

11 de agosto, 1901.

\section{Fechas de la oposición}

Constitución del tribunal: 3 de abril, 1911.

Presentación de los opositores: 10 de abril, 1911.

Votación y propuesta: 16 de abril, 1911.

\section{Tribunal}

Presidente: Eusebio Sánchez Reina.

Vocales: Jerónimo López de Ayala, Rafael Altamira Crevea, Lorenzo Moret Remisa. Secretario: Manuel Martín Veña.

\section{Opositores}

Juan Salvador Minguijón Adrián.

No comparecieron: José María Calatayud, Vicente Castañeda, Fernando de Abalo, José Santaló, Pío Ballesteros, Esteban García, Miguel María de Pareja, Juan Ruiz de Obregón, Narciso Alonso, Francisco de Paula Amat, José María Fernández de Echavarri, José Ortiz, Joaquín de Palacios, Fernando Torralba, Adoración Martínez, Francisco Monedero, César Mantilla, Mariano Gómez, José Sánchez, Pascual Tierra, Pedro Navarro, Felipe Gil Casares.

\section{Votación}

Juan Salvador Minguijón es votado y propuesto por unanimidad.

\section{Materiales}

De tipo administrativo: actas, oficios del negociado, oficios varios sobre conformación del tribunal, hoja de servicios de Juan Salvador Minguijón.

De tipo académico o referentes a los ejercicios:

- Cuestionario elaborado por el tribunal (147 temas).

- Ejercicio escrito correspondiente al primer ejercicio. Dos temas: "El derecho de la personalidad en la España goda"; "La evolución de la constitución política de la España Monárquico-representativa”.

- Escrito de libros consultados por el opositor.

- Programa aportado por Juan Salvador Minguijón (111 temas).

- Memoria aportada por Juan Salvador Minguijón: La propiedad rural y el trabajo agrícola en Aragón en los siglos XI y XII. 


\section{Signatura}

AGA 32/07324. Legajo 5351-5.

\section{Cátedra}

Instituciones de Derecho canónico.

\section{Universidad}

Salamanca.

\section{Anuncio}

R.O. de 27 de julio, 1907. Gaceta del 2 de agosto.

\section{Reglamento aplicable}

11 de agosto, 1901.

\section{Fechas de la oposición}

Constitución del tribunal: 4 de noviembre, 1908.

Presentación de los opositores: 23 de noviembre, 1908.

Votación y propuesta: 17 de diciembre, 1908.

\section{Tribunal}

Presidente: José Salvador Barrera (Obispo de Madrid-Alcalá).

Vocales: Didio González Ibarra, Joaquín Girón y Arcas, Luis Mendizábal, Adolfo Moris, Donato Jiménez.

Secretario: Vicente López Vigo.

\section{Opositores}

Isidro Beato Sala.

José María Campos Pulido.

José Fernández González.

Isidoro Iglesias García.

No comparecieron: Francisco de P. Amat, José Cimas, José María González, Juan Perigallo, Juan Salvador Manguijón.

\section{Votación y propuesta}

José María Campos ganó la votación por cuatro votos (López, Jiménez, Mendizábal y Barrera) contra dos votos de José Fernández (González, Moris,) y uno de Iglesias (Girón). 


\section{Materiales}

De tipo administrativo: actas, oficios del negociado, oficios varios sobre conformación del tribunal, anuncio de la oposición.

De tipo académico o referentes a los ejercicios:

- Cuestionario elaborado por el tribunal (130 temas).

- Ejercicio escritos correspondientes al primer ejercicio. Dos temas: "Noción de los códigos que integran el Corpus Iuris Canonici"; "Congregaciones de cardenales".

- Trabajos escritos correspondientes al ejercicio práctico (cuarto ejercicio).

- Escritos de libros consultados por cada opositor.

\section{Signatura}

AGA 32/07326. Legajo 5353-2.

\section{Cátedra}

Derecho administrativo.

\section{Universidad}

Santiago y Sevilla.

\section{Anuncio}

R. O. de 27 de julio de 1907, Gaceta del 2 de agosto.

Se nombró el tribunal por R. O. de 14 de febrero de 1909, Gaceta de 4 de marzo.

\section{Reglamento aplicable}

11 de agosto, 1901.

\section{Fechas de la oposición}

Constitución del tribunal: 17 de febrero, 1910.

Presentación de los opositores: 21 de febrero, 1910.

Votación y propuesta: 8 de marzo, 1910.

\section{Tribunal}

Presidente: Vicente Santamaría de Paredes.

Vocales: Salvador Cuesta, Gonzalo del Castillo, Jerónimo Vida, Leopoldo de Michelena, Cirilo Palomo.

Secretario: Antonio Goicoechea.

\section{Opositores}

Antonio Mesa Moles. 
No comparecieron: Francisco de P. Amat, José González de Echevarri, Francisco García de Cáceres, Gregorio de Pereda, César Mantilla, Juan Salvador Minguijón, Emilio Benavente, Isidro Beato, Mariano Gómez, Manuel Miguel Traviesas, Joaquín Girón, Tomás Juan Elorrieta, Manuel de Bedmar, Alejandro Rey.

\section{Votación y propuesta}

Antonio Mesa fue votado y propuesto por unanimidad.

Optó por la cátedra de Sevilla.

\section{Materiales}

De tipo administrativo: actas, oficios varios sobre conformación del tribunal.

De tipo académico o referentes a los ejercicios:

- Cuestionario elaborado por el tribunal (10o temas).

- Ejercicios escritos correspondientes al primer ejercicio. Dos temas: "Pósitos españoles"; "Comercio interior; pesos y medidas; moneda; tasas y monopolios".

- Trabajo escrito correspondient al ejercicio práctico (cuarto ejercicio).

- Escrito de libros consultados por el opositor.

- Programa presentado por Antonio Mesa.

- Memoria presentada por Antonio Mesa.

\section{Signatura}

AGA 32/07327. Legajo 5353-5.

\section{Cátedra}

Derecho político español comparado con el extranjero.

\section{Universidad}

Salamanca.

\section{Anuncio}

R.O. de 9 de julio, 1908.

\section{Reglamento aplicable}

11 de agosto, 1901.

\section{Fechas de la oposición}

Constitución: 11 de noviembre, 1911.

Presentación de los opositores: 16 de noviembre, 1911.

Votación y propuesta: 13 de diciembre, 1911. 


\section{Tribunal}

Presidente: Vicente Santamaría Paredes.

Vocales: Eduardo Hinojosa, Adolfo Moris, Adolfo González Posada.

Secretario: Miguel Moya.

\section{Opositores}

Tomás Juan Elorrieta Artaza.

No comparecieron: Joaquín Mencos García de Paredes, Antonio Mesa y Moles, José González de Echevarri, Francisco García de Cáceres, Gregorio de Pereda, César Mantilla, Pascual Sierra Ruiz, Juan Salvador Minguijón, Ramón Sancho, Manuel Miguel Traviesas, Gonzalo Fernández de Córdoba, Isidro Beato.

\section{Votación y propuesta}

Tomás Juan Elorrieta fue votado y propuesto por unanimidad.

\section{Materiales}

De tipo administrativo: actas, oficios del negociado, oficios varios sobre conformación del tribunal.

De tipo académico o referentes a los ejercicios:

- Cuestionario elaborado por el tribunal (132 temas).

- Ejercicio escrito correspondiente al primer ejercicio. Dos temas: "Carácter general de la Constitución política de los Reinos de León y Castilla"; "Ley española de imprenta de 1883. Comparación con la de otros países".

- Ejercicio práctico: "La inmunidad parlamentaria".

- Escrito de libros consultados por el opositor.

- Programa aportado por Tomás Juan Elorrieta para la cátedra de Constituciones y leyes orgánicas de los Estados que se gobiernan por el régimen Parlamentario (6o lecciones), Escuela de Estudios Especiales del Ateneo de Madrid. Consta un apéndice con notas bibliográficas.

- Programa aportado por Tomás Juan Elorrieta para la cátedra de derecho político vacante en la Universidad de Salamanca (10o lecciones).

- Trabajo de investigación aportado por Tomás Juan Elorrieta: El reinado de la ley en Inglaterra, 1911.

\section{Signatura}

AGA 32/07329. Legajo 5354-4.

\section{Cátedra}

Derecho internacional público y privado. 


\section{Universidad}

Salamanca.

\section{Anuncio}

R.O. de 9 de julio, 1908.

\section{Reglamento aplicable}

11 de agosto, 1901.

\section{Fechas de la oposición}

Constitución del tribunal: 4 de enero, 1911.

Presentación de los opositores: 24 de enero, 1911.

Votación y propuesta: 19 de febrero, 1911.

\section{Tribunal}

Presidente: Rafael Conde Luque.

Vocales: Manuel Torres Campos, Ramón María de Dalmau (marqués de Olivart). Secretario: Gonzalo Fernández de Córdoba.

\section{Opositores}

Ernesto Amador Carrandi.

Carlos García Oviedo.

Ignacio de Casso Romero.

Isidro Beato Sala.

No comparecieron: Joaquín Mencos García de Paredes, Federico Santander Ruiz Giménez, Pedro González García, Juan Ruiz de Obregón, Manuel de Lasala, Adoración Martínez, José María González de Echevarri, Máximo Peña Mantecón, José Ortiz, Julián Aramendia, José Fernández González, César Mantilla, Juan Pascual Sierra Ruiz, Eduardo Canencia, Ramón Sancho, Emilio Benavente, Ricardo Mur.

\section{Votación y propuesta}

Primera votación:

- Ernesto Amador: un voto (Torres Campos).

- Carlos García Oviedo: un voto (Dalmau).

- Ignacio de Casso: un voto (Fernández de Córdoba).

- Isidro Beato Sala: un voto (Conde y Luque).

La segunda votación fue ganada por Isidro Beato por tres votos (Conde Luque, Torres Campos y Fernández de Córdoba) contra un voto a favor de Casso (Dalmau). Fue propuesto para la cátedra de Salamanca. 


\section{Materiales}

De tipo administrativo: actas, oficios del negociado, oficios varios sobre conformación del tribunal.

De tipo académico o referentes a los ejercicios:

- Cuestionario elaborado por el tribunal (174 temas).

- Ejercicio escrito correspondiente al primer ejercicio. Dos temas: "Derecho y deberes de los Estados en el orden internacional"; "El derecho internacional privado y la legislación comparada".

- Ejercicio práctico.

- Escrito de libros consultados por los opositores.

- Programa aportado por Isidro Beato (77 temas).

- Memoria aportada por Isidro Beato: Conflictos interprovincionales en España.

\section{Signatura}

AGA 32/o7331. Legajo 5356-4.

\section{Cátedra}

Instituciones de Derecho romano.

\section{Universidad}

Santiago y Sevilla.

\section{Anuncio}

R.O. de 9 de julio, 1908.

\section{Reglamento aplicable}

11 de agosto, 1901.

\section{Fechas de la oposición}

Constitución del tribunal: 19 de enero, 1911.

Presentación de los opositores: 28 de enero, 1911.

Votación y propuesta: 21 de febrero, 1911.

\section{Tribunal}

Presidente: Eduardo de Hinojosa.

Vocales: Francisco de Casso y Fernández, Ismael Calvo, Esteban Jiménez de la Flor, Melquíades Álvarez González, José Castillejo Duarte.

Secretario: Eusebio Díaz González. 


\section{Opositores}

Rodrigo Fernández García de la Villa.

Felipe Gil Casares.

Manuel Miguel Traviesas.

No comparecieron: Isidro Beato, Emilio Benavent, Cándido Cerdeira, José María Fábregas, Fernando Ferreiro, José María González, José López, Adoración Martínez, José Monge, Rafael Oller, José Ortiz, Máximo Peña, Juan Perigallo, Manuel Rey, Pascual Roca, Julián Rodríguez, Ramón Sancho, Nicolás San Román, Fernando Torralba.

\section{Votación}

Votación del número primero:

- Rodrigo Fernández: tres votos (Díaz, Jiménez y Casso).

- Manuel Miguel Traviesas: cuatro votos (Castillejo, Álvarez, Calvo e Hinojosa).

Votación del número segundo:

- Rodrigo Fernández: un voto (Álvarez).

- Felipe Gil Casares: seis votos (Castillejo, Díaz, Jiménez, Casso, Calvo e Hinojosa).

Manuel Miguel Traviesas optó por la cátedra de Sevilla y Felipe Gil aceptó la de Santiago. Fueron propuestos.

\section{Materiales}

De tipo administrativo: actas, oficios del negociado, oficios varios sobre conformación del tribunal.

- Cuestionario elaborado por el tribunal (16o temas).

- Ejercicio escrito correspondiente al primer ejercicio. Dos temas: "Fases principales en la historia del derecho penal romano"; "Hipoteca de una cosa incorporada. Pluralidad de hipotecas".

- Ejercicios prácticos.

- Escrito de libros consultados por los opositores.

- Programa aportado por Felipe Gil Casares (72 lecciones).

- Programa aportado por Manuel Miguel Traviesas (58 lecciones).

- Trabajo doctrinal aportado por Felipe Gil Casares: “De la condición jurídica del esclavo en Roma".

- Trabajo doctrinal aportado por Manuel Miguel Traviesas: “La representación”. 


\section{Signatura}

AGA 32/o7326. Legajo 5353-4.

\section{Cátedra}

Historia general del Derecho español.

\section{Universidad}

Valladolid.

\section{Anuncio}

R.O. de 9 de julio, 1908.

\section{Reglamento aplicable}

11 de agosto, 1901.

\section{Fechas de la oposición}

Constitución: 24 de octubre, 1910.

Presentación de los opositores: 3 de noviembre, 1910.

Votación y propuesta: 17 de octubre, 1910.

\section{Tribunal}

Presidente: Joaquín Fernández Prida.

Vocales: Rafael Ureña, Jerónimo López de Ayala, Calixto Valverde.

Secretario: Felipe Clemente de Diego.

\section{Opositores}

César Mantilla Ortiz.

Juan Salvador Minguijón Adrián.

No comparecieron: José María González de Echevarri, Pascual Sierra Ruiz, Ramón Sancho y Brased.

\section{Votación y propuesta}

La votación fue ganada por César Mantilla por cuatro votos (Valverde, López de Ayala, Ureña y Fernández Prida) contra un voto a favor de Minguijón (de Diego). Fue propuesto.

\section{Materiales}

De tipo administrativo: actas, oficios del negociado, oficios varios sobre conformación del tribunal.

De tipo académico o referentes a los ejercicios:

- Cuestionario elaborado por el tribunal (147 temas). 
- Escrito del primer ejercicio. Dos temas: "La evolución del Derecho privado en Cataluña"; "La evolución de la Constitución política en la España monárquicorepresentativa".

- Ejercicios prácticos.

- Escritos de libros consultados.

- Programa aportado por César Mantilla (83 lecciones).

- Memoria aportada por Salvador Minguijón: El régimen jurídico de la propiedad rural y del trabajo agrícola en los fueros municipales de Aragón.

- Hoja de servicio de César Mantilla.

\section{Signatura}

AGA 32/o7332. Legajo 5356-6.

\section{Cátedra}

Historia general del Derecho español.

\section{Universidad}

Central.

\section{Anuncio}

R.O. de 29 de julio, 1909. Gaceta del 9 de agosto.

\section{Reglamento aplicable}

11 de agosto, 1901.

\section{Fechas de la oposición}

Constitución del tribunal: 11 de enero, 1911.

Presentación de los opositores: 21 de enero, 1911.

Votación y propuesta: 18 de febrero, 1911.

\section{Tribunal}

Presidente: Gumersindo de Azcárate.

Vocales: Eduardo de Hinojosa, Rafael de Ureña, Felipe Clemente de Diego.

Secretario: Julio Pujol Alonso.

\section{Opositores}

Laureano Díez-Canseco Berjón.

Juan Salvador Manguijón.

No comparecieron José Castillejo, Luis Gestoso, Mariano Gómez, César Mantilla, Leopoldo Palacios, Ramón Sancho, Eduardo Vilarino. 


\section{Votación}

Todos los votos fueron para Laureano Díez-Canseco excepto el de Hinojosa, que votó a Juan Salvador Minguijón.

Fue propuesto Díez-Canseco.

\section{Materiales}

De tipo administrativo: actas, oficios del negociado, oficios varios sobre conformación del tribunal, ejemplar del Boletín Oficial de 3 de agosto de 1910.

- Cuestionario elaborado por el tribunal (147 temas).

- Ejercicio escrito correspondiente al primer ejercicio. Dos temas: "Colección de Fórmulas visigóticas descubierta por Ambrosio de Morales en un Códice ovetense"; "El Espéculo".

- Ejercicios prácticos.

- Escrito de libros consultados por los opositores.

- Programa aportado por Laureano Díez-Canseco (98 lecciones).

- Trabajo doctrinal aportado por Laureano Díez-Canseco: Sobre la formación de la ciudad de León y de su organización municipal (Contribución al estudio del origen del concejo leonés y castellano).

\section{Signatura}

AGA 32/07326. Legajo 5353-3.

\section{Cátedra}

Derecho penal.

\section{Universidad}

Santiago.

\section{Anuncio}

R.O. de 29 de julio, 1909. Gaceta del 9 de agosto.

\section{Reglamento aplicable}

11 de agosto, 1901.

\section{Fechas de la oposición}

Constitución: 10 de octubre, 1910.

Presentación de los opositores: 24 de octubre, 1910.

Votación y propuesta: 4 de noviembre, 1910. 


\section{Tribunal}

Presidente: Eduardo Hinojosa.

Vocales: José María Valdés, Félix Pío de Aramburu, Eduardo Vilariño Magdalena, Vicente de Mendoza Castaño, Casto Barahona y Holgado.

Secretario: Enrique Benito de la Llave.

\section{Opositores}

Pedro Isaac Rovira Carreró.

No comparecieron: Emilio Benavente, José Campos, Gonzalo Fernández de Córdoba, Felipe Gil, Mariano Gómez, César Mantilla, Ramón Sancho.

\section{Votación y propuesta}

Pedro Isaac Rovira fue votado y propuesto por unanimidad.

\section{Materiales}

De tipo administrativo: actas, oficios del negociado, oficios varios sobre conformación del tribunal.

De tipo académico o referentes a los ejercicios:

- Cuestionario elaborado por el tribunal (178 temas).

- Ejercicio escrito correspondiente al primer ejercicio. Dos temas: "La herencia y sus leyes en relación con la existencia del fenómeno social de la criminalidad"; "La instrucción y la educación de los condenados en el régimen penitenciario".

- Ejercicio práctico.

- Escrito de libros consultados por el opositor.

\section{Signatura}

AGA 32/07331. Legajo 5356-3.

\section{Cátedra}

Derecho penal.

\section{Universidad}

Granada.

\section{Anuncio}

Gaceta del 21/09/1909.

\section{Reglamento aplicable}

11 de agosto, 1901. 


\section{Fechas de la oposición}

Constitución del tribunal: 7 de noviembre, 1910.

Presentación de los opositores: 21 de noviembre, 1910.

Votación y propuesta: 13 de diciembre, 1910.

\section{Tribunal}

Presidente: Ismael Calvo.

Vocales: Francisco Javier González de Castejón, Isidro Pérez Oliva, José María Valdés Rubio.

Secretario: Inocencio Jiménez Vicente.

\section{Opositores}

Eugenio Cuello Calón.

No comparecieron: Antonio Mesa, Gonzalo Fernández de Córdoba, José María de Campos, César Mantilla, Mariano Gómez, Pedro Isaac Rovira, Emilio Benavent, Pascual Sierra, José María González Echevarri.

\section{Votación}

Eugenio Cuello Calón fue votado y propuesto por unanimidad.

\section{Materiales}

Actas, con los siguientes documentos:

- Cuestionario elaborado por el tribunal (173 temas).

- Ejercicio escrito correspondiente al primer ejercicio. Dos temas: "Fórmulas que adoptan las legislaciones para expresar un concepto respectivo de la responsabilidad penal"; El sistema de las penas paralelas".

- Ejercicio práctico.

- Escrito de libros consultados por el opositor.

- Programa aportado por Eugenio Cuello (61 lecciones).

- Trabajo de investigación aportado por Eugenio Cuello: "La cuestión de la criminalidad juvenil".

\section{Signatura}

AGA 32/07332. Legajo 5353-7.

\section{Cátedra}

Derecho internacional público y privado. 


\section{Universidad}

Zaragoza.

\section{Anuncio}

R.O. de 21 de enero, 1910. Gaceta del 2 de febrero.

\section{Reglamento aplicable}

11 de agosto, 1901.

\section{Fechas de la oposición}

Constitución del tribunal: 7 de noviembre, 1910.

Presentación de los opositores: 21 de noviembre, 1910.

Votación y propuesta: 15 de diciembre, 1910.

\section{Tribunal}

Presidente: Rafael Conde Luque.

Vocales: Manuel Torres Campos, Aniceto de Sela, Ramón María de Dalmau (marqués de Olivart).

Secretario: Gonzalo Fernández de Córdoba.

\section{Opositores}

Isidro Beato Sala.

Mariano Gómez González.

Manuel de Lasala Llanas.

No comparecieron: Emilio Benavent, José Ferrández, José María González de Echevarri, Francisco Rivera.

\section{Votación}

Primera votación:

- Isidro Beato: un voto (Fernández de Córdoba).

- Mariano Gómez: dos votos (Torres Campos y Sela).

- Manuel de Lasala: dos votos (Olivart y Conde).

Segunda votación:

- Mariano Gómez: dos votos (Torres Campos y Sela).

- Manuel de Lasala: tres votos (Fernández de Córdoba, Olivart y Conde).

Fue propuesto Lasala.

\section{Materiales}

De tipo administrativo: actas, oficios del negociado, oficios varios sobre conformación del tribunal. 
- Cuestionario elaborado por el tribunal (130 temas).

- Ejercicio escrito correspondiente al primer ejercicio. Dos temas: "Causas de extinción de las obligaciones nacidas de los tratados"; "Los cónsules extranjeros en España. Ley orgánica de la Carrera Consular española”.

- Ejercicios prácticos.

- Escrito de libros consultados por los opositores.

- Programas aportados por Manuel de Lasala (53 y 45 lecciones).

- Trabajo doctrinal aportado por Manuel de Lasala: "Exámen crítico de la doctrina de Drago y de la Convención de El Haya, de 18 de octubre de 1907, respecto al empleo de la fuerza para el cobro de las deudas de los Estados".

- Obra aportada por Manuel de Lasala: La medida penal, prólogo de José Valdés Rubio, Est. Tipográfico de Leandro Pérez, Huesca, 1898.

\section{Signatura}

AGA 32/o7330. Legajo 5355-3.

\section{Cátedra}

Derecho político español comparado con el extranjero.

\section{Universidad}

Zaragoza.

\section{Anuncio}

25 de enero, 1910.

\section{Reglamento aplicable}

11 de agosto, 1901.

\section{Fechas de la oposición}

Constitución del tribunal: 7 de octubre, 1912.

Presentación de los opositores: 12 de octubre, 1912.

Votación y propuesta: 2 de diciembre, 1912.

\section{Tribunal}

Presidente: Vicente Santamaría de Paredes.

Vocales: Eduardo de Hinojosa, Miguel Moya, Adolfo González Posada.

Secretario: Adolfo Moris. 


\section{Opositores}

Miguel Allué.

Emilio Benavent y Hernández.

Ramón Sancho Braset.

Luis de Valle Pascual.

No comparecieron otros 35 aspirantes.

\section{Votación}

Luis de Valle Pascual ganó la votación con todos los votos menos el de Hinojosa, que votó a Emilio Benavent. Fue propuesto.

\section{Materiales}

De tipo administrativo: actas, oficios del negociado, oficios varios sobre conformación del tribunal.

De tipo académico o referentes a los ejercicios:

- Cuestionario elaborado por el tribunal (132 temas).

- Ejercicio escrito correspondiente al primer ejercicio. Dos temas: "Concepto, naturaleza y formas de la representación en general"; "Las constituciones escritas".

- Ejercicios prácticos.

- Escrito de libros consultados por el opositor.

- Programa aportado por Luis de Valle y Pascual (117 temas).

- Trabajo de investigación aportado por Luis de Valle y Pascual: "Influencia Política del feudalismo en los reinos de León y Castilla".

\section{Signatura}

AGA 32/07342. Legajo 5361-1 y un legajo sin numerar.

\section{Cátedra}

Derecho penal.

\section{Universidad}

Barcelona.

\section{Anuncio}

R.O. de 18 de julio de 1910 (Gaceta del 29).

\section{Reglamento aplicable}

8 de abril, 1910 . 


\section{Fechas de la oposición}

Constitución del tribunal: 11 de noviembre, 1910.

Presentación de los opositores: 26 de noviembre, 1910.

Votación y propuesta: 21 de diciembre, 1910.

\section{Tribunal}

Presidente: Ismael Calvo.

Vocales: Francisco Javier González de Castejón, José Valdés Rubio, Isidro Pérez Oliva.

Secretario: Inocencio Jiménez Vicente.

\section{Opositores}

Eugenio Cuello Calón.

No comparecieron: Pedro Isaac Rovira, Manuel de Lasala, Mariano Gómez, Emilio Benavente, José María Pujó.

\section{Votación}

Eugenio Cuello fue votado y propuesto por unanimidad.

\section{Materiales}

De tipo administrativo: actas, oficios del negociado, oficios varios sobre conformación del tribunal.

De tipo académico o referentes a los ejercicios:

- Cuestionario elaborado por el tribunal (173 temas).

- Escritos del primer ejercicio. Dos temas: "El delito en su concepto. Puntos de vista jurídico, doctrinal y legal; "Concepto de Política criminal”.

- Ejercicios prácticos (tercer ejercicio).

- Escrito de libros solicitados por el opositor.

- Programa aportado por Eugenio Cuello (61 lecciones).

- Trabajo doctrinal aportado por Eugenio Cuello: La cuestión de la criminalidad juvenil.

Obras aportadas por Eugenio Cuello:

- El Alcoholismo. Sus efectos, causas y remedios, trabajo premiado en el concurso de estudios sociales organizado en septiembre de 1905 por el círculo de obreros de Salamanca, Imp. Andrés Iglesias, Salamanca, 1906.

- La infancia delincuente y abandonada en la antigua legislación penal española, Revista Penitenciaria, año II, tomo II, entrega $12 .^{\mathrm{a}}$, 1905.

- Instituciones penales, Revista Penitenciaria, año I, tomo I, entrega $4 .^{\mathrm{a}}, 1904$.

- Instituciones penales, Revista Penitenciaria, año I, tomo I, entrega 6. ${ }^{\mathrm{a}}, 1904$.

- Instituciones penales. Menores delincuentes y abandonados en Italia, Revista 
Penitenciaria, año II, tomo II, entrega 1. ${ }^{\mathrm{a}}, 1905$.

- Instituciones penales. Menores delincuentes y abandonados en Italia, Revista Penitenciaria, año II, tomo II, entrega 2. ${ }^{\mathrm{a}}, 1905$.

- Origen y desarrollo del movimiento protector de la infancia abandonada y de la juventud delincuente, Revista General de Legislación y Jurisprudencia, año 53, tomo $107,1905$.

- Sobre la formación del personal penitenciario, Revista General de Legislación y Jurisprudencia, año 52, tomo 104, 1904.

- El tratamiento de la vagancia y de la mendicidad, Revista General de Legislación y Jurisprudencia, año 58, tomo 117, 1910.

- La mafia, La Lectura. Revista de ciencias y de artes, año II, núm.24, 1902.

\section{Signatura}

AGA 32/07331. Legajo 5355-4.

\section{Cátedra}

Estudios superiores de Derecho penal y Antropología criminal.

\section{Universidad}

Central.

\section{Anuncio}

18 de julio, 1910. Gaceta del 29.

\section{Reglamento aplicable}

8 de abril, 1910.

\section{Fechas de la oposición}

Constitución del tribunal: 5 de abril, 1911.

Presentación de los opositores: 19 de abril, 1911.

Votación y propuesta: 29 de abril, 1911.

\section{Tribunal}

Presidente: Gumersindo de Azcárate.

Vocales: Félix Pío de Aramburu, César Silió Cortés, José María Valdés Rubio.

Secretario: Pascual Téstor Pascual.

\section{Opositores}

Quintiliano Saldaña García. 
Leopoldo Palacios Morini.

Constante Amor Nareiro.

Tomás Alonso de Armiño.

No comparecieron: Cándido Cerdeira, Pedro Isaac Rovira, Adoración Martínez, Eugenio Cuello, Mariano Gómez, Inocencio Jiménez, Rafael Marín, Enrique de Benito, Francisco Rivera, Carlos Roda, Gabriel Cayón.

\section{Votación}

Primera votación:

- Quintiliano Saldaña: un voto (Téstor).

- Leopoldo Palacios: dos votos (Aramburu y Azcárate).

- Constante Amor: un voto (Valdés).

- Tomás Alonso: un voto (Silió).

Segunda votación:

- Quintiliano Saldaña: tres votos (Téstor, Valdés y Silió).

- Leopoldo Palacios: dos votos (Aramburu y Azcárate).

Fue propuesto Quintiliano Saldaña.

\section{Materiales}

De tipo administrativo: actas, oficios del negociado, oficios varios sobre conformación del tribunal.

De tipo académico o referentes a los ejercicios:

- Cuestionario elaborado por el tribunal (141 temas).

- Ejercicio escrito correspondiente al primer ejercicio. Dos temas: "Las pasiones y los crímenes"; "Conceptos de la degradación".

- Ejercicios prácticos.

- Escrito de libros consultados por los opositores.

- Programa aportado por Quintiliano Saldaña (84 lecciones).

- Trabajo de investigación aportado por Quintiliano Saldaña: "La política criminal en Alemania" (dos cuadernos).

- Traducción aportada por Quintiliano Saldaña: Franz von Liszt, Tratado de derecho penal, $18 .^{\mathrm{a}}$ edición con adaptación a la legislación penal española, Imprenta Helénica, Madrid, 1911.

\section{Signatura}

AGA 32/o7331. Legajo 5356-2.

\section{Cátedra}

Derecho administrativo. 


\section{Universidad}

Santiago.

\section{Anuncio}

R.O. de 18 de Julio, 1910.

\section{Reglamento aplicable}

8 de abril, 1910.

\section{Fechas de la oposición}

Constitución del tribunal: 1 de abril, 1911.

Presentación de los opositores: 20 de abril, 1911.

Votación y propuesta: 8 de mayo, 1911.

\section{Tribunal}

Presidente: Augusto González Besada.

Vocales: Eduardo Sanz Escartín, Adolfo González Posada, Alfonso González Lozano.

Secretario: Antonio Royo Villanova.

\section{Opositores}

Miguel Allué Salvador.

Julián Aremendía Palacio.

Domingo Villar Grangel.

Cándido Cerdeira y Fernández.

No comparecieron: Jesús Arias de Velasco, José Santaló, Juan Marco Eloriaga, Emilio Benevent, Ramón Sandro, Federico Santander, Matías Peñalba, Isidro Beato, Gregorio de Pereda.

\section{Votación:}

Se acordó por unanimidad no haber lugar a la provisión de la cátedra.

\section{Materiales}

Únicamente se conservan las actas con los siguientes documentos unidos:

- Ejercicio escrito correspondiente al primer ejercicio. Dos temas: "Relaciones de la administración como función de Estado con las demás funciones del mismo"; "Examen de la ley de orden público."

- Ejercicio prácticos.

- Escrito de libros consultados por los opositores. 


\section{Signatura}

AGA 32/o7343. Legajo 5361-2.

\section{Cátedra}

Derecho penal.

\section{Universidad}

Granada.

\section{Anuncio}

31 de julio, 1911 (Gaceta del 13 de agosto).

\section{Reglamento aplicable}

8 de abril, 1910 .

\section{Fechas de la oposición}

Constitución del tribunal: 28 de febrero, 1912.

Presentación de los opositores: 11 de marzo, 1912.

Votación y propuesta: 1 de abril, 1912.

\section{Tribunal}

Presidente: Joaquín Fernández Prida.

Vocales: José Valdés Rubio, Faustino Álvarez del Manzano, Pascual Testor.

Secretario: Antonio Gómez Tortosa.

\section{Opositores}

José María Campos y Pulido.

Emilio Langle Rubio.

Carlos García Oviedo.

Alberto de Segovia.

José Monge Bernal.

Ignacio Carrera.

Constante Amor.

Faustino Ballvé.

\section{Votación}

Carlos García Oviedo obtuvo todos los votos menos el de Valdés, quien votó a Constante Amor. Carlos García fue propuesto. 


\section{Materiales}

De tipo administrativo: actas, oficios del negociado, oficios varios sobre conformación del tribunal.

De tipo académico o referentes a los ejercicios:

- Cuestionario elaborado por el tribunal (179 temas).

- Escritos del primer ejercicio. Dos temas: "Concepto de psicología criminal y particularmente de la psiquiatría; "Sistema de la servidumbre penal inglesa y de Crofton".

- Ejercicios prácticos (tercer ejercicio).

- Escrito de libros solicitados por los opositores.

- Programa aportado por Carlos García (92 lecciones).

- Trabajo doctrinal aportado por Carlos García: Ideas jurídico-penales contenidas en el Romancero español.

- Trabajo doctrinal aportado por José Monge: El bandolerismo en Andalucía.

\section{Signatura}

AGA 32/07334. Legajo 5357-2.

\section{Cátedra}

Elementos de Derecho natural.

\section{Universidad}

Valladolid.

\section{Anuncio}

R. O. 31 de julio de 1911, Gaceta del 13 de agosto.

\section{Reglamento aplicable}

8 de abril, 1910.

\section{Fechas de la oposición}

Constitución del tribunal: 17 de enero, 1912.

Presentación de los opositores: 30 de enero, 1912.

Votación y propuesta: 2 de marzo, 1912.

\section{Tribunal}

Presidente: Eduardo de Hinojosa.

Vocales: Rafael Rodríguez de Cepeda, Luis Mendizábal, Laureano Díez Canseco.

Secretario: Rafael Atard. 


\section{Opositores}

Francisco Rivera Pastor.

José Santaló Rodríguez.

Eduardo Callejo de la Cuesta.

José Vázquez Estévez.

Fidel Abad Cavia.

Pedro de Prada Lagarejos.

José María Álvarez Martín.

José de Liñán Eguizábal.

No comparecieron otros 17 aspirantes.

\section{Votación}

Primera votación:

- Francisco Rivera: un voto (Atard).

- José María Álvarez: un voto (Díez).

- José Santaló: un voto (Hinojosa).

- Eduardo Callejo: un voto (Mendizábal).

- José de Liñán: un voto (Rodríguez de Cepeda).

Segunda votación:

- Francisco Rivera: un voto (Atard).

- José María Álvarez: un voto (Díez).

- Eduardo Callejo: tres votos (Rodríguez de Cepeda, Hinojosa, Mendizábal).

Fue propuesto Eduardo Callejo de la Cuesta.

\section{Materiales}

De tipo administrativo: actas, oficios del negociado, oficios varios sobre conformación del tribunal.

- Cuestionario elaborado por el tribunal (161 temas).

- Ejercicio escrito correspondiente al primer ejercicio. Dos temas: "El perdón del ofendido"; "La responsabilidad civil nacida del delito".

- Ejercicios prácticos.

- Escrito de libros consultados por los opositores.

- Programa aportado por Eduardo Callejo (65 lecciones).

- Trabajo doctrinal aportado por Eduardo Callejo: "La cuestión del feminismo".

\section{Signatura}

AGA 32/o7331. Legajo 5356-2.

\section{Cátedra}

Derecho administrativo. 


\section{Universidad}

Santiago.

\section{Anuncio}

31 de julio de 1911 (Gaceta del 31 de agosto).

\section{Reglamento aplicable}

8 de abril, 1910.

\section{Fechas de la oposición}

Constitución del tribunal: 13 de enero, 1912.

Presentación de los opositores: 31 de enero, 1912.

\section{Tribunal}

Presidente: Faustino Rodríguez San Pedro.

Vocales: Javier de Ugarte, Adolfo González Posada, Antonio Royo Villanova.

Secretario: Alfonso González Lozano.

\section{Opositores}

Gregorio de Pereda Ugarte.

Renunció por motivos de salud el 5 de febrero.

No compareció Emilio Benavent Hernández.

\section{Materiales}

Únicamente se conservan las actas con los siguientes documentos unidos:

- Ejercicio escrito correspondiente al primer ejercicio. Dos temas: "Aguas terrestres"; "La materia contencioso-administrativa".

- Ejercicio práctico: "Razonamiento y bosquejo articulado para unas bases para un proyecto de ley especial sobre minicipalización de servicios".

\section{Signatura}

AGA 32/07333. Legajo 5357-1.

\section{Cátedra}

Economía política y Hacienda pública.

\section{Universidad}

Zaragoza. 


\section{Anuncio}

R.O. de 31 de julio, 1911 (Gaceta del 13 de agosto).

\section{Reglamento aplicable}

8 de abril, 1910 .

\section{Fechas de la oposición}

Constitución del tribunal: 12 de marzo, 1912.

Presentación de los opositores: 9 abril, 1912.

Votación y propuesta: 23 de mayo, 1912.

\section{Tribunal}

Presidente: Alejandro Roselló.

Vocales: José Pérez de Vargas, José Gómez Acebo, Javier de Ugarte y Pagés.

Secretario: Francisco Bernis Carrasco.

\section{Opositores}

Mariano Gómez González.

Jaime Algarra Postius.

No compareció Gregorio de Pereda Ugarte.

\section{Votación}

- Mariano Gómez: dos votos (Gómez Acebo, Ugarte).

- Jaime Algarra: tres votos (Bernis, Vargas, Roselló).

Fue propuesto Jaime Algarra.

\section{Materiales}

De tipo administrativo: actas y oficio de elevación del expediente.

De tipo académico o referentes a los ejercicios:

- Cuestionario elaborado por el tribunal (138 temas).

- Ejercicios escritos correspondientes al primer ejercicio. Dos temas: "La nacionalización de seguro"; "El proceso de concentración en los bancos modernos".

- Escrito de libros consultados por los opositores.

- Programas aportados por Jaime Algarra: Economía política (38 lecciones) y hacienda pública (41 lecciones).

- Memoria aportada por Jaime Algarra: "El crédito comunal belga".

- Trabajo de investigación aportado por Jaime Algarra: "El cambio internacional en España".

- Trabajo de investigación aportado por Jaime Algarra: "Formación del precio de las carnes en el mercado de Barcelona". 


\section{Signatura}

AGA 32/o7335. Legajos 5357-3. Hay dos legajos con la misma numeración.

\section{Cátedra}

Derecho penal.

\section{Universidad}

Sevilla.

\section{Anuncio}

R. O. 31 de julio de 1911, Gaceta del 13 de agosto.

\section{Reglamento aplicable}

8 de abril, 1910.

\section{Fechas de la oposición}

Constitución del tribunal: 9 de enero, 1913.

Presentación de los opositores: 20 de enero, 1913.

Votación y propuesta: 3 de febrero, 1913.

\section{Tribunal}

Presidente: Joaquín Fernández Prida.

Vocales: José Valdés Rubio, Félix Pío Aramburu, Pascual Testor Pascual.

Secretario: Antonio Gómez Tortosa.

\section{Opositores}

Federico Castejón Martínez.

José María Campos Pulido.

Agustín Rodríguez Aguilera.

Manuel Carrasco Reyes.

No comparecieron: José María González de Echevarri, Gregorio de Pereda Ugarte, Salvador Salom y Antequera, Nicolás Rodríguez Aniceto, Mariano Gómez González, Emilio Benavent Hernández.

\section{Votación}

Federico Castejón fue votado y propuesto por unanimidad. Nombrado el 13 de febrero de 1913. 


\section{Materiales}

De tipo administrativo: actas, oficios del negociado, oficios varios sobre conformación del tribunal.

- Cuestionario elaborado por el tribunal (192 temas).

- Ejercicios escritos correspondientes al primer ejercicio. Dos temas: "Examen doctrinal y positivo del precepto legal y la obediencia debida", "El alcholismo en sus relaciones con la delincuencia”.

- Ejercicios prácticos.

- Escrito de libros consultados por los opositores.

- Programa aportado por Federico Castejón (81 lecciones).

- Obra aportada por Federico Castejón: Estudio de las nuevas direcciones del Derecho civil en Italia, Federico Castejón Anales de la Junta para Ampliación de Estudios e Investigaciones Científicas, Madrid, 1912.

- Obra aportada por Federico Castejón: Ensayo sobre las notas de diferenciación e integración de los Derechos penal y civil, Reus Editores, Madrid, 1913.

- Obra aportada por Federico Castejón: Asexualización de anormales, Revista General de Legislación y Jurisprudencia, Año 59, Tomo 119, Madrid, 1911.

- Trabajo doctrinal aportado por Federico Castejón: La legislación penitenciaria española (tres cuadernos y un apéndice).

- Traducción por Federico Castejón: A. Prins, La defensa social y las transformaciones del derecho penal, Reus Editores, Madrid, 1912.

\section{Signatura}

AGA 32/07346. Legajo 5363-2.

\section{Cátedra}

Derecho civil español, común y foral.

\section{Universidad}

Valencia.

\section{Anuncio}

R. O. de 31 de julio de 1912, Gaceta del 13 de agosto.

\section{Reglamento aplicable}

8 de abril, 1910.

\section{Fechas de la oposición}

Constitución del tribunal: 15 de noviembre, 1915. 
Presentación de los opositores: 29 de noviembre, 1915.

Votación y propuesta: 14 de diciembre, 1915.

\section{Tribunal}

Presidente: Eduardo Gómez de Baquero.

Vocales: Adolfo Bonilla San Martín, Felipe Sánchez Román, Gregorio Burón.

Secretario: Rafael Marín Lázaro.

\section{Opositores}

Salvador Salom Antequera.

José María Ventura Payás.

Gabriel Bonilla Marín.

No comparecieron: Federico Castejón, Miguel Allué, José María González de Echevarri, Ernesto Amador, Gregorio de Pereda, Máximo Peña, Isidoro Iglesias, José María Campos, Joaquín Guichot, Roberto Gómez, José María Pujol.

\section{Votación}

Primera Votación:

- Salvador Salom: un voto (Bonilla).

- José María Ventura: dos votos (Marín y Burón).

- Gómez de Baquero y Sánchez Román votaron no haber lugar a la provisión.

Segunda votación:

- Salvador Salom: dos votos (Bonilla y Sánchez Román).

- José María Ventura: tres votos (Gómez de Baquero, Marín y Burón).

Fue propuesto José María Ventura.

\section{Materiales}

De tipo administrativo: actas, oficios del negociado, oficios varios sobre conformación del tribunal.

De tipo académico o referentes a los ejercicios:

- Cuestionario elaborado por el tribunal (179 temas).

- Escritos del primer ejercicio. Dos temas: "Derechos de los cónyuges en los bienes gananciales"; "Legítima de los hijos naturales reconocidos y legitimados por concesión real".

- Ejercicios prácticos.

- Escrito de libros consultados por los opositores.

- Programa aportado por José María Ventura (102 lecciones).

- Trabajo doctrinal aportado por José María Ventura: "Breves consideraciones sobre el contrato de trabajo". 


\section{Signatura}

AGA 32/o7329. Legajo 5354-8.

\section{Cátedra}

Historia general de Derecho español.

\section{Universidad}

Oviedo.

\section{Anuncio}

R. O. del 31 de julio de 1912, Gaceta del 13 de agosto.

\section{Reglamento aplicable}

8 de abril, 1910 .

\section{Fechas de la oposición}

Constitución del tribunal: 3 de enero, 1913.

Elaboración del cuestionario: 6 de enero, 1913.

\section{Tribunal}

Presidente: Eduardo Hinojosa.

Vocales: César Mantilla, Rafael Altamira, Rafael Ureña.

Secretario: Laureano Díez Canseco.

\section{Opositores}

No compareció ningún opositor. Se declaró desierta la vacante.

Firmaron la instancia los siguientes:

Rafael Acosto Inglott.

Máximo Peña Mantecón.

Miguel Allné Salvador.

José María Ventura Pallás.

Joaquín Gichot Barrera.

Gabriel Bonilla Masin.

Gregorio de Pereda Ugarte.

\section{Materiales}

Actas, oficios del negociado, oficios varios sobre conformación del tribunal, cuestionario elaborado por el tribunal (152 temas). 


\section{Signatura}

AGA 32/o7338. Legajos 5359-1 (hay dos legajos con la misma numeración) y 5359-1.

AGA 32/07339.

\section{Cátedra}

Derecho administrativo.

\section{Universidad}

Central.

\section{Anuncio}

R.O. 31 de julio, 1912 (Gaceta del 12 de agosto).

\section{Reglamento aplicable}

8 de abril, 1910.

\section{Fechas de la oposición}

Constitución del tribunal: 18 de abril, 1916.

Presentación de los opositores: 1 de mayo, 1916.

Votación y propuesta: 12 de mayo, 1916.

\section{Tribunal}

Presidente: Augusto González Besada.

Vocales: Adolfo González Posada, Javier Ugarte, Eduardo Sanz Escartín (en lugar del fallecido Jerónimo Vida).

Secretario: Cirilo Palomo.

\section{Opositores}

José Gascón Marín.

Pablo de Azcárate Flórez.

\section{Votación}

José Gascón obtuvo todos los votos menos el de Posada, quien votó a Pablo Azcárate.

José Gascón fue propuesto. 


\section{Materiales}

De tipo administrativo: actas, oficios del negociado, hoja de servicios de José Gascón. De tipo académico o referentes a los ejercicios:

- Cuestionario elaborado por el tribunal (152 temas).

- Escritos del primer ejercicio. Dos temas: "Examen crítico de los derechos adquiridos desde el punto de vista internacional"; "Soluciones de derecho uniforme sobre la letra de cambio y el pagaré a la orden”.

- Ejercicios prácticos (tercer ejercicio).

- Escrito de libros consultados por los opositores.

- Programa aportado por José Gascón (78 lecciones).

Obras aportadas por José Gascón.

- Trabajos varios (volumen recopilatorio de numerosas publicaciones en revistas nacionales e internacionales, así como en congresos).

- Trabajo inédito aportado por José Gascón: La Real Orden de 23 de julio de 1907. Posibilidad legal de municipalizar servicios.

- Apuntes de Derecho Político extranjero, Tip. De Emilio Casañal, Zaragoza, 1901.

- La enseñanza del Derecho y la Autonomía universitaria en Francia. Estudio comparado; Tip. De Emilio Casañal, Zaragoza, 1909.

- Nociones de Derecho administrativo y legislación provincial y municipal. Contestación a los temas de estas materias del Programa para los exámenes de aspirantes a secretarios de ayuntamientos, Imprenta de la Revista de Legislación, Madrid, 1907.

- Oposiciones al cuerpo de aspirantes a la judicatura y Ministerio Fiscal. Contestación a las preguntas relativas a Derecho político, Hijos de Reus, Madrid, 1909.

- La extradición ante el Derecho internacional, Tip. De M. Turmo, Zaragoza, 1896.

- Mancomunidades Provinciales, Manuales Reus, Madrid, 1914.

- Derecho Patrio. Rudimentos de Derecho (con Agustín Catalán Latorre), Tip. De Emilio Casañal, Zaragoza, 1908.

- Municipalización de servicios, Librería General de Victoriano Suárez, Madrid, 1904.

- Limitaciones del derecho de propiedad por interés público. Memoria premiada por la Real Academia de Ciencias Morales y Políticas en el concurso ordinario de 1904, Establecimiento tipográfico de Jaime Ratés, Madrid, 1906.

- Los sindicatos y la libertad de contratación. Imp. Del Asilo de Huérfanos del S.C. de Jesús, 1904. 


\section{Signatura}

AGA 32/o7327. Legajo 5353-8.

\section{Cátedra}

Derecho administrativo.

\section{Universidad}

Santiago.

\section{Anuncio}

Real orden de 31 de julio de 1912 (Gaceta del 12 de agosto).

\section{Reglamento aplicable}

8 de abril, 1910.

\section{Fechas de la oposición}

Constitución: 8 de abril, 1913.

Presentación de los opositores: 19 de abril, 1913.

Votación y propuesta: 10 de mayo, 1913.

\section{Tribunal}

Presidente: Augusto González Besada.

Vocales: Javier Ugarte, Adolfo González Posada, Jerónimo Vida.

Secretario: Cirilo Palomo.

\section{Opositores}

Pablo de Azcárate Flórez.

Cándido Cerdeira Fernández.

José María Gioh Pi.

Domingo Villar Grangel.

No comparecieron otros 24 aspirantes.

\section{Votación y propuesta}

Pablo de Azcárate ganó la votación por tres votos (Palomo, Posada y Vida) contra dos de Domingo de Villar (Ugarte y Besada). Fue propuesto.

\section{Materiales}

El único documento administrativo conservado, aparte de las actas, es el oficio de elevación del expediente, firmado por el presidente del tribunal.

Las actas contienen los siguientes escritos:

- Primer ejercicio. Dos temas: "El derecho administrativo y la teoría de la división de poderes"; "El municipio según la ley". 
- Ejercicio práctico.

- Libros consultados por los opositores.

\section{Signatura}

AGA 32/o7337. Legajo 5358-6.

\section{Cátedra}

Instituciones de Derecho canónico.

\section{Universidad}

Barcelona.

\section{Anuncio}

Real orden de 31 de julio de 1912 (Gaceta del 12 de agosto).

\section{Reglamento aplicable}

8 de abril de 1910.

\section{Fechas de la oposición}

1913, 12 de abril de 1913: constitución del tribunal.

1913, 17 de abril: presentación de los opositores.

1913, 30 de abril, el tribunal decide, a la vista de las fechas, suspender hasta el nuevo curso y demorar la publicidad del temario.

1914, 8 de enero, se reanuda la oposición, comenzando los ejercicios.

1914, 21 de febrero: votación y propuesta.

\section{Tribunal}

Presidente: D. Rafael Conde y Luque (Consejero de Instrucción Pública) R.O. 2/03/1913 - Gaceta 8 de marzo 1913. Que sustituye a Montero Ríos que renunció. Vocales: Luis Calpena (Academia); Cipriano Herce (magistral de la catedral de Madrid), Francisco Cueva; (31/07/1912) Gaceta 12 de agosto 1912.

Secretario: Manuel Cabrera Warleta.

Han renunciado el Arzobispo de Valencia (Valeriano Menéndez Conde) y D. Didio González Ibarra y los vocales suplentes Sr. Obispo de Madrid (José María Salvador Barrera) y D. Víctor Díaz de Ordoñez, entrando como suplentes Manuel Cabrera y Cipriano Herce.

\section{Opositores}

Francisco Gómez del Campillo. 
Narciso M. ${ }^{a}$ Viñas y Daura.

Manuel Muñoz Flores.

Baltasar Cordoner y Vidal.

Juan Mon y Darcos.

Ramon Sabaté y Balcello.

José M. ${ }^{\text {a }}$ Campos Pulido.

José Ferrandez y Gonzalez (desiste y no continua en enero de 1914).

José Pou y Foxa.

Teodoro Andrés Marcos.

Excluido Antonio Martínez Pajares.

Hubo otros firmantes que no se presentaron Luis Navarro Canales, Amado Salas Medina Morales, Jaime Algarra y Portius, Eduardo Cancucia Gómez, Miguel Allue Salvador, Ignacio Barjan y Marti, José de Liñan y Eguizabal, Miguel de la Villa García, Fidel Abad y de Cavia, Lorenzo Alier y Casse, Isidoro Iglesias García. El 17 de febrero se retira José M. ${ }^{a}$ Campos Pulido.

\section{Votación y propuesta,}

1914,21 de febrero. Votación:

1. ${ }^{a}$ Sr. Cabrera vota a Gómez del Campillo; Herce vota a Manuel Muñoz Flores; Calpena vota a Teodoro Andrés Marcos; Cuevas vota a Teodoro Andrés Marcos y el Presidente Rafael Conde vota a Francisco Gómez del Campillo.

Nadie tiene tres votos.

2. ${ }^{\text {a }}$ Votación. Cabrera vota a Gómez del Campillo; Herce vota a Gómez del Campillo; Calpena a Teodoro Andrés Marcos; Cuevas vota a Teodoro Andrés Marcosy el presidente Rafael Conde vota a Francisco Gómez del Campillo.

Se formula propuesta a favor de Francisco Gómez del Castillo.

\section{Materiales}

Temario preparado por el Tribunal, 116 temas.

Ejercicios manuscritos de los opositores (pregunta "Requisitos formales para la validez del matrimonio según el decreto Ne temeré" y "De las terceras ordenes seculares". Caso práctico comentario del Cap. XII titulo VIII libro III, del Corpus, sobre beneficios vacantes. Elenco de temas y fuentes consultadas en el cuarto ejercicio).

\section{Signatura}

AGA 32/07337. Legajo 5358-7.

\section{Cátedra}

Derecho mercantil de España y de las principales naciones de Europa y América. 


\section{Universidad}

Valladolid.

\section{Anuncio}

13 de julio, 1913. Gaceta del 14.

\section{Reglamento aplicable}

8 de abril de 1910.

\section{Fechas de la oposición}

1914, 1 de abril: constitución del tribunal.

1914, 4 abril: presentación de los opositores.

1914: 23 de abril votación y propuesta.

\section{Tribunal}

Presidente: Ismael Calvo Madroño (Consejero de Instrucción Pública) . (R.O. 12 de enero de 1914- Gaceta de 16 de febrero). Previamente había renunciado el primer propuesto D. Gabino Bugallal.

Vocales: Faustino Álvarez del Manzano, Felipe Clemente de Diego, Lorenzo de Benito Endara, (31 de julio de 1913, Gaceta de 14 de agosto).

Secretario: Francisco de Paula Rives y Martí (Secretario Judicial).

\section{Opositores}

José M. ${ }^{a}$ González de Echavarri y Vivancos.

Hubo otros firmantes que no se presentaron, publicados en la Gaceta de Madrid el 23 de febrero de 1914.

\section{Votación y propuesta,}

Todos los miembros del Tribunal votaron a favor del único aspirante Se formula propuesta a favor de D. José M. ${ }^{a}$ González de Echavarri y Vivancos.

\section{Materiales}

Temario preparado por el Tribunal, 157 temas.

Ejercicios manuscritos del opositor (¿́Las operaciones efectuadas en bolsa y no publicadas ¿̇son válidas y surten efectos jurídicos o deben estimarse como juegos de azar y ser declaradas nulas con arreglo a los preceptos del Código Civil?). 


\section{Signatura}

AGA 32/o7336. Legajo 5358-4.

\section{Cátedra}

Instituciones de Derecho romano.

\section{Universidad}

Valladolid.

\section{Convocatoria}

R.O. de 31 de julio de 1913. Gaceta del 14 de agosto.

\section{Reglamento aplicable}

8 de abril, 1910.

\section{Fechas de la oposición}

Constitución del tribunal: 15 de diciembre, 1913.

Presentación de los opositores: 19 de diciembre, 1913.

Votación y propuesta: 13 de enero, 1914.

\section{Tribunal}

Presidente: Ismael Calvo Madroño.

Vocales: Rafael de Ureña, Felipe Clemente de Diego, Esteban Jiménez de la Flor. Secretario: Luis España.

\section{Opositores}

José Fernández González.

No comparecieron: Isidoro Iglesias, Rodrigo Fernández, Gabriel Bonilla, José María Campos, Gregorio de Pereda, Manuel Rey, Máximo Peña, Salvador Salón, José María Ventura.

\section{Votación}

José Fernández y González fue votado y propuesto por unanimidad.

\section{Materiales}

De tipo administrativo: actas, oficios del negociado, oficios varios sobre conformación del tribunal.

De tipo académico o referentes a los ejercicios:

- Cuestionario elaborado por el tribunal (171 temas).

- Ejercicios escritos correspondientes al primer ejercicio. Dos temas: “Acciones 
quod jussu, exercitatoria, institutoria y de peculia. Acciones noxales"; "Por medio de qué personas se podía comparecer en juicio".

- Ejercicio práctico.

- Escrito de libros consultados por el opositor.

\section{Signatura}

AGA 32/07341. Legajo 5360-4.

\section{Cátedra}

Derecho político español, comparado con el extranjero.

\section{Universidad}

Valencia.

\section{Anuncio}

R. O. 31 de julio de 1913, Gaceta del 14 de agosto.

\section{Reglamento aplicable}

8 de abril, 1910.

\section{Fechas de la oposición}

Constitución del tribunal: 16 de enero, 1915.

Presentación de los opositores: 21 de enero, 1915.

Votación y propuesta: 2 de marzo, 1915.

\section{Tribunal}

Presidente: Vicente Santamaría de Paredes.

Vocales: Juan de Armada Losada (Marqués de Figueroa), Adolfo González Posada, José María Rogelio Jove.

Secretario: Manuel de Bofarull.

\section{Opositores}

Francisco Martínez Lumbreras.

Nicolás Rodríguez Aniceto.

Juan Luis Martín Mengot.

José Alberto Jardón Santa Eulalia.

Mariano Gómez González.

No comparecieron: Miguel Allué, Ramón Sancho, Federico Santander, Gabriel Bonilla, Miguel María Pareja, Santiago García Oltra, Máximo Peña, Salvador Salom Antequera, Santiago Varela, José María González de Echevárri. 


\section{Votación}

Los cinco opositores pasaron al cuarto ejercicio.

La votación final dio el siguiente resultado:

- José Alberto Jardón: dos votos (Jove y Posada).

- Mariano Gómez González: tres votos (Santamaría, Figueroa y Bofarull).

Mariano Gómez fue propuesto.

\section{Materiales}

De tipo administrativo: actas, oficios del negociado, hoja de servicios de Mariano Gómez.

De tipo académico o referentes a los ejercicios:

- Cuestionario elaborado por el tribunal (130 temas).

- Escritos del primer ejercicio. Dos temas: "Concepto histórico y jurídico del Estado federal"; "Cuestión acerca de la existencia del feudalismo en los reinos de León y Castilla”.

- Ejercicios prácticos (tercer ejercicio).

- Escritos de libros solicitados por los opositores.

- Programa aportado por Mariano Gómez (113 lecciones).

- Trabajo doctrinal aportado por Mariano Gómez: Sistemas de representación proporcional.

\section{Signatura}

AGA 32/07337. Legajo 5358-5.

\section{Cátedra}

Historia general del Derecho español.

\section{Universidad}

Oviedo.

\section{Anuncio}

R.O. de 31 de julio, 1913 (Gaceta del 14 de agosto).

\section{Reglamento aplicable}

8 de abril, 1910.

\section{Fechas de la oposición}

Constitución del tribunal: 16 de enero, 1914.

Presentación de los opositores: 29 de enero, 1914.

Votación y propuesta: 6 de febrero, 1914. 


\section{Tribunal}

Presidente: Joaquín Fernández Prida.

Vocales: Rafael de Ureña, Laureano Díez Canseco, Jerónimo Béquer.

Secretario: César Mantilla Ortiz.

\section{Opositores}

Rafael Acosta Inglott.

José Ignacio de Sautu se retiró el día 4 de febrero de 1914.

No comparecieron: José María Álvarez Martín, Miguel Allué, José María González de Echevarri, Adoración Martínez, Feliciano Álvarez González, Arturo Suárez, Ernesto Amador, Pedro de Prada, Pío Blanco, Gregorio de Pereda, Ricardo Esmandía, Ramón Prieto, Máximo Peña, José María Pallás, Isidoro Iglesias, Gabriel Bonilla, José María Campos.

\section{Votación}

Rafael Acosta obtuvo tres votos (Mantilla, Béquer y Ureña). Canseco y Prida votaron por la no provisión. Rafael Acosta fue propuesto.

\section{Materiales}

De tipo administrativo: actas, oficios del negociado, oficios varios sobre conformación del tribunal.

De tipo académico o referentes a los ejercicios:

- Cuestionario elaborado por el tribunal (170 temas).

- Escritos del primer ejercicio. Dos temas: "El municipio en Castilla y León"; "Organización social y política de Álava".

- Ejercicios prácticos.

- Escrito de libros consultados por el opositor.

- Programa aportado por Rafael Acosta (116 lecciones).

- Trabajo doctrinal aportado por Rafael Acosta (dos cuadernos): "Relaciones de los fueros de Daroca y Teruel".

\section{Signatura}

AGA 32/o7349. Legajo 5364-3.

\section{Cátedra}

Elementos de Derecho natural.

\section{Universidad}

Granada. 


\section{Anuncio}

R.O. de 20 de julio, 1914. Gaceta del 30.

\section{Reglamento aplicable}

8 de abril, 1910.

\section{Fechas de la oposición}

Constitución del tribunal: 2 de diciembre, 1916.

Presentación de los opositores: 6 de diciembre, 1916.

Votación y propuesta: 22 de diciembre, 1916.

\section{Tribunal}

Presidente: Rafael Altamira Crevea.

Vocales: Adolfo Bonilla, Laureano Díez Canseco, Francisco Javier González Castejón.

Secretario: Jesús Requejo.

\section{Opositores}

Francisco Rivera Pastor.

No comparecieron: Pedro de Prada, Gregorio de Pereda, Gabriel Bonilla, Blas Ramos Sobrino, Gonzalo Fernández de Córdoba, Manuel Gacio, José Alberto Jardón, Manuel Barrera, Manuel Carrasco.

\section{Votación}

Todos los vocales votaron por la no provisión. El presidente Altamira votó a Francisco Rivera.

\section{Materiales}

De tipo administrativo: actas, oficios del negociado, oficios varios sobre conformación del tribunal.

De tipo académico o referentes a los ejercicios:

- Cuestionario elaborado por el tribunal (153 temas).

- Escrito del primer ejercicio. Dos temas: "Biología jurídica"; "Teorías de la dictadura tutelar y los gobiernos por comisión”.

- Ejercicio práctico.

- Escrito de libros consultados por el opositor. 


\section{Signatura}

AGA 32/o7345. Legajo 5362-4.

\section{Cátedra}

Derecho administrativo.

\section{Universidad}

Valencia.

\section{Anuncio}

R.O. de 20 de julio, 1914. Gaceta del 30.

Había sido anunciada a traslación por R.O. de 28 de marzo de 1914 (Gaceta del 3 de abril).

\section{Reglamento aplicable}

8 de abril, 1910 .

\section{Fechas de la oposición}

Constitución del tribunal: 27 de enero, 1916.

Presentación de los opositores: 5 de febrero, 1916.

Votación y propuesta: 23 de febrero, 1916.

\section{Tribunal}

Presidente: Vicente Santamaría de Paredes.

Vocales: Antonio Royo Villanova, Niceto Alcalá Zamora, Rafael de Ureña.

Secretario: José María de Olózaga.

\section{Opositores}

Gregorio de Pereda Ugarte.

Luis Gestoso Tudela.

No comparecieron: Federico Santander, José María Ventura Gabriel Bonilla, Máximo Peña, Francisco Martínez Lumbreras.

\section{Votación}

Primera Votación:

- Gregorio de Pereda: dos votos (Royo Villanova y Ureña).

- Luis Gestoso: un voto (Santamaría).

- Olózaga y Alcalá Zamora votaron por la no provisión. 
Segunda votación:

- Gregorio de Pereda: tres votos (Alcalá Zamora, Royo Villanova y Ureña).

- Luis Gestoso: un voto (Santamaría).

- Olózaga votó por la no provisión.

Fue propuesto Gregorio de Pereda.

\section{Materiales}

De tipo administrativo: actas, oficios del negociado, oficios varios sobre conformación del tribunal, hoja de servicios de Gregorio de Pereda.

De tipo académico o referentes a los ejercicios:

- Cuestionario elaborado por el tribunal (129 temas).

- Escritos del primer ejercicio. Dos temas: "Operaciones de deslinde y amojonamiento de los montes públicos"; "Plazos para la interposición del recurso contencioso administrativo".

- Ejercicios prácticos.

- Escrito de libros consultados por los opositores.

- Programa aportado por Gregorio de Pereda (78 lecciones).

- Trabajo doctrinal aportado por Gregorio de Pereda: "Conflictos suscitados por las autoridades administrativas a las judiciales”.

\section{Signatura}

AGA 32/o7340. Legajo 5360-1.

\section{Cátedra}

Derecho civil español, común y foral.

\section{Universidad}

Santiago y Salamanca.

\section{Anuncio}

R.O. de 21 de julio de 1914.

Se agrega la cátedra de Salamanca (Gaceta del 10 de diciembre de 1914).

\section{Reglamento aplicable}

8 de abril, 1910.

\section{Fechas de la oposición}

Constitución del tribunal: 8 de enero, 1917.

Presentación de los opositores: 24 de enero, 1917. 
Votación 19 de febrero, 1917.

Propuesta: 20 de febrero, 1917.

\section{Tribunal}

Presidente: Antonio Royo Villanova.

Vocales: Juan de Armada Losada (Marqués de Figueroa), José Martos de la Fuente, Felipe Clemente de Diego.

Secretario: Enrique Barredo.

\section{Opositores}

Francisco Candil Calvo.

Leopoldo García- Alas y García Argüelles.

Mariano Caro del Arroyo.

Gabriel Bonilla Marín.

Demófilo de Buen Lozano.

Salvador Salom Antequera se retiró.

No comparecieron: Luis Porteiro, Luis Jordana de Pozas, Gregorio de Pereda, Joaquín Uguet, Mariano Caso, José María Ventura Pallás, Nicolás Rodríguez Aniceto, Pascual Sierra, José García, Máximo Peña.

\section{Votación}

Los cinco opositores pasaron al cuarto ejercicio.

En la primera ronda de la votación final Demófilo de Buen obtuvo todos los votos menos el de Barredo, que votó a Candil.

La segunda ronda dio el siguiente resultado:

- Gabriel Bonilla: tres votos (Barredo, de Diego, de la Fuente).

- Francisco Candil: dos votos (Antonio Royo y Marqués de Figueroa).

Demófilo de Buen optó por la cátedra de Salamanca y Francisco Candil aceptó la de Santiago. Fueron propuestos.

\section{Materiales}

De tipo administrativo: actas, oficios sobre conformación del tribunal.

De tipo académico o referentes a los ejercicios:

- Cuestionario elaborado por el tribunal (175 temas).

- Escritos del primer ejercicio. Dos temas: "Teoría general de la adquisición y pérdida de los derechos", "Separación de bienes entre cónyuges".

- Ejercicios prácticos (tercer ejercicio).

- Programa aportado por Demófilo de Buen (133 lecciones).

- Programa aportado por Gabriel Bonilla (137 lecciones).

- Trabajo inédito aportado por Demófilo de Buen: Sobre el concepto de la prescripción y las diferencias entre prescripción y caducidad. 
- Trabajo inédito aportado por Gabriel Bonilla: La propiedad privada.

- Obra aportada por Demófilo de Buen: De la usucapión (con Leopoldo Alas y Enrique R. Ramos), Centro de Estudios Históricos, Junta para la Ampliación de Investigaciones Científicas, Madrid, 1916.

\section{Signatura}

AGA 32/07350. Legajo 5364-5.

\section{Cátedra}

Derecho penal.

\section{Universidad}

Central.

\section{Anuncio}

R. O. 31 de julio de 1915, Gaceta del 7 de agosto.

\section{Reglamento aplicable}

8 de abril, 1910.

\section{Fechas de la oposición}

Constitución del tribunal: 9 de febrero, 1918.

Presentación de los opositores: 15 de marzo, 1918.

Votación y propuesta: 26 de marzo, 1918.

\section{Tribunal}

Presidente: Ángel Salcedo.

Vocales: Adolfo Bonilla, Quintiliano Saldaña, Fernando Cadalso.

Secretario: Carlos García Oviedo.

\section{Opositores}

Luis Jiménez de Asúa (también aparece como Luis Jiménez Asúa).

Federico Castejón Martínez de Arizala.

Constante Amor Naveiro.

Enrique de Benito de la Llave.

No comparecieron: Salvador Salom Antequera, Eugenio Cuello Calón, Leopoldo Palacios.

Pasaron al cuarto ejercicio Luis Jiménez Asúa, Federico Castejón y Enrique de Benito. 


\section{Votación}

Primera votación:

- Luis Jiménez Asúa: dos votos (Saldaña, Bonilla).

- Federico Castejón: un voto (García).

- Enrique de Benito: dos votos (Cadalso, Salcedo).

Segunda votación:

- Luis Jiménez Asúa: tres votos (García, Saldaña, Bonilla).

- Enrique de Benito: dos votos (Cadalso, Salcedo).

Luis Jiménez de Asúa fue propuesto.

\section{Materiales}

De tipo administrativo: actas, oficios del negociado, oficios varios sobre conformación del tribunal.

De tipo académico o referentes a los ejercicios:

- Cuestionario elaborado por el tribunal (163 temas).

- Escrito del primer ejercicio. Dos temas: "Teorías sobre la degeneración y el delito"; "Actos internos del delito. Actos externos preparatorios".

- Ejercicios prácticos.

- Escritos de libros consultados por los opositores.

- Programa aportado por Luis Jiménez de Asúa (96 lecciones).

- Trabajo doctrinal aportado por Luis Jiménez de Asúa: "La política criminal en las legislaciones europeas y norteamericanas".

\section{Signatura}

AGA 32/07347. Legajo 5363-3.

\section{Cátedra}

Derecho político español comparado con el extranjero.

\section{Universidad}

Sevilla.

\section{Anuncio}

R. O. 31 de julio de 1915, Gaceta del 7 de agosto.

\section{Reglamento aplicable}

8 de abril, 1910. 


\section{Fechas de la oposición}

Constitución del tribunal: 2 de marzo, 1916.

Presentación de los opositores: 7 de marzo, 1916.

Votación y propuesta: 25 de marzo, 1916.

\section{Tribunal}

Presidente: Ángel Salcedo Ruiz.

Vocales: Adolfo Bonilla San Martín, Adolfo González Posada, José Manuel Pedregal y Sánchez.

Secretario: Gonzalo del Castillo Alonso.

\section{Opositores}

José Alberto Jardón Santa Eulalia.

No comparecieron: Gregorio de Pereda Ugarte, Luis Gestoso Tudela, Federico Santander, José María Ventura Gabriel Bonilla, Máximo Peña, Francisco Martínez Lumbreras, Nicolás Rodríguez, Miguel María de Pareja, Enrique Martí, Demófilo de Buen Lozano, Máximo Peña, José María Yanguas, José Monge.

\section{Votación}

José Alberto Jardón fue votado y propuesto por unanimidad.

\section{Materiales}

De tipo administrativo: actas, oficios del negociado, oficios varios sobre conformación del tribunal.

De tipo académico o referentes a los ejercicios:

- Cuestionario elaborado por el tribunal (118 temas).

- Escritos del primer ejercicio. Dos temas: "El senado español”; "El municipio en España desde los orígenes hasta la Edad Moderna”.

- Ejercicio práctico.

- Programa aportado por José Alberto Jardón (101 lecciones).

- Trabajo doctrinal aportado por José Alberto Jardón: "Ensayos filosófico-políticos (segunda serie). Crítica de las doctrinas de Duguit”. 


\section{Signatura}

AGA 32/07351. Legajo 5365-1.

\section{Cátedra}

Instituciones de Derecho canónico.

\section{Universidad}

Salamanca.

\section{Anuncio}

R. O. 31 de julio de 1915, Gaceta del 6 de agosto.

\section{Reglamento aplicable}

8 de abril, 1910.

\section{Fechas de la oposición}

Constitución del tribunal: 25 de enero, 1916.

Presentación de los opositores: 8 de febrero, 1916.

Votación y propuesta: 25 de marzo, 1916.

\section{Tribunal}

Presidente: José Salvador Barrera, obispo de Madrid-Alcalá.

Vocales: Rafael Ureña, Francisco Cueva y Palacio, Manuel Cabrera Warleta.

Secretario: Lorenzo Moret.

\section{Opositores}

Baltasar Cardoner.

Eloy Montero Gutiérrez.

José Pou Foxá.

José Escobedo González.

Teodoro Andrés Marcos.

Juan Ferrer Galdiano.

Narciso María Viñas.

Eugenio Lorenzo Rodríguez.

Miguel de la Villa y García.

No comparecieron: Leopoldo García-Alas y García Argüelles, Mariano Caro y del Arroyo, Adoración Martínez, Armando Álvarez, Mariano Marcial, Miguel Sancho, Isidoro Iglesias, Rafael Torrecilla, Ramón Sabaté, Ramiro Golpe, Pedro de Prada, Pedro Navarro. 


\section{Votación}

Teodoro Andrés Marcos fue votado y propuesto por unanimidad.

\section{Materiales}

De tipo administrativo: actas, oficios del negociado, oficios varios sobre conformación del tribunal.

De tipo académico o referentes a los ejercicios:

- Cuestionario elaborado por el tribunal (107 temas).

- Escrito del primer ejercicio. Dos temas: "Fundación, innovación y extinción de los institutos religiosos"; "Idea general de los sacramentos y sacramentales".

- Ejercicios prácticos.

- Escritos de libros consultados por los opositores.

- Programa aportado por Teodoro Andrés Marcos (105 lecciones).

- Trabajo doctrinal aportado por Teodoro Andrés Marcos: "Instituciones canónicas en la Iglesia hispano-romana y visigótica".

- Trabajo doctrinal aportado por Teodoro Andrés Marcos: "Las inmunidades eclesiásticas en la Iglesia hispano-romana y visigoda".

\section{Signatura}

AGA 32/o7338. Legajo 5359-1 (hay dos legajos con la misma numeración).

\section{Cátedra}

Derecho internacional público y privado.

\section{Universidad}

Barcelona.

\section{Anuncio}

R. O. 31 de julio de 1915, Gaceta del 7 de agosto.

\section{Reglamento aplicable}

8 de abril, 1910 .

\section{Fechas de la oposición}

Constitución del tribunal: 1 de enero, 1916.

Presentación de los opositores: 14 de enero, 1916.

Votación y propuesta: 23 de enero, 1916. 


\section{Tribunal}

Presidente: Rafael Conde Luque.

Vocales: Juan de Armada Losada (Marqués de Figueroa), Francisco Javier Pérez de Vargas (Marqués de la Merced), Manuel Lasala Llanas.

Secretario: José Castán Tobeñas.

\section{Opositores}

José María Yanguas Mesía (firma como Messía).

José María Trías de Bes.

No comparecieron: Nicolás Rodríguez Aniceto, Demófilo de Buen, Cándido Cerdeira Trelles, Luis Gestoso, Ernesto Amador, Gregorio de Pereda, Santiago Varela.

\section{Votación}

José María Trías de Bes fue votado y propuesto por unanimidad.

\section{Materiales}

De tipo administrativo: actas, oficios del negociado, oficios varios sobre conformación del tribunal.

De tipo académico o referentes a los ejercicios:

- Cuestionario elaborado por el tribunal (71 temas de derecho internacional privado y 71 de derecho internacional público).

- Escritos del primer ejercicio. Dos temas: "La noción política y jurídica de poder del Estado, en relación con la teoría de la división de los Poderes; "Consecuencias jurídicas de la existencia o inexistencia de una potestad discrecional en la administración".

- Ejercicios prácticos (tercer ejercicio).

- Escrito de libros consultados por los opositores.

- Programa aportado por José María Trías (136 lecciones de derecho internacional privado y 64 de derecho internacional público).

- Trabajos prácticos aportados por José María Trías: “Avance pedagógico. Trabajos prácticos realizados por los alumnos de la cátedra de derecho internacional en la Universidad de Barcelona". 


\section{Signatura}

AGA 32/07350. Legajo 5364-6.

\section{Cátedra}

Derecho civil español, común y foral.

\section{Universidad}

Central.

\section{Anuncio}

R.O. de 26 de mayo, 1916 (Gaceta del 2 de junio).

\section{Reglamento aplicable}

8 de abril, 1910.

\section{Fechas de la oposición}

Constitución del tribunal: 20 de octubre, 1916.

Presentación de los opositores: 25 de octubre, 1916.

Votación y propuesta: 1 de diciembre, 1916.

\section{Tribunal}

Presidente: Ismael Calvo.

Vocales: Tomás Montejo, Calixto Valverde, Niceto Alcalá Zamora.

Secretario: Felipe Clemente de Diego.

\section{Opositores}

Francisco de Casso Hernández.

Leopoldo García-Alas y García Argüelles.

Salvador Salom Antequera.

Francisco Candil Calvo.

Felipe Sánchez-Román Gallifa.

Gabriel Bonilla.

Manuel Miguel Traviesas.

Mariano Caro del Arroyo.

Demófilo de Buen Lozano.

José María Ventura Pallás.

No comparecieron: José García Revilla, José Castillejo, Domingo Villar, Enrique Ramos, Ignacio de Cano.

Pasaron al cuarto ejercicio: Francisco de Casso y Hernández, Leopoldo GarcíaAlas y García Argüelles, Felipe Sánchez-Román Gallifa, Gabriel Bonilla, Mariano Caro y del Arroyo, Demófilo de Buen y Lozano. 


\section{Votación}

La votación fue ganada por Felipe Sánchez-Román Gallifa con todos los votos menos el de Niceto Alcalá Zamora, que votó a Demófilo de Buen.

Felipe Sánchez-Román Gallifa fue propuesto.

\section{Materiales}

De tipo administrativo: actas, oficios del negociado, oficios varios sobre conformación del tribunal.

De tipo académico o referentes a los ejercicios:

- Cuestionario elaborado por el tribunal (235 temas).

- Escrito del primer ejercicio. Dos temas: "Progresión legislativa del Derecho civil español común"; "Estudio doctrinal y legal de los albaceas".

- Ejercicios prácticos.

- Escritos de libros consultados por los opositores.

- Programa aportado por Felipe Sánchez-Román Gallifa (176 lecciones).

- Trabajo doctrinal aportado por Felipe Sánchez-Román Gallifa: "Contribución al estudio de las obligaciones naturales en el Código Civil".

\section{Signatura}

AGA 32/o7336. Legajo 5358-2.

\section{Cátedra}

Política social y Legislación comparada del trabajo.

\section{Universidad}

Central.

\section{Anuncio}

R.O. de 26 de mayo, 1916 (Gaceta del 2 de junio).

\section{Reglamento aplicable}

8 de abril, 1910.

\section{Fechas de la oposición}

Constitución del tribunal: 17 de enero, 1917.

Presentación de los opositores: 25 de enero, 1917.

Votación y propuesta: 25 de marzo, 1917. 


\section{Tribunal}

Presidente: Gumersindo Azcárate.

Vocales: Joaquín Sánchez Toca, Gabriel Maura Gamazo, Antonio Flores de Lemus.

Secretario: José Gascón Marín.

\section{Opositores}

Luis Olariaga Pujana.

Francisco Bernis Carrasco.

Leopoldo Palacios Morini.

No comparecieron: Fernando de los Ríos, Jaime Algarra, Juan Jesús Carrasco, Francisco de Lasso, Pablo de Azcárate, José María Yanguas, Amado Castroviejo, Máximo Peña, José Calvo Sotelo, Hipólito González, Domingo Villar, José Castillejo, Arturo Suárez, José López Laso, Rafael Díaz Aguado, Juan Martín, Enrique Martí, Placio Buylla (¿), Pedro Layso (?).

Tomás Juan Elorrieta y Recaredo Fernández de Velasco se retiraron.

\section{Votación}

Primera votación:

- Luis Olariaga: dos votos (Sánchez de Toca y Maura).

- Francisco Bernis: un voto (Flores).

- Leopoldo Palacios: dos votos (Gascón y Azcárate).

Segunda votación:

- Luis Olariaga: tres votos (Flores, Sánchez de Toca y Maura).

- Leopoldo Palacios: dos votos (Gascón y Azcárate).

Luis Olariaga fue propuesto.

\section{Materiales}

De tipo administrativo: actas, oficios del negociado, oficios varios sobre conformación del tribunal.

De tipo académico o referentes a los ejercicios:

- Cuestionario elaborado por el tribunal (125 temas).

- Escritos del primer ejercicio. Dos temas: "La asociación patronal de resistencia, la asociación industrial, y las corporaciones patronales"; "El contrato de aprendizaje".

- Ejercicios prácticos.

- Escrito de libros consultados por los opositores.

- Programa aportado por Luis Olariaga (61 lecciones).

- Trabajo doctrinal aportado por Luis Olariaga: "Sobre el problema agrario". 


\section{Signatura}

AGA 32/o7348. Legajo 5363-6.

\section{Cátedra}

Economía política y Elementos de Hacienda pública.

\section{Universidad}

Murcia.

\section{Anuncio}

R. O. de 26 de mayo de 1916, Gaceta de 2 de junio.

\section{Reglamento aplicable}

8 de abril, 1910 .

\section{Fechas de la oposición}

Constitución del tribunal: 20 de octubre, 1916.

Presentación de los opositores: 6 de noviembre, 1916.

Votación y propuesta: 18 de noviembre, 1916.

\section{Tribunal}

Presidente: Eduardo Sanz Escartín.

Vocales: Melchor Salvá, Francisco Javier Jiménez Pérez de Vargas, Adolfo Álvarez Buylla.

Secretario: Vicente Gay.

\section{Opositores}

Ramón Carande Thobar (también aparece como Thovar).

No comparecieron: Antonio Álvarez del Manzano, Luis Jordana de Pozas, Adoración Martínez, Máximo Peña, Mariano Marcial, Luis Tatay.

\section{Votación}

Ramón Carande fue votado y propuesto por unanimidad.

\section{Materiales}

De tipo administrativo: actas, oficios del negociado, oficios varios sobre conformación del tribunal.

De tipo académico o referentes a los ejercicios:

- Cuestionario elaborado por el tribunal (122 temas). 
- Escrito del primer ejercicio. Dos temas: "Los factores determinantes"; "El impuesto sobre los intereses de préstamos y obligaciones".

- Ejercicios prácticos.

- Escrito de libros consultados por el opositor.

- Programas aportados por Ramón Carande: Economía política, 49 lecciones; hacienda pública, 52 lecciones.

\section{Signatura}

AGA 32/o7349. Legajo 5364-2.

\section{Cátedra}

Instituciones de Derecho romano.

\section{Universidad}

Murcia.

\section{Anuncio}

R. O. de 26 de mayo de 1916, Gaceta de 2 de junio.

\section{Reglamento aplicable}

8 de abril, 1910.

\section{Fechas de la oposición}

Constitución del tribunal: 12 de febrero, 1917.

Presentación de los opositores: 26 de febrero, 1917.

El 26 de marzo se suspenden los ejercicios por enfermedad del hijo del vocal Eusebio Díaz.

Votación y propuesta: 30 de marzo, 1917.

\section{Tribunal}

Presidente: Joaquín Fernández Prida.

Vocales: Eduardo Hinojosa, Felipe Clemente de Diego, Eusebio Díaz.

Secretario: Agustín González Rodríguez.

\section{Opositores}

Laureano Sánchez Gallego.

Julián Carlón Hurtado.

Enrique R. Ramos Ramos.

José López Soro. 
Mariano Caro del Arroyo.

Esteban Madruga Jiménez.

No comparecieron: Manuel Martínez Pedroso, Pedro Navarro, José María Aparici, Rodrigo Fernández, Álvaro Calvo, Adoración Martínez, Juan Ferrer, Rafael Pou.

\section{Votación}

Primera votación:

- Laureano Sánchez: dos votos (Díaz y Prida).

- Enrique Ramos: dos votos (de Diego e Hinojosa).

- Mariano Caro: un voto (González).

Segunda votación:

- Laureano Sánchez: tres votos (González, Díaz y Prida).

- Enrique Ramos: dos votos (de Diego e Hinojosa).

Laureano Sánchez fue propuesto.

\section{Materiales}

De tipo administrativo: actas, oficios del negociado, oficios varios sobre conformación del tribunal.

De tipo académico o referentes a los ejercicios:

- Cuestionario elaborado por el tribunal (156 temas).

- Escrito del primer ejercicio. Dos temas: "Origen y desenvolvimiento histórico del dominio"; "Servidumbres rústicas".

- Ejercicios prácticos.

- Escritos de libros consultados por los opositores.

- Trabajo doctrinal aportado por Laureano Sánchez: "El ejercicio de los poderes paterfamiliares".

- Programa aportado por Laureano Sánchez (111 lecciones).

\section{Signatura}

AGA 32/o7348. Legajo 5363-5.

\section{Cátedra}

Procedimientos judiciales y práctica forense.

\section{Universidad}

Salamanca y Murcia. 


\section{Anuncio}

Para Murcia, R.O. de 26 de mayo, 1916.

Para Salamanca, R.O. de 16 de febrero, 1917. Gaceta del 28.

\section{Reglamento aplicable}

8 de abril, 1910.

\section{Fechas de la oposición}

Constitución del tribunal: 8 de enero, 1918.

Presentación de los opositores: 21 de enero, 1918.

Votación: 9 de febrero, 1918.

Elección y propuesta: 10 de febrero, 1918.

\section{Tribunal}

Presidente: Eduardo Gómez de Baquero.

Vocales: Tomás Montejo, Javier Ugarte.

Secretario: Javier Comín.

Lorenzo Moret abandonó el tribunal el día 24 de marzo.

\section{Opositores}

Juan Ferrer Galdeano.

José García Revillo.

Francisco Marcos Pelayo.

José Xiráu Palou.

Matías Domínguez Ballarín.

No comparecieron otros 19 aspirantes.

Alfonso Sergio Orbaneja se retiró tras conocer los temas del primer ejercicio.

\section{Votación}

Primera votación:

- Francisco Marcos: dos votos (Comín, Montejo).

- José Xiráu: dos votos (Ugarte, Gómez de Baquero).

La segunda votación arrojó el mismo resultado.

Tercera votación:

- Francisco Marcos: tres votos (Ugarte, Comín, Montejo).

- José Xiráu: un voto (Gómez de Baquero).

La votación del número segundo fue ganada por unanimidad por José Xiráu.

Francisco Marcos optó por la cátedra de Salamanca y José Xiráu aceptó la de Murcia. Fueron propuestos. 


\section{Materiales}

De tipo administrativo: actas, oficios del negociado, oficios varios sobre conformación del tribunal.

De tipo académico o referentes a los ejercicios:

- Cuestionario elaborado por el tribunal (152 temas).

- Escritos del primer ejercicio. Dos temas: "El sumario"; "Procedimiento en los tribunales de honor y su crítica".

- Ejercicios prácticos.

- Escrito de libros consultados por los opositores.

- Programa aportado por Francisco Marcos (229 lecciones).

- Trabajo doctrinal aportado por Francisco Marcos: "La legislación notarial y el instrumento público".

- Programa aportado por José Xiráu (144 lecciones).

- Trabajo doctrinal aportado por José Xiráu: "La caducidad de la instancia".

\section{Signatura}

AGA 32/07349. Legajo 5364-1.

\section{Cátedra}

Derecho administrativo.

\section{Universidad}

Santiago.

\section{Anuncio}

Gaceta del 2 de julio, 1916.

Había sido anunciada a traslación por R.O. de 1 de mayo, 1916 (Gaceta del 7).

\section{Reglamento aplicable}

8 de abril, 1910.

\section{Fechas de la oposición}

Constitución del tribunal: 27 de octubre, 1916.

Presentación de los opositores: 3 de noviembre, 1916.

Fin de los ejercicios: 24 de noviembre, 1916.

\section{Tribunal}

Presidente: Vicente Santamaría.

Vocales: Rafael Ureña, Tomás Elorrieta, José Gascón Marín.

Secretario: Luis España. 


\section{Opositores}

Enrique Martín Jara.

Luis Gestoso Tudela.

Nicolás Rodríguez Aniceto.

No comparecieron: Francisco Martínez Lumbreras, José María Yanguas Messía, Álvaro Olea, Pedro Fernández y González, Antonio Martín Lázaro, Máximo Peña, Domingo Villar, Manuel Rey.

Luis Gestoso Tudela y Nicolás Rodríguez Aniceto se retiraron el día 13 de noviembre.

Enrique Martín Jara se retiró el día 22 de noviembre a causa de una "fatiga nerviosa (surmenage)".

\section{Materiales}

De tipo administrativo: actas, oficios del negociado, oficios varios sobre conformación del tribunal.

Además:

- Hojas de servicios de José García-Valenzuela y de Luis Jordana de Pozas.

- Certificado médico de 22 de noviembre de 1916 sobre el estado de salud de Enrique Martín.

De tipo académico o referentes a los ejercicios:

- Cuestionario elaborado por el tribunal (110 temas).

- Escrito del primer ejercicio. Dos temas: "Concepto de Administración Pública"; "Represión de las perturbaciones del orden público. Medios Extraordinarios".

- Ejercicio práctico.

- Escrito de libros consultados por el opositor.

Obra presentada por José García-Valenzuela:

“Estatuto inédito de Avignon de 1243", Imprenta El Defensor de Granada, 1895. Memoria premiada con el primer premio en el certamen abierto por la Real Sociedad Económica de Amigos del País de la provincia de Granada en el año 1895.

\section{Signatura}

AGA 32/07344. Legajo 5362-1.

\section{Cátedra}

Derecho administrativo.

\section{Universidad}

Valencia y Santiago. 


\section{Anuncio}

Para Valencia por R.O. de 2 de febrero, 1917.

Para Santiago, R.O. de 30 de junio de 1917.

Por R.O. de 21 de julio de 1912 se había nombrado tribunal para juzgar las oposiciones a las cátedras de Derecho administrativo vacantes en Madrid y Santiago, pero tal provisión fue abandonada.

\section{Reglamento aplicable}

8 de abril, 1910.

\section{Fechas de la oposición}

Constitución del tribunal: 9 de febrero, 1918.

Presentación de los opositores: 13 de febrero, 1918.

Votación: 26 de marzo, 1918.

Elección de la cátedra y propuesta: 27 de marzo, 1918.

\section{Tribunal}

Presidente: Adolfo González Posada.

Vocales: Ángel Salcedo, José Gascón Marín, José Maluquer Salvador.

Secretario: Gonzalo del Castillo.

\section{Opositores}

Álvaro Olea Pimentel.

Recaredo Fernández Velasco.

Luis Jordana de Pozas.

Nicolás Rodríguez Aniceto.

Enrique Martí Jara.

Nicolás Zorrilla Vicario.

Joaquín Uguet Soriano.

Luis Gestoso Tudela se retiró el día 3 de marzo de 1918.

Firmaron la instancia 29 aspirantes para la cátedra de Valencia y 17 para la de Santiago.

\section{Votación}

Luis Jordana de Pozas obtuvo por unanimidad el primer puesto.

Votación del número segundo:

- Recaredo Fernández: dos votos (Maluquer y Salcedo).

- Enrique Martí: tres votos (Posada, Gascón y Castillo).

Jordana de Pozas optó por la cátedra de Valencia y Enrique Martí aceptó la de Santiago. Fueron propuestos. 


\section{Materiales}

De tipo administrativo: actas, oficios del negociado, oficios varios sobre conformación del tribunal. Consta la hoja de servicios de Jordana de Pozas.

De tipo académico o referentes a los ejercicios:

- Cuestionario elaborado por el tribunal (117 temas).

- Escritos del primer ejercicio. Dos temas: "Nacimiento de la relación del funcionario con la administración"; "El municipio".

- Ejercicios prácticos.

- Escrito de libros consultados por los opositores.

Materiales de Jordana:

- Programa (92 lecciones).

- La organización Agraria en Inglaterra, Tip. G. Casañal, Zaragoza, 1914.

- La organización agraria en Irlanda, Tip. G. Casañal, Zaragoza, 1914.

- Ensayo sobre la Administración consultiva de fomento, Memoria general de los trabajos realizados durante el año 1916, Consejo Provincial de Fomento de Zaragoza, Ministerio de Fomento, Tipografía del Hospicio provincial, Zaragoza, 1917.

- Apuntes para un estudio del movimiento obrero en Zaragoza, Asociación Internacional para la Protección legal de los trabajadores, sección española, núm. 41, Madrid, 1915.

- La cuestión agraria en Irlanda. Su historia y estado actual, Imprenta de la sucesora de M. Minuesa de los Ríos, Madrid, 1916.

- Los accidentes del trabajo agrícola en España, Hijos de Reus Editores, Madrid, 1913.

- Trabajo doctrinal aportado: "Ensayo sobre la entidades representativas y profesionales en el Derecho administrativo español".

Materiales de Martí:

- Programa (85 lecciones).

- Trabajo doctrinal aportado: "La policía rural en las ordenanzas municipales de la provincia de Salamanca”.

- Trabajo doctrinal aportado: "Contribución al estudio del derecho administrativo comparado. El gobierno de la ciudad inglesa”.

\section{Signatura}

AGA 32/07336. Legajo 5358-1.

\section{Cátedra}

Derecho internacional público y privado.

\section{Universidad}

Valladolid. 


\section{Anuncio}

R.O. de 28 de febrero, 1917.

Había sido anunciada a traslación por R.O. de 17 de noviembre, 1916.

\section{Reglamento aplicable}

8 de abril, 1910.

\section{Fechas de la oposición}

Constitución del tribunal: 16 de febrero, 1918.

Presentación de los opositores: 24 de febrero, 1918.

Votación y propuesta: 11 de marzo, 1918.

\section{Tribunal}

Presidente: Antonio López Muñoz.

Vocales: Rafael Conde Luque, Laureano Díez Canseco, Trinidad Jurado.

Secretario: Manuel de Lasala.

\section{Opositores}

José María Yanguas Messía.

Camilo Barcia Trelles.

Mauro Miguel Romero.

No comparecieron: Álvaro Olea Pimentel, Luis Gestoso Tudela, Nicolás Rodríguez Aniceto, Emilio Yangle Rubio, Federico Santander Ruiz.

\section{Votación}

José María Yanguas ganó la votación con los votos de todos los jueces menos el de Conde Luque, que votó a Camilo Barcía. José María Yanguas fue propuesto.

\section{Materiales}

De tipo administrativo: actas, oficios del negociado, oficios varios sobre conformación del tribunal, instancias de la provisión por traslación.

De tipo académico o referentes a los ejercicios:

- Cuestionario elaborado por el tribunal (132 temas).

- Ejercicios escritos correspondientes al primer ejercicio. Dos temas: "Influencia de Hugo Grocio en la ciencia y en la vida internacional"; "El protectorado sobre Marruecos".

- Ejercicios prácticos.

- Escrito de libros consultados por los opositores.

- Programa aportado por José María Yanguas (52 y 54 lecciones).

- Trabajo doctrinal aportado por José María Yanguas: El divorcio en el derecho internacional privado. 


\section{Signatura}

AGA 32/07345. Legajo 5362-2.

\section{Cátedra}

Economía política y Hacienda pública.

\section{Universidad}

Granada.

\section{Anuncio}

R.O. de 19 de abril, 1917. Gaceta del 30.

Había sido anunciada a traslación por R.O. de 31 de agosto de 1916 (Gaceta del 10 de septiembre).

\section{Reglamento aplicable}

8 de abril, 1910.

\section{Fechas de la oposición}

Constitución del tribunal: 1 de febrero, 1918.

Presentación de los opositores: 13 de febrero, 1918.

Votación y propuesta: 7 de marzo, 1918.

\section{Tribunal}

Presidente: Eduardo Sanz y Escartín.

Vocales: Adolfo Álvarez Buylla, Francisco Javier Jiménez, Fernando Ruano.

Secretario: Vicente Gay.

\section{Opositores}

Agustín Viñuales Pardo.

No comparecieron: Francisco Martínez Lumbreras, Máximo Peña, Miguel María Pareja, Joaquín Uguet.

\section{Votación}

Agustín Viñuales Pardo fue votado y propuesto por unanimidad.

\section{Materiales}

De tipo administrativo: actas, oficios del negociado, oficios varios sobre conformación del tribunal. 
De tipo académico o referentes a los ejercicios:

- Cuestionario elaborado por el tribunal (121 temas).

- Escritos del primer ejercicio. Dos temas: "Bancos de Estado. Empresas del Estado"; "Exposición crítica de la Ley de Contabilidad".

- Ejercicio práctico.

- Escrito de libros consultados por el opositor.

- Programas aportados por Agustín Viñuales (economía, 52 lecciones; hacienda pública, 53 lecciones).

- Trabajo doctrinal aportado por Agustín Viñuales: "Ensayo sobre el trade-unionismo en los Estados Unidos de Norte-América”.

\section{Signatura}

AGA 32/07349. Legajo 5364-4.

\section{Cátedra}

Derecho mercantil de España y de las principales naciones de Europa y América.

\section{Universidad}

Barcelona.

\section{Anuncio}

R.O. de 19 de abril, 1917. Gaceta del 30.

\section{Reglamento aplicable}

8 de abril, 1910.

\section{Fechas de la oposición}

Constitución del tribunal: 13 de diciembre, 1917.

Presentación de los opositores: 14 de diciembre, 1917.

Votación y propuesta: 22 de diciembre, 1917.

\section{Tribunal}

Presidente: Luis Palomo Ruiz.

Vocales: Adolfo Bonilla, Rafael Ureña, Lorenzo de Benito.

Secretario: Antonio de la Figuera.

\section{Opositores}

Modesto Talens.

No comparecieron: Enrique R. Ramos, Luis Gestoso, Nicolás Rodríguez. 
Victoriano Nuño, Salvador Salom Antequera, y José Riera se retiraron el día 26 de enero.

\section{Votación}

Se acordó por unanimidad la no provisión de la cátedra.

\section{Materiales}

De tipo administrativo: actas, oficios del negociado, oficios varios sobre conformación del tribunal.

De tipo académico o referentes a los ejercicios:

- Cuestionario elaborado por el tribunal (169 temas).

- Escrito del primer ejercicio. Dos temas: "Incompatibilidades para ejercer el ejercicio de comercio en Derecho español y extranjero"; "De los actos mercantiles".

- Ejercicio práctico.

- Escrito de libros consultados por el opositor.

\section{Signatura}

AGA 32/o7345. Legajo 5362-3.

\section{Cátedra}

Elementos de Derecho natural.

\section{Universidad}

Granada.

\section{Anuncio}

R.O. de 21 de mayo, 1917. Gaceta del 28.

\section{Reglamento aplicable}

8 de abril, 1910.

\section{Fechas de la oposición}

Constitución del tribunal: 14 de marzo, 1918.

Presentación de los opositores: 4 de abril, 1918.

Votación y propuesta: 6 de mayo, 1918.

\section{Tribunal}

Presidente: Antonio Royo Villanova. 
Vocales: Adolfo González Posada, Eduardo Callejo de la Cuesta, Francisco Javier González de Castejón.

Secretario: Álvaro Calvo.

\section{Opositores}

Mariano Puigdollers Oliver.

Eugenio Lorenzo Rodríguez.

Rafael Calatrava Ros.

Juan Mon Pascual.

Jacinto Falens Valero.

Blas Ramos Sobrino.

Pedro de Prada Lagarejos.

José Ramón Pérez Bances.

Francisco Rivera Pastor.

Enrique Izquierdo Jiménez.

No comparecieron otros 18 aspirantes.

\section{Votación}

Primera Votación:

- Rafael Calatrava: un voto (Callejo).

- Blas Ramos: un voto (Castejón).

- Pedro de Prada: un voto (Calvo).

- Francisco Rivera: dos votos (Royo Villanova y González Posada).

Segunda votación:

- Blas Ramos: tres votos (Calvo, Callejo y Castejón).

- Francisco Rivera: dos votos (Royo Villanova y González Posada).

Fue propuesto Blas Ramos.

\section{Materiales}

De tipo administrativo: actas, oficios del negociado, oficios varios sobre conformación del tribunal.

Además:

- Recurso del profesor auxiliar de la Facultad de Derecho de Granada José García Valenzuela de fecha 30 de mayo de 1917 por el que se impugna el anuncio de la oposición y se solicita que se anuncie la cátedra a concurso.

- Protesta del opositor Francisco Rivera de fecha 8 de mayo de 1918.

De tipo académico o referentes a los ejercicios:

- Cuestionario elaborado por el tribunal (134 temas).

- Escritos del primer ejercicio. Dos temas: "El problema de la colisión de derechos"; "Teoría del gobierno". 
- Ejercicios prácticos.

- Escrito de libros consultados por los opositores.

- Programa aportado por Blas Ramos (81 lecciones).

- Trabajo doctrinal aportado por Blas Ramos: "Criterios de valoración jurídica". Se conserva, probablemente por error, el expediente de depuración del maestro José Jiménez Gálvez, resuelto el 19 de diciembre de 1939.

\section{Signatura}

AGA 32/07353. Legajo 5366-2.

\section{Cátedra}

Derecho político español comparado con el extranjero.

\section{Universidad}

Murcia.

\section{Anuncio}

R. O. del 9 de julio de 1917, Gaceta del 17.

\section{Reglamento aplicable}

8 de abril, 1910 .

\section{Fechas de la oposición}

Constitución del tribunal: 7 de enero, 1919.

Presentación de los opositores: 20 de enero, 1919.

Votación y propuesta: 4 de febrero, 1919.

\section{Tribunal}

Presidente: Juan de Armada Losada (Marqués de Figueroa).

Vocales: Adolfo Álvarez Buylla, Adolfo González Posada, Gonzalo del Castillo.

Secretario: Juan Infante.

\section{Opositores}

Nicolás Rodríguez Aniceto.

Recaredo Fernández Velasco.

Vicente Llovera Codorniu.

Los tres fueron declarados aptos para pasar al cuarto ejercicio.

No comparecieron: José María de Prada, Buenaventura Benito, Miguel Cuevas, Enrique Martí, Luis Jordana de Pozas, Juan Ferrer, Mariano Marcial, Rafael Díaz, Ángel Galarza, Enrique Izquierdo, Luis Victoria. 


\section{Votación}

Nicolás Rodríguez: tres votos (del Castillo, Infante y Buylla).

Recaredo Fernández: dos votos (Posada y Figueroa).

Fue propuesto Nicolás Rodríguez.

\section{Materiales}

De tipo administrativo: actas, oficios del negociado, oficios varios sobre conformación del tribunal. Hoja de servicios de Nicolás Rodríguez.

De tipo académico o referentes a los ejercicios:

- Cuestionario elaborado por el tribunal (122 temas).

- Escrito del primer ejercicio. Dos temas: "El principio de las nacionalidades. Estado actual del problema"; "Carácter general de la constitución política de los reinos de León y Castilla".

- Ejercicios prácticos.

- Escritos de libros consultados por los opositores.

- Programa de "Derecho político español comparado" aportado por Nicolás Rodríguez (73 lecciones).

- Trabajo doctrinal aportado por Nicolás Rodríguez: "Notas para un estudio de Maquiavelo y Niestsche".

\section{Signatura}

AGA 32/07351. Legajo 5365-1.

AGA 32/07352. Legajo 5365-2.

\section{Cátedra}

Derecho civil español, común y foral. Dos cátedras.

\section{Universidad}

Murcia.

\section{Anuncio}

R. O. de 9 de julio de 1917, Gaceta del 17.

\section{Reglamento aplicable}

8 de abril, 1910.

\section{Fechas de la oposición}

Constitución del tribunal: 12 de marzo, 1918.

Presentación de los opositores: 22 de febrero, 1918.

Votación y propuesta: 4 de mayo, 1918. 


\section{Tribunal}

Presidente: Luis Maldonado.

Vocales: Felipe Clemente de Diego, Adolfo Bonilla, Fermín Canella.

Secretario: Cirilo Palomo.

\section{Opositores}

Salvador Salom Antequera.

Ramón Casariego Casariego.

Francisco Candil Calvo.

Luis Leante Lapazarán.

Leopoldo García-Alas y García Argüelles.

Mariano Caro del Arroyo.

José Castán Tobeñas.

Mariano Marcial Fernández.

No comparecieron: Manuel González, José Xirau, Nicolás Zorilla, Manuel María Gaitero, Mariano Azcoiti, Victoriano Nuño, Adoración Martínez, Francisco Marco, Vicente de la Serna, Ramón de la Rica. Enrique Ramos y Luis Porteiro con instancia fuera de plazo.

\section{Votación}

José Castán fue votado y propuesto por unanimidad para el primer lugar.

Primera votación para el segundo lugar:

- Salom: dos votos (Palomo y Bonilla).

- Candil: un voto (Maldonado).

- Alas: dos votos (Clemente y Canella).

Segunda votación para el segundo lugar:

- Salom: tres votos (Maldonado, Palomo y Bonilla).

- Alas: dos votos (Clemente y Canella).

Salvador Salom fue propuesto para el segundo lugar.

\section{Materiales}

De tipo administrativo: actas, oficios del negociado, oficios varios sobre conformación del tribunal.

De tipo académico o referentes a los ejercicios:

- Cuestionario elaborado por el tribunal (107 temas).

- Escrito del primer ejercicio. Dos temas: "Tendencias modernas en los estudios de Derecho civil"; "Causas que ponen fin a la tutela y cuestiones que sugieren".

- Ejercicios prácticos.

- Escritos de libros consultados por los opositores.

- Programa aportado por José Castán (199 lecciones). 
- Programa aportado por Salvador Salom (189 lecciones).

- Trabajo doctrinal aportado por Salvador Salom: "Apuntes para la reforma del Código Civil español en lo relativo al derecho agrario”.

- Trabajo doctrinal aportado por Salvador Salom: "Trabajos de Derecho civil".

\section{Signatura}

AGA 32/07346. Legajo 5363-1.

\section{Cátedra}

Instituciones de Derecho canónico.

\section{Universidad}

Murcia.

\section{Anuncio}

R. O. del 9 de julio de 1917, Gaceta del 17.

\section{Reglamento aplicable}

8 de abril, 1910.

\section{Fechas de la oposición}

Constitución del tribunal: 24 de enero, 1918.

Presentación de los opositores: 13 de febrero, 1918.

Votación y propuesta: 16 de marzo, 1918.

\section{Tribunal}

Presidente: Prudencio Melo Alcalde, obispo de Madrid-Alcalá.

Vocales: Salvador Torres Aguilar, Rafael de Ureña, Javier Vales Jailde.

Secretario: Francisco Gómez del Campillo.

\section{Opositores}

Juan Carreras Arañón.

Miguel Sancho Izquierdo.

Eugenio Lorenzo Izquierdo.

Jesús Romero García.

Miguel de la Villa García.

José Bernal Montero.

Baltasar Cardoner y Vidal.

José Pou de Foxá. 
José Escobedo González Alberú.

No comparecieron: Nicolás de Otto, Buenaventura Benito, Eloy Montero, Rafael Aguado, Enrique Izquierdo.

\section{Votación}

Primera Votación:

- Miguel Sancho: un voto (Ureña).

- Baltasar Cardoner: un voto (Gómez del Campillo).

- Miguel de la Villa: un voto (Vales).

- José Pou: dos votos (Torres Aguilar y Obispo de Madrid-Alcalá).

La segunda votación fue ganada por unanimidad por José Pou. Fue propuesto.

\section{Materiales}

De tipo administrativo: actas, oficios del negociado, oficios varios sobre conformación del tribunal.

De tipo académico o referentes a los ejercicios:

- Cuestionario elaborado por el tribunal (199 temas).

- Escritos del primer ejercicio. Dos temas: "De la codificación canónica”; "Forma del matrimonio canónico".

- Ejercicios prácticos.

- Escrito de libros consultados por los opositores.

- Programa aportado por José Pou (68 lecciones).

- Trabajo doctrinal aportado por José Pou: "El pase regio".

- Trabajo doctrinal aportado por José Pou: “Los españoles y el Derecho canónico".

- Trabajo doctrinal sin título aportado por José Pou fechado en mayo de 1913.

\section{Signatura}

AGA 32/07357. Legajo 5368-2.

\section{Cátedra}

Historia general del Derecho español.

\section{Universidad}

Murcia.

\section{Anuncio}

R. O. del 9 de julio de 1917, Gaceta del 17.

El tribunal fue nombrado por R.O. de 31 de enero de 1919. Gaceta del 11 de febrero. 


\section{Reglamento aplicable}

8 de abril, 1910.

\section{Fechas de la oposición}

Constitución del tribunal: 12 de abril, 1919.

Presentación de los opositores: 24 de abril, 1919.

Votación y propuesta: 4 de mayo, 1919.

\section{Tribunal}

Presidente: Carlos Groizard.

Vocales: Laureano Díez Canseco, Salvador Salom Antequera, Juan Salvador Minguijón.

Secretario: Rafael Acosta.

\section{Opositores}

Alejandro Gallart Folch.

Ramón Prieto Bances.

Galo Sánchez Sánchez.

No comparecieron: Luis Pidal, Melchor Fernández, Adoración Martínez, Pío Blanco, José María Ots, Rafael Díaz, Enrique Izquierdo, Enrique Ramos, Luis Porteiro, José Navarro, Vicente Guilarte, Manuel Melgarejo, Rafael Pou.

\section{Votación}

Galo Sánchez fue votado y propuesto por unanimidad.

\section{Materiales}

De tipo administrativo: actas, oficios del negociado, oficios varios sobre conformación del tribunal.

De tipo académico o referentes a los ejercicios:

- Cuestionario elaborado por el tribunal (114 temas).

- Escritos del primer ejercicio. Dos temas: "Sistemas de fuentes del derecho catalán; "El derecho penal de la España de la Reconquista".

- Ejercicios prácticos (tercer ejercicio).

- Escrito de libros solicitados por los opositores.

- Programa aportado por Galo Sánchez (73 lecciones).

- Obra aportada por Galo Sánchez: Fueros Castellanos de Soria y Alcalá de Henares, Centro de Estudios Históricos, Junta para la Ampliación de Estudios e Investigaciones históricas, Madrid, 1919. 


\section{Signatura}

AGA 32/o7357. Legajo 5368-3.

\section{Cátedra}

Derecho administrativo.

\section{Universidad}

Murcia.

\section{Anuncio}

R. O. del 13 de abril de 1918, Gaceta del 23.

\section{Reglamento aplicable}

8 de abril, 1910.

\section{Fechas de la oposición}

Constitución del tribunal: 10 de marzo, 1919.

Presentación de los opositores: 24 de marzo, 1919.

Votación y propuesta: 14 de abril, 1919.

\section{Tribunal}

Presidente: Antonio Royo Villanova.

Vocales: Luis Jordana de Pozas, José Gascón Marín, Gregorio de Pereda Ugarte.

Secretario: Enrique Martí Jara.

\section{Opositores}

Recaredo Fernández de Velasco.

Álvaro Olea Pimentel.

Joaquín Uguet Soriano.

Nicolás Zorrilla Vicario.

No comparecieron: Luis Gestoso, José Gallo, José Valenzuela, Nicolás rodríguez Aniceto, José María Vidal, Francisco Jufrera, Francisco Martínez Lumbreras, Marcelo Pascual.

\section{Votación}

La primera votación dio el siguiente resultado:

- Recaredo Fernández: dos votos (Martí y Gascón).

- Álvaro Olea: un voto (Royo).

- Joaquín Uguet: dos votos (Jordana y Pereda).

La segunda votación dio el siguiente resultado: 
- Recaredo Fernández: dos votos (Royo, Martí y Gascón).

- Joaquín Uguet: dos votos (Jordana y Pereda).

Recaredo Fernández fue propuesto.

\section{Materiales}

De tipo administrativo: actas, oficios del negociado, oficios varios sobre conformación del tribunal.

De tipo académico o referentes a los ejercicios:

- Cuestionario elaborado por el tribunal (123 temas).

- Escritos del primer ejercicio. Dos temas: "La costumbre en el Derecho administrativo. Los principios generales del derecho", "El concepto doctrinal de la policía”.

- Ejercicios prácticos (tercer ejercicio).

- Escrito de libros solicitados por los opositores.

- Programa aportado por Recaredo Fernández (77 lecciones).

Obras aportadas por Recaredo Fernández:

- El Estatuto de los funcionarios. Principios generales. Legislación extranjera. Legislación española, Prólogo de Antonio Royo Villanova, Sociedad Española de Librería, Madrid, 1916.

- El derecho de revolución y la revolución conforme a derecho, Tesis de doctorado, Establecimiento tipográfico de A. Marzo, Madrid, 1915.

- Teoría jurídica de las concesiones administrativas, Imprenta Ibérica, Madrid, 1918. Publicado en la Revista de Derecho privado.

- La acción popular en el Derecho administrativo. El autor indica en una nota adjunta que su publicación comenzará próximamente en la Revista de Legislación y Jurisprudencia.

\section{Signatura}

AGA 32/o7353. Legajo 5366-3.

\section{Cátedra}

Derecho mercantil de España y de las principales naciones de Europa y América.

\section{Universidad}

Murcia.

\section{Anuncio}

R.O. de 16 de abril, 1918. Gaceta del 23. 


\section{Reglamento aplicable}

8 de abril, 1910.

\section{Fechas de la oposición}

Constitución del tribunal: 9 de enero, 1920.

Presentación de los opositores: 21 de enero, 1920.

Votación y propuesta: 31 de enero, 1920.

\section{Tribunal}

Presidente: Luis Maldonado.

Vocales: Lorenzo de Benito Endara, Prudencio Requejo, Antonio Díaz Domínguez.

Secretario: José María González Echevarri.

\section{Opositores}

Victoriano Nuño Beato.

Álvaro Calvo Alfageme.

Ricardo Mur Sancho.

Pasaron al cuarto ejercicio Nuño y Mur.

No comparecieron: Emilio Miñana, Hipólito González, Luis Gestoso, Adoración Martínez, Ramón de la Rica, José María Pi, José María Colas, José María Gadea, Luis Soler, José María Boix, Enrique Ramos, Luis Lumos.

\section{Votación}

Ricardo Mur fue votado y propuesto por unanimidad.

\section{Materiales}

De tipo administrativo: actas, oficios del negociado, oficios varios sobre conformación del tribunal.

De tipo académico o referentes a los ejercicios:

- Cuestionario elaborado por el tribunal (122 temas).

- Escritos del primer ejercicio. Dos temas: "Inscripción de documentos mercantiles en el Registro Civil"; "Concepto de transporte marítimo".

- Ejercicios prácticos.

- Escritos de libros consultados por los opositores.

- Programa aportado por Ricardo Mur (70 lecciones).

- Trabajo doctrinal aportado por Ricardo Mur: "De las cláusulas de no responsabilidad en los conocimientos". 


\section{Signatura}

AGA 32/o7358. Legajo 5368-4.

\section{Cátedra}

Elementos de Derecho natural.

\section{Universidad}

Murcia.

\section{Anuncio}

R.O. de 16 de abril, 1918. Gaceta del 29.

\section{Reglamento aplicable}

8 de abril, 1910 .

\section{Fechas de la oposición}

Constitución del tribunal: 10 de abril, 1919.

Presentación de los opositores: 21 de abril, 1919.

Votación y propuesta: 12 de mayo, 1919.

\section{Tribunal}

Presidente: Eduardo Sanz y Escartín (Conde de Lizarraga).

Vocales: Nicasio Sánchez Mata, Fernando Pérez Bueno, Luis Mendizábal Martín.

Secretario: Blas Ramos Sobrino.

\section{Opositores}

Mariano Puigdollers Oliver.

Juan Carreras Arañó.

José María Aparixi Rodríguez.

José Ramón Pérez Bances.

No comparecieron: José María Izquierdo, Álvaro Calvo, Miguel Sancho, Miguel Pareja, Francisco Sanz, Buenaventura Benito, Joaquín Huguet, Manuel Rey, Antonio Guillén, Diego Hernández, Ricardo Mur, Enrique Izquierdo, Julián Carlón.

\section{Votación}

Primera votación:

- Mariano Puigdollers Oliver: un voto (Sánchez Mata).

- Juan Carreras y Arañó: dos votos (Pérez Bueno, Mendizábal).

- José Ramón Pérez Bances: dos votos (Ramos y Sanz).

Segunda votación: 
- Juan Carreras y Arañó: tres votos (Mendizábal, Pérez Bueno y Sánchez Mata).

- José Ramón Pérez Bances: dos votos (Ramos y Sanz).

Juan Carreras fue propuesto.

\section{Materiales}

De tipo administrativo: actas, oficios del negociado, oficios varios sobre conformación del tribunal.

De tipo académico o referentes a los ejercicios:

- Cuestionario elaborado por el tribunal (138 temas).

- Escritos del primer ejercicio. Dos temas: "La relación de Derecho. ¿Es el Derecho una relación bilateral?; "Concepto filosófico de la Naturaleza y su relación con el problema del Derecho Natural”.

- Ejercicios prácticos (tercer ejercicio).

- Escrito de libros solicitados por los opositores.

- Programa aportado por Juan Carreras (72 lecciones).

- Trabajo doctrinal aportado por Juan Carreras: Influencia del cristianismo en la legislación penal.

- Trabajo doctrinal aportado por Juan Carreras: Filosofía de la ley. Análisis crítico de la doctrina de Santo Tomás de Aquino.

\section{Signatura}

AGA 32/07357. Legajo 5368-1.

\section{Cátedra}

Derecho penal.

\section{Universidad}

Murcia.

\section{Anuncio}

R. O. del 16 de abril de 1918, Gaceta del 23.

\section{Reglamento aplicable}

8 de abril, 1910.

\section{Fechas de la oposición}

Constitución del tribunal: 7 de abril, 1919.

Reconstitución del tribunal: 16 de abril, 1919.

Presentación de los opositores: 3 de mayo, 1919.

Votación y propuesta: 21 de mayo, 1919. 


\section{Tribunal}

Presidente: Pascual Testor (en sustitución del fallecido Ismael Calvo).

Vocales: Federico Castejón, Eugenio Cuello, Enrique de Benito.

Secretario: Luis Jiménez de Asúa.

\section{Opositores}

Mariano Ruiz-Funes García.

Emilio Langle Rubio.

Isaías Sánchez Sánchez Tejerina.

Álvaro Gallar Najar.

No comparecieron: Enrique Zarandieta, Nicolás Rodríguez Aniceto, Máximo Peña, Ricardo Mur, Buenaventura Benito.

\section{Votación}

Primera votación:

- Mariano Ruiz-Funes García: dos votos (Testor y Cuello Calón).

- Emilio Langle: un voto (Castejón).

- Isaías Sánchez: dos votos (Asúa y de Benito).

En la segunda votación Mariano Ruiz-Funes obtuvo todos los votos. Fue propuesto.

\section{Materiales}

De tipo administrativo: actas, oficios del negociado, oficios varios sobre conformación del tribunal.

De tipo académico o referentes a los ejercicios:

- Cuestionario elaborado por el tribunal (137 temas).

- Escritos del primer ejercicio. Dos temas: "El delito. Nociones jurídicas. Nociones sociológicas; "El trabajo penitenciario".

- Ejercicios prácticos (tercer ejercicio).

- Escrito de libros solicitados por los opositores.

- Programa aportado por Mariano Ruiz-Funes (70 lecciones).

- Trabajo doctrinal aportado por Mariano Ruiz-Funes: El problema de la responsabilidad criminal de las personas jurídicas.

- Obra aportada por Mariano Ruiz-Funes: Derecho consuetudinario y economía popular en la provincia de Murcia, Memoria premiada por la Real Academia de Ciencias Morales y Políticas en 1914; Establecimiento tipográfico de Jaime Ratés, Madrid, 1916. 


\section{Signatura}

AGA 32/o7353. Legajo 5366-5.

\section{Cátedra}

Derecho internacional público y privado.

\section{Universidad}

Murcia.

\section{Anuncio}

R. O. del 16 de abril de 1918, Gaceta del 23.

\section{Reglamento aplicable}

8 de abril, 1910.

\section{Fechas de la oposición}

Constitución del tribunal: 14 de noviembre, 1919.

Presentación de los opositores: 24 de noviembre, 1919.

Votación y propuesta: 12 de diciembre, 1919.

\section{Tribunal}

Presidente: Rafael Conde Luque.

Vocales: Aniceto Sela Sampil, Adolfo Moris Fernández Vallín, José María Trías de Bes.

Secretario: José María Yanguas Messía.

\section{Opositores}

Camilo Barcia Trelles.

José Ramón Orue Arregui.

Los dos pasaron al cuarto ejercicio por unanimidad.

No comparecieron: Luis Gestoso, Adoración Martínez, Emilio Langle, Nicolás Rodríguez Aniceto, José Villalonga, Alejandro Gallart, Rafael Hitos.

\section{Votación}

Camilo Barcia y Trelles: tres votos (Yanguas, Sela y Moris).

José Ramón Orue y Arregui: dos votos (Trías, Conde).

Fue propuesto Camilo Barcia Trelles.

\section{Materiales}

Actas, que incluyen los siguientes documentos: 
- Cuestionario elaborado por el tribunal (145 temas).

- Escrito del primer ejercicio. Dos temas: "Las grandes uniones administrativas internacionales"; "Desarrollo histórico de la ciencia del Derecho Internacional privado".

- Ejercicios prácticos.

- Escritos de libros consultados por los opositores.

- Consta el programa aportado por Camilo Barcia Trelles (107 lecciones).

No se conservan documentos de tipo administrativo.

\section{Signatura}

AGA 32/07359. Legajo 5369-5.

\section{Cátedra}

Derecho mercantil de España y de las principales naciones de Europa y América.

\section{Universidad}

Murcia.

\section{Anuncio}

R. O. del 16 de abril de 1818, Gaceta del 23.

\section{Reglamento aplicable}

8 de abril, 1910.

\section{Fechas de la oposición}

Constitución del tribunal: 28 de noviembre, 1921.

Presentación de los opositores: 2 de diciembre, 1921.

Votación: 14 de diciembre, 1921.

\section{Tribunal}

Presidente: Francisco Manzano y Alfaro.

Vocales: Lorenzo de Benito, José María González de Echávarri, Ricardo Mur.

Secretario: Francisco Candil.

\section{Opositores}

Salvador Martínez-Moya y Crespo.

Álvaro Calvo Alfageme.

Victoriano Nuño.

No comparecieron: Enrique Ramos Ramos. 


\section{Votación}

Se acordó por mayoría que ninguno de los opositores pasase al cuarto ejercicio. Votaron en contra de este acuerdo Echávarri y Manzano.

\section{Materiales}

De tipo administrativo: actas, oficio de elevación al Ministerio de I.P. del expediente.

De tipo académico o referentes a los ejercicios:

- Cuestionario elaborado por el tribunal (162 temas).

- Escritos del primer ejercicio. Dos temas: "España en la edad contemporánea.

Precedentes, formación y crítica del Código de 1829"; "Del contrato de seguro sobre la vida".

- Ejercicios prácticos (tercer ejercicio).

\section{Signatura}

AGA 32/o7353. Legajo 5366-4.

\section{Cátedra}

Derecho político español comparado con el extranjero.

\section{Universidad}

Santiago.

\section{Anuncio}

R. O. del 21 de agoto de 1919, Gaceta del 22.

\section{Reglamento aplicable}

8 de abril, 1910.

\section{Fechas de la oposición}

Constitución del tribunal: 23 de febrero, 1920.

Presentación de los opositores: 26 de febrero, 1920.

Votación y propuesta: 20 de marzo, 1920.

\section{Tribunal}

Presidente: Adolfo González Posada.

Vocales: Luis de Valle Pascual, Mariano Gómez González, Gonzalo del Castillo.

Secretario: Nicolás Rodríguez Aniceto. 


\section{Opositores}

Francisco Martínez Lumbreras.

Joaquín Uguet Soriano.

Álvaro Olea Pimentel.

Los tres opositores pasaron al cuarto ejercicio.

\section{Votación}

Primera votación:

- Francisco Martínez: un voto (Aniceto).

- Joaquín Uguet: un voto (Gómez).

- Álvaro Olea: un voto (del Castillo).

Posada y Valle Pascual votaron por la no provisión.

La segunda votación dio idéntico resultado.

Se declaró la oposición desierta.

\section{Materiales}

Actas, que incluyen los siguientes documentos:

- Cuestionario elaborado por el tribunal (116 temas).

- Escrito del primer ejercicio. Dos temas: "Sistemas de representación de minorías en general"; "El régimen parlamentario y el presidencial".

- Ejercicios prácticos: "Recursos contra la inconstitucionalidad de las leyes en Derecho comparado".

- Escritos de libros consultados por los opositores.

Los únicos documentos de tipo administrativo que se conservan son:

- Renuncia al cargo de vocal de Arsenio Misol, de 13 de noviembre, 1919.

- Nota de remisión de las instancias de los opositores, de 27 de enero, 1920.

Por último, consta una carta mecanografiada del opositor Álvaro Olea dirigida al presidente Adolfo González Posada, de 14 de enero, 1919.

\section{Signatura}

AGA 32/07354. Legajo 5366-7.

\section{Cátedra}

Economía política.

\section{Universidad}

Central.

\section{Anuncio}

R. O. del 21 de agosto de 1919, Gaceta del 22. 


\section{Reglamento aplicable}

8 de abril, 1910.

\section{Fechas de la oposición}

Constitución del tribunal: 12 de enero, 1920.

Presentación de los opositores: 21 de enero, 1920.

Votación y propuesta: 4 de febrero, 1920.

\section{Tribunal}

Presidente: Eduardo Sanz y Escartín (Conde de Lizarraga).

Vocales: Amando Ricardo Castroviejo Nobajas, Vicente Gay Forner, Ramón Carande Thobar.

Secretario: Agustín Viñuales Pardo.

\section{Opositores}

Antonio Flores de Lemus.

José María Zumalacárregui.

No comparecieron: Jaime Algarra, Francisco Bernis, Francisco Marcos.

\section{Votación}

Antonio Flores de Lemus fue votado y propuesto por unanimidad.

\section{Materiales}

De tipo administrativo: actas, oficios del negociado, oficios varios sobre conformación del tribunal.

De tipo académico o referentes a los ejercicios:

- Cuestionario elaborado por el tribunal (168 temas).

- Escrito del primer ejercicio. Dos temas: "Teorías del dinero III. La teoría de la cantidad"; “Teorías del dinero VII: Enumeración de las principales propuestas para estabilizar el nivel de los precios".

- Ejercicios prácticos.

- Escritos de libros consultados por los opositores.

- Programa aportado por José María Zumalacárregui (105 lecciones).

- "Programa de un curso de Economía política " aportado por Antonio Flores (51 lecciones).

- Trabajo doctrinal aportado por José María Zumalacárregui: “Ensayo de una posición personal dentro de algunas escuelas económicas".

- Obra aportada por Antonio Flores: "La reforma arancelaria. Consideraciones y materiales. Volumen I, Alemania”, Imprenta de Antonio Marzo, Madrid, 1905. 


\section{Signatura}

AGA 32/07355. Legajo 5367-2.

\section{Cátedra}

Procedimientos judiciales y práctica forense.

\section{Universidad}

Santiago.

\section{Anuncio}

R. O. del 21 de agosto de 1919, Gaceta del 22.

\section{Reglamento aplicable}

8 de abril, 1910 .

\section{Fechas de la oposición}

Constitución del tribunal: 15 de febrero, 1921.

Presentación de los opositores: 26 de febrero, 1921.

Votación y propuesta: 12 de marzo, 1921.

\section{Tribunal}

Presidente: Natalio Rivas.

Vocales: Gabriel Bonilla, José María Gadea, Magín Fábrega.

Secretario: Francisco Marcos Pelayo.

\section{Opositores}

Juan Ferrer Galdiano.

Luis Navarro Canales.

Francisco Beceña González.

Matías Domínguez Ballarín.

No comparecieron: Ricardo Mur, Manuel José Fal y Conde, Joaquín Uguet, Adoración Martínez, José Casais, Servando Ucana y Núñez.

\section{Votación}

- Francisco Beceña González: dos votos (Bonilla y Rivas).

- Matías Domínguez Ballarín: tres votos (Fábrega, Gadea y Marcos).

Matías Domínguez fue propuesto. 


\section{Materiales}

De tipo administrativo: actas, oficios del negociado, oficios varios sobre conformación del tribunal.

De tipo académico o referentes a los ejercicios:

- Cuestionario elaborado por el tribunal (168 temas).

- Escrito del primer ejercicio. Dos temas: "Ingreso y ascenso en la carrera judicial"; "Sistemas procesales".

- Ejercicios prácticos.

- Escritos de libros consultados por los opositores.

- Programa aportado por Domínguez Ballarín (108 lecciones).

- Trabajo doctrinal aportado por Domínguez Ballarín: "Extensión que, en el enjuiciamiento civil moderno, debe tener en el arbitrio judicial. Antecedentes histórico-positivos de la cuestión en Derecho procesal español y opinión sobre ella".

\section{Signatura}

AGA 32/07358. Legajo 5368-5.

\section{Cátedra}

Historia general del Derecho español.

\section{Universidad}

Barcelona y Salamanca.

\section{Anuncio}

R. O. del 21 de agosto de 1919, Gaceta del 22.

\section{Reglamento aplicable}

8 de abril, 1910.

\section{Fechas de la oposición}

Constitución del tribunal: 4 de abril, 1921.

Presentación de los opositores: 30 de abril, 1921.

Votación: 21 de mayo, 1921.

Propuesta: 22 de mayo, 1921.

\section{Tribunal}

Presidente: Eloy Bullón Fernández.

Vocales: Laureano Díez Canseco, Francisco de Casso, José Rivero de Aguilar.

Secretario: Rafael Acosta. 


\section{Opositores}

José Manuel Segura Soriano.

Ramon Coll Rodes.

Galo Sánchez Sánchez.

Alejandro Gallart Folch.

José García Revillo.

José María Ots Capdequi.

No comparecieron: Demófilo de Buen Lozano, Juan Antonio Llorente García, Nicolás Rodríguez Aniceto, Rodrigo Fernández y García de la Villa, Máximo Peña Mantecón, Ramón Prieto y Bances.

\section{Votación}

Votación del primer lugar:

- Ramon Coll: dos votos (Rivero y Bullón).

- José María Ots: tres votos (Acosta, Casso, Canseco).

En la votación del segundo lugar fue elegido por unanimidad José Manuel Segura.

José María Ots optó por la cátedra de Barcelona y José Manuel Segura aceptó la de Salamanca.

\section{Materiales}

De tipo administrativo: actas, oficios del negociado.

De tipo académico o referentes a los ejercicios:

- Cuestionario elaborado por el tribunal (136 temas).

- Escritos del primer ejercicio. Dos temas: "Fuentes para el estudio de la historia del derecho; "El servicio militar durante la Reconquista".

- Ejercicios prácticos (tercer ejercicio).

- Escrito de libros solicitados por los opositores.

- Programa aportado por José Manuel Segura (52 lecciones).

- Programa aportado por José María Ots (101 lecciones).

- Obra aportada por José María Ots: D. Manuel Josef de Ayala y la historia de nuestra legislación de Indias. I. Valor de la recopilación de 1680. Reprinted from the Hispanic American Historical Review, vol.III, No. 3, August, 1920.

- Trabajo doctrinal aportado por José Manuel Segura: El fuero de Baza. 


\section{Signatura}

AGA 32/o7354. Legajo 5366-6.

\section{Cátedra}

Derecho internacional público y privado.

\section{Universidad}

Central.

\section{Anuncio}

R. O. del 21 de agosto de 1919, Gaceta del 22.

\section{Reglamento aplicable}

8 de abril, 1910.

\section{Fechas de la oposición}

Constitución del tribunal: 19 de febrero, 1920.

Presentación de los opositores: 4 de marzo, 1920.

Votación y propuesta: 13 de mayo, 1920.

\section{Tribunal}

Presidente: César Silio Cortés.

Vocales: Gonzalo Fernández de Córdoba, Luis Gestoso Acosta, Salvador Cabeza de León.

Secretario: Manuel de Lasala Llanas.

\section{Opositores}

Tomás Elorrieta Artaza.

José María de Yanguas Messía.

No comparecieron: Camilo Barcia y Trelles, Luis Gestoso, Nicolás Rodríguez Aniceto, Isidro Beato, Demófilo de Buen, Francisco Marcos, Enrique Martí, José María Trías.

\section{Votación}

José María de Yanguas Messía fue votado y propuesto por unanimidad.

\section{Materiales}

De tipo administrativo: actas, oficios del negociado, oficios varios sobre conformación del tribunal.

De tipo académico o referentes a los ejercicios: 
- Cuestionario elaborado por el tribunal (168 temas).

- Escrito del primer ejercicio. Dos temas: "Concepto de la sociedad internacional”; "A partir de qué momento producirá sus efectos el ejercicio de la opción que autorizan los artículos 18 y 19 del Código Civil”.

- Ejercicios prácticos.

- Escritos de libros consultados por los opositores.

Materiales de Yanguas:

- Programas: Derecho Internacional Público (50 lecciones) y Derecho Internacional Privado (5o lecciones).

- Trabajo doctrinal: "El divorcio en el derecho internacional privado".

- "Apuntes de Derecho Internacional Público", recogidos de las explicaciones del

Dr. Yanguas Messía, Curso de 1918 a 1919, Universidad Literaria de Valladolid, 1919.

- "Apuntes de Derecho Internacional Privado", recogidos de las explicaciones del Dr. Yanguas Messía, Curso de 1918 a 1919, Universidad Literaria de Valladolid, 1919.

- "España y la Sociedad de Naciones", Conferencia de extensión universitaria pronunciada el sábado 15 de febrero de 1919, Universidad de Valladolid, 1919.

- "La expansión colonial en África y el Estatuto Internacional de Marruecos, Imprenta Alianza Tipográfica, Madrid, 1915.

\section{Signatura}

AGA 32/07356. Legajo 5367-5.

\section{Cátedra}

Elementos de Derecho natural.

\section{Universidad}

Zaragoza y Santiago.

\section{Anuncio}

Gaceta del 21 de agosto de 1919.

\section{Reglamento aplicable}

8 de abril, 1910.

\section{Fechas de la oposición}

Constitución del tribunal: 24 de febrero, 1920.

Presentación de los opositores: 6 de marzo, 1920. 
Votación: 6 de mayo, 1920.

Propuesta: 7 de mayo, 1920.

\section{Tribunal}

Presidente: Luis Maldonado.

Vocales: Nicasio Sánchez Mata, Blas Ramos Sobrino, Luis Mendizábal.

Secretario: Juan Carreras.

\section{Opositores}

Mariano Puigdollers Oliver.

Buenaventura Benito.

Eloy Montero.

Rafael Calatrava.

Miguel Sancho Izquierdo.

José María Aparici Rodríguez.

Manuel Marina Merlín.

Arturo Suárez Malfeito.

José Mingorro San Martín.

José Crespo Salazar.

Julián Gastón Hurtado.

José Pérez Bancés.

Wenceslao González Oliveros.

Cristóbal Cavallero Rubio.

\section{Votación}

Primera votación del número primero:

- Miguel Sancho Izquierdo: un voto (Mendizábal).

- José Crespo Salazar: un voto (Maldonado).

- José Pérez Bancés: un voto (Ramos).

- Mariano Puigdollers: un voto (Carreras).

- Wenceslao González Oliveros: un voto (Sánchez Mata).

Segunda votación del número primero:

- Miguel Sancho Izquierdo: tres votos (Carreras, Sánchez Mata y Mendizábal).

- José Pérez Bancés: dos votos (Ramos y Maldonado).

Primera votación del número segundo:

- Mariano Puigdollers: un voto (Mendizábal).

- Eloy Montero: un voto (Sánchez Mata).

- Manuel Marina: un voto (Maldonado).

- José Pérez Bancés: un voto (Ramos).

- Rafael Calatrava: un voto (Carreras). 
Segunda votación del número segundo:

- Mariano Puigdollers: tres votos (Carreras, Sánchez Mata y Mendizábal).

- Wenceslao González Oliveros: dos votos (Ramos y Maldonado).

Miguel Sancho Izquierdo optó por la cátedra de Zaragoza y Mariano Puigdollers aceptó la de Santiago. Fueron propuestos.

\section{Materiales}

De tipo administrativo: actas, oficios del negociado, oficios varios sobre conformación del tribunal.

De tipo académico o referentes a los ejercicios:

- Cuestionario elaborado por el tribunal (125 temas).

- Escritos del primer ejercicio. Dos temas: "El Renacimiento. La reforma religiosa. Influencia en la Filosofía del Derecho"; "Los derechos de igualdad y de independencia. Concepto de los mismos y sus limitaciones".

- Ejercicios prácticos (tercer ejercicio).

- Escrito de libros solicitados por los opositores.

Materiales Miguel Sancho:

- Programa (95 lecciones).

- Trabajo doctrinal: Los derechos inatos [sic] al hombre conforme al Derecho Natural.

- Trabajo doctrinal: La función del derecho natural en la reforma del arrendamiento de fincas rústicas.

- Trabajo doctrinal: Investigación de un concepto racional del derecho.

Materiales Mariano Puigdollers:

- Programa aportado (69 lecciones).

- Trabajo doctrinal: La justicia.

- Trabajo doctrinal: La filosofía del derecho de Victor Cathrein. Tesis doctoral, curso 1918-19.

\section{Signatura}

AGA 32/o7356. Legajo 5367-4.

\section{Cátedra}

Derecho civil español, común y foral.

\section{Universidad}

Zaragoza, Murcia y Oviedo.

\section{Anuncio}

Para Zaragoza por R.O. de 21 de agosto de 1919 (Gaceta del 22). 
Las cátedras de Murcia y Oviedo fueron agregadas por R.O. de 24 de diciembre de 1919 (Gaceta del 28).

\section{Reglamento aplicable}

8 de abril, 1910 .

\section{Fechas de la oposición}

Constitución del tribunal: 8 de abril, 1920.

Presentación de los opositores: 12 de abril, 1920.

Votación y propuesta: 14 de mayo, 1920.

\section{Tribunal}

Presidente: Manuel Gullón García Prieto.

Vocales: Cleto Troncoso, Gregorio Burón, José Castán.

Secretario: Salvador Salom Antequera.

\section{Opositores}

Esteban Madruga Jiménez.

Francisco Candil Calvo.

Leopoldo García Alas García Argüelles.

No comparecieron: Ramón Casariego, Enrique Ramos.

\section{Votación}

Primera votación del número primero:

- Francisco Candil: dos votos (Castán y Troncoso).

- Leopoldo García Alas: dos votos (Salom y Gullón).

- Burón votó por la no provisión.

Segunda votación del número primero:

- Francisco Candil: un voto (Troncoso).

- Leopoldo García Alas: tres votos (Castán, Salom y Gullón).

- Burón votó por la no provisión.

Votación del número segundo:

- Francisco Candil obtuvo todos los votos menos el de Burón, quien votó por la no provisión.

Votación del número tercero:

Todos votaron por la no provisión menos Burón, quien votó a Madruga.

Leopoldo García Alas optó por la cátedra de Oviedo y Francisco Candil por la de Murcia. La provisión de la de Zaragoza fue declarada desierta. 


\section{Materiales}

De tipo administrativo: actas, oficios del negociado, oficios varios sobre conformación del tribunal. Ejemplar de la Gaceta de 18 de julio de 1919.

De tipo académico o referentes a los ejercicios:

- Cuestionario elaborado por el tribunal (179 temas).

- Escritos del primer ejercicio. Dos temas: "Compraventa. Sistemas bajo los cuales ha sido organizada; "Teoría del riesgo profesional en relación con la ley de accidentes de trabajo".

- Ejercicios prácticos (tercer ejercicio).

- Escrito de libros solicitados por los opositores.

Programas de los opositores:

- Por Francisco Candil (primer curso:65 lecciones; segundo curso: 134).

- Por Leopoldo García Alas (primer curso: 48 lecciones; segundo curso: 78 lecciones).

Trabajos doctrinales de los opositores:

- Por Francisco Candil: Algunas notas, sobre las conferencias del Profesor Rodolfo Stammler, en la Universidad de Halle-Wittenberg, sobre "Práctica de ética y Filosofía del Derecho".

- Por Leopoldo García Alas: Sobre la distinción entre bienes en muebles e inmuebles.

\section{Signatura}

AGA 32/07355. Legajo 5367-3.

\section{Cátedra}

Derecho mercantil de España y de las principales naciones de Europa y América.

\section{Universidad}

Barcelona.

\section{Anuncio}

Gaceta del 22 de agosto, 1919.

El tribunal fue nombrado por R.O. de 4 de noviembre de 1919.

\section{Reglamento aplicable}

8 de abril, 1910.

\section{Fechas de la oposición}

Constitución del tribunal: 10 de enero, 1920. 
Presentación de los opositores: 22 de enero, 1920.

Votación y propuesta: 11 de febrero, 1920.

\section{Tribunal}

Presidente: Francisco Manzano.

Vocales: Antonio de la Figuera, Prudencio Requejo, Lorenzo de Benito Endara.

Secretario: Antonio Díaz Domínguez.

\section{Opositores}

Victoriano Nuño Arín.

José Xirau Palou.

Álvaro Calvo Alfagem.

Mario Ruiz Batán.

Jesús Firmat.

José María Boix Raspall.

Ricardo Mur Sancho.

Manuel Carrasco Formiguera.

No comparecieron: José Casais, Nicolás Santos, José Forns, José Gadea, Antonio Nin, Adoración Martínez, Hipólito González.

\section{Votación}

- José María Boix Raspall: tres votos (Díaz, de la Figuera y Benito).

- Manuel Carrasco Formiguera: un voto (Manzano).

- Requejo votó en blanco.

Fue propuesto José María Boix Raspall.

\section{Materiales}

De tipo administrativo: actas, oficios del negociado, oficios varios sobre conformación del tribunal.

De tipo académico o referentes a los ejercicios:

- Cuestionario elaborado por el tribunal (157 temas).

- Escrito del primer ejercicio. Dos temas: "Compañías colectivas"; "Las instituciones y el Derecho mercantil en los antiguos imperios asiáticos".

- Ejercicios prácticos.

- Escritos de libros consultados por los opositores.

- Programa aportado por José María Boix Raspall (7o lecciones).

- Trabajo doctrinal aportado por José María Boix Raspall: "La publicidad comercial y el Registro Mercantil". 


\section{Signatura}

AGA 32/07360. Legajo 5369-8.

\section{Cátedra}

Instituciones de Derecho canónico.

\section{Universidad}

Oviedo y Sevilla.

\section{Anuncio}

R. O. del 21 de agosto de 1919, Gaceta del 22, anuncia la oposición de la cátedra de Oviedo. Para Sevilla por R. O. del 30 de diciembre de 1919, Gaceta del 22 de enero.

\section{Reglamento aplicable}

Reglamento de 8 de abril de 1910.

\section{Fechas de la oposición}

1921, 3 de noviembre: constitución del tribunal.

1921, 16 de noviembre: presentación de los opositores.

1921, 3 de diciembre: votación.

1921, 4 de diciembre, propuesta.

\section{Tribunal}

Presidente: Sr. Obispo de Madrid, Prudencio Melo. Consejero de Instrucción Pública.

Vocales: D. Juan Moneva Puyol, D. Francisco Cueva Palacio, Isidoro Iglesia y García.

Secretario: Monsén José Pou y de Foxa.

\section{Opositores}

José Bernal y Montero.

José Escobedo y González Alberú.

Armando Álvarez Rodríguez.

Nicolás Santos de Otto y Escudero.

Eloy Montero y Gutiérrez, Pbro.

\section{Votación y propuesta}

Todos los jueces votan en primer lugar a D. Eloy Montero Gutiérrez.

Para la segunda plaza D. José Pou Foxa vota a D. Nicolás Otto Escudero, D. Isi- 
doro Iglesia vota a D. Nicolás Otto Escudero, D. Francico Cueva vota a José Escobedo y González Alberú; D. Juan Moneva vota a D. Nicolás Otto Escudero, Mons. Melo vota a José Escobedo.

$\mathrm{Al}$ día siguiente tras elegir D. Eloy Montero la cátedra de Sevilla, se propone a éste para esa plaza y en consecuencia a D. Nicolás de Otto para la cátedra de Oviedo.

\section{Materiales}

Temario preparado por el Tribunal, 116 temas.

Ejercicios manuscritos de los opositores. (Deberes positivos de los clérigos. Potestad ordinaria y delegada. Otras clasificaciones de la jurisdicción. Reducción de los clérigos al estado seglar. Comentario del c. 42 del Código de Derecho canónico). El Código de Derecho canónico. Su historia, su espíritu y sus innovaciones principales en el tratado de clérigos y en materia matrimonial y penal, Memoria presentada por D. Eloy Montero Gutiérrez, firmada en París, julio 1921.

Programa de Instituciones de Derecho canónico de la Universidad Literaria de Valladolid de 1918, (con censura eclesiástica) presentado por el Prof. Auxiliar Eloy Montero y Gutiérrez.

Obispados de Aragón en la Edad Media. Obispado de Barbastro. Sus vicisitudes históricas; su estado actual; peligros que amenazan a esta diócesis en lo porvenir, con cuatro anexos documentales. Trabajo presentado por D. Nicolás de Otto. Ensayo de Programa de "Instituciones de Derecho canónico", Madrid 16 de noviembre de 1921, presentado por D. Nicolás de Otto.

NOTA: Consta que se reparten la redacción del programa entre los miembros del tribunal. Moneva hace treinta temas de los libros cuarto y quinto del Codex. Cueva treinta temas del libro III, Iglesias treinta temas del libro II, y Pou veinticinco temas del libro I y cinco de generalidades incluido materia de concordatos.

En la Memoria final consta que fueron veinticuatro las sesiones celebradas, cinco opositores, y las dietas devengadas 2.821 pts.

\section{Signatura}

AGA 32/07359. Legajo 5369-4.

\section{Cátedra}

Derecho administrativo.

\section{Universidad}

Santiago. 


\section{Anuncio}

R. O. del 30 de diciembre de 1919, Gaceta del 20 de febrero de 1920.

\section{Reglamento aplicable}

8 de abril, 1910.

\section{Fechas de la oposición}

Constitución del tribunal: 31 de enero, 1922.

Presentación de los opositores: 9 de febrero, 1922.

Votación y propuesta: 18 de febrero, 1922.

\section{Tribunal}

Presidente: José Gascón Marín.

Vocales: Pablo de Azcárate, Antonio Royo Villanova, Gregorio de Pereda.

Secretario: Luis Jordana de Pozas.

\section{Opositores}

Álvaro Olea Pimentel.

José Valenzuela.

No comparecieron: Luis Gestoso, Máximo Peña, Juan Marco Elorriaga, Francisco Martínez Lumbreras, Joaquín Uguet, Augusto Bacariza.

\section{Votación}

José Valenzuela ganó la votación por cuatro votos contra uno de Álvaro Olea (de Pereda). Fue propuesto.

\section{Materiales}

De tipo administrativo: actas, oficios del negociado, certificación académica personal de José Valenzuela.

De tipo académico o referentes a los ejercicios:

- Cuestionario elaborado por el tribunal (122 temas).

- Escritos del primer ejercicio. Dos temas: "Recursos y responsabilidad que nacen de los actos de los ayuntamientos"; "Organización de la jurisdicción contencioso-administrativa".

- Ejercicios prácticos (tercer ejercicio).

- Escrito de libros solicitados por los opositores.

- Programa aportado por José Valenzuela (84 lecciones).

- Obra aportada por José Valenzuela: Condición jurídica del municipio, Biblioteca de la Revista general de Legislación y Jurisprudencia, volumen XV, 1919. 


\section{Signatura}

AGA 32/o7358. Legajo 5368-6.

\section{Cátedra}

Derecho político español, comparado con el extranjero.

\section{Universidad}

Santiago.

\section{Anuncio}

R.O. de 7 de julio, 1920. Gaceta del 12.

\section{Reglamento aplicable}

8 de abril, 1910.

\section{Fechas de la oposición}

Constitución del tribunal: 27 de junio, 1921.

Presentación de los opositores: 12 de julio, 1921.

Votación y propuesta: 22 de julio, 1921.

\section{Tribunal}

Presidente: Francisco Manzano Alfaro.

Vocales: Gonzalo del Castillo, Luis del Valle Pascual, Mariano Gómez González. Secretario: Enrique Martí Jara.

\section{Opositores}

Álvaro Olea Pimentel.

Carlos Ruiz del Castillo.

José María Gil Robles Quiñones.

No comparecieron: Nicolás Pérez Serrano, Manuel Barrera, José Casais, Adoración Martínez, José Viarú, Buenaventura Benito, Mariano Marcial, Juan Ferrer, José Pérez Bances, Francisco Campos, José Mingarro, José Crespo, Nicolás Zorrilla, Francisco Martínez Lumbreras, Cristóbal Caballero, Guillermo Cabrera.

\section{Votación}

- Carlos Ruiz del Castillo: tres votos (Gómez, del Valle, del Castillo).

- José María Gil Robles: dos votos (Martí y Manzano).

Carlos Ruiz del Castillo fue propuesto. 


\section{Materiales}

De tipo administrativo: actas, oficios del negociado, oficios varios sobre conformación del tribunal.

De tipo académico o referentes a los ejercicios:

- Cuestionario elaborado por el tribunal (144 temas).

- Escritos del primer ejercicio. Dos temas: "La soberanía y la Sociedad de las Naciones"; "Del Funcionamiento del Congreso en España".

- Ejercicios prácticos (tercer ejercicio).

- Escrito de libros solicitados por los opositores.

- Programa aportado por Carlos Ruiz del Castillo (62 lecciones).

\section{Signatura}

AGA 32/07359. Legajo 5369-3.

\section{Cátedra}

Derecho administrativo.

\section{Universidad}

La Laguna.

\section{Anuncio}

R.O. de 9 de septiembre, 1920. Gaceta del 18.

\section{Reglamento aplicable}

8 de abril, 1910.

\section{Fechas de la oposición}

Constitución del tribunal: 9 de febrero, 1922.

Presentación de los opositores: 20 de febrero, 1922.

Votación y propuesta: 23 de febrero, 1922.

\section{Tribunal}

Presidente: José Gascón Marín.

Vocales: Pablo de Azcárate, Antonio Royo Villanova, Gregorio de Pereda.

Secretario: Luis Jordana de Pozas.

\section{Opositores}

Álvaro Olea Pimentel.

Justo Villanueva Gómez. 
No comparecieron: Luis Estremera, José Valenzuela, Juan Ferrer, Máximo Peña, Guillermo Cabrera, José Casais.

\section{Votación}

Primera votación:

- Álvaro Olea: un voto (Royo).

- Justo Villanueva: dos votos (Jordana y Pereda).

Gascón y Azcárate votaron por la no provisión.

En la segunda votación Justo Villanueva obtuvo tres votos (Jordana, Royo y Pereda). Gascón y Azcárate votaron por la no provisión.

Justo Villanueva fue propuesto.

\section{Materiales}

De tipo administrativo: actas, oficios del negociado.

De tipo académico o referentes a los ejercicios:

- Cuestionario elaborado por el tribunal (123 temas).

- Escritos del primer ejercicio. Dos temas: "Concesiones administrativas de aguas públicas", "Reclutamiento y organización del ejército. Derecho Positivo".

- Ejercicios prácticos (tercer ejercicio).

- Escrito de libros solicitados por los opositores.

- Programa aportado por Justo Villanueva (75 lecciones).

- Obra doctrinal aportada por Justo Villanueva: Estudios sobre las Juntas de administración local.

\section{Signatura}

AGA 32/07361. Legajo 5370-3.

\section{Cátedra}

Derecho penal.

\section{Universidad}

La Laguna.

\section{Anuncio}

R.O. de 9 de septiembre de 1920. Gaceta del 18.

\section{Reglamento aplicable}

8 de abril, 1910 . 


\section{Fechas de la oposición}

Constitución del tribunal: 1 de marzo, 1923.

Presentación de los opositores: 12 de marzo, 1923.

Votación y propuesta: 20 de marzo, 1923.

\section{Tribunal}

Presidente: Adolfo Bonilla San Martín.

Vocales: Luis Jiménez de Asúa, Enrique de Benito, Antonio Mesa.

Secretario: Mariano Ruiz Funes.

\section{Opositores}

Emilio Langle Rubio.

Enrique Zarandieta.

No comparecieron: Juan Ferrer, Francisco García Espinosa, Máximo Peña, José Mingarro, Cristóbal Caballero.

\section{Votación}

Emilio Langle Rubio fue votado y propuesto por unanimidad.

\section{Materiales}

De tipo administrativo: actas, oficios varios del negociado, oficios sobre conformación del tribunal, hoja de servicios de Emilio Langle.

De tipo académico o referentes a los ejercicios:

- Cuestionario elaborado por el tribunal (128 temas).

- Escritos del primer ejercicio. Dos temas: "La responsabilidad penal en las personas sociales. La delincuencia colectiva"; "La teoría de los motivos del delito".

- Ejercicios prácticos (tercer ejercicio).

- Escrito de libros solicitados por los opositores.

- Programa aportado por Emilio Langle.

- Trabajo doctrinal aportado por Emilio Langle: Estudios de política criminal. Memoria presentada a la Junta para Ampliación de Estudios e Investigaciones Científicas. 


\section{Signatura}

AGA 32/07359. Legajo 5369-2.

\section{Cátedra}

Elementos de Derecho natural.

\section{Universidad}

La Laguna.

\section{Anuncio}

R.O. de 9 de Septiembre, 1920 (Gaceta del 18).

\section{Reglamento aplicable}

8 de abril, 1910.

\section{Fechas de la oposición}

Constitución del tribunal: 28 de enero, 1922.

Presentación de los opositores: 9 de febrero, 1922.

Votación y propuesta: 23 de febrero, 1922.

\section{Tribunal}

Presidente: Prudencio Melo Alcalde, obispo de Madrid-Alcalá.

Vocales: Nicasio Sánchez Mata, Gonzalo del Castillo, Miguel Sancho Izquierdo.

Secretario: Mariano Puigdollers.

\section{Opositores}

Cristóbal Caballero Rubio.

Arturo Suárez Malfeito.

Wenceslao González Oliveros.

\section{Votación}

Primera votación:

- Cristóbal Caballero: dos votos (Sancho y Puigdollers).

- Arturo Suárez: un voto (Sánchez Mata).

- Wenceslao González: dos votos (del Castillo y Obispo de Madrid-Alcalá).

En la segunda votación Wenceslao González obtuvo todos los votos. Fue propuesto.

\section{Materiales}

De tipo administrativo: actas, oficios del negociado. 
De tipo académico o referentes a los ejercicios:

- Cuestionario elaborado por el tribunal (124 temas).

- Escritos del primer ejercicio. Dos temas: "Derecho natural en la filosofía presocrática. Las doctrinas de Sócrates y Platón”; “Actividades del Estado. Poder, funciones y órganos".

- Ejercicios prácticos (tercer ejercicio).

- Escrito de libros solicitados por los opositores.

- Programa aportado por Wenceslao González (71 lecciones).

- Obra doctrinal aportada por Wenceslao González: Los pretendidos derechos sobre la propia persona.

\section{Signatura}

AGA 32/07360. Legajo 5369-7.

\section{Cátedra}

Historia general del Derecho español.

\section{Universidad}

La Laguna.

\section{Anuncio}

R.O. de 9 de septiembre, 1920 (Gaceta del 18).

\section{Reglamento aplicable}

8 de abril, 1910.

\section{Fechas de la oposición}

Constitución del tribunal: 27 de noviembre, 1921.

Presentación de los opositores: 9 de diciembre, 1921.

Retirada del opositor: 14 de diciembre, 1921. Se retira durante el tercer ejercicio.

\section{Tribunal}

Presidente: Rafael Altamira.

Vocales: Francisco de Casso, Laureano Sánchez Gallego, Recaredo Fernández de Velasco.

Secretario: Galo Sánchez Sánchez.

\section{Opositores}

Arturo Suárez y Malfeito. 


\section{Materiales}

De tipo administrativo: actas, oficios varios del negociado.

De tipo académico o referentes a los ejercicios:

- Cuestionario elaborado por el tribunal (108 temas).

- Escritos del primer ejercicio. Dos temas: "El derecho romano vulgar"; "Organización social y política de los guanches en la época de la conquista de Canarias”.

- Ejercicio práctico (tercer ejercicio).

\section{Signatura}

AGA 32/07360. Legajo 5369-9.

\section{Cátedra}

Instituciones de Derecho canónico.

\section{Universidad}

La Laguna.

\section{Anuncio}

R.O. de 9 de septiembre, 1920 (Gaceta del 18).

\section{Reglamento aplicable}

Reglamento de 8 de abril de 1910.

\section{Fechas de la oposición}

1921, 5 de noviembre: constitución del tribunal.

1921, 25 de noviembre: presentación de los opositores.

1921, 3 de diciembre votación y propuesta.

\section{Tribunal}

Presidente: Sr. Obispo de Madrid, Prudencio Melo y Alcalde. Consejero de Instrucción Pública.

Vocales: D. Juan Moneva Puyol, D. Francisco Cueva Palacio, Isidoro Iglesia y García.

Secretario: Monsén José Pou y de Foxa.

\section{Opositores}

José Bernal y Montero.

Juan Ferrer y Galdiano. Decae al no presentarse el día 25.

Armando Álvarez Rodríguez. 


\section{Votación y propuesta}

Pou Foxa, D. Isidoro Iglesia , D. Francico Cueva Palacio y D. Juan Moneva votan a D. Armando Álvarez Rodríguez. Mons. Melo vota a D. José Bernal.

En consecuencia se propone Catedrático de Instituciones de Derecho canónico de la Sección Universitaria de La Laguna que fue Universidad de San Fernando a D. Armando Álvarez y Rodríguez.

\section{Materiales}

Temario preparado por el Tribunal, 116 temas.

"Las personas jurídicas en el Código canónico", trabajo presentado por Armando Álvarez Rodríguez.

Programa de Instituciones de Derecho canónico, firmado por Amando Álvarez Rodríguez.

NOTA: Consta que se reparten la redacción del programa los miembros del Tribunal. Moneva hace 30 temas de los libros cuarto y quinto del Codex. Cueva 30 temas del libro III, Iglesias 30 temas del libro II, y Pou 25 temas del libro I y 5 de generalidades incluido materia de concordatos. Ninguno Mons, Melo.

La Memoria al finalizar los ejercicios certifica que fueron 11 sesiones las celebradas en noviembre y 4 en diciembre, y que las dietas devengadas ascendieron a $1.555,80$ pts.

\section{Signatura}

AGA 32/07359. Legajo 5369-1.

\section{Cátedra}

Derecho político español, comparado con el extranjero.

\section{Universidad}

La Laguna.

\section{Anuncio}

Gaceta del 18 de septiembre de 1920.

\section{Reglamento aplicable}

8 de abril, 1910.

\section{Fechas de la oposición}

Constitución del tribunal: 17 de abril, 1922.

Presentación de los opositores: 29 de abril, 1922.

Votación y propuesta: 11 de mayo, 1922. 


\section{Tribunal}

Presidente: Francisco Manzano Alfaro.

Vocales: Adolfo González Posada, Luis del Valle, Enrique Martí Jara.

Secretario: Nicolás Rodríguez Aniceto.

\section{Opositores}

José María Gil Robles Quiñones.

José Mingarro.

\section{Votación}

- José María Gil Robles: tres votos (Rodríguez Aniceto, del Valle, Manzano).

- José Mingarro: dos votos (Martí y Posada).

José María Gil Robles fue propuesto.

\section{Materiales}

De tipo administrativo: actas, oficios del negociado, oficios varios sobre conformación del tribunal.

De tipo académico o referentes a los ejercicios:

- Cuestionario elaborado por el tribunal (135 temas).

- Escritos del primer ejercicio. Dos temas: "Comprobación de poderes en las asambleas legislativas"; "Derecho a la obtención de cargos públicos. Derecho a la petición".

- Ejercicios prácticos (tercer ejercicio).

- Escrito de libros solicitados por los opositores.

- Programa aportado por José María Gil Robles (350 lecciones).

- Obra doctrinal aportada por José María Gil Robles: El Derecho y el Estado y el Estado de Derecho.

- Obra doctrinal aportada por José María Gil Robles: La desmembración del imperio Austro-Húngaro.

\section{Signatura}

AGA 32/07361. Legajo 5370-1.

\section{Cátedra}

Derecho penal.

\section{Universidad}

Salamanca. 


\section{Anuncio}

R.O. de 11 de noviembre de 1920. Gaceta del 14.

Fue anunciada a traslación por R.O. de 10 de junio de 1920.

\section{Reglamento aplicable}

8 de abril, 1910.

\section{Fechas de la oposición}

Constitución del tribunal: 8 de febrero, 1923.

Presentación de los opositores: 23 de febrero, 1923.

Votación y propuesta: 10 de marzo, 1923.

\section{Tribunal}

Presidente: Adolfo Bonilla San Martín.

Vocales: Luis Jiménez de Asúa, Enrique de Benito, Antonio Mesa.

Secretario: Mariano Ruiz Funes.

\section{Opositores}

Emilio Langle y Rubio.

Máximo Peña Mantecón.

José Antón del Olmet Oneca.

No comparecieron: Luis Gestoso, Antonio Martínez del Campo.

Enrique Zarandieta quedó excluido.

\section{Votación}

José Antón fue votado y propuesto por unanimidad.

\section{Materiales}

De tipo administrativo: actas, oficios varios del negociado, oficios sobre conformación del tribunal.

De tipo académico o referentes a los ejercicios:

- Cuestionario elaborado por el tribunal (133 temas).

- Escritos del primer ejercicio. Dos temas: "Derecho penal germánico y canónico"; "Evolución penitenciaria en España”.

- Ejercicios prácticos (tercer ejercicio).

- Escrito de libros solicitados por los opositores.

Materiales de Oneca:

- Programa (75 lecciones).

- El perdón judicial. Monografías del seminario de Derecho penal de la universidad de Madrid. Separado de la Revista de Ciencias Jurídicas y Sociales. Tip. De la Rev. de Arch., Bibl. y Museos, Madrid, 1922. 
- Derecho penal. Obra ajustada al Programa de primer ejercicio de oposiciones al Cuerpo de Aspirantes a la Judicatura y al Ministerio Fiscal, de 5 de enero de 1922. Editorial Reus, Madrid, 1922.

- Trabajo doctrinal: Las ideas penales de Dorado Montero.

\section{Signatura}

AGA 32/07360. Legajo 5369-6.

\section{Cátedra}

Derecho internacional público y privado.

\section{Universidad}

Murcia.

\section{Anuncio}

R. O. del 27 de enero de 1921, Gaceta del 30.

\section{Reglamento aplicable}

8 de abril, 1910.

\section{Fechas de la oposición}

Constitución del tribunal: 14 de noviembre, 1921.

Presentación de los opositores: 25 de noviembre, 1921.

Votación y propuesta: 9 de diciembre, 1921.

\section{Tribunal}

Presidente: Rafael Conde Luque.

Vocales: Aniceto Sela, Mariano Ruiz Funes, José María Yanguas.

Secretario: Camilo Barcia.

\section{Opositores}

Luis Gestoso Tudela.

José Ramón de Orue Arregui.

No comparecieron: Emilio Langle Rubio.

\section{Votación}

Luis Gestoso ganó la votación por tres votos (Barcia, Ruiz Funes y Sela) contra dos de Orue (Yanguas y Conde). Luis Gestoso fue propuesto. 


\section{Materiales}

De tipo administrativo: actas, oficios varios del negociado.

De tipo académico o referentes a los ejercicios:

- Cuestionario elaborado por el tribunal (133 temas).

- Escritos del primer ejercicio. Dos temas: "Contenido del Derecho internacional privado"; "Normas reguladoras de la ausencia".

- Ejercicios prácticos (tercer ejercicio).

- Escrito de libros solicitados por los opositores.

Materiales de Gestoso:

- Programa (65 lecciones de Derecho internacional público y 65 de Derecho internacional privado).

- Obra doctrinal: Teoría de la referencia.

- El concepto de orden público internacional. Discurso presentado en la Universidad de Madrid durante el curso de 1910-1911. Tipográfica "La Itálica", Madrid, 1913.

\section{Signatura}

AGA 32/07361. Legajo 5370-2.

\section{Cátedra}

Derecho administrativo.

\section{Universidad}

Salamanca.

\section{Anuncio}

R.O. de 27 de octubre, 1921. Gaceta del 6 de noviembre.

\section{Reglamento aplicable}

8 de abril, 1910 .

\section{Fechas de la oposición}

Constitución del tribunal: 22 de enero, 1923.

Presentación de los opositores: 3 de febrero, 1923.

Votación y propuesta: 18 de febrero, 1923.

\section{Tribunal}

Presidente: José Gascón Marín.

Vocales: Adolfo González Posada, Carlos García Oviedo, Recaredo Fernández Velasco.

Secretario: Justo Villanueva. 


\section{Opositores}

Álvaro Olea Pimentel.

José Valenzuela Soler.

Sabino Álvarez Blanco-Sendín.

José Crespo Salazar.

No comparecieron: José García Revillo, José García Revillo y García, José Viani. Justo Villanueva renunció.

\section{Votación}

Primera votación:

- Álvaro Olea: un voto (Villanueva).

- Sabino Álvarez: dos votos (Fernández de Velasco y García Oviedo).

- José Crespo: dos votos (Posada y Gascón).

Segunda votación:

- Álvaro Olea: un voto (Villanueva).

- Sabino Álvarez: un voto (Fernández de Velasco).

- José Crespo: tres votos (García Oviedo, Posada y Gascón).

José Crespo fue propuesto.

\section{Materiales}

De tipo administrativo: actas, oficios varios del negociado, oficios sobre conformación del tribunal.

De tipo académico o referentes a los ejercicios:

- Cuestionario elaborado por el tribunal (125 temas).

- Escritos del primer ejercicio. Dos temas: "Consideración legal y científica del Derecho administrativo"; "Funciones administrativas de los alcaldes, tenientes, síndicos, regidores y alcaldes de barrio. Secretarios de ayuntamientos".

- Ejercicios prácticos (tercer ejercicio).

- Escrito de libros solicitados por los opositores.

- Programa aportado por José Crespo (91 lecciones).

- Trabajo doctrinal aportado por José Crespo: El concepto y la idea del Derecho según Stammler.

- Trabajo doctrinal aportado por José Crespo: ¿Democracia o eficacia? Nuevas orientaciones del Derecho público. 


\section{Signatura}

AGA 32/13392. Legajo 6981-3.

\section{Cátedra}

Derecho civil español, común y foral.

\section{Universidad}

Santiago.

\section{Anuncio}

R.O. de 27 de octubre, 1921. Gaceta del 6 noviembre.

\section{Reglamento aplicable}

8 de abril, 1910.

\section{Fechas de la oposición}

Constitución del tribunal: 5 de marzo, 1927.

Presentación de los opositores: 30 de marzo, 1927.

Votación y propuesta: 9 de abril, 1927.

\section{Tribunal}

Presidente: Clemente de Diego.

Vocales: Felipe Gil Casares, Felipe Sánchez-Román Gallifa, Leopoldo García Alas (sustituyó a Ignacio de Casso a partir del 30 de marzo, telegrama del 18 de marzo). Secretario: Francisco Candil.

\section{Opositores}

Vicente Guilarte.

José Viñas Mey.

Francisco de Pelsmaeker abandona la oposición (comunicación del 6 de abril).

No comparecieron: Nicolás Santos de Otto y Escudero, José Arias, José GarcíaRevillo, Wenceslao González, Enrique Rajoy, Alfonso García Valdecasas, Eugenio Tarragato.

\section{Votación}

José Viñas Mey obtuvo todos los votos menos el de Sánchez-Román, quien votó a Vicente Guilarte. Viñas fue propuesto.

\section{Materiales}

De tipo administrativo: actas, oficios varios del negociado, telégrafos relativos 
a la conformación del tribunal, instancias de los aspirantes con acreditación de méritos.

De tipo académico o referentes a los ejercicios:

- Cuestionario elaborado por el tribunal (156 temas).

- Escritos del primer ejercicio. Dos temas: "Relaciones personales entre los cónyuges"; "Filiación legítima".

- Ejercicios prácticos (tercer ejercicio).

- Escrito de libros consultados por los opositores.

- Programa aportado por José Viñas (112 lecciones).

\section{Signatura}

AGA 32/07362. Legajo 5371-2.

\section{Cátedra}

Instituciones de Derecho romano.

\section{Universidad}

Salamanca.

\section{Anuncio}

R.O. de 17 de marzo, 1922. Gaceta del 30.

\section{Reglamento aplicable}

8 de abril, 1910.

\section{Fechas de la oposición}

Constitución del tribunal: 3 de abril, 1923.

Presentación de los opositores: 16 de abril, 1923.

Votación y propuesta: 26 de abril, 1923.

\section{Tribunal}

Presidente: Luis Maldonado.

Vocales: José Castillejo, José Fernández González, José López de Rueda.

Secretario: Laureano Sánchez Gallego.

\section{Opositores}

Wenceslao Roces Suárez.

Esteban Madrugá Jiménez.

Carlos Sánchez Pequeño. 
No comparecieron: Manuel Martínez Pedroso, Rodrigo Fernández García, Victoriano Nuño, Álvaro Olea.

Manuel Torres López fue excluido por falta de documentación.

\section{Votación}

Wenceslao Roces ganó la votación por tres votos contra uno de Carlos Sánchez Pequeño (López de Rueda). Sánchez Gallego votó por la no provisión.

\section{Materiales}

De tipo administrativo: actas, oficios varios del negociado, oficios sobre conformación del tribunal.

De tipo académico o referentes a los ejercicios:

- Cuestionario elaborado por el tribunal (132 temas).

- Escritos del primer ejercicio. Dos temas: "República. Restablecimiento del consulado"; "Estudio del comodato, precario y depósito".

- Ejercicios prácticos (tercer ejercicio).

- Escrito de libros solicitados por los opositores.

- Programa aportado por Wenceslao Roces (9o lecciones).

- Obra doctrinal aportada por Wenceslao Roces: Génesis de la superficie como derecho real dentro del derecho romano clásico.

\section{Signatura}

AGA 32/o7362 y 32/07363. Legajo 5371-3.

\section{Cátedra}

Economía política y Hacienda pública.

\section{Universidad}

Salamanca.

\section{Anuncio}

R.O. de 20 de julio, 1922. Gaceta del 7 de agosto.

\section{Reglamento aplicable}

8 de abril, 1910.

\section{Fechas de la oposición}

Constitución del tribunal: 23 de abril, 1923.

Presentación de los opositores: 4 de mayo, 1923.

Votación y propuesta: 10 de mayo, 1923. 


\section{Tribunal}

Presidente: Elías Tormo.

Vocales: Antonio Flores de Lemus, Gonzalo del Castillo Alonso, Vicente Gay.

Secretario: Agustín Viñuales Pardo.

\section{Opositores}

Enrique Rodríguez Mata.

No comparecieron: José Crespo Salazar, Adoración Martínez Durán, Gabriel Franco López.

\section{Votación}

Enrique Rodríguez Mata es votado y propuesto por unanimidad.

\section{Materiales}

De tipo administrativo: actas, oficios varios del negociado, oficios sobre conformación del tribunal.

De tipo académico o referentes a los ejercicios:

- Cuestionario elaborado por el tribunal (113 temas).

- Escritos del primer ejercicio. Dos temas: "El patrimonio fiscal"; "La sal. Imposición sobre el consumo de la sal".

- Ejercicios prácticos (tercer ejercicio).

- Escrito de libros solicitados por el opositor.

Materiales de Enrique Rodríguez:

- Obra doctrinal: Historia política y hacienda pública.

- Obra doctrinal: El impuesto de la renta en Francia.

\section{Signatura}

AGA 32/o7361. Legajo 5370-4.

\section{Cátedra}

Derecho penal.

\section{Universidad}

Oviedo.

\section{Anuncio}

R.O. de 20 de julio de 1922. Gaceta del 11 de agosto. 


\section{Reglamento aplicable}

8 de abril, 1910.

\section{Fechas de la oposición}

Constitución del tribunal: 13 de marzo, 1923.

Presentación de los opositores: 14 de marzo, 1923.

Votación y propuesta: 26 de marzo, 1923.

\section{Tribunal}

Presidente: Adolfo Bonilla San Martín.

Vocales: Luis Jiménez de Asúa, Enrique de Benito, Antonio Mesa.

Secretario: Mariano Ruiz Funes.

\section{Opositores}

Isaías Sánchez Sánchez Tejerina.

No comparecieron: Máximo Peña, Cristóbal Caballero, Emilio Langle Rubio, Enrique Zarandieta, José Antón del Olmet Oneca.

No fueron admitidos: José Mingarro, Armando Álvarez Rodríguez.

\section{Votación}

Isaías Sánchez Sánchez Tejerina fue votado y propuesto por unanimidad.

\section{Materiales}

De tipo administrativo: actas, oficios varios del negociado, oficios sobre conformación del tribunal, hoja de servicios de Isaías Sánchez Sánchez Tejerina.

De tipo académico o referentes a los ejercicios:

- Cuestionario elaborado por el tribunal (128 temas).

- Escritos del primer ejercicio. Dos temas: "Complicidad moral, material y correspectiva"; "El trabajo en las prisiones".

- Ejercicios prácticos (tercer ejercicio).

- Escrito de libros solicitados por el opositor.

- Programa aportado por Isaías Sánchez Sánchez Tejerina (76 lecciones).

- Trabajo doctrinal aportado por Isaías Sánchez Sánchez Tejerina:

- Obra aportada por Isaías Sánchez Sánchez Tejerina: El Estado de necesidad en el Derecho penal, Tip. de la Revista de Archivos, Bibliotecas y Museos, Madrid, 1923. 


\section{Signatura}

AGA 32/13389. Legajo 6979-2.

\section{Cátedra}

Derecho mercantil de España y de las principales naciones de Europa y América.

\section{Universidad}

La Laguna.

\section{Anuncio}

R.O. de 23 de agosto, 1922. Gaceta del 29.

Un primer tribunal fue nombrado por R.O. de 21 de septiembre, 1925.

El segundo fue nombrado por R.O. de 21 de enero, 1928.

\section{Reglamento aplicable}

8 de abril, 1910.

\section{Fechas de la oposición}

Constitución del tribunal: 12 de noviembre, 1928.

Presentación de los opositores: 28 de noviembre, 1928.

Votación y propuesta: 25 de diciembre, 1928.

\section{Tribunal}

Presidente: Felipe Clemente de Diego.

Vocales: Antonio de la Figuera, Salvador Salom Antequera, Agustín Viñuales.

Secretario: Emilio Langle.

\section{Opositores}

Francisco Hernández Borondo.

No comparecieron: José de Benito, Adoración Martínez, Enrique Martín, Victoriano Nuño, Álvaro Calvo, Salvador Martínez, José Viani, Miguel Cabeza, Ramón Buide, Lino Torre, José Valiente.

\section{Votación}

Francisco Hernández Borondo obtuvo dos votos (de la Figuera y de Diego) contra tres por la no provisión (Salom, Viñuales y Langle).

Se acordó la no provisión.

\section{Materiales}

De tipo administrativo: actas, oficios varios del negociado, instancias de los aspirantes con acreditación de méritos. 
De tipo académico o referentes a los ejercicios:

- Cuestionario elaborado por el tribunal (126 temas).

- Escritos del primer ejercicio. Dos temas: "Casa, fondo, o hacienda comercial";

"Contrato de pasaje".

- Ejercicios prácticos (tercer ejercicio).

- Escrito de libros consultados por el opositor.

\section{Signatura}

AGA 32/07362. Legajo 5371-1.

\section{Cátedra}

Derecho internacional público y privado.

\section{Universidad}

La Laguna.

\section{Anuncio}

R.O. de 23 de agosto, 1922. Gaceta del 29.

\section{Reglamento aplicable}

8 de abril, 1910 .

\section{Fechas de la oposición}

Constitución del tribunal: 23 de febrero, 1923.

Presentación de los opositores: 6 de marzo, 1923.

Votación y propuesta: 15 de marzo, 1923.

\section{Tribunal}

Presidente: Aniceto Sela.

Vocales: Isidro Beato, Salvador Cabeza, José María Trías.

Secretario: José María Yanguas.

\section{Opositores}

José Ramón de Orúe y Arregui.

No comparecieron: Enrique Martín, Álvaro Olea, José Viani, Luis Extremera.

\section{Votación}

José Ramón de Orúe fue votado y propuesto por unanimidad. 


\section{Materiales}

De tipo administrativo: actas, oficios varios del negociado, hoja de servicios de José Ramón de Orúe y otros documentos (partida de nacimiento, certificado del registro de penados, etc.)

De tipo académico o referentes a los ejercicios:

- Cuestionario elaborado por el tribunal (138 temas).

- Escritos del primer ejercicio. Dos temas: "El derecho inter-regional"; "Adquisición, conservación, pérdida y recuperación de la nacionalidad”.

- Ejercicios prácticos (tercer ejercicio).

- Escrito de libros solicitados por el opositor.

Materiales de Orúe:

- Programa aportado por José Ramón de Orúe (50 lecciones de Derecho internacional público y 53 de Derecho internacional privado).

- Programa de Derecho internacional privado (64 lecciones), universidad de Madrid, curso 1919-1920. Por José Ramón de Orúe, Librería General de Victoriano Suárez, Madrid, 1920.

- Obra doctrinal: Contribución al estudio de instituciones del nuevo Derecho internacional.

Obras en revistas aportadas por Orúe:

- Contribución al estudio de la propiedad privada enemiga durante el conflicto europeo. Revista General de Legislación y Jurisprudencia, marzo de 1920, tomo 136, entrega III.

- Contribución al estudio de la propiedad privada enemiga durante el conflicto europeo (conclusión). Revista General de Legislación y Jurisprudencia, junio de 1920, tomo 136, entrega IV.

- El tatuaje en la antropología criminal, Revista General de Legislación y Jurisprudencia, marzo-abril de 1916, tomo 128.

- La última fase de la dactiloscopia, Revista General de Legislación y Jurisprudencia, enero-febrero de 1917, tomo 130.

- Noticias bibliográficas, El derecho penal del porvenir. La unificación del Derecho penal en Suiza, por Luis Jiménez de Asúa, Revista General de Legislación y Jurisprudencia, marzo-abril de 1917, tomo 130.

- Contribución al estudio jurídico de las represalias, Revista General de Legislación y Jurisprudencia, mayo de 1922, tomo 140, entrega V.

- Orientaciones prácticas sobre Derecho procesal internacional, El Procurador español, núm. 22, año XVI.

- La legislación de guerra en Francia sobre naturalización, Revista de Ciencias Jurídicas y Sociales, octubre-noviembre de 1918, año I, núm. 4.

- Extensión de los privilegios diplomáticos en el Pacto de la Liga de Naciones, Revista de Ciencias Jurídicas y Sociales, abril-junio de 1922, año V, núm. 18. 


\section{Signatura}

AGA 32/07363. Legajo 5371-4.

\section{Cátedra}

Procedimientos judiciales y práctica forense.

\section{Universidad}

La Laguna.

\section{Anuncio}

R.O. de 23 de agosto, 1922. Gaceta del 29.

\section{Reglamento aplicable}

8 de abril, 1910 .

\section{Fechas de la oposición}

Constitución del tribunal: 1 de abril, 1923.

Presentación de los opositores: 1 de mayo, 1923.

Votación y propuesta: 9 de mayo, 1923.

\section{Tribunal}

Presidente: José Gascón Marín.

Vocales: Melquíades Álvarez, Quintín Palacios Herranz, José Xirau Palou.

Secretario: Matías Domínguez Ballarín.

\section{Opositores}

Francisco Beceña González.

Luis Navarro Canales.

\section{Votación}

Francisco Beceña es votado y propuesto por unanimidad.

\section{Materiales}

De tipo administrativo: actas, oficios varios del negociado, oficios sobre conformación del tribunal.

De tipo académico o referentes a los ejercicios:

- Cuestionario elaborado por el tribunal (129 temas).

- Escritos del primer ejercicio. Dos temas: "Concepto de lo que oficialmente se 
llama redacción de instrumentos públicos"; "Concepto de parte en el derecho procesal civil".

- Ejercicios prácticos (tercer ejercicio).

- Escrito de libros solicitados por el opositor.

Publicaciones de Francisco Beceña en revistas:

- Valor jurídico de la demanda (notas a una sentencia del Tribunal Supremo), Revista de Derecho Privado, año VIII, núm. 77.

- Los procedimientos ejecutivos en el derecho procesal español. Notas de sistematización, Revista de Derecho Privado, año VIII, núms. 82 y 83.

- Nota bibliográfica: Chiovenda, G., Principios de derecho procesal civil, Revista de Derecho Privado, año X, núm. 111.

- Sobre la formación de la magistratura, Revista de Derecho Privado, año IX, núm. 92.

- Costas en el procedimiento civil (notas de sistematización), Revista de Derecho Privado, año X, núms. 101.

\section{Signatura}

AGA 32/07366. Legajo 5373-3.

\section{Cátedra}

Historia general del Derecho español.

\section{Universidad}

Salamanca.

\section{Anuncio}

R.O. de 22 de enero, 1925. Gaceta del 2 de febrero.

\section{Reglamento aplicable}

8 de abril, 1910.

\section{Fechas de la oposición}

Constitución del tribunal: 18 de febrero, 1926.

Presentación de los opositores: 1 de marzo, 1926.

Votación y propuesta: 16 de marzo, 1926.

\section{Tribunal}

Presidente: Felipe Clemente de Diego (en sustitución de Rafael Altamira). Vocales: Rafael Ureña, Laureano Díez Canseco, Juan Salvador Minguijón. Secretario: Galo Sánchez Sánchez. 


\section{Opositores}

Tomás Gómez Piñán.

Manuel Torres López.

No comparecieron: Eugenio Tarragato, Esteban Madruga, Román Riaza, Máximo Peña, Miguel María de Pareja.

\section{Votación}

Manuel Torres fue votado y propuesto por unanimidad.

\section{Materiales}

De tipo administrativo: actas, oficios varios del negociado, certificación académica y hoja de servicios de Manuel Torres.

De tipo académico o referentes a los ejercicios:

- Cuestionario elaborado por el tribunal (105 temas).

- Escritos del primer ejercicio. Dos temas: "Concepto del Estado y la Monarquía entre los visigodos. Limitaciones morales y jurídicas del poder real”; "Historia de la formación de la nobleza medieval. Sus privilegios característicos”.

- Ejercicio práctico (tercer ejercicio).

Materiales de Torres López:

- Programa (95 lecciones).

- Trabajo doctrinal: Mis ideas sobre el contenido y la enseñanza de la "historia" y de la "historia del derecho español."

- Trabajo doctrinal: Iglesias propias. Notas y documentos sobre la doctrina de las iglesias propias y la práctica del sistema de apropiación en León y Castilla durante la Edad Media (dos tomos).

- La doctrina de las iglesias propias en los autores españoles, Anuario de Historia del Derecho español, Tomo II, Madrid, 1925.

\section{Signatura}

AGA 32/07367. Legajo 5374-2.

\section{Cátedra}

Derecho político español, comparado con el extranjero.

\section{Universidad}

Murcia y La Laguna.

\section{Anuncio}

Para Murcia, R.O. de 22 de enero, 1925. Gaceta del 2 de febrero. 
Para La Laguna, R.O. de 18 de febrero, 1925. Gaceta del 21 de febrero. Hubo anterior anuncio por R.O. de 12 de septiembre, 1923. Gaceta del 15. Fue anunciada a traslación por excedencia de Gil Robles por R.O. de 22 de enero de 1923.

\section{Reglamento aplicable}

8 de abril, 1910.

\section{Fechas de la oposición}

Constitución del tribunal: 17 de octubre, 1925.

Presentación de los opositores: 11 de noviembre, 1925.

Votación: 5 de diciembre, 1925.

Propuesta: 7 de diciembre, 1925.

\section{Tribunal}

Presidente: Adolfo González Posada.

Vocales: Gonzalo del Castillo Alonso, Niceto Alcalá Zamora, Fernando de los Ríos. Secretario: Carlos Ruiz del Castillo.

\section{Opositores}

José Mingarro San Martín.

Teodoro González García.

Carlos Sanz Cid.

Se retiraron: José Viani Caballero, Ramón Gil y Armada.

\section{Votación}

Para el primer lugar fue votado por unanimidad Teodoro González García.

La votación del segundo lugar fue ganada por Carlos Sanz Cid con todos los votos menos el de Ruiz del Castillo, que votó a José Mingarro.

Teodoro González optó por la cátedra de Murcia y Carlos Sanz aceptó la de La Laguna.

\section{Materiales}

De tipo administrativo: actas, oficios del negociado, oficios varios sobre conformación del tribunal, certificados a favor de Teodoro González y Carlos Sanz (académicos, de nacimiento, hoja de servicios). Carlos Sanz presenta certificat d'assiduité de la Université de Paris y otro de la École Libre de Sciences Politiques. De tipo académico o referentes a los ejercicios:

- Cuestionario elaborado por el tribunal (113 temas).

- Escritos del primer ejercicio. Dos temas: "El concepto jurídico y político del Estado. El Estado como organismo"; "La teoría de las constituciones escritas". 
- Ejercicios prácticos (tercer ejercicio).

- Escrito de libros solicitados por los opositores.

Materiales de Teodoro González:

- Memoria y programa (72 lecciones).

- Obra doctrinal: La obra del profesor Laski. El pensamiento político en Inglaterra. Estado y soberanía.

- Trabajo de investigación: La soberanía del parlamento inglés.

Materiales de Carlos Cid:

- Programa (33 lecciones).

- Esquema para una sistemática del Derecho político tal como puede ser expuesto en un curso.

- Obra doctrinal: La escuela francesa del solidarismo. Estudio a modo de introducción al sistema del profesor Mr. Duguit.

- Tesis doctoral de Carlos Sanz: El Municipio. Ensayo de un estudio del mismo, en los principios, en la historia y en la legislación, Imprenta y encuadernación de Julio Cosano, Madrid, 1917.

- La constitución de Bayona. Labor de redacción y elementos que a ella fueron aportados, según los documentos que se guardan en los Archives Nationales de París y en los Papeles Reservados de la Biblioteca del Palacio Real, Editorial Reus, Madrid, 1922.

\section{Signatura}

AGA 32/07367. Legajo 5374-3.

\section{Cátedra}

Procedimientos judiciales y práctica forense.

\section{Universidad}

La Laguna.

\section{Anuncio}

R.O. de 22 de enero, 1925. Gaceta del 2 de febrero.

\section{Reglamento aplicable}

8 de abril, 1910.

\section{Fechas de la oposición}

Constitución del tribunal: 7 de octubre, 1925.

Presentación de los opositores: 29 de octubre, 1925.

Votación y propuesta: 7 de noviembre, 1925. 


\section{Tribunal}

Presidente: Tomás Montejo Rica.

Vocales: Francisco Javier Comín, Quintín Palacios, José Xirau Palou.

Secretario: Francisco Beceña.

\section{Opositores}

Mauro Miguel Romero.

No comparecieron: Álvaro Olea Pimentel, Victoriano Nuño-Beato Asin, Joaquín Uguet Soriano, Luis Navarro Canales.

\section{Votación}

Mauro Miguel Romero fue propuesto con tres votos a favor (Montejo, Comín y Palacios) y dos por la no provisión (Beceña y Xirau).

\section{Materiales}

De tipo administrativo: actas, oficios varios del negociado, oficios sobre conformación del tribunal.

Consta protesta del aspirante Álvaro Olea por la que solicita le sean devueltas las 75 pesetas por no haber podido concurrir a la oposición.

De tipo académico o referentes a los ejercicios:

- Cuestionario elaborado por el tribunal (126 temas).

- Escritos del primer ejercicio. Dos temas: "El procedimiento contencioso administrativo"; "Examen de las escrituras referentes a la extinción o resolución de obligaciones, [...]".

- Ejercicios prácticos (tercer ejercicio).

- Escrito de libros solicitados por el opositor.

\section{Signatura}

AGA 32/07364. Legajo 5372-2.

\section{Cátedra}

Derecho penal.

\section{Universidad}

La Laguna.

\section{Anuncio}

R.O. de 22 de enero, 1925. Gaceta del 2 de febrero. 


\section{Reglamento aplicable}

8 de abril, 1910.

\section{Fechas de la oposición}

Constitución del tribunal: 3 de noviembre, 1925 .

Presentación de los opositores: 16 de noviembre, 1925.

Votación y propuesta: 28 de noviembre, 1925.

\section{Tribunal}

Presidente: José Gascón Marín.

Vocales: Inocencio Jiménez Vicente, Constancio Bernaldo de Quirós, Antonio Mesa.

Secretario: José Antón Oneca.

\section{Opositores}

José Guallart López de Goicoechea.

Arturo Rodríguez Muñoz (José Arturo según su hoja de servicios).

No comparecieron: Máximo Peña Mantecón.

Lino Torre quedó excluido por instancia extemporánea.

\section{Votación}

Primera votación:

- José Guallart: dos votos (Antón Oneca, Jiménez).

- Arturo Rodríguez: dos votos (Quirós, Mesa).

- Gascón votó por la no provisión.

Segunda votación:

- José Guallart: un voto (Jiménez).

- Arturo Rodríguez: tres votos (Antón Oneca, Quirós, Mesa).

- Gascón votó por la no provisión.

Arturo Rodríguez fue propuesto.

\section{Materiales}

De tipo administrativo: actas, oficios varios del negociado, oficios sobre conformación del tribunal, hoja de servicios de Arturo Rodríguez.

De tipo académico o referentes a los ejercicios:

- Cuestionario elaborado por el tribunal (119 temas).

- Escritos del primer ejercicio. Dos temas: "Caracteres esenciales del delito. La tipicidad"; "Las penas cororales".

- Ejercicios prácticos (tercer ejercicio).

- Escrito de libros solicitados por los opositores. 
- Programa aportado por Arturo Rodríguez (95 lecciones).

- Memoria sobre el contenido, carácter, límites, etc. del Derecho penal, por Arturo Rodríguez.

- Tesis doctoral aportada por Arturo Rodríguez: Unidad y pluralidad de acciones $y$ de delitos.

\section{Signatura}

AGA 32/07364. Legajo 5372-1.

\section{Cátedra}

Instituciones de Derecho canónico.

\section{Universidad}

La Laguna.

\section{Anuncio}

R.O. de 22 de enero, 1925. Gaceta del 2 de febrero.

La cátedra fue anunciada a traslación por R.O. de 18 de julio de 1923.

\section{Reglamento aplicable}

8 de abril, 1910.

\section{Fechas de la oposición}

Constitución del tribunal: 13 de octubre, 1925.

Presentación de los opositores: 26 de octubre, 1925.

Votación y propuesta: 6 de noviembre, 1925.

\section{Tribunal}

Presidente: Leopoldo Eijo Garay, obispo de Madrid-Alcalá.

Vocales: Francisco Cueva Palacio, Teodoro Andrés Marcos, Manuel Cabrera Warleta.

Secretario: Juan Aguilar Jiménez.

\section{Opositores}

José Escobedo González Alberú.

Eugenio Tarragato y Contreras.

No comparecieron: José Bernal, Tomás Gómez Piñán.

\section{Votación}

José Escobedo es votado y propuesto por unanimidad. 


\section{Materiales}

De tipo administrativo: actas, oficios varios del negociado, oficios sobre conformación del tribunal.

De tipo académico o referentes a los ejercicios:

- Cuestionario elaborado por el tribunal (128 temas).

- Escritos del primer ejercicio. Dos temas: "De la ley canónica en general”; "Erección, innovación y supresión de los beneficios eclesiásticos”.

- Ejercicios prácticos (tercer ejercicio).

- Escrito de libros solicitados por los opositores.

- Programa aportado por José Escobedo (114 lecciones).

- Memoria en la que se razona el programa adjunto, por José Escobedo.

- Obra aportada por José Escobedo: Las nuevas orientaciones del derecho. Socialización, espiritualización, interpretación y abuso del derecho, Tipografía de la Revista de Archivos, Madrid, 1925.

\section{Signatura}

AGA 32/07365. Legajo 5373-1.

\section{Cátedra}

Historia general del Derecho español.

\section{Universidad}

Murcia.

\section{Anuncio}

R.O. de 18 de febrero, 1925. Gaceta del 21.

La catedra ya había sido anunciada a oposición por R.O. de 12 de septiembre de 1923. Gaceta del 16.

Fue anunciada a traslación por R.O. de 28 de julio de 1923.

\section{Reglamento aplicable}

8 de abril, 1910.

\section{Fechas de la oposición}

Constitución del tribunal: 23 de febrero, 1926.

Presentación de los opositores: 8 de marzo, 1926.

Votación y propuesta: 23 de marzo, 1926. 


\section{Tribunal}

Presidente: Felipe Clemente de Diego (en sustitución de Rafael Altamira). Vocales: Rafael Ureña, Laureano Díez Canseco, Juan Salvador Minguijón. Secretario: Galo Sánchez Sánchez.

\section{Opositores}

Tomás Gómez Piñán.

No comparecieron: Carlos Sánchez Pequeño, Manuel Torres, Luis Pidal, Vicente García Desfilis, Esteban Madrugá, Román Riaza.

\section{Votación}

Tomás Gómez Piñán fue votado y propuesto por unanimidad.

\section{Materiales}

De tipo administrativo: actas, oficios varios del negociado.

De tipo académico o referentes a los ejercicios:

- Cuestionario elaborado por el tribunal (104 temas).

- Escritos del primer ejercicio. Dos temas: "La penetración del elemento romano en el derecho visigodo"; "Naturaleza y fines del Estado en la Edad media".

- Ejercicio práctico (tercer ejercicio).

- Programa aportado por Tomás Gómez (65 lecciones).

- Memoria pedagógica aportada por Tomás Gómez (65 lecciones)

- Trabajo doctrinal aportado por Tomás Gómez: El celibato.

- Obra aportada por Luis Pidal: El perdón. Sucinto histórico y crítico, Tipografía de la Sociedad Editorial de España, Madrid, 1913.

- Obra aportada por Luis Pidal: El iberismo, el porvenir del Derecho internacional y el concepto de la paz, Cándido Alonso y Compañía, Madrid, 1917.

\section{Signatura}

AGA 32/07366. Legajo 5373-5.

\section{Cátedra}

Historia general del Derecho español.

\section{Universidad}

La Laguna.

\section{Anuncio}

R.O. de 18 de febrero, 1925. Gaceta del 21 de febrero. 
Había sido anunciada a oposición por R.O. de 28 de febrero de 1922. Gaceta del 16.

\section{Reglamento aplicable}

8 de abril, 1910.

\section{Fechas de la oposición}

Constitución del tribunal: 12 de abril, 1926.

Presentación de los opositores: 22 de abril, 1926.

Votación y propuesta: 6 de mayo, 1926.

\section{Tribunal}

Presidente: Felipe Clemente de Diego. En sustitución de Rafael Altamira. La comunicación de dimisión de Altamira menciona el "imprevisto llamamiento para una nueva sesión del Tribunal de Justicia Internacional”.

Vocales: Rafael Ureña, Laureano Díez Canseco, Juan Salvador Minguijón.

Secretario: Galo Sánchez Sánchez.

\section{Opositores}

Román Riaza Martínez-Ossorio.

No comparecieron: Manuel Torres, Tomás Gómez, Vicente García Desfilis.

Eugenio Tarragato fue excluido. Consta protesta contra su exclusión.

\section{Votación}

Román Riaza fue votado y propuesto por unanimidad.

\section{Materiales}

De tipo administrativo: actas, oficios varios del negociado, oficios sobre conformación del tribunal.

El presidente del tribunal Felipe Clemente de Diego eleva en fecha 29 de enero de 1925 comunicación al Ministerio de I.P. con el objeto de simultanear los ejercicios de oposición a las cátedras de Murcia, Salamanca y La Laguna. El Director Gral. de Enseñanza Superior y secundaria lo deniega el 8 de febrero de 1926.

De tipo académico o referentes a los ejercicios:

- Cuestionario elaborado por el tribunal (105 temas).

- Escritos del primer ejercicio. Dos temas: "El municipio hispano romano"; "Consecuencias del delito. La inimicitia y la composición. Responsabilidad comunal y familiar. Las penas aflictivas".

- Ejercicio práctico (tercer ejercicio).

- Programa aportado por Román Riaza (51 lecciones). 
- Obra aportada por Román Riaza: La escuela española de derecho natural (Extracto de la conferencia pronunciada en la Real Academia de Jurisprudencia y Legislación, el día 27 de abril de 1925), Revista de Cultura y Vida Universitaria, Tipografía "La Académica", Zaragoza, 1925.

- Obra aportada por Román Riaza: La Interpretación de las leyes y la doctrina de Francisco Suárez, Tipografía de la Revista de Archivos, Bibliotecas y Museos, Madrid, 1925.

\section{Signatura}

AGA 32/o7366. Legajo 5373-4.

\section{Cátedra}

Instituciones de Derecho romano.

\section{Universidad}

Santiago y La Laguna.

\section{Anuncio}

R.O. de 18 de febrero, 1925. Gaceta del 21.

La cátedra de Santiago había sido anunciada por R.O. de 11 de noviembre de 1920 y la de La Laguna por anuncio en la Gaceta de 19 de octubre de 1921.

\section{Reglamento aplicable}

8 de abril, 1910.

\section{Fechas de la oposición}

Constitución del tribunal: 7 de enero, 1926.

Presentación de los opositores: 23 de enero, 1926.

Votación: 4 de febrero, 1926.

Propuesta: 5 de febrero, 1926.

\section{Tribunal}

Presidente: Felipe Clemente de Diego.

Vocales: José Fernández y González, Jerónimo González y Martínez, José Pou de Foxá.

Secretario: Wenceslao Roces.

\section{Opositores}

Esteban Madruga. 
José Arias Ramos.

No comparecieron: Antonio Córdova, Carlos Sánchez Peguero.

Francisco Pelsmaeker e Ivañez se retiró el 27 de enero.

\section{Votación}

José Arias ganó la votación para el primer lugar por tres votos (de Diego, Fernández, Pou) contra dos de Esteban Madrugá (Roces y González).

Esteban Madruga fue votado por unanimidad para el segundo lugar.

José Arias optó por la cátedra de Santiago y Esteban Madruga aceptó la de La Laguna. Fueron propuestos.

\section{Materiales}

De tipo administrativo: actas, oficios varios del negociado, hojas de servicios de José Arias y Esteban Madrugá.

De tipo académico o referentes a los ejercicios:

- Cuestionario elaborado por el tribunal (105 temas).

- Escritos del primer ejercicio. Dos temas: "La manus iniecto y la pignoris capio"; "Modos de extinción de las obligaciones ope exceptionis".

- Ejercicios prácticos (tercer ejercicio).

- Programa aportado por José Arias.

- Programa aportado por Esteban Madruga (82 lecciones).

- Trabajo doctrinal aportado por José Arias: La existimatio y sus causas modificativas.

- Trabajo doctrinal aportado por Esteban Madrugá: El ejercicio y la tutela de los derechos en Roma.

\section{Signatura}

AGA 32/07367. Legajo 5374-1.

\section{Cátedra}

Economía política y Hacienda pública.

\section{Universidad}

La Laguna.

\section{Anuncio}

R.O. de 18 de febrero de 1925. Gaceta del 21.

Fue anunciada a oposición en momento anterior, por R.O. de 30 de diciembre de 1919. Gaceta del 20 de febrero de 1920. 


\section{Reglamento aplicable}

8 de abril, 1910.

\section{Fechas de la oposición}

Constitución del tribunal: 17 de noviembre, 1925.

Presentación de los opositores: 26 de noviembre, 1925.

Votación y propuesta: 14 de diciembre, 1925.

\section{Tribunal}

Presidente: Adolfo Álvarez Buylla.

Vocales: Antonio Flores de Lemus, Ramón Carande, Amando Castroviejo.

Secretario: Agustín Viñuales Pardo.

\section{Opositores}

José Álvarez de Cienfuegos.

No comparecieron: Antonio Bravo y Díaz-Cañedo, Enrique Rodríguez, Alfonso de Viedma, Guillermo Cabrera, Teodoro González, Gabriel Franco.

Fueron excluidos: Buenaventura Benito, Juan Ferrer.

\section{Votación}

José Álvarez de Cienfuegos es votado y propuesto por unanimidad.

\section{Materiales}

De tipo administrativo: actas, oficios varios del negociado, oficios sobre conformación del tribunal, certificados a favor de José Álvarez (académico, registro de penados, Junta para la Ampliación de Estudios).

De tipo académico o referentes a los ejercicios:

- Cuestionario elaborado por el tribunal (114 temas).

- Escritos del primer ejercicio. Dos temas: "El interés del capital”; "La contribución industrial en España".

- Ejercicios prácticos (tercer ejercicio).

- Escrito de libros solicitados por el opositor.

- Memoria sin indicación de su autor: Concepto de la sistemática de las asignaturas de Economía política y hacienda pública que se desarrolla en los programas y breves reflexiones sobre el modo de realizar su exposición en cátedra. - Programas aportados por José Álvarez de Cienfuegos: Economía política (52 lecciones) y elementos de hacienda pública (34 lecciones).

- Trabajo doctrinal de José Álvarez de Cienfuegos: Historia del desarrollo de la política ferroviaria española hasta la ordenación ferroviaria de 12 de julio de 1924. 


\section{Signatura}

AGA 32/07364. Legajo 5372-4.

\section{Cátedra}

Derecho civil español, omún y foral.

\section{Universidad}

La Laguna.

\section{Anuncio}

R.O. de 18 de febrero, 1925. Gaceta del 21.

La cátedra ya había sido anunciada a oposición por R.O. de 9 de septiembre de 1920. Gaceta del 18.

\section{Reglamento aplicable}

8 de abril, 1910.

\section{Fechas de la oposición}

Constitución del tribunal: 27 de octubre, 1925.

Presentación de los opositores: 9 de noviembre, 1925.

Votación y propuesta: 21 de noviembre, 1925.

\section{Tribunal}

Presidente: Felipe Clemente de Diego.

Vocales: Felipe Sánchez Román, Gil Gil y Gil, Guillermo García Valdecasas.

Secretario: Rafael Atard.

Gil Gil y Gil abandona el tribunal el 12 de noviembre por enfermedad. Consta su carta dirigida al presidente del tribunal.

\section{Opositores}

José Viñas Mey.

Esteban Madrugá Jiménez.

Vicente Guilarte González.

No comparecieron: Antonio Córdova, Teodoro González, Hipólito González, Lino Torre, José Arias.

\section{Votación}

Todos votan la no provisión de la cátedra. 


\section{Materiales}

De tipo administrativo: actas, oficios varios del negociado, oficios sobre conformación del tribunal.

De tipo académico o referentes a los ejercicios:

- Cuestionario elaborado por el tribunal (149 temas).

- Escritos del primer ejercicio. Dos temas: "La sucesión legítima o abintestato"; "El concepto del contrato".

- Ejercicios prácticos (tercer ejercicio).

- Escrito de libros solicitados por los opositores.

- Programa aportado por Vicente Guilarte (105 lecciones).

- Trabajo doctrinal aportado por Vicente Guilarte: La naturaleza jurídica del llamado contrato de suministro de energía eléctrica.

\section{Signatura}

AGA 32/07365. Legajo 5373-2.

\section{Cátedra}

Elementos de Derecho natural.

\section{Universidad}

Oviedo.

\section{Anuncio}

R.O. de 18 de febrero, 1925. Gaceta del 21.

La catedra ya había sido anunciada a oposición por R.O. de 20 de julio de 1922. Gaceta del 11.

\section{Reglamento aplicable}

8 de abril, 1910.

\section{Fechas de la oposición}

Constitución del tribunal: 1 de marzo, 1926.

Presentación de los opositores: 12 de marzo, 1926.

Votación y propuesta: 23 de marzo, 1926.

\section{Tribunal}

Presidente: Elías Tormo Monzó.

Vocales: Blas Ramos Sobrino, Miguel Sancho Izquierdo, Nicasio Sánchez Mata. Secretario: Mariano Puigdollers. 
Luis Mendizábal presente su renuncia, por concurrir a la oposición su hijo Alfredo Mendizábal.

\section{Opositores}

Alfredo Mendizábal Villalba.

No comparecieron: José Mingarro, José María Farré, Manuel Marina, Miguel María de Pareja, Julián Carlón, Ramón Buide, Arturo Suárez, Cristóbal Caballero, José Escobedo, Wenceslao Roces.

\section{Votación}

Todos votan a Alfredo Mendizábal excepto Ramos, que vota por la no provisión. Alfredo Mendizábal es propuesto.

\section{Materiales}

De tipo administrativo: actas, oficios varios del negociado, oficios sobre conformación del tribunal, certificaciones a favor de Alfredo Mendizábal (académica, partida de nacimiento, antecedentes penales, etc.)

De tipo académico o referentes a los ejercicios:

- Cuestionario elaborado por el tribunal (113 temas).

- Escritos del primer ejercicio. Dos temas: Transmisión y modificación de los derechos. La obligación"; "La justicia distributiva y los tributos".

- Ejercicio práctico (tercer ejercicio).

- Obra aportada por Alfredo Mendizábal: La doctrina de la justicia según la "Suma Teológica", Revista de Cultura y Vida Universitaria, Tipografía la "La Académica", Zaragoza, 1925.

- Tesis para el grado de doctor, aportada por Alfredo Mendizábal: Investigación acerca de la naturaleza, fundamento jurídico y eficacia de los tratados de paz.

- Memoria y programa presentados por Alfredo Mendizábal (76 lecciones).

\section{Signatura}

AGA 32/07364. Legajo 5372-3.

\section{Cátedra}

Economía política y Hacienda pública.

\section{Universidad}

Murcia.

\section{Anuncio}

Gaceta del 21 de febrero, 1925. 


\section{Reglamento aplicable}

8 de abril, 1910.

\section{Fechas de la oposición}

Constitución del tribunal: 26 de octubre, 1925.

Presentación de los opositores: 7 de noviembre, 1925.

Votación y propuesta: 16 de noviembre, 1925.

\section{Tribunal}

Presidente: Adolfo Álvarez Buylla.

Vocales: Antonio Flores de Lemus, Ramón Carande, Amando Castroviejo.

Secretario: Agustín Viñuales Pardo.

\section{Opositores}

Gabriel Franco y López.

No comparecieron: constan instancias de José Álvarez de Cienfuegos y Antonio Bravo y Díaz-Cañedo.

\section{Votación}

Gabriel Franco es votado y propuesto por unanimidad.

\section{Materiales}

De tipo administrativo: actas, oficios varios del negociado, certificado de la Junta de Ampliación de Estudios a favor de Gabriel Franco.

De tipo académico o referentes a los ejercicios:

- Cuestionario elaborado por el tribunal (114 temas).

- Escritos del primer ejercicio. Dos temas: "Sucinta historia de la Economía política en Francia hasta la aparición de la fisiocracia", "El dinero. La llamada teoría política del dinero".

- Ejercicios prácticos (tercer ejercicio).

- Escrito de libros solicitados por el opositor.

- Obra doctrinal aportada por Gabriel Franco: Los impuestos cedulares y el impuesto global sobre la renta en Francia.

- Programas aportados por Gabriel Franco: Economía política (43 lecciones) y elementos de hacienda pública (54 lecciones).

- Defensa de los programas de Economía política y elementos de hacienda pública, con unas breves consideraciones acerca de la enseñanza de estas asignaturas en las facultades de Derecho de España, por Gabriel Franco. 


\section{Signatura}

AGA 32/13394 y 13395. Legajo 6982-2.

\section{Cátedra}

Derecho mercantil de España y de las principales naciones de Europa y América.

\section{Universidad}

Central.

\section{Anuncio}

Gaceta de 19 de noviembre, 1925.

\section{Fechas de la oposición}

1927, 7 de abril: constitución del tribunal.

1927, 3 de mayo: presentación de los opositores.

1927, 10 de junio: votación y propuesta.

\section{Tribunal}

Presidente: Felipe Clemente de Diego.

Vocales: Antonio de la Figuera y Lezcano, Emilio Miñana y José M. ${ }^{a}$ González de Echávarri.

Secretario: Felipe Sánchez-Román Gallifa.

\section{Opositores}

Francisco Bernis Carrasco.

Agustín Vicente y Gella.

Tomás J. Elorrieta y Artaza.

José de Benito Mampel.

Antonio Sacristán Colás.

José Valiente Soriano.

Joaquín Garrigues Díaz-Cañabate.

Todos pasan a la votación final.

\section{Votación y propuesta}

1927, 10 de junio. Votación: Joaquín Garrigues se lleva los votos de Sánchez Román, De Diego y Figuera; Echávarri vota no provisión; Miñana vota a Valiente Soriano. Se formula propuesta a favor de Joaquín Garrigues y Díaz-Cañabate.

\section{Materiales}

Opositor Francisco Bernis (AGA 32/13395): Programa de Derecho mercantil (6o 
lecciones), Memoria, Trabajo de firma ("Regulación jurídica de la Banca privada").

Opositor Agustín Vicente y Gella (AGA 32/13395): Trabajo de firma ("Naturaleza jurídica de las resoluciones de la asamblea general de una sociedad anónima"); en AGA 32/13394 la Memoria ("Memoria sobre el alcance y desarrollo que debe tener en las Universidades la asignatura Derecho mercantil..”) y el Programa (107 lecciones).

Opositor Joaquín Garrigues (AGA 32/13395): Trabajo de firma ("El depósito irregular y su aplicación en Derecho mercantil - Historia y derecho comparado), Memoria y Programa (69 lecciones: "Proyecto de curso en forma de programa de Derecho mercantil de España y de las Principales naciones de Europa y América"). Retiraron sus materiales Elorrieta (28 de junio, 1927) Valiente (misma fecha), De Benito (2 de septiembre, 1927.) y Sacristán (13 de septiembre, 1927).

Obran en el expediente las instancias y, en su caso, las relaciones de méritos de catorce firmantes.

\section{Signatura}

AGA 32/13398. Legajo 6983-5.

\section{Cátedra}

Derecho político español, comparado con el extranjero.

\section{Universidad}

Sevilla.

\section{Anuncio}

R.O. de 17 de diciembre, 1925. Gaceta del 19.

\section{Reglamento aplicable}

8 de abril, 1910 .

\section{Fechas de la oposición}

Constitución del tribunal: 14 de enero, 1927.

Presentación de los opositores: 26 de enero, 1927.

Votación y propuesta: 19 de febrero, 1927.

\section{Tribunal}

Presidente: Adolfo González Posada.

Vocales: Gonzalo del Castillo Alonso, Adolfo Pous, Tomás Elorrieta. 
Secretario: Teodoro González García.

\section{Opositores}

José Viani Caballero.

Manuel Martínez Pedroso.

Ramón Gil y Armada.

Justino Azcárate.

No comparecieron: Carlos Sanz Cid, José Arturo Rodríguez, Teodoro González, Sabino Álvarez.

\section{Votación}

Primera votación:

- José Viani: un voto (González).

- Manuel Martínez Pedroso: dos votos (Posada y Pous).

- Ramón Gil y Armada: un voto (Ruiz del Castillo).

- Justino Azcárate: un voto (Elorrieta).

En la segunda votación Martínez Pedroso obtuvo todos los votos. Fue propuesto.

\section{Materiales}

De tipo administrativo: actas, instancias de los aspirantes con acreditaciones de méritos.

De tipo académico o referentes a los ejercicios:

- Cuestionario elaborado por el tribunal (115 temas).

- Escritos del primer ejercicio. Dos temas: "Concepto de Derecho constitucional. Critica de las ideas de Esmein y Orlando. La concepción de Hauriou”; "Relaciones entre la Iglesia y el Estado".

- Ejercicios prácticos (tercer ejercicio): Constitucionalidad de una ley que en Inglaterra, Norte América, Francia y España prorrogara el mandato parlamentario. - Escrito de libros consultados por los opositores.

Materiales de Martínez Pedroso:

- Notas sobre la sistemática y enseñanza del Derecho político comparado.

- Plan de un curso de Derecho político comparado (57 lecciones).

- Ejemplos de un nuevo método para la construcción de una teoría general del Estado.

Materiales de Justino Azcárate:

- Memoria explicativa del programa, y texto del mismo.

- Memoria de investigación: La democracia moderna. La democracia en la nueva tendencia hacia el gobierno de los Estados nacionales, por los órganos ejecutivos; en la organización soviética y en la Sociedad de Naciones. 


\section{Signatura}

AGA 32/13540 y 13541. Legajo 9147.

\section{Cátedra}

Derecho civil español, común y foral.

\section{Universidad}

Zaragoza y Salamanca.

\section{Anuncio}

R.O. de 19 de enero, 1926. Gaceta del 26. Se convocaba también la provisión de la cátedra de Santiago.

Aparecen instancias de opositores que indican convocatorias anteriores de éstas cátedras: para Salamanca el 16 de noviembre de 1921; para Zaragoza el 12 de julio, 1920. Se menciona que tales convocatorias fueron suspendidas por el directorio militar.

\section{Reglamento aplicable}

8 de abril, 1910.

\section{Fechas de la oposición}

Constitución del tribunal: 31 de enero, 1927.

Presentación de los opositores: 10 de febrero, 1927.

Votación: 6 de marzo, 1927. La propuesta el día siguiente.

\section{Tribunal}

Presidente: Clemente de Diego.

Vocales: Felipe Gil Casares, Felipe Sánchez-Román Gallifa, Ignacio de Casso.

Secretario: Francisco Candil.

\section{Opositores}

Vicente Guilarte.

José Viñas Mey.

Alfonso García Valdecasas.

Eugenio Tarragato.

Martín Luis Sancho.

Nicolás Santos de Otto y Escudero. Se retira el 28 de febrero. 


\section{Votación}

Por unanimidad Valdecasas ganó la votación del primer lugar y Martín Luis Sancho la del segundo.

Valdecasas optó por la cátedra de Zaragoza y Sancho por la de Zaragoza. Fueron propuestos.

\section{Materiales}

De tipo administrativo: actas, oficios varios del negociado, telégrafos relativos a la conformación del tribunal, instancias de los aspirantes con acreditación de méritos. De tipo académico o referentes a los ejercicios:

- Cuestionario elaborado por el tribunal (150 temas).

- Escritos del caso práctico.

- Escritos del primer ejercicio. Dos temas: "Sistemas matrimoniales. Concepto, clasificación e idea de cada uno"; "Servidumbres de luces, vistas y desagües de edificios. Derecho foral".

Materiales de Valdecasas:

- Programa.

- Memoria pedagógica.

- Trabajo de investigación: Algunas consideraciones sobre el artículo 464 del Código Civil.

- Tesi di laurea: La fórmula H.M.H.N.S. nelle iscrizioni funerarie romane, R. Universitá di Bologna, 1924-25.

Materiales de Sancho:

- Programa.

- Algunas consideraciones sobre la didáctica del Derecho civil.

El problema de las deudas de dinero en el Derecho actual, Universidad. Revista de Cultura y Vida Universitaria, Zaragoza, 1926.

- Trabajo de investigación: El testamento mancomunado del Derecho aragonés.

- El gremio zaragozano del siglo XVI. Datos para una historia de la organización corporativa del trabajo en España, Tip. "La Academica”, Zaragoza, 1925.

Materiales de De Otto:

- Programas.

- Elementos de Derecho civil aragonés, Imp. moderna de Isabelino Castillón, Barbastro, 1924.

- Trabajo de investigación: Formas típicas de explotación de la tierra en Cataluña y Aragón.

Materiales de Tarragato:

- Programa.

- Modo de entender el opositor, el concepto, contenido, carácter, limites, método, procedimiento, fuentes y medios de enseñanza de la disciplina. 
- Consta un sobre con documentos. "I. De mis conferencias en Alemania. II. En prensa. La causa de las obligaciones por el Prof. Henri Capitant. Traducción y notas".

- Trabajo de investigación: Ungerechtfertigt-Bereicherung.

- Trabajo del opositor acerca de el [sic] Fuero Juzgo y Las Partidas con especial referencia a la historia interna.

- La afinidad. Estudio histórico y de derecho comparado, prólogo de Jerónimo González, introducción de Max Gmur, Góngora, Madrid, 1925.

- El divorcio en las legislaciones comparadas. La fórmula de la discrepancia objetiva, prólogo de Quintiliano Saldaña, introducción de Wilhelm Kahl, Góngora, Madrid, 1925. Fue objeto de una Noticia bibliográfica en la Revista General de Legislación y Jurisprudencia, abril 1925, Tomo 146, Núm. IV, por Julio Martínez de la Fuente.

- Dr. Richter, Brief aus Spanien, Deutsche Juristen-Zeitung, Den 1 Januar 1925.

- Dr. Jur., Untersuchunsrichter, Brief aus Spanien, Deutsche Juristen-Zeitung, Den 15 März, 1926.

- Traducción de Otto Kehrle, Sobre el estado de las cárceles españolas, francesas y suizas. No aparece procedencia.

- La capacidad de la mujer casada, Revista General de Legislación y Jurisprudencia, julio 1924, Tomo 145, Núm. VII.

Materiales de Viñas:

- Programa.

- Noticias bibliográficas, J. González, El derecho real de superficie; Pinto Loureiro y Mario de Almeida, Código civil portugués nos Tribunais, Revista de Derecho Privado, enero 1923, Núm. 112.

- La prenda irregular, Revista de Derecho Privado, noviembre 1925, Núm. 146.

- El derecho de retención, Revista de Derecho Privado, abril 1922, Núm. 103.

Materiales de Guilarte: programa.

Consta un trabajo de investigación sin autor: Sobre la naturaleza del llamado contrato de suministro de energía eléctrica.

\section{Signatura}

AGA 32/ 13458. Legajo 8135-2.

\section{Cátedra}

Derecho administrativo.

\section{Universidad}

Santiago. 


\section{Anuncio}

R.O. de 19 de enero, 1926. Gaceta del 26.

\section{Reglamento aplicable}

8 de abril, 1910.

\section{Fechas de la oposición}

Constitución del tribunal: 28 de octubre, 1926.

Presentación de los opositores: 10 de noviembre, 1926.

Votación y propuesta: 9 de diciembre, 1926.

\section{Tribunal}

Presidente: José Gascón Marín.

Vocales: Antonio Royo Villanova, Antonio Mesa, Antonio Goicoechea.

Secretario: José Valenzuela.

\section{Opositores}

Juan Gil Armada.

Joaquín García Labella.

Sabino Álvarez Blanco Guendín.

Álvaro Olea Pimentel.

Todos pasaron a la votación final.

No comparecieron: Ramón Buide, José Viani, Miguel Cuevas, Joaquín Uguet, Juan Marco Elorriaga, Jesús Fernández Novoa.

\section{Votación}

Primera votación:

- García Labella: dos votos (Mesa y Gascón).

- Sabino Álvarez Guendín: dos votos (Valenzuela, Goicoechea).

- Álvaro Olea: un voto (Royo).

Segunda votación:

- García Labella: dos votos (Royo, Mesa y Gascón).

- Sabino Álvarez Guendín: dos votos (Valenzuela, Goicoechea).

Joaquín García Labella fue propuesto.

\section{Materiales}

De tipo administrativo: actas, instancias de los aspirantes con acreditación de méritos.

De tipo académico o referentes a los ejercicios:

- Cuestionario elaborado por el tribunal (132 temas). 
- Escritos del primer ejercicio. Dos temas: "La actividad administrativa y el intervencionismo del Estado"; "Accidentes de trabajo y enfermedades profesionales". - Ejercicio práctico (tercer ejercicio).

- Escrito de libros consultados por el opositor.

Materiales de Joaquín García Labella:

- Programa.

- Memoria.

- Trabajo de investigación: Algunas consideraciones sobre las garantías jurisdiccionales, en nuestra disciplina jurídica.

Materiales de Juan Gil Armada:

- Programa.

- Memoria.

- Trabajo de investigación: La trasformación de la estructura y del funcionamiento del Estado en especial relación con la idea de soberanía, con la noción del municipio, base de la vida local, y con el concepto de responsabilidad.

Materiales de Álvaro Olea Pimentel.

- Programa.

- Memoria.

- Problemas del Estado. Cuartillas para un estudio de "la actividad administrativa", Revista General de Legislación y Jurisprudencia, agosto de 1922, Tomo 141, entrega II, p. 135 .

\section{Signatura}

AGA 32/13399. Legajo 6984-2.

\section{Cátedra}

Derecho mercantil de España y de las principales naciones de Europa y América.

\section{Universidad}

Murcia y Santiago.

\section{Anuncio}

R.O. de 24 de enero, 1927. Gaceta del 27.

\section{Fechas de la oposición}

1928, 16 de enero: constitución del tribunal.

1928, 27 de enero: presentación de los opositores.

1928, 10 de marzo: votación. La propuesta el 11 de marzo. 


\section{Tribunal}

Presidente: Antonio Royo Villanova.

Vocales: Ricardo Mur, Prudencio Requejo, Adolfo Morís.

Secretario: Emilio Langle.

\section{Opositores}

Antonio Sacristán Colás.

Lino Torre Silva.

José de Benito Mampel.

Salvador Martínez Moya Crespo.

Todos pasan a la votación final.

No comparecieron: Ramón Buide, Landelino Moreno, José Viani, Álvaro Olea, Enrique Martín, Manuel Giménez, Luis Lamana Lizarbe, Antonio Hoyuela, José Alguer, Álvaro Calvo, Miguel Cabeza, Francisco Hernández, Vicente Guilarte. Victoriano Nuño abandonó por sufrir "desvanecimientos" (Consta comunicación del 29 de enero).

\section{Votación y propuesta}

La votación del primer lugar fue ganada por Antonio Sacristán con todos los votos menos el de Requejo, que votó por la no provisión.

Primera votación del segundo lugar:

- José de Benito: dos votos (Langle y Villanova).

- Salvador Martínez Moya: un voto (Morís).

- Mur y Requejo votaron por la no provisión de la cátedra.

Segunda votación del segundo lugar:

- José de Benito: tres votos (Morís, Langle y Villanova).

- Mur y Requejo votaron por la no provisión de la cátedra.

Sacristán optó por la cátedra de Santiago y de Benito aceptó la de Murcia.

\section{Materiales}

De tipo administrativo: actas, instancias de los aspirantes con acreditación de méritos.

De tipo académico o referentes a los ejercicios:

- Cuestionario elaborado por el tribunal (129 temas).

- Escritos del primer ejercicio. Dos temas: "Del préstamo mercantil"; "De los contratos mercantiles de garantía”.

- Ejercicios prácticos (tercer ejercicio).

Materiales de Antonio Sacristán:

- Programa (73 lecciones).

- Memoria explicativa del método de investigación y de enseñanza y del conteni- 
do de la asignatura "Derecho mercantil de España y de las principales naciones de Europa y América".

- Trabajo de investigación: Apuntes sobre el concepto de cosa fungible. Comodato de títulos.

- Memoria: Casa fondo o hacienda comercial, premiada por el Círculo de la Unión Mercantil, 1924.

Materiales de José de Benito:

- Derecho mercantil. Obra ajustada al programa del primer ejercicio de oposiciones al Cuerpo de Aspirantes a la Judicatura y al Ministerio fiscal, de 5 de enero de 1922, Reus, Madrid, 1922.

- Memoria pedagógica.

- Trabajo de investigación: La doctrina de la personalidad de las sociedades mercantiles. Sus problemas en el orden teórico y sus consecuencias en el campo legislativo.

- Prólogo y notas a Vivante, César; La unidad del Derecho privado en materia de obligaciones, Librería General de Victoriano Suárez, Madrid, 1925.

\section{Signatura}

AGA 32/13393. Legajo 6982-1.

\section{Cátedra}

Elementos de Derecho natural.

\section{Universidad}

Santiago.

\section{Anuncio}

R.O. de 7 de febrero, 1927. Gaceta del 17.

\section{Reglamento aplicable}

8 de abril, 1910.

\section{Fechas de la oposición}

Constitución del tribunal: 13 de octubre, 1927.

Presentación de los opositores: 27 de octubre, 1927.

Votación y propuesta: 3 de diciembre, 1927.

\section{Tribunal}

Presidente: Laureano Díez Canseco. 
Vocales: Blas Ramos, Luis Mendizábal, Fernando Pérez Bueno.

Secretario: Miguel Sancho.

\section{Opositores}

Luis Recasens Siches.

Antonio Luna García.

Enrique Luño Peña.

No comparecieron: Ramón Gil, Pedro Moreno, Antonio Hoyuela.

Cristóbal Caballero abandona el 4 de noviembre.

Pasaron al cuarto ejercicio Luna, Recasens y Luño.

\section{Votación}

Luis Recasens fue votado y propuesto por unanimidad.

\section{Materiales}

De tipo administrativo: actas, oficios varios del negociado, instancias de los aspirantes con acreditación de méritos. Ejemplares de la Gaceta: 8 de octubre de 1925, 31 de julio de 1926, 23 de mayo de 1925.

De tipo académico o referentes a los ejercicios:

- Cuestionario elaborado por el tribunal (138 temas).

- Escritos del primer ejercicio. Dos temas: "Exámen histórico-crítico de la institución de la esclavitud"; "La cuestión del divorcio".

- Ejercicios prácticos (tercer ejercicio).

Memoria y programa (61 lecciones) de Recasens.

Trabajos de investigación de Recasens:

- La filosofía jurídica alemana actual.

- El positivismo jurídico. Leon Duguit: exposición y examen crítico de sus doctrinas. Obras de Recasens:

- Aspectos de la vida académica y científica germana en la post-guerra. Conferencia pronunciada el día 24 de febrero de 1927, Conferencias dadas en el Centro de Intercambio Intelectual Germano-español, Madrid, 1927.

- Il concetto di diritto subiettivo innanzi alla filosofía giuridica, Estratto dalla Rivista Internazionale di Fillosofia del Diritto, A.VI, Fasc.IV, Arti Grafique Ugo Pinnarò, Roma, 1926.

- La filosofía jurídica de Francisco Suárez. Con un estudio previo sobre sus antecedentes en la patrística y en la escolástica, Librería general de Victoriano Suárez, Madrid, 1927.

- Concepto lógico-genérico del Derecho. La nota de coactividad, Revista General de Legislación y Jurisprudencia (publicado en el núm. de octubre de 1921), Reus, Madrid, 1924. 
- El profesor D. Mario Saénz en Madrid, Revista General de Legislación y Jurisprudencia, 1925, Tomo 146, núm VI, p. 846.

- El sistema filosófico-jurídico expuesto por Platón en su "República". Síntesis interpretativa y comentada, Estudio leído en la Cátedra de Derecho natural de la Universidad de Barcelona en febrero de 1920, Publicado en la Revista jurídica de Cataluya, Imprenta Casanovas, Barcelona.

\section{Signatura}

AGA 32/13384. Legajo 6977-1.

\section{Cátedra}

Derecho civil español, común y foral.

\section{Universidad}

Barcelona.

\section{Anuncio}

R.O. de 20 de mayo, 1927. Gaceta del 31.

\section{Reglamento aplicable}

8 de abril, 1910.

\section{Fechas de la oposición}

Constitución del tribunal: 5 de mayo, 1928.

Presentación de los opositores: 5 de mayo, 1928.

Votación y propuesta: 20 de junio, 1928.

\section{Tribunal}

Presidente: Felipe Clemente de Diego.

Vocales: Ignacio de Casso, Esteban Madruga, Alfonso García de Valdecasas.

Secretario: José Viñas Mey.

\section{Opositores}

Nicolás Santos de Otto Escudero.

José Alguer Micó.

Blas Pérez González.

Joaquín de Dalmases Jordana.

Agustín Vicente Gella. 
No comparecieron: Vicente Guilarte, Demófilo de Buen, Francisco de Pelsmaeker, Faustino Ballvé, Luis Recasens y Siches, Ramón Coll, Francisco Campos, Antonio María Simarro.

\section{Votación}

Primera votación:

- Nicolás Otto: un voto (Viñas).

- Blas Pérez: dos votos (Valdecasas y de Diego).

- Joaquín Dalmases: dos votos (Madruga y Casso).

En la segunda votación todos votaron a Blas Pérez. Fue propuesto.

\section{Materiales}

De tipo administrativo: actas, oficios varios del negociado, instancias de los aspirantes con certificaciones académicas y hojas de servicio y otros méritos.

De tipo académico o referentes a los ejercicios:

- Cuestionario elaborado por el tribunal (168 temas).

- Escritos del primer ejercicio. Dos temas: "Efectos jurídicos del matrimonio respecto a las personas de los cónyuges"; "La institución del heredero en el derecho foral, especialmente en el catalán".

- Ejercicios prácticos (tercer ejercicio).

- Escrito de libros consultados por los opositores.

Programas aportados:

- Por Nicolas S. de Otto (primer curso, 82 lecciones; segundo curso, 67 lecciones).

- Por Blas Pérez (208 lecciones).

- Por Agustín Vicente: (170 lecciones).

- Por José Alguer (primer curso, 79 lecciones; segundo curso, 81 lecciones).

Trabajos doctrinales aportados:

- Por Nicolas S. de Otto: El hombre civil y el hombre comercial.

- Por Nicolas S. de Otto: Formas típicas de explotación de la tierra en Cataluña y Aragón.

- Por Blas Pérez: El requisito de la viabilidad en el código civil.

- Por Agustín Vicente: Naturaleza jurídica de las resoluciones de la asamblea general de una sociedad anónima.

- Por Agustín Vicente: La división de los contratos en el derecho romano justinianeo.

Memorias pedagógicas de José Alguer, Agustín Vicente, Nicolás de Otto y Blas Pérez.

Obra aportadas:

- José Alguer, Tratado de la avería común. Según la historia, la teoría, el dere- 
cho positivo y las reglas de York y Amberes de 1924, con prólogo de Pedro Hors y Bau, Tipología de Santiago Vives, Barcelona, 1926.

- José Alguer: El concepto de la buena fe en la génesis y en la técnica del derecho privado, Imprenta Casanovas, Barcelona, 1928.

\section{Signatura}

AGA 32/13391. Legajo 6981-1.

\section{Cátedra}

Instituciones de Derecho canónico.

\section{Universidad}

Central.

\section{Anuncio}

R.O. de 7 de junio, 1927. Gaceta del 15.

\section{Reglamento aplicable}

8 de abril, 1910.

\section{Fechas de la oposición}

Constitución del tribunal: 12 de noviembre, 1928.

Presentación de los opositores: 27 de noviembre, 1928.

Votación y propuesta: 12 de diciembre, 1928.

\section{Tribunal}

Presidente: Leopoldo Eijo Garay, obispo de Madrid-Alcalá.

Vocales: Laureano Díez Canseco, José María Campos Pulido, Isidro Iglesias García.

Secretario: Nicolás S. de Otto.

\section{Opositores}

Tomás Gómez Piñán.

Teodoro Andrés Marcos.

Eloy Montero Gutiérrez.

Francisco Romero Otazo.

No comparecieron: José Escobedo, Heraclio Sánchez, José Pou, Enrique Ramos, Laureano Sánchez.

Pasaron al cuarto ejercicio: Piñán, Andrés Marcos y Montero Gutiérrez. 


\section{Votación}

Eloy Montero ganó la votación por tres votos (Iglesias, Campos, Obispo de Madrid-Alcalá) contra dos de Tomás Gómez Piñán (Díez Canseco y de Otto). Fue propuesto.

\section{Materiales}

De tipo administrativo: actas, oficios varios del negociado, instancias presentadas por los aspirantes con acreditaciones de méritos. Ejemplares de la Gaceta de Madrid de 13 de diciembre de 1927 y 9 de noviembre de 1928.

Referentes a los ejercicios:

- Cuestionario elaborado por el tribunal (128 temas).

- Escritos del primer ejercicio. Dos temas: "Noción y naturaleza de la jerarquía Potestad de la Iglesia"; "Bautismo. Significación jurídica. Su trascendencia canónica".

- Ejercicios prácticos (tercer ejercicio).

- Escrito de libros consultados por los opositores.

Programas aportados:

- Por Francisco Romero (62 lecciones).

- Por Gómez Piñán (77 lecciones).

Trabajos de investigación:

- Por Eloy Montero: El espíritu del código de Derecho canónico.

- Por Gómez Piñán: Antonio Agustín (1516-1586). Su significación en el estudio de la ciencia canónica.

Memorias pedagógicas de Piñan, Montero y Romero.

Obras de Eloy Montero:

- La guerra ante el Derecho y ante la Iglesia, Gran Imprenta Católica, Madrid, 1915. Publicado en la Revista del Clero español.

- Programa de Instituciones de Derecho canónico, Escuelas Profesionales de Artes y Oficios, Sevilla, 1922.

- Tratado de matrimonio canónico y causas matrimoniales, Imprenta de Eulogio de la Heras, Sevilla, 1927.

- Instituciones de Derecho canónico, Tomos I y II. Tipografía de Alberto Fontana, Madrid, 1928.

Obras de Francisco Romero:

- El penitencial silense. Trabajo leído en la apertura del curso académico de 1928 a 1929 en el seminario conciliar de Madrid, Imprenta de A. Sáez, Madrid, 1928. 


\section{Signatura}

AGA 32/13387 y 32/13388. Legajo 6979-1.

\section{Cátedra}

Derecho civil español, común y foral.

\section{Universidad}

Santiago y La Laguna.

\section{Anuncio}

R.O. de 7 de octubre, 1927. Gaceta del 23.

\section{Reglamento aplicable}

8 de abril, 1910.

\section{Fechas de la oposición}

Constitución del tribunal: 21 de abril, 1930.

Presentación de los opositores: 7 de mayo, 1930.

Votación: 31 de mayo, 1930.

Propuesta: 1 de junio, 1930.

\section{Tribunal}

Presidente: Antonio Royo Villanova.

Vocales: Demófilo de Buen, Felipe Sánchez-Román, Francisco Candil.

Secretario: Alfonso García de Valdecasas.

\section{Opositores}

Federico de Castro Bravo.

Vicente Guilarte.

José Alguer Micó.

Joaquín de Dalmases Jordana.

No comparecieron: Nicolás Santos de Otto y Escudero, Blas Pérez González, Francisco de Pelsmaeker, Francisco Campos, Cristino Jiménez, Antonio Hoyuela, Sandalio Moreno.

\section{Votación}

Primera votación del primer lugar:

- De Castro: dos votos (Candil y de Buen).

- Guilarte: un voto (Sánchez-Román).

- Dalmases: dos votos (Valdecasas y Royo).

En la segunda votación todos votaron a de Castro. 
Primera votación del segundo lugar:

- Alguer: un voto (de Buen).

- Guilarte: dos votos (Sánchez-Román y Royo).

- Dalmases: dos votos (Valdecasas y Candil).

En la segunda votación todos votaron a Guilarte.

De Castro optó por la cátedra de La Laguna y Guilarte aceptó la de Santiago. Fueron propuestos.

\section{Materiales}

De tipo administrativo: actas, oficios varios del negociado, comunicaciones sobre conformación del tribunal, instancias de los aspirantes con acreditación de méritos.

De tipo académico o referentes a los ejercicios:

- Cuestionario elaborado por el tribunal (111 temas).

- Escritos del primer ejercicio. Dos temas: "Aparcería"; "Naturaleza jurídica del cargo de contador-partidor".

- Ejercicios prácticos (tercer ejercicio).

- Escrito de libros consultados por los opositores.

Programas aportados:

- Por Federico de Castro.

- Por Vicente Guilarte: (170 lecciones).

- Por José Alguer (170 lecciones).

Trabajos doctrinales aportados:

- Por Federico de Castro: Los conceptos de deuda y responsabilidad en el derecho de obligaciones.

- Por Vicente Guilarte: Sobre la naturaleza jurídica del llamado contrato de suministro de energía.

Memorias pedagógicas de Federico de Castro, Vicente Guilarte y José Alguer.

Obras aportadas por Federico de Castro:

- El autocontrato en el derecho privado español. Ensayo de construcción jurídica, Presentado como tesis para aspirar a la obtención de grado de doctor en derecho, Editorial Reus, Madrid, 1929.

- Revista de revista jurídicas. Alemanas, Revista General De Legislación y Jurisprudencia, 1928, Tomo 152, Núm. V, p. 621.

- Revista de revista jurídicas. Alemanas, Revista General De Legislación y Jurisprudencia, 1928, Tomo 152, Núm. I, p. 101.

- Revista de revista jurídicas. Alemanas, Revista General De Legislación y Jurisprudencia, 1928, Tomo 152, Núm. III, p. 361.

- Revista de revistas. Alemanas, Revista General De Legislación y Jurisprudencia, 1928, Tomo 153, Núm. VI, p. 698. 
- El autocontrato en el derecho privado español, Revista General De Legislación y Jurisprudencia, 1927, Tomo 151, Núms. III-IV, p. 334.

- Cesión del arrendamiento y subarrendamiento, Revista General De Legislación y Jurisprudencia, 1930, Tomo 156, Núm. II, p. 130.

- Haff, Karl, Institutionen des deutschen Privatsrechts auf rechtsvergleichender und soziologischer Grundlage zugleich Einführung ins bürgerliche Recht, Boletín Bibliográfico del Centro de Intercambio Intelectual Germano-español, 1928, n. ${ }^{\circ}$ 4, p. 68.

- El artículo 141 de la Ley Hipotecaria, Revista de Derecho Privado, 1929, Núm. 195, p. 417.

Obras aportadas por José Alguer:

- Tratado de la avería común. Según la historia, la teoría, el derecho positivo y las reglas de York y Amberes de 1924, con prólogo de Pedro Hors y Bau, Tipología de Santiago Vives, Barcelona, 1926.

- El concepto de la buena fe en la génesis y en la técnica del derecho privado, Imprenta Casanovas, Bercelona, 1928.

- La teoría de la avería común y las leyes marítimas escandinavas (Tesis doctoral), Imprenta hijo de Domingo Casanovas, Barcelona, 1928.

- Notes bibliogràfiques, Paul Jörs, Römisches Rechst, Revista Jurídica de Catalunya, Volum XXXV, 1929.

- Notes bibliogràfiques, José M. Omar y Gelpí, Los tribunales de comercio, bases para su restablecimiento en España, Revista Jurídica de Catalunya, Volum XXXV, 1929.

- Nota bibliográfica, François Gorphe, Le principe de la bonne foi Revista Jurídica de Catalunya, Volum XXXIV, 1928.

\section{Signatura}

AGA 32/13392. Legajo 6981-2.

\section{Cátedra}

Economía política y Hacienda pública.

\section{Universidad}

La Laguna.

\section{Anuncio}

R.O. de 7 de octubre de 1927. Gaceta del 23.

\section{Reglamento aplicable}

8 de abril, 1910. 


\section{Fechas de la oposición}

Constitución del tribunal: 6 de abril, 1929.

Presentación de los opositores: 3 de mayo, 1929.

Votación y propuesta: 24 de junio, 1929.

\section{Tribunal}

Presidente: Laureano Díez Canseco.

Vocales: Antonio Flores de Lemus, Vicente Gay, Enrique Rodríguez Mata.

Secretario: Gabriel Franco.

Antonio Flores de Lemus abandona el tribunal por enfermedad el 12 de junio.

\section{Opositores}

Eulogio Alonso-Villaverde Morís.

Álvaro Olea Pimentel.

\section{Votación}

Eulogio Alonso-Villaverde Morís ganó la votación por tres votos (Mata, Franco y Canseco) contra uno de Olea (Gay). Fue propuesto.

\section{Materiales}

De tipo administrativo: actas, oficios varios del negociado, instancia del aspirante Olea con hoja de servicios.

De tipo académico o referentes a los ejercicios:

- Cuestionario elaborado por el tribunal (148 temas).

- Escritos del primer ejercicio. Dos temas: "Del valor. Teoría subjetiva"; "La tasa militar. El impuesto sobre el aumento del patrimonio. El impuesto sobre el capital".

- Ejercicios prácticos (tercer ejercicio).

- Escrito de libros solicitados por los opositores.

Memorias pedagógicas de Alonso-Villaverde y Olea.

Programas aportados:

- Por Olea: Economía política (5o lecciones) y hacienda pública (52 lecciones).

- Por Alonso-Villaverde: Economía política (37 lecciones) y hacienda pública (34 lecciones).

Trabajos doctrinales:

- Alonso-Villaverde: Contribución al estudio del problema de la "inflation" en España.

- Alonso-Villaverde: El Estado y el individuo en su relación político- económica y social.

- Olea: Salario mínimo. 


\section{Signatura}

AGA 32/13398. Legajo 6984-1.

\section{Cátedra}

Instituciones de Derecho romano.

\section{Universidad}

La Laguna.

\section{Anuncio}

R.O. de 7 de octubre, 1927. Gaceta del 23.

\section{Reglamento aplicable}

8 de abril, 1910.

\section{Fechas de la oposición}

Constitución del tribunal: 21 de febrero, 1929.

Presentación de los opositores: 8 de marzo, 1929.

Votación y propuesta: 14 de abril, 1929.

\section{Tribunal}

Presidente: Laureano Díez Canseco.

Vocales: Manuel Miguel Traviesas, Rafael Acosta, Laureano Sánchez Gallego.

Secretario: José Pou de Foxá.

\section{Opositores}

Francisco Pelsmaeker Ibañez.

Carlos Sánchez Peguero.

No comparecieron: Vicente Guilarte, José Viani, José Rodríguez Febles.

\section{Votación}

Francisco Pelsmaeker obtuvo todos los votos menos el de Traviesas, quien votó por la no provisión. Fue propuesto.

\section{Materiales}

De tipo administrativo: actas, instancias de los aspirantes con acreditación de méritos.

De tipo académico o referentes a los ejercicios: 
- Cuestionario elaborado por el tribunal (140 temas).

- Escritos del primer ejercicio. Dos temas: "La patria potestas con relación a las personas", "Requisitos positivos y negativos de las justas nupcias".

- Ejercicios prácticos (tercer ejercicio).

Materiales de Pelsmaeker:

- Mis ideas sobre el contenido y la enseñanza de las Instituciones de Derecho romano".

- Trabajo de investigación: Algunas notas sobre la aestimatum.

- Programa (81 lecciones).

- La audiencia en las colonias españolas de América, Memoria presentada para el grado de Doctor, Tipografía de la "Revista de Archivos", Madrid, 1925.

Materiales de Sánchez Peguero:

- D. 1, 3, 32, pr. Contribución al estudio de las fuentes del Derecho romano, Universidad. Revista de Cultura y Vida Universitaria, Tipografía "La Académica", Zaragoza, 1928.

- La enseñanza del Derecho romano, Universidad. Revista de Cultura y Vida Universitaria, Tipografía "La Académica”, Zaragoza, 1926.

- Ensayo para un estudio sobre la "lex julia municipalis", Extrait des Mélanges de Droit Romain, Gand y París, 1926.

- Carácter, contenido, límites, método y fuetes para las instituciones de derecho romano.

- Programa (62 lecciones).

- La insuficiencia de las leyes en el Derecho romano. Apuntes para un estudio, Talleres tipográficos Berdejo Castañal, Zaragoza, 1924.

\section{Signatura}

AGA 32/13395. Legajo 6983-2.

\section{Cátedra}

Historia general del Derecho español.

\section{Universidad}

La Laguna.

\section{Anuncio}

R.O. de 26 de noviembre, 1927. Gaceta del 3 de diciembre.

\section{Reglamento aplicable}

8 de abril, 1910. 


\section{Fechas de la oposición}

Constitución del tribunal: 1 de febrero, 1929.

Presentación de los opositores: 14 de febrero, 1929.

Votación y propuesta: 18 de marzo, 1929.

\section{Tribunal}

Presidente: Laureano Canseco.

Vocales: César Mantilla, Galo Sánchez, José Manuel Segura Soriano.

Secretario: Manuel Torres López.

\section{Opositores}

José Antonio Rubio Sacristán.

Fernando Vida Nájera.

\section{Votación}

José Antonio Rubio obtuvo todos los votos menos el de Mantilla, quien votó por la no provisión. Rubio fue propuesto.

\section{Materiales}

De tipo administrativo: actas, instancias de Fernando Vida.

De tipo académico o referentes a los ejercicios:

- Cuestionario elaborado por el tribunal (137 temas).

- Escritos del primer ejercicio. Dos temas: "La legislación visigótica antes de Eurico"; "La plebs urbana y los collegia".

- Ejercicios prácticos (tercer ejercicio).

- Escrito de libros consultados por los opositores.

José Antonio Rubio retiró sus materiales el 21 de abril de 1931, los cuales eran:

- Programa.

- Trabajo de investigación: Notas y documentos para el derecho medieval castellano".

Se conserva la memoria pedagógica de José Antonio Rubio. 


\section{Signatura}

AGA 32/13397. Legajo 6983-4.

El expediente está digitalizado.

\section{Cátedra}

Elementos de Derecho natural.

\section{Universidad}

La Laguna.

\section{Anuncio}

R.O. de 26 de noviembre, 1927. Gaceta del 3 de diciembre.

\section{Reglamento aplicable}

8 de abril, 1910.

\section{Fechas de la oposición}

Constitución del tribunal: 29 de septiembre, 1928.

Presentación de los opositores: 17 de octubre, 1928.

Votación y propuesta: 16 de noviembre, 1928.

\section{Tribunal}

Presidente: Laureano Díez Canseco.

Vocales: Blas Ramos, Alfredo Mendizábal, Agustín Viñuales.

Secretario: Luis Recasens Siches.

\section{Opositores}

Antonio Luna García.

No comparecieron: Enrique Luño Peña, Ramón Gil.

\section{Votación}

Antonio Luna fue votado y propuesto por unanimidad.

\section{Materiales}

De tipo administrativo: actas, instancias de los aspirantes con acreditación de méritos.

De tipo académico o referentes a los ejercicios:

- Cuestionario elaborado por el tribunal (160 temas).

- Escritos del primer ejercicio. Dos temas: "Los problemas jurídicos y políticos en la filosofía patrística"; "La filosofía de Husserl y sus diversas aplicaciones al derecho". 
- Ejercicio práctico (tercer ejercicio): Comentario al capítulo IX del libro I de Mariana "Del rey y de la institución real" intitulado "De cómo el príncipe no está exento de guardar las leyes".

Materiales de Antonio Luna:

- Trabajo de investigación: El valor de la costumbre como fuente del derecho.

- Memoria.

- Programa (85 lecciones).

\section{Signatura}

AGA 32/13395. Legajo 6983-1

\section{Cátedra}

Derecho internacional público y privado.

\section{Universidad}

La Laguna.

\section{Anuncio}

R.O. de 26 de noviembre, 1927. Gaceta del 3 de diciembre.

\section{Reglamento aplicable}

8 de abril, 1910.

\section{Fechas de la oposición}

Constitución del tribunal: 27 de octubre, 1928.

Presentación de los opositores: 8 de noviembre, 1928.

Votación y propuesta: 20 de noviembre, 1928.

\section{Tribunal}

Presidente: Antonio Royo Villanova.

Vocales: Adolfo Morís, José Yanguas, Camilo Barcia.

Secretario: José R. de Orúe (por fallecimiento del Ramón María de Dalmau, marqués de Olivart).

\section{Opositores}

Luis Sela Sempil.

No comparecieron: José Viani, Pedro Moreno.

\section{Votación}

Por unanimidad se acordó no haber lugar a la provisión de la cátedra. 


\section{Materiales}

De tipo administrativo: actas, instancias de los aspirantes con acreditación de méritos.

De tipo académico o referentes a los ejercicios:

- Cuestionario elaborado por el tribunal (120 temas).

- Escritos del primer ejercicio. Dos temas: "La limitación de armamentos en el pacto de la Sociedad de Naciones"; "Teoría del respeto de los derechos adquiridos".

- Ejercicio práctico (tercer ejercicio): "Los agentes diplomáticos en el Derecho español”.

- Escrito de libros consultados por el opositor.

\section{Signatura}

AGA 32/13405. Legajo 6985-6.

\section{Cátedra}

Procedimientos judiciales, práctica forense y redacción de instrumentos públicos.

\section{Universidad}

La Laguna.

\section{Anuncio}

R.O. de 10 de diciembre, 1927. Gaceta del 18.

\section{Reglamento aplicable}

8 de abril, 1910.

\section{Fechas de la oposición}

Constitución del tribunal: 10 de enero, 1929.

Presentación de los opositores: 24 de enero, 1929.

Votación y propuesta: 22 de febrero, 1929.

\section{Tribunal}

Presidente: Antonio Royo Villanova.

Vocales: Francisco Marcos Pelayo, Manuel Miguel Traviesas, Quintín Palacios.

Secretario: Francisco Beceña.

\section{Opositores}

Rafael de Pina.

Fausto Vicente Gella. 
No comparecieron: Álvaro Olea Pimentel, Luis Navarro Canales, José Guallart. Fausto Vicente Gella se retiró antes del primer ejercicio.

\section{Votación}

Rafael de Pina obtuvo tres votos (Royo, Palacios y Pelayo) contra dos por la no provisión (Beceña y Traviesas). Fue propuesto.

\section{Materiales}

De tipo administrativo: actas, oficios varios del negociado.

De tipo académico o referentes a los ejercicios:

- Cuestionario elaborado por el tribunal (132 temas).

- Escritos del primer ejercicio. Dos temas: "División de acciones por la naturaleza jurídica de la resolución a cuya consecución se destinan. Acciones de condena"; "Los juicios universales de expropiación: La quiebra: Órganos de dirección y gestión: facultades de los síndicos: atribuciones de las juntas".

- Ejercicios prácticos (tercer ejercicio).

- Escrito de libros solicitados por el opositor.

Materiales de Rafael de Pina:

- Proyecto de programa de Procedimientos Judiciales, Práctica Forense y Redacción de Instrumentos Públicos (68 lecciones).

- Memoria pedagógica.

- Trabajo de Investigación: El recurso de casación civil en interés de la ley.

- Tesis para el grado de doctor: Los funcionarios públicos y el derecho de huelga, Madrid, 1927.

\section{Signatura}

AGA 32/13405. Legajo 6985-5.

\section{Cátedra}

Procedimientos judiciales, práctica forense y redacción de instrumentos públicos. En algunos documentos del expediente (actas) se denomina Derecho procesal.

\section{Universidad}

Salamanca.

\section{Anuncio}

R.O. de 27 de julio, 1926. Gaceta del 4 de agosto.

Segunda convocatoria por R.O. de 20 de diciembre de 1927. Gaceta del 27. 


\section{Reglamento aplicable}

8 de abril, 1910.

\section{Fechas de la oposición}

Constitución del tribunal: 4 de abril, 1929.

Presentación de los opositores: 17 de abril, 1929.

Votación y propuesta: 14 de mayo, 1929.

\section{Tribunal}

Presidente: Laureano Díez Canseco. Por R.O. de 17 de septiembre de 1927 se admite la renuncia del anterior presidente, Tomás Montejo Rica.

Vocales: Mauro Miguel Romero, Casto Barahona, Quintín Palacios.

Secretario: Francisco Beceña.

Se indica que se desestimó la recusación del aspirante José García Revillo contra los jueces Montejo y Comín. No consta escrito de recusación ni resolución.

\section{Opositores}

Fausto Vicente Gella.

José Serrano Suárez.

No comparecieron: Adolfo Cuéllar, Nicolás de Otto, Álvaro Olea Pimentel, Victoriano Nuño Beato Asin, José García Revillo, Máximo Peña, Justo Villanueva, José Viani, Rafael de Pina, Francisco Marcos Pelayo, Luis Navarro Canales, Mauro Miguel Romero (vocal).

Fausto Vicente Gella se retiró al comienzo del primer ejercicio "manifestando encontrarse enfermo".

\section{Votación}

Serrano fue votado y propuesto por unanimidad.

\section{Materiales}

De tipo administrativo: actas, oficios varios del negociado, oficios sobre conformación del tribunal.

De tipo académico o referentes a los ejercicios:

- Cuestionario elaborado por el tribunal (115 temas).

- Escritos del primer ejercicio. Dos temas: "La libre designación por el ejecutivo; el juez inglés; estudio de la organización judicial inglesa"; "La prueba en el procedimiento penal".

- Ejercicios prácticos (tercer ejercicio).

- Escrito de libros solicitados por el opositor.

Materiales de Serrano: 
- Programa de Procedimientos Judiciales (81 lecciones).

- Programa de Práctica Forense y Redacción de Iinstrumentos Públicos (35 lecciones).

Materiales de Adolfo Cuéllar:

- Las garantías del ciudadano frente a la Administración, Conferencia pronunciada en la "Casa del Estudiante" el 20 de marzo de 1926, Imprenta "La exposición”, Sevilla, 1926.

- Derecho Municipal Comparado. El problema de la democracia y la eficacia en el régimen municipal moderno, Tesis doctoral leída el 23 de abril de 1919, Imprenta "La exposición”, Sevilla, sin fecha.

\section{Signatura}

AGA 32/13400. Legajo 6984-3.

\section{Cátedra}

Derecho mercantil de España y de las principales naciones de Europa y América

\section{Universidad}

Santiago.

\section{Anuncio}

R.O. de 5 de junio, 1928. Gaceta del 12.

\section{Fechas de la oposición}

1930, 27 de enero: constitución del tribunal

1930, 12 de febrero: presentación de los opositores

1930, 5 de marzo: votación y propuesta.

\section{Tribunal}

Presidente: Tomás Montejo.

Vocales: Emilio Langle, Antonio de la Figuera, José de Benito.

Secretario: Joaquín Garrigues.

\section{Opositores}

Lino Torre Silva.

Salvador Martínez Moya Crespo.

Miguel Cabeza Anide.

Torre y Martínez Moya pasan a la votación final.

No comparecieron: Faustino Giménez Arnau, Ramón Buide, Landelino Moreno, Francisco Hernández, Victoriano Nuño. 


\section{Votación y propuesta}

Salvador Martínez Moya fue votado y propuesto por unanimidad.

\section{Materiales}

De tipo administrativo: actas, instancias de los aspirantes con acreditación de méritos, ejemplar de la Gaceta de 3 de octubre de 1933.

De tipo académico o referentes a los ejercicios:

- Cuestionario elaborado por el tribunal (110 temas).

- Escritos del primer ejercicio. Dos temas: "La acción como derecho"; "La administración de la quiebra”.

- Ejercicios prácticos (tercer ejercicio).

Materiales de Salvador Martínez Moya:

- Programa (102 lecciones).

- Memoria.

- Trabajo de investigación: Las órdenes en frutos.

Materiales de Miguel Cabeza:

- La unificación de las leyes cambiarias, tesis doctoral, Tipografía de la "Revista de Archivos", Madrid, 1925.

- Trabajo de investigación: El cheque circular italiano.

- Memoria pedagógica y programa (136 lecciones).

Materiales de Lino Torre:

- Programa (96 lecciones).

- Trabajo de investigación: La violación de la fe comercial.

- Trabajo de investigación: Orientaciones mercantiles.

- Razón del plan adoptado. Exposición del programa.

\section{Signatura}

AGA 32/13383. Legajo 6977-2.

\section{Cátedra}

Derecho penal.

\section{Universidad}

La Laguna.

\section{Anuncio}

Gaceta de 19 de enero, 1929 (R. O. de 15 de enero). 


\section{Reglamento aplicable}

Reglamento de 8 de abril, 1910.

\section{Fechas de la oposición}

1931, 9 de febrero: constitución del tribunal.

1931, 9 de marzo: presentación de los opositores.

1931, 30 de marzo: votación y propuesta.

\section{Tribunal}

Nombramiento: R.O. de 20 de marzo de 1930, Gaceta del 27, con rectificación en la de 1 de abril.

Presidente: Antonio Royo Villanova.

Vocales: Inocencio Jiménez Vicente, Antonio Mesa y Moles, Luis Jiménez de Asúa.

Secretario: José Antón Oneca.

\section{Opositores}

José Guallart y López de Goicoechea (Auxiliar Universidad de Zaragoza).

Emilio González López (Ayudante Universidad de Madrid).

Jaime Masaveu y Masaveu (Auxiliar Universidad de Madrid).

José Viani y Caballero (Auxiliar Universidad de Valladolid).

Se presentaron solo los dos primeros, y ambos llegaron a la votación final.

\section{Votación y propuesta}

1931, 30 de marzo. Emilio González López se lleva los votos de Jiménez de Asúa, Antón Oneca y Royo Villanova. Guallart los de Jiménez Vicente y Mesa y Moles. Se formula propuesta a favor de Emilio González López.

\section{Materiales}

Opositor Emilio González López: Programa de Derecho penal (68 lecciones), Memoria Pedagógica (62 pp.)

Guallart retiró sus materiales (27 de abril, 1931). Un recibo de firma ilegible deja constancia de que años después se retiraron "del Archivo del Ministerio de Instrucción Pública los trabajos presentados... por el opositor Don Emilio González López" (26 de enero, 1935).

Obran en el expediente las instancias de los firmantes, con excepción de la de González López. Obran también los escritos correspondientes a los ejercicios primero (respuesta a dos temas sorteados del cuestionario establecido por el tribunal al comienzo de las pruebas) y tercero (caso práctico) de los dos opositores. 


\section{Signatura}

AGA 32/13403. Legajo 6985-3.

\section{Cátedra}

Derecho internacional público y privado.

\section{Universidad}

La Laguna.

\section{Anuncio}

R.O. de 8 de marzo, 1929. Gaceta del 15.

\section{Reglamento aplicable}

8 de abril, 1910 .

\section{Fechas de la oposición}

Constitución del tribunal: 31 de marzo, 1930.

Presentación de los opositores: 21 de abril, 1930.

Votación y propuesta: 5 de mayo, 1930.

\section{Tribunal}

Presidente: Antonio Royo Villanova.

Vocales: Adolfo Morís, Manuel Lasala, Isidro Beato.

Secretario: Camilo Barcia.

Se admitió la renuncia de José Yanguas (R.O. 8 de marzo de 1929).

\section{Opositores}

Luis Sela Sempil.

No comparecieron: José Viani, Pedro Moreno, Eulogio Alonso.

\section{Votación}

Luis Sela fue votado y propuesto por unanimidad.

\section{Materiales}

De tipo administrativo: actas, instancias de los aspirantes con acreditación de méritos.

De tipo académico o referentes a los ejercicios:

- Cuestionario elaborado por el tribunal (125 temas).

- Escritos del primer ejercicio. Dos temas: "Las teorías de Francisco de Vitoria 
relativas a la autoridad internacional del emperador y del Papa"; "El contrato de transporte en Derecho internacional privado".

- Ejercicio práctico (tercer ejercicio).

- Escrito de libros consultados por el opositor.

Materiales de Luis Sela:

- Memoria.

- Programa de Derecho internacional público: (74 lecciones).

- Programa de Derecho internacional privado: (47 lecciones).

- James Brown Scott, Revista General de Legislación y Jurisprudencia, diciembre de 1927, Tomo 151, núm.VI, p. 632.

- El Instituto de Derecho Internacional de Lausana, Revista General de Legislación y Jurisprudencia, abril de 1928, Tomo 152, núm.IV, p. 396.

Trabajos de investigación de Luis Sela:

- Los mandatos de tutela en el Derecho internacional.

- La función consultiva del Tribunal Permanente de Justicia Internacional, 1926.

- La función consultiva del Tribunal Permanente de Justicia Internacional, 1928.

- Servicios públicos municipales. La concesión administrativa como un modo de gestión de los mismos.

\section{Signatura}

AGA 32/13404. Legajo 6985-4.

\section{Cátedra}

Derecho mercantil.

\section{Universidad}

La Laguna.

\section{Anuncio}

R.O. de 18 de marzo, 1929. Gaceta del 23.

\section{Fechas de la oposición}

1930, 30 de septiembre: constitución del tribunal.

1930, 21 de octubre: presentación de los opositores.

1930, 5 de diciembre: votación y propuesta.

\section{Tribunal}

Presidente: Antonio Royo Villanova. 
Vocales: Agustín Viñuales (en sustitución de José María Boix), Antonio de la Figuera, Joaquín Garrigues.

Secretario: Rafael de Pina.

\section{Opositores}

Álvaro Calvo Alfageme.

Victoriano Nuño Beato.

Enrique Martín Guzmán.

Francisco Hernández Boronde.

Calvo, Nuño y Hernández pasan a la votación final.

No comparecieron: Lino Torre Silva, Miguel Cabeza Anide.

\section{Votación y propuesta}

Francisco Hernández Boronde obtuvo todos los votos menos el de Viñuales, quien votó a Calvo. Fue propuesto.

\section{Materiales}

De tipo administrativo: actas, instancias de los aspirantes con acreditación de méritos.

De tipo académico o referentes a los ejercicios:

- Escritos del primer ejercicio. Dos temas: "Concepto y clasificaciones del contrato mercantil. Formas de celebración. Perfección del contrato, especialmente entre ausentes. Interpretación de los contratos de comercio. Prueba: sus medios"; "Concepto legal de quiebra en el sistema español".

- Ejercicios prácticos (tercer ejercicio).

Materiales de Francisco Hernández Boronde:

- Proyecto de programa (59 lecciones).

- Memoria pedagógica.

- Trabajo de investigación: La cuestión de la vigencia de los "Rooles de Oleron" en España.

\section{Signatura}

AGA 32/13401. Legajo 6985-1.

\section{Cátedra}

Derecho canónico.

\section{Universidad}

Sevilla. 


\section{Anuncio}

R.O. de 23 de mayo, 1929. Gaceta del 24.

\section{Reglamento aplicable}

8 de abril, 1910.

\section{Fechas de la oposición}

Constitución del tribunal: 10 de noviembre, 1930.

Presentación de los opositores: 24 de noviembre, 1930.

Votación y propuesta: 12 de diciembre, 1930.

\section{Tribunal}

Presidente: Leopoldo Eijo Garay, obispo de Madrid-Alcalá.

Vocales: Adolfo Morín, José María Campos Pulido, Eloy Montero Gutiérrez.

Secretario: José Escobedo.

\section{Opositores}

Heraclio Sánchez Rodríguez.

Manuel Giménez Fernández (profesor auxiliar encargado de la asignatura en Sevilla).

Manuel Marín Peña.

No comparecieron: Paulino Pedret, Francisco Hernández.

Pasaron al cuarto ejercicio Giménez y Marín.

\section{Votación}

Manuel Giménez fue votado y propuesto por unanimidad.

\section{Materiales}

De tipo administrativo: actas, oficios varios del negociado, instancias presentadas por los aspirantes con acreditaciones de méritos.

Referentes a los ejercicios:

- Cuestionario elaborado por el tribunal (157 temas).

- Escritos del primer ejercicio. Dos temas: "Concepto del Derecho canónico. Relaciones con otras ciencias. Su influjo sobre las demás ramas jurídicas"; "La jurisdicción meramente gubernativa y la contenciosa en el procedimiento canónico".

- Ejercicios prácticos (tercer ejercicio).

- Escrito de libros consultados por los opositores.

Materiales de Manuel Giménez:

- Memoria.

- Programa (92 lecciones).

- Trabajo de investigación: El concilio IV provincial mejicano. 
Materiales de Manuel Marín:

- Programa (71 lecciones).

- Memoria. Sin título.

\section{Signatura}

AGA 32/13395. Legajo 6983-3.

\section{Cátedra}

Historia del Derecho.

\section{Universidad}

Santiago.

\section{Anuncio}

R.O. de 6 de junio, 1929. Gaceta del 13.

\section{Reglamento aplicable}

8 de abril, 1910.

\section{Fechas de la oposición}

Constitución del tribunal: 27 de noviembre, 1930.

Presentación de los opositores: 9 de diciembre, 1930.

Votación y propuesta: 19 de diciembre, 1930.

\section{Tribunal}

Presidente: Felipe Clemente de Diego.

Vocales: César Mantilla, Rafael Acosta, Claudio Sánchez Albornoz.

Secretario: José Manuel Segura Soriano.

\section{Opositores}

Paulino Pedret Casado.

Fernando Vida Nájera.

\section{Votación}

Todos votaron por la no provisión menos Acosta, quien votó a Fernando Vida Nájera. Se declaró desierta la provisión.

\section{Materiales}

De tipo administrativo: actas, instancias con acreditación de méritos. 
De tipo académico o referentes a los ejercicios:

- Cuestionario elaborado por el tribunal (118 temas).

- Escritos del primer ejercicio. Dos temas: "Fuentes del derecho musulmán. El Korán. La sunnat y otras fuentes", "Los consejos durante la Casa de Austria".

- Ejercicios prácticos (tercer ejercicio).

- Escrito de libros consultados por los opositores.

Paulino Pedret retiró sus materiales el 19 de diciembre de 1930.

\section{Signatura}

AGA 32/13561. Legajo 9576-6.

\section{Cátedra}

Derecho civil.

\section{Universidad}

Central.

\section{Anuncio}

3 de septiembre, 1929. Gaceta del 11.

La convocatoria fue anulada y suspendida definitivamente por la tramitación del expediente por R.O. de 5 de febrero, 1930. Gaceta del 6 (disposición 1. ${ }^{a}$ ).

\section{Reglamento aplicable}

8 de abril, 1910.

\section{Fechas de la oposición}

No consta que la oposición se celebrara.

\section{Tribunal}

No consta.

\section{Opositores}

Constan algunas instancias depositadas por error en ese legajo, que son de otra facultad.

\section{Materiales}

Oficios del negociado e instancias de opositores. 


\section{Signatura}

AGA 32/13561. Legajo 9576-13.

\section{Cátedra}

Derecho penal.

\section{Universidad}

Central.

\section{Anuncio}

R.O. de 3 de septiembre, 1929. Gaceta del 11.

Suspendida definitivamente la tramitación del expediente por R.O. de 5 de febrero de 1930. Gaceta del 6, Disposición 1. ${ }^{\mathrm{a}}$

\section{Reglamento aplicable}

8 de abril, 1910.

\section{Fechas de la oposición}

No consta que la oposición se celebrara.

\section{Tribunal}

No consta.

\section{Opositores}

Constan instancia de los siguientes aspirantes:

José Guallart López de Goicoechea.

Luis Jiménez de Asúa.

Enrique de Benito de la Llave.

José Antón Oneca.

Jaime Masaveu Masaveu.

\section{Materiales}

Oficios del negociado e instancias de los aspirantes, con acreditación de méritos. 


\section{Signatura}

AGA 32/13402. Legajo 6985-2.

\section{Cátedra}

Derecho mercantil.

\section{Universidad}

Murcia.

\section{Anuncio}

R.O. de 8 de noviembre, 1929. Gaceta del 15.

\section{Fechas de la oposición}

1931, 12 de enero: constitución del tribunal.

1931, 27 de enero: presentación de los opositores.

1931, 17 de marzo: votación y propuesta.

\section{Tribunal}

Presidente: Antonio Royo Villanova.

Vocales: Leopoldo García Alas García Argüelles, Salvador Salom Antequera, Joaquín Garrigues.

Secretario: José de Benito.

\section{Opositores}

Lino Torre Silva.

Salvador Martínez Moya Crespo.

Miguel Cabeza Anide.

Álvaro Calvo Alfageme.

Torre y Calvo pasan a la votación final.

No comparecieron: Enrique Martín, Antonio Polo, Agustín Vicente, Francisco Hernández, Victoriano Nuño.

\section{Votación y propuesta}

Álvaro Calvo ganó la votación con todos los votos menos el de Villanova, que votó Lino Torre. Fue propuesto.

\section{Materiales}

De tipo administrativo: actas, instancias de los aspirantes con acreditación de méritos. 
De tipo académico o referentes a los ejercicios:

- Cuestionario elaborado por el tribunal (122 temas).

- Escritos del primer ejercicio. Dos temas: "Sociedades de capital variable. Comercialización de sociedades cooperativas. Formas superiores de cooperación. Trusts y Kartells. Otras formas especiales"; "Avería simple: sus causas y su liquidación. Arribada forzosa. Abordaje. Salvamento y asistencia".

- Ejercicios prácticos (tercer ejercicio).

Materiales de Álvaro Calvo:

- Trabajo de investigación: La doctrina del aval.

- Concepto, método y fuentes del Derecho mercantil.

Materiales de Miguel Cabeza:

- La unificación de las leyes cambiarias, tesis doctoral, Tipografía de la "Revista de Archivos", Madrid, 1925.

- Trabajo de investigación: El cheque circular italiano.

- Memoria pedagógica y programa (9o lecciones).

Materiales de Lino Torre:

- Programa (74 lecciones).

Razón de plan adoptado.

- Trabajo de investigación: El nombre ante el Derecho mercantil.

- La cláusula "salvo ingreso en caja" en la cuenta corriente, Tipología Suc. De Paredes, Santiago, 1924.

\section{Signatura}

AGA 32/13389. Legajo 6980-2.

\section{Cátedra}

Derecho natural.

\section{Universidad}

Santiago.

\section{Anuncio}

R.O. de 7 de marzo, 1930. Gaceta del 11.

\section{Reglamento aplicable}

8 de abril, 1910.

\section{Fechas de la oposición}

Constitución del tribunal: 3 de noviembre, 1931. 
Presentación de los opositores: 16 de noviembre, 1931.

Votación y propuesta: 6 de diciembre, 1931.

\section{Tribunal}

Presidente: Antonio Royo Villanova.

Vocales: Gonzalo del Castillo, Blas Ramos, Miguel Sancho.

Secretario: Luis Recasens Siches.

\section{Opositores}

Enrique Luño Peña.

José Viani Caballero.

No comparecieron: Antonio Luna, Ramón Gil, Paulino Pedret, Cristóbal Caballero, Luis Hernández.

\section{Votación}

Enrique Luño ganó la votación por tres votos (Recasens, Sancho y Castillo) contra uno de José Viani (Royo) y uno por la no provisión (Ramos). Fue propuesto.

\section{Materiales}

De tipo administrativo: actas, oficios varios del negociado, instancias de los aspirantes con acreditación de méritos.

De tipo académico o referentes a los ejercicios:

- Cuestionario elaborado por el tribunal (121 temas).

- Escritos del primer ejercicio. Dos temas: "La teoría pura del Derecho según Kelsen y su escuela"; "Nacionalismo y cosmopolitismo".

- Ejercicios prácticos (tercer ejercicio).

- Escrito de libros consultados por los opositores.

Materiales aportados por Enrique Luño:

- Programa (54 lecciones).

- Memoria pedagógica: El Derecho natural. Su carácter, contenido y límites. Método y Plan para su exposición.

- Trabajo de investigación: Prolegómenos de filosofía del Derecho I. Fundamentación valorativa.

- Artículo publicado en revistas: Il pragmatismo giuridico di Q. Saldaña, Estratto dalla Rivista Internazionale di Filosofia del Diritto, Anno XI, Fasc.II, Roma, 1931. 


\section{Signatura}

AGA 32/13393. Legajo 6982-3

\section{Cátedra}

Historia general de Derecho.

\section{Universidad}

Central.

\section{Anuncio}

R.O. de 25 de marzo, 1930. Gaceta del 1 de abril.

\section{Reglamento aplicable}

8 de abril, 1910.

\section{Fechas de la oposición}

Constitución del tribunal: 17 de diciembre, 1930.

Presentación de los opositores: 17 de diciembre, 1930.

Votación y propuesta: 10 de enero, 1931.

\section{Tribunal}

Presidente: Rafael Altamira.

Vocales: Juan Salvador Minguijón, José María Ots, Claudio Sánchez Albornoz (catedrático de historia de España antigua y media de Madrid).

Secretario: Ramón Prieto Bances.

\section{Opositores}

Galo Sánchez Sánchez.

Manuel Torres López.

No comparecieron: Román Riaza Martínez-Ossorio, Vicente Guilarte, Juan Beneyto.

\section{Votación}

Galo Sánchez fue votado y propuesto por unanimidad.

\section{Materiales}

De tipo administrativo: actas, instancias de los aspirantes con acreditación de méritos.

De tipo académico o referentes a los ejercicios:

- Cuestionario elaborado por el tribunal (113 temas). 
- Escritos del primer ejercicio. Dos temas: "Herculano", "Hinojosa".

- Ejercicios prácticos (tercer ejercicio).

- Escrito de libros consultados por los opositores.

Materiales aportados por Galo Sánchez:

- Programa (51 lecciones).

- Memoria.

- Artículo: Para la historia de la redacción del antiguo derecho territorial castellano, del Anuario de Historia del Derecho español, Tipografía de Archivos, Madrid, 1930.

\section{Signatura}

AGA 32/13390. Legajo 6980-1.

\section{Cátedra}

Derecho procesal.

\section{Universidad}

Sevilla y Salamanca.

\section{Anuncio}

R.O. de 7 de julio, 1930. Gaceta del 11.

\section{Reglamento aplicable}

8 de abril, 1910.

\section{Fechas de la oposición}

Constitución del tribunal: 22 de octubre, 1931.

Presentación de los opositores: 4 de noviembre, 1931.

Votación: 25 de noviembre, 1931.

Propuesta el 26 de noviembre.

\section{Tribunal}

Presidente: Aniceto Sela.

Vocales: Francisco Beceña, Manuel Miguel Traviesas, José Xirau.

Secretario: Nicolás Pérez Serrano.

\section{Opositores}

Emilio Gómez Orbaneja.

Antonio Luna García.

Adolfo Cuéllar Rodríguez. 
No comparecieron: Niceto Alcalá- Zamora Castillo, Francisco J. Dotres, Leonardo Prieto Castro, José Guallart, Francisco Marcos, Pedro Moreno Lostau, Luis Navarro Canales, José Monge.

\section{Votación}

Emilio Gómez Orbaneja fue votado y propuesto por unanimidad para el primer lugar. Para el segundo lugar se acordó por unanimidad no haber lugar a la provisión.

Emilio Gómez Orbaneja optó por la cátedra de Salamanca.

\section{Materiales}

De tipo administrativo: actas, oficios varios del negociado, instancias de los aspirantes con acreditaciones de méritos adjuntas.

De tipo académico o referentes a los ejercicios:

- Cuestionario elaborado por el tribunal (130 temas).

- Escritos del primer ejercicio. Dos temas: "El juicio de testamentaría"; "Actos de jurisdicción voluntaria referentes al derecho de sucesiones, al de propiedad y al de posesión".

- Ejercicios prácticos (tercer ejercicio).

- Escritos de libros solicitados por los opositores.

Materiales aportados por Gómez Orbaneja:

- Trabajo doctrinal: La confesión judicial anticipada. Si cabe una confesión propia en el periodo alegatorio. El artículo 549 de la Ley de E.C.

- Trabajo doctrinal: Las teorías de la cosa juzgada. Su valor sistemático.

- Memoria y programa (99 lecciones).

Materiales aportados por Adolfo Cuéllar:

- Memoria sobre el contenido, carácter límites, método, procedimiento pedagógico, fuentes y elementos de conocimiento, de la disciplina "Derecho procesal".

- Programa (110 lecciones).

Materiales aportados por Alcalá-Zamora

- El desistimiento espontáneo y el arrepentimiento activo (Memoria doctoral), Imprenta del Colegio Nacional de Sordomudos, Madrid, 1928.

- La condena en costas, Imprenta del Colegio Nacional de Sordomudos, Madrid, 1930.

- Salgado de Somoza en la literatura alemana sobre concurso de acreedores, Trabajo presentado a la Junta para la Ampliación de Estudios, 1932.

- Los recursos en nuestras leyes procesales, Revista Crítica de Derecho Inmobiliario, Año VI, Núm. 61, 1930.

- Los recursos en nuestras leyes procesales (conclusión), Revista Crítica de Derecho Inmobiliario, Año VI, Núm. 62, 1930. 
- Lo que debe ser el Ministerio Público, Revista General de Legislación y Jurisprudencia, Tomo 155, núm.V, noviembre de 1929, p. 519.

\section{Signatura}

AGA 32/13385 y 32/13386. Legajo 6978.

\section{Cátedra}

Derecho procesal.

\section{Universidad}

Zaragoza.

\section{Anuncio}

R.O. de 7 de julio, 1930. Gaceta del 11.

\section{Reglamento aplicable}

8 de abril, 1910.

\section{Fechas de la oposición}

Constitución del tribunal: 19 de enero, 1932.

Presentación de los opositores: 2 de febrero, 1932.

Votación y propuesta: 12 de marzo, 1932.

\section{Tribunal}

Presidente: Antonio Royo Villanova.

Vocales: Francisco Beceña, Tomás Montejo, Gabriel Bonilla.

Secretario: José Serrano.

\section{Opositores}

Niceto Alcalá-Zamora Castillo.

Leonardo Prieto Castro.

No comparecieron: Emilio Gómez Orbaneja, Antonio Luna, Adolfo Cuéllar, José

Guallart, Francisco Marcos, Pedro Moreno y Loustau, Luis Navarro Canales.

\section{Votación}

Leonardo Prieto ganó la votación por tres votos (Serrano, Beceña, Bonilla) contra dos de Niceto Alcalá-Zamora (Montejo y Royo). Fue propuesto. 


\section{Materiales}

De tipo administrativo: actas, oficios varios del negociado, instancias de los aspirantes con acreditaciones de méritos adjuntas.

De tipo académico o referentes a los ejercicios:

- Cuestionario elaborado por el tribunal (131 temas).

- Escritos del primer ejercicio. Dos temas: "El interdicto"; "El derecho y el interés como título para recurrir en la vía contencioso-administrativa”.

- Ejercicios prácticos (tercer ejercicio).

- Escritos de libros solicitados por los opositores.

- Memoria pedagógica de Niceto Alcalá-Zamora.

Artículos de Leonardo Prieto publicados en revistas:

- Notas Bibliográficas: Rosenberg (Dr. Leo): Lehrbuch des deutschen Zivilprozessrechts, Revista de Derecho Privado, núm. 220, Tomo XIX, año 1932, p. 31.

- Notas Bibliográficas: Larenz (Karl): Rechtgeschäfts, Revista de Derecho Privado, núm. 213, Tomo XVIII, año 1931, p. 205.

- La acción en el derecho español (I), Boletín de la Universidad de Granada, año III, núm. 13, abril de 1931.

Traducciones de Leonardo Prieto y un artículo sobre él:

- La reforma del procedimiento civil en Alemania, por el Dr. H. Schoch, Revista de Derecho Privado, núm. 211, Tomo XVIII, año 1931, p. 106.

- Manuel de la Plaza, Notas Bibliográficas: Prieto Castro (Leonardo): La acción en el derecho español, Revista de Derecho Privado, núms. 214-215, Tomo XVIII, año 1931, p. 255.

Obras de Alcalá-Zamora

- El desistimiento espontáneo y el arrepentimiento activo (Memoria doctoral), Imprenta del Colegio Nacional de Sordomudos, Madrid, 1928.

- Un español mal comprendido. Salgado de Somoza en la literatura alemana sobre concurso de acreedores, Ediciones Morata, Nueva Generación, Madrid, 1932.

- La condena en costas, Imprenta del Colegio Nacional de Sordomudos, Madrid, 1930.

Trabajos de investigación de Alcalá-Zamora:

- Niceto Alcalá-Zamora, Salgado de Somoza en la literatura alemana sobre concurso de acreedores, Trabajo presentado a la Junta para la Ampliación de Estudios, 1932.

- Niceto Alcalá-Zamora, Prácticas, usos y costumbres en el derecho procesal.

- Niceto Alcalá-Zamora, Consideraciones acerca de la reforma procesal.

Artículos de Niceto Alcalá-Zamora publicados en revistas:

- Los recursos en nuestras leyes procesales, Revista Crítica de Derecho Inmobiliario, Año VI, Núm. 61, 1930. 
- Los recursos en nuestras leyes procesales (conclusión), Revista Crítica de Derecho Inmobiliario, Año VI, Núm. 62, 1930.

- Lo que debe ser el Ministerio Público, Revista General de Legislación y Jurisprudencia, Tomo 155, núm.V, noviembre de 1929, p. 519.

\section{Signatura}

AGA 32/13444. Legajo 7003-4.

\section{Cátedra}

Estudios superiores de Ciencia política y Derecho político.

\section{Universidad}

Central.

\section{Anuncio}

R.O. de 25 de agosto, 1930. Gaceta del 28.

\section{Reglamento aplicable}

No se menciona.

\section{Fechas de la oposición}

Constitución del tribunal: 18 de noviembre, 1930.

Presentación de los opositores: 20 de noviembre, 1930.

Primer ejercicio: 20 de noviembre, 1930.

Votación y propuesta: 22 de noviembre, 1930.

\section{Tribunal}

Presidente: José Gascón Marín.

Vocales: Adolfo González Posada, Eduardo Sanz Escartín (Conde de Lizárraga).

\section{Opositores}

Fernando de los Ríos Urruti (catedrático de Derecho político de Granada).

No comparecieron: Teodoro González García (catedrático de Derecho político de Murcia).

\section{Votación}

Fernando de los Ríos fue votado y propuesto por unanimidad.

Se mencionan sus "brillantes ejercicios practicados". 


\section{Materiales}

- Actas.

- Oficio (o manuscrito) del negociado de 3 de noviembre de 1930.

No constan los ejercicios, ni obras del opositor, ni programa, ni memoria.

\section{Signatura}

AGA 32/13459. Legajo 8136-1.

AGA 32/13460. Legajo 8136-1.

\section{Cátedra}

Filosofía del Derecho.

\section{Universidad}

Central.

\section{Anuncio}

1 de agosto, 1931. Gaceta del 5 .

\section{Reglamento aplicable}

25 de junio, 1931.

\section{Fechas de la oposición}

Constitución del tribunal: 11 de marzo, 1932.

Presentación de los opositores: 12 de marzo, 1932.

Votación y propuesta: 21 de abril, 1932.

\section{Tribunal}

Presidente: José Ortega y Gasset.

Vocales: Luis Jiménez de Asúa, Miguel Sancho Izquierdo, Fernando Pérez Bueno.

Secretario: José Xirau.

\section{Opositores}

Luis Recasens Siches.

Francisco Rivera Pastor.

Blas Ramos Sobrino.

No comparecieron: Antonio Luna García.

\section{Votación}

Luis Recasens fue votado y propuesto por unanimidad. 


\section{Materiales}

De tipo administrativo: actas, oficios varios del negociado, instancias de los aspirantes con acreditación de méritos.

De tipo académico o referentes a los ejercicios:

- Cuestionario elaborado por el tribunal (138 temas).

- Escritos del quinto ejercicio: "Un pasaje del libro quinto de la República de Platón".

- Escritos del sexto ejercicio: “¿Cómo podrá caracterizarse la actitud íntima del hombre actual frente al Derecho en general? (comienzo del enunciado)".

Materiales de Recasens:

- Programa.

- Misión y perspectiva de la Filosofía del Derecho.

- Cuestionario de Teoría general de la Ciencia Jurídica, Universidad de Valladolid, 1930-31.

- El sentimiento y la idea de lo justo. Psicologismo y objetivismo en la Filosofía del Derecho, Conferencia dada el 30 de noviembre de 1928, Centro de Intercambio Intelectual Germano-español, Madrid, 1929.

- Aspectos de la vida académica y científica germana en la post-guerra. Conferencia pronunciada el día 24 de febrero de 1927, Conferencias dadas en el Centro de Intercambio Intelectual Germano-español, Madrid, 1927.

- La filosofía jurídica de Francisco Suárez. Con un estudio previo sobre sus antecedentes en la patrística y en la escolástica, Librería general de Victoriano Suárez, Madrid, 1927.

- En torno al subsuelo filosófico de las ideologías políticas, Reus, Madrid, 1928.

- La unitat de la construccio jurídica i el dret intenacional. Un estudi de filosofia del dret internacional, extret de la Miscel-lània Patxot, Librería Verdaguer, Barcelona, 1931.

- El actual viraje del socialismo germánico, Talleres Gráficos de E. Giménez, Madrid, 1928.

- Prólogo a la traducción de Hans Kelsen, Compendio esquemático de una Teoría General del Estado. Madrid, 1927.

- Con Justino de Azcárate Florez, traducción de Hans Kelsen, Compendio esquemático de una Teoría General del Estado, Núñez y Comp., Barcelona.

Traducción, prólogo y extensas adiciones a Giorgio del Vecchio, Filosofía del Derecho, dos tomos, Bosch, Barcelona, 1929.

- Las teorías políticas de Francisco de Vitoria. Con un estudio sobre el desarrollo de la idea del contrato social, Suc. de Rivadeneyra, Madrid, 1931.

- Traducción de J. Maury, Observaciones sobre las ideas del profesor H. Kelsen, Revista de Derecho Privado, octubre 1929, núm. 193.

- Direcciones contemporáneas del pensamiento jurídico, Labor, BarcelonaBuenos Aires, 1929 
Artículos en revistas de Siches:

- Il concetto di diritto subiettivo innanzi alla filosofía giuridica, Estratto dalla Rivista Internazionale di Filosofia del Diritto, A.VI, Fasc.IV, Arti Grafique Ugo Pinnarò, Roma, 1926.

- La filosofía del diritto in Germania. Suo stato allá fine del primo quarto del secolo XX, estratto dalla Rivista Internazionale di Filosofia del Diritto, anno VIII, Fasc. I.

- Notas Bibliográficas, Revista de Derecho Privado, diciembre de 1928, núm. 183.

- Artículos en el Boletín Bibliográfico del Centro de Intercambio Intelectual Germano-español. Núms: 1 (1927); 2 (1928); 3 (1929); 4 (1929).

Materiales de Rivera Pastor:

- Programa.

- Concepto, método y límites de la Filosofía del Derecho y del Estado, según algunas recientes investigaciones.

- Prólogo a Gabriel Compayré, Herbart y la educación por la instrucción, Ediciones de la Lectura, Madrid, 1922.

- Estudio preliminar a Eugen Huber, El Derecho y su realización, dos volúmenes, Biblioteca del Instituto Hispano-Americano-Portugués de Derecho comparado, Madrid, 1929.

- Estudio preliminar a Roger Picard, El control obrero en la gestión de las empresas, Instituto Íbero- Americano de Derecho comparado, Madrid, 1926.

- Examen crítico de las ideas filosófico-jurídicas de Max Stirner, Imp. de Fortanet, Madrid, 1920.

- Análisis de los elementos constitutivos del Derecho, Asociación Española para el Progreso de las Ciencias, Madrid.

- Lógica de la libertad. Principios de la doctrina del Derecho, Biblioteca Moderna de Filosofía y Ciencias Sociales, Tip. Artística, Madrid, 1918.

- Con Constancio Bernaldo de Quirós, El problema de los foros en el noroeste de España, Instituto de Reformas Sociales, Sob. De la Suc. de Minuesa de los Ríos, Madrid, 1923.

- El nuevo orden jurídico, segunda edición, Francisco Beltrán, Madrid.

- Las doctrinas del Derecho y del Estado, Librería General de Victoriano Suárez, Madrid, 1910.

- Artículos en la Revista de Derecho Privado: núms. 98 (1921); 99 (1921); 104 (1922); 105 (1922).

- Las corporaciones de trabajo en España, Boletín de la Institución Libre de Enseñanza, núm. 849, enero de 1931. 


\section{Signatura}

AGA 32/13561. Legajo 9576-3.

\section{Cátedra}

Derecho municipal comparado.

\section{Universidad}

Central.

\section{Anuncio}

3 de agosto, 1931. Gaceta del 5 .

Por Orden de 12 de abril de 1932 la tramitación del expediente queda en suspenso.

\section{Reglamento aplicable}

25 de junio, 1931.

\section{Fechas de la oposición}

No consta que la oposición se celebrara.

\section{Tribunal}

No constan propuestas de nombramiento.

\section{Opositores}

Constan instancias de los siguientes:

Sabino Álvarez Guendín.

Recaredo Fernández de Velasco.

Luis Jordana de Pozas.

José Valenzuela Soler.

\section{Materiales}

Oficios del negociado e instancias de los aspirantes, con acreditación de méritos. 


\section{Signatura}

AGA 32/13461. Legajo 8136-2.

\section{Cátedra}

Historia del Derecho.

\section{Universidad}

Barcelona, Santiago y La Laguna.

\section{Anuncio}

Orden de 4 de agosto, 1931. Gaceta del 6.

Se agregó la de La Laguna por Orden de 20 de febrero de 1932. Gaceta del 23 y 24.

\section{Reglamento aplicable}

25 de junio, 1931.

\section{Fechas de la oposición}

Constitución del tribunal: 28 de enero, 1933.

Presentación de los opositores: 30 de enero, 1933.

Votación y propuesta: 30 de marzo, 1933.

\section{Tribunal}

Presidente: Claudio Sánchez Albornoz.

Vocales: Galo Sánchez, José María Ots, José María Ramos Loscertales.

Secretario: Ramón Prieto.

\section{Opositores}

Juan Beneyto Pérez.

Fernando Valls Taberner.

Luis García de Valdeavellano Arcimis.

No comparecieron: José Peraza de Ayala, Luisa Cuesta Gutiérrez, Paulino Pedret Casado, Jaime M. Mans Puigarnau, Pablo Ibañez Navarro.

\section{Votación}

Para el primer lugar Luis García de Valdeavellano fue votado y propuesto por unanimidad.

Para los lugares segundo y tercero se voto por unanimidad la no provisión. Valdeavellano optó por la cátedra de Barcelona. 


\section{Materiales}

De tipo administrativo: actas, instancias de los aspirantes con acreditación de méritos.

Referentes a los ejercicios.

- Informes de los jueces sobre los trabajos de investigación presentados.

- Las actas recogen las evaluaciones de los jueces sobre los ejercicios de cada opositor.

- Escritos del ejercicio quinto: trascripción y comentario de contratos medievales; textos de la Lex Visigothorum.

- Escritos del ejercicio sexto: "Los bienes muebles en el derecho medieval español"; "El beneficio en España hasta el siglo XIV".

Materiales de Luis García de Valdeavellano:

- Memoria sobre el concepto, método, fuentes y programas.

- La cuota de libre disposición en el derecho hereditario de León y Castilla en la alta Edad Media. Notas y documentos, del Anuario de Historia del Derecho español, Tipografía de Archivos, Madrid, 1933.

- El mercado. Apuntes para su estudio en León y Castilla durante la Edad Media, del Anuario de Historia del Derecho español, Tipografía de Archivos, Madrid, 1932.

Beneyto retira sus materiales el 17 de abril, 1933.

Valls retira sus materiales el 29 de abril, 1933.

\section{Signatura}

AGA 32/13456, 13457, 13458, 13459 y 1346o. Legajo 8135-1.

\section{Cátedra}

Derecho administrativo.

\section{Universidad}

Santiago.

\section{Anuncio}

Orden de 16 de enero, 1932. Gaceta del 22.

\section{Reglamento aplicable}

25 de junio, 1931.

\section{Fechas de la oposición}

Constitución del tribunal: 6 de abril, 1933 . 
Presentación de los opositores: 7 de abril, 1933.

Votación y propuesta: 3 de mayo, 1933.

\section{Tribunal}

Presidente: Adolfo González Posada.

Vocales: José Gascón Marín, Recaredo Fernández Velasco, José Valenzuela.

Secretario: Nicolás Pérez Serrano.

\section{Opositores}

Sabino Álvarez Blanco Guendín.

Francisco Félix Montiel Giménez.

No comparecieron: Segismundo Royo.

\section{Votación}

Álvarez Guendín fue votado y propuesto por unanimidad.

\section{Materiales}

De tipo administrativo: actas, instancias de los aspirantes con acreditación de méritos.

- Notas de evaluación de los jueces sobre los trabajos de investigación y obras de los opositores.

- Las actas recogen las evaluaciones de los jueces sobre los ejercicios.

- Escritos del ejercicio sexto.

Materiales de Álvarez Guendín:

- Concepto, método, fuentes y programa.

- La vigencia del Derecho canónico en España, Revista de España y América, 1923, núm. 17.

- Contribución al estudio de una reforma política, Revista General de Legislación y Jurisprudencia, septiembre de 1925, Tomo 147, núm.III, p. 230.

- La concesión y el contrato de Derecho público, Revista General de Legislación y Jurisprudencia, abril de 1930, Tomo 156, núm.IV, p. 423.

- Las tasas de administración de los recursos municipales. Las funciones y prerrogativas de los Secretarios de Corporaciones locales, Gaceta de Administración Local, octubre de 1927, núm.10.

- El interés social como causa de expropiación forzosa, Renovación Social, marzo de 1926, núm.33.

- Le nouveau statut municipal espagnol, Bulletin Mensuel de la Société de Législation Comparée, avril-juin 1924, N. ${ }^{\circ} 4-6$, p. 190.

- Aglomeraciones urbanas y ensanche de poblaciones, Publicaciones de la Unión de Municipios Españoles, Madrid, 1930. 
- Trabajo de investigación: Los contratos públicos.

- Teoría General de las fuentes de Derecho. Consideración especial de las de Derecho Público, prólogo de Recaredo Fernández de Velasco, Reus, Madrid, 1925.

- Regionalismo. Estudio general, prólogo de José María F. Ladreda, Talleres tipográficos Altamirano, Oviedo, 1932

- Las mancomunidades municipales, Tesis doctoral, Tipografía de la "Revista de Archivos, Bibliotecas y Museos”, Madrid, 1921.

- Expropiación forzosa. Su concepto jurídico, Reus, Madrid, 1925.

- Trabajo de investigación: Registro y clasificación de expedientes y documentos.

- Federalismo y autonomismo, Revista de Derecho Público, junio de 1932, núm. 6, p. 167.

- Rescisión, modificación y revisión de contratos públicos, Administración y Progreso, febrero de 1933, núm. 10, p. 4.

- La Constitución y los Estatutos regionales, Administración y Progreso.

Artículos de Álvarez Guendín en la Revista General de Legislación y Jurisprudencia: dos artículos de 1923; Tomo 147, núm. III (1925); Tomo 151, núm. V (1927); Tomo 151, núm. V (1927); Tomo 152, núm. VI (1928); Tomo 154, núm. I (1929); Tomo 156, núm. IV (1930).

Artículos de Álvarez Guendín en la revista El Municipio español:

- Solución para llevar a cabo las obras de urbanización y ensanche. La concesión como uno de los medios para ello, El Municipio español, febrero 1928.

- La fe pública de los Secretarios de Ayuntamiento, El Municipio español, abril 1928.

- El servicio municipal de abastecimiento de agua a particulares en sus relaciones con la Hacienda del Estado, en lo que respecta al impuesto de utilidades, $E l$ Municipio español, junio, 1928.

- El gobierno de las ciudades bávaras, El Municipio español, octubre, 1928.

- Relación entre el Secretario y las Corporaciones. El derecho de advertencia, El Municipio español, enero 1929.

- La patente nacional de circulación de automóviles y los derechos municipales sobre badenes, El Municipio español, enero 1930.

- Los Cantones suizos y las Regiones españolas, El Municipio español, agosto 1930.

- Actuación administrativa del Ayuntamiento de Oviedo, Eficacia municipal, El Municipio español, octubre 1930.

- Un juicio sobre la Asamblea de Valencia. La organización municipal. El Municipio español, diciembre 1930.

- Los estatutos de los organismos locales y la revisión constitucional, El Municipio español, abril 1931. 
- Crítica del procedimiento electoral para la designación de representantes en la Asamblea constituyente, El Municipio español, junio 1930.

Materiales de Montiel:

- Trabajo de investigación: Notas elementales para un estudio comparativo del régimen jurídico municipal en la Ley de 1877 y en el Estatuto de 1924.

- Las instituciones administrativas en el regadío del Segura. Un caso de "colaboración”, Publicaciones de la Universidad de Murcia, Murcia, 1933.

- Memoria y programa.

- Trabajo de investigación: Tres temas de Derecho público.

\section{Signatura}

AGA 32/13520. Legajo 9137-2.

\section{Cátedra}

Derecho canónico.

\section{Universidad}

Murcia.

\section{Anuncio}

18 de enero, 1932. Gaceta del 23.

\section{Reglamento aplicable}

25 de junio, 1931.

\section{Fechas de la oposición}

Constitución del tribunal: 24 de junio, 1935.

Presentación de los opositores: 25 de junio, 1935.

Votación y propuesta: 20 de julio, 1935.

\section{Tribunal}

Presidente: Leopoldo García Alas Garcia Argüelles (por renuncia de Galo Sánchez aceptada por Orden de 19 de octubre, 1932).

Vocales: Manuel Cabrera, Juan Moneva, Nicolás de los Santos Otto.

Secretario: Tomás Gómez Piñán.

\section{Opositores}

Heraclio Sánchez Rodríguez.

José María Rego Machinea.

Jesús Mérida Pérez. 
No comparecieron: Cándido Campos, Francisco de la Villa, Paulino Pedret, José Bernal, Manuel Marín.

\section{Votación}

- Heraclio Sánchez: un voto (García Alas).

- José María Rego: un voto (Otto).

- Jesús Mérida: tres votos (Piñán, Cabrera, Moneva).

Jesús Mérida fue propuesto.

\section{Materiales}

- De tipo administrativo: actas, instancias presentadas por los aspirantes con acreditaciones de méritos.

- Escritos del quinto ejercicio: "anulación de matrimonio"; "jubilación de prebendados".

- Escritos del sexto ejercicio. Dos temas: "Plan de vida diocesano en un régimen de separación absoluta entre la Iglesia y el Estado"; "Crítica del sistema probatorio canónico".

- Jesús Mérida retiró sus trabajos. Consta escrito de solicitud de 18 de mayo de 1940.

- Heraclio Sánchez retiró sus trabajos el 5 de agosto de 1935.

- José María Rego. Idem.

- Cándido Campos también retiró. Sin fecha.

- Bernal los retiró el 31 de octubre, 1935.

\section{Signatura}

AGA 32/13466. Legajo 8138-2.

\section{Cátedra}

Derecho político.

\section{Universidad}

Murcia.

\section{Anuncio}

Orden de 18 de enero, 1932. Gaceta del 27.

\section{Reglamento aplicable}

25 de junio, 1931. 


\section{Fechas de la oposición}

Constitución del tribunal: 23 de febrero, 1933.

Presentación de los opositores: 25 de febrero, 1933 (por error se indica 25 de marzo).

Votación y propuesta: 22 de marzo, 1933.

\section{Tribunal}

Presidente: Adolfo Posada.

Vocales: Carlos Sanz Cid, Carlos Ruiz del Castillo, Nicolás Rodríguez Aniceto.

Secretario: Nicolás Pérez Serrano.

\section{Opositores}

Eduardo Luis Llorens Lariana.

José Viani Caballero.

No comparecieron: Sabino Álvarez Guendín, Epifanio Lorda, Francisco Félix Montiel, Francisco Ayala.

\section{Votación}

Eduardo Llorens fue propuesto por unanimidad.

\section{Materiales}

De tipo administrativo: actas, instancias de los aspirantes con acreditación de méritos.

Referentes a los ejercicios:

- Informes de los jueces sobre los trabajos de investigación presentados.

- Las actas recogen las evaluaciones de los jueces sobre los ejercicios.

- Escritos del ejercicio quinto: sobre el artículo 66 de la Constitución. Posibilidad del referéndum y de la iniciativa legislativa popular (resumen del enunciado).

- Escritos del ejercicio sexto: "Representación proporcional y régimen parlamentario".

No se conservan trabajos de los opositores.

\section{Signatura}

AGA 32/13477. Legajo 8588-3.

\section{Cátedra}

Derecho internacional privado.

\section{Universidad}

Central. 


\section{Anuncio}

Orden de 10 de febrero, 1932. Gaceta del 16.

\section{Reglamento aplicable}

25 de junio, 1931.

\section{Fechas de la oposición}

Constitución del tribunal: 4 de abril, 1934.

Presentación de los opositores: 6 de abril, 1934.

Votación y propuesta: 5 de mayo, 1934.

\section{Tribunal}

Presidente: Leopoldo García Alas García Argüelles.

Vocales: Camilo Barcia Trelles, José María Trías de Bes, José Castán Tobeñas.

Secretario: Aniceto Sela.

\section{Opositores}

Federico de Castro Bravo.

Joaquín Fernández García Mendoza. Se retira el 28 de abril.

No comparecieron: Adolfo Miaja: José Viñas, José Quero, Luis Gestoso, José Galvañ, José Ramón de Orúe.

\section{Votación}

Federico de Castro fue propuesto por unanimidad.

\section{Materiales}

De tipo administrativo: actas, instancia de Esperabé con acreditación de méritos. Escrito de José de Yanguas dirigido al presidente del tribunal por el cual comunica su solicitud al Ministerio de Instrucción Pública de reposición en su cátedra de Derecho internacional privado. Fechada el 3 de mayo, 1934.

Referentes a los ejercicios:

- Cuestionario elaborado por el tribunal (20 temas).

- Informes de los jueces sobre los trabajos de investigación presentados.

- Las actas recogen las evaluaciones de los jueces sobre los ejercicios de cada opositor.

- Escrito del ejercicio quinto (ejercicio práctico).

- Escritos del ejercicio sexto: "Las leyes de la post-guerra sobre formación de nacionalidad. La doble nacionalidad y la ciudadanía automática de los extranjeros".

- Programa de Derecho Internacional Privado de Joaquín Fernández. 


\section{Signatura}

AGA 32/13465. Legajo 8138-1.

\section{Cátedra}

Derecho político.

\section{Universidad}

Central.

\section{Anuncio}

Orden de 17 de febrero, 1932. Gaceta del 19.

Se admiten las renuncias al cargo de vocal de Teodoro González (Orden de 26 de mayo de 1932) y Nicolás Pérez Serrano (Orden de 21 de mayo de 1932).

\section{Reglamento aplicable}

25 de junio, 1931.

\section{Fechas de la oposición}

Constitución del tribunal: 4 de octubre, 1932.

Presentación de los opositores: 15 de octubre, 1932.

Votación y propuesta: 24 de octubre, 1932.

\section{Tribunal}

Presidente: Luis Jiménez de Asúa.

Vocales: Carlos Ruiz del Castillo, Nicolás Rodríguez Aniceto, Adolfo Posada.

Secretario: Carlos Sanz Cid

\section{Opositores}

Nicolás Pérez Serrano.

No comparecieron: Teodoro González García, Manuel Martínez Pedroso.

\section{Votación}

Nicolás Pérez Serrano fue propuesto por unanimidad.

\section{Materiales}

De tipo administrativo: actas, instancias de los aspirantes con acreditación de méritos.

Referentes a los ejercicios:

- Informes de los jueces sobre los trabajos de investigación presentados. 
- Las actas recogen las evaluaciones de los jueces sobre los ejercicios del opositor.

- Escritos del ejercicio quinto: "Antecedentes y comentario al art. 84 de la vigente Constitución española” (resumen del enunciado).

- Escritos del ejercicio sexto: "Concepción unitaria y pluralista de la soberanía". Materiales de Nicolás Pérez Serrano:

- Programa.

- Trabajo de investigación: La diputación permanente de Cortes en nuestro derecho histórico.

- La reforma constitucional en Austria, Política. Revista mensual de doctrina y crítica, febrero 1930, núm. 2.

- El contrato de hospedaje en su doble aspecto civil y mercantil, Imp. del Asilo de Huérfanos del S.C. de Jesús, Madrid, 1930.

- La Constitución española. Antecedentes, texto, comentario, Editorial Revista de Derecho Privado, Madrid, 1932.

- Notas bibliográfica; Schmitt (Carl), La defensa de la Constitución (trad. De Manuel Sánchez Sarto), Revista de Derecho Público, septiembre de 1932, núm. 9, p.284.

- El proyecto de constitución portuguesa, separado de la Revista de Derecho público, núms. 7 y 8, julio-agosto de 1932, Madrid, 1932.

- Con C. González Posada, Constituciones de Europa y América. Selección de textos vigentes, traducción y notas, Estudio preliminar de Adolfo Posada, tomos I y II, Librería General de Victoriano Suárez, Madrid, 1927.

\section{Signatura}

AGA 32/13462, 13463 y 13464. Legajo 8137-1.

La caja 32/13462 está digitalizada.

\section{Cátedra}

Derecho internacional público.

\section{Universidad}

Central.

\section{Anuncio}

Orden de 3 de agosto, 1931. Gaceta del 5.

Por Orden de 10 de febrero de 1932 se divide la cátedra en Derecho internacional público y Derecho internacional privado. Gaceta del 16.

Se abre un segundo plazo para admisión de instancias por Orden de 9 de marzo de 1932. Gaceta del 10. 


\section{Reglamento aplicable}

25 de junio, 1931.

\section{Fechas de la oposición}

Constitución del tribunal: 22 de octubre, 1932.

Presentación de los opositores: 22 de octubre, 1932.

Votación y propuesta: 30 de noviembre, 1932.

\section{Tribunal}

Presidente: Camilo Barcia Trelles.

Vocales: Aniceto Sela, Salvador Cabeza de León, Casto Barahona.

Secretario: Manuel de Lasala.

\section{Opositores}

Adolfo Miaja de la Muela.

Antonio Luna García.

José Quero Molares.

José Ramón de Orúe Arregui.

No comparecieron: Blas Ramos, Juan Galvañ, Luis Gestoso, Román Riaza, Leopoldo Palacios, Jesús Esperabé.

\section{Votación}

Antonio Luna ganó la votación por tres votos (Lasala, Barahona, y Cabeza) contra dos de Adolfo Miaja (Sela y Barcia). Fue propuesto.

\section{Materiales}

De tipo administrativo: actas, instancias de los aspirantes con acreditación de méritos.

Referentes a los ejercicios:

- Cuestionario elaborado por el tribunal (42 temas).

- Informes de los jueces sobre los trabajos de investigación presentados.

- Las actas recogen las evaluaciones de los jueces sobre los ejercicios de cada opositor.

- Escritos del ejercicio quinto: "La doctrina de Monroe" (resumen del enunciado).

- Escritos del ejercicio sexto: "Desenvolvimiento histórico de la Justicia internacional. Etapas del procedimiento arbitral. El arbitraje obligatorio".

Materiales de Antonio de Luna:

- Programa.

- Memoria. Dos tomos. 
- Trabajo de investigación: Il valore della consuetudine come fonte del diritto, Universitá di Bologna, lavoro presentato al Concorso "Vottorio Emanuele".

- Trabajo de investigación: El Derecho internacional público en la Constitución española.

- Notas bibliográficas, Radbruch (G.), Introducción a la Ciencia del Derecho, Revista de Derecho Privado, septiembre de 1930, núm.204, p.285.

- Notas bibliográficas, Bustamante y Montoro (Antonio), Stammler. Ensayo de valoración. La Habana, 1931, Revista de Derecho Privado, 1932, núm.222, tomo XIX.

Materiales de Orué:

- Programa.

- Trabajo de investigación: Sistema de Derecho internacional público.

- Sumario-Plan de las once conferencias sobre el tema La Sociedad de Naciones: su consideración jurídico-internacional a cargo del Dr. José Ramón de Orúe y Arregui, Imp. De Suc. De M. Curbelo, La Laguna, 1924.

- Discurso leído en la solemne apertura del curso académico de 1923 a 1924, Imprenta de Suc. De M. Curbelo, La Laguna, 1923.

- La Sociedad de Naciones, prólogo de Rafael Altamira, Góngora, Madrid, 1925.

- Derecho internacional privado. Contestaciones adaptadas al programa de oposiciones a notarías determinadas, publicado el 19 de junio de 1926, Reus, Biblioteca de oposiciones, Madrid, 1928.

- Los mandatos-tutela de la Sociedad de Naciones, Anales de la Universidad de Valencia, 1925-1926, cuadernos 42 a 44. También publicado en Jurisprudencia Argentina, octubre de 1926, núm. 169,

- La Sociedad de Naciones. Obra declarada oficialmente de mérito por el Consejo de Instrucción Pública, Segunda edición, Reus, Madrid, 1932.

- Manual de Derecho internacional privado español, Reus, Madrid, 1928.

- Con José María Trías de Bes, Derecho internacional público y privado, Obra adaptada al programa de oposiciones a la carrera fiscal, publicado el 16 de noviembre de 1926, Reus, Madrid, 1927.

- La soberanía de los Estados y su necesaria evolución, Tip. "La Académica", Zaragoza, 1925.

Artículos de Orué publicados en la Revista de Ciencias Sociales y Jurídicas:

- Desconocimiento de las leyes guerreras durante el conflicto mundial, Revista de Ciencias Sociales y Jurídicas, 1925, núm. 32.

- Extensión de los privilegios diplomáticos en el Pacto de la Liga de Naciones, Revista de Ciencias Sociales y Jurídicas, 1922, núm. 18.

- La legislación de guerra en Francia sobre naturalización, Revista de Ciencias Sociales y Jurídicas, 1918, núm. 4.

- Artículos publicados en la Revista General de Legislación y Jurisprudencia: 
- Contribución al estudio de las represalias, Revista General de Legislación y Jurisprudencia, mayo de 1922, tomo 140, entrega V, p. 411.

- La Sociedad de Naciones y sus actuales problemas, Revista General de Legislación y Jurisprudencia, abril de 1927, tomo 150, núm. IV, p. 398.

- Contribución al estudio de la propiedad privada enemiga durante el conflicto europeo, Revista General de Legislación y Jurisprudencia, marzo de 1920, tomo 136, entrega III, p. 209.

- Contribución al estudio de la propiedad privada enemiga durante el conflicto europeo (conclusión), Revista General de Legislación y Jurisprudencia, junio de 1920, tomo 136, entrega VI, p.515.

- La nacionalidad por anexión y los derechos privados en los recientes tratados de paz, Revista General de Legislación y Jurisprudencia, marzo de 1926, tomo 146, núm. III, p.269.

- Preceptos internacionales en la Constitución de la República española, Revista General de Legislación y Jurisprudencia, abril de 1932, tomo 160, núm. VI, p.385.

Materiales de José Quero:

- Traducción (con Trías de Bes) de Julio Diena, Derecho internacional público, tercera edición italiana, Bosch, Bercelona, 1932

Miaja retiró sus materiales el 18 de enero de 1933.

Consta un trabajo de investigación sin título ni autor. Es un tomo incompleto que comienza por la página 29.

\section{Signatura}

AGA 32/13466. Legajo 8138-3.

Algunas obras están digitalizadas.

\section{Cátedra}

Derecho procesal.

\section{Universidad}

Santiago.

\section{Anuncio}

31 de mayo, 1932. Gaceta del 2 de junio.

\section{Reglamento aplicable}

25 de junio, 1931. 


\section{Fechas de la oposición}

Constitución del tribunal: 3 de noviembre, 1932.

Presentación de los opositores: 4 de noviembre, 1932.

Votación y propuesta: 25 de noviembre, 1932.

\section{Tribunal}

Presidente: José Xirau.

Vocales: José María Giralt, Juan Serra Puig, Francisco Beceña.

Secretario: Emilio Gómez Orbaneja.

\section{Opositores}

Niceto Alcalá-Zamora Castillo.

No comparecieron: Agustín Iscar, Enrique Martín, Valentín Silva.

\section{Votación}

Niceto Alcalá-Zamora Castillo fue propuesto por unanimidad.

\section{Materiales}

De tipo administrativo: actas, instancias de los aspirantes con acreditación de méritos.

Referentes a los ejercicios:

- Cuestionario elaborado por el tribunal (22 temas).

- Informes de los jueces sobre los trabajos de investigación presentados.

- Las actas recogen las evaluaciones de los jueces sobre los ejercicios del opositor.

- Escrito del ejercicio quinto (caso práctico).

- Escrito del ejercicio sexto: "El hecho notorio y el conocimiento privado del juez".

Materiales de Alcalá-Zamora

- Programa. Tomo digitalizado.

- Estudio acerca del concepto, método, fuentes y programas del Derecho procesal. Tomo digitalizado.

- Trabajo de investigación: Contribución al estudio de las manifestaciones consuetudinarias en el Derecho procesal.

- Trabajo de investigación: Consideraciones acerca de la reforma procesal en España. Datado en diciembre, 1931.

- Labor desarrollada por el opositor como vocal de la Comisión Jurídica Asesora de Justicia.

- El desistimiento espontáneo y el arrepentimiento activo (Memoria doctoral), Imprenta del Colegio Nacional de Sordomudos, Madrid, 1928.

- Un español mal comprendido. Salgado de Somoza en la literatura alemana 
sobre concurso de acreedores, Ediciones Morata, Nueva Generación, Madrid, 1932.

- La condena en costas, Imprenta del Colegio Nacional de Sordomudos, Madrid, 1930.

- Los recursos en nuestras leyes procesales, Revista Crítica de Derecho Inmobiliario, Año VI, Núm. 61, 1930.

- Los recursos en nuestras leyes procesales (conclusión), Revista Crítica de Derecho Inmobiliario, Año VI, Núm. 62, 1930.

- Lo que debe ser el Ministerio Público, Revista General de Legislación y Jurisprudencia, Tomo 155, núm.V, noviembre de 1929, p.519.

- En torno al "Codice di prcedura penale" italiano, Revista de Derecho Público, julio-agosto 1932, núms. 7 y 8.

- Un grave problema judicial y político. La justicia municipal, Revista de las Tribunales y de Legislación Universal, 14 de mayo de 1932, núm. 20.

- La ética profesional y el régimen jurídico de las Corporaciones forenses, $R e$ vista de las Tribunales y de Legislación Universal, 22 de octubre de 1932, Tomo LXVI, núm. 48.

\section{Signatura}

AGA 32/13477. Legajo 5888-1.

\section{Cátedra}

Historia del Derecho.

\section{Universidad}

Santiago.

\section{Anuncio}

31 de mayo, 1932. Gaceta del 2 de junio.

\section{Reglamento aplicable}

25 de junio, 1931.

\section{Fechas de la oposición}

Constitución del tribunal: 2 de julio, 1934.

Presentación de los opositores: 4 de julio, 1934.

Votación y propuesta: 24 de julio, 1934. 


\section{Tribunal}

Presidente: Galo Sánchez.

Vocales: Manuel Torres López, Román Riaza, Tomás Gómez Piñán.

Secretario: Luis García de Valdeavellano.

\section{Opositores}

Juan Beneyto Pérez.

José López Ortiz.

No comparecieron: José Pedraza, Rodrigo Villabriga, Vicente Granell, Paulino Pedret.

\section{Votación}

López Ortiz fue propuesto por unanimidad.

\section{Materiales}

- Actas.

Escrito de Beneyto por el que solicita la devolución de sus materiales. 5 de junio de 1935.

Referentes a los ejercicios:

- Informes de los jueces sobre los trabajos de investigación presentados.

- Las actas recogen las evaluaciones de los jueces sobre los ejercicios de los opositores.

- Escritos del ejercicio quinto (caso práctico): trascripción y comentario de un diploma del siglo XIII.

- Escritos del ejercicio sexto: "Tránsito de la justicia privada a la justicia pública en España”.

Materiales de López Ortiz:

- Concepto, método, fuentes y programas de la Historia del Derecho español.

- Derecho musulmán, Labor, Barcelona-Buenos Aires, 1932.

- La jurisprudencia y el estilo de los tribunales musulmanes de España, Del Anuario de Historia del Derecho español, Tipografía de Archivos, Madrid, 1933. - Algunos capítulos del formulario notarial de Abensalmún de Granada, Del Anuario de Historia del Derecho español, Tipografía de Archivos, Madrid, 1928. - La recepción de la escuela malequí en España, Del Anuario de Historia del Derecho español, Tipografía de Archivos, Madrid, 1931.

- El tribunal de los omeyas cordobeses, Cruz y Raya, Madrid, 1933. 


\section{Signatura}

AGA 32/13529 y 32/13530. Legajo 9141.

\section{Cátedra}

Derecho mercantil.

\section{Universidad}

Oviedo.

\section{Anuncio}

O. de 5 de agosto, 1932. Gacetas del 7 y 9.

\section{Fechas de la oposición}

1934, 26 de noviembre: constitución del tribunal.

1934, 6 de diciembre: presentación de los opositores.

1935, 15 de marzo: votación y propuesta.

\section{Tribunal}

Presidente: Enrique Rodríguez Mata.

Vocales: José de Benito, Joaquín Garrigues, José Castán.

Secretario: Álvaro Calvo.

\section{Opositores}

Antonio Polo Díez.

Miguel Cabeza Anide (profesor auxiliar de Santiago).

Rodrigo Uría (profesor auxiliar de Oviedo).

Todos pasan a la votación final.

No comparecieron: Victoriano Nuño Beato, Enrique Martín Guzmán, Miguel Pascual, Rosendo Ferrán.

\section{Votación y propuesta}

Antonio Polo ganó la votación por tres votos (de Benito, Garrigues, Mata) contra dos de Miguel Cabeza (Calvo y Castán). Fue propuesto.

\section{Materiales}

De tipo administrativo: actas, instancias con acreditación de méritos.

De tipo académico o referentes a los ejercicios:

- Escritos del quinto ejercicio.

- Escritos del sexto ejercicio: "La letra de cambio" (Polo); "Capital social y patrimonio social” (Uría), "La resolución de los contratos mercantiles" (Cabeza). 
Materiales de Antonio Polo:

- Traducción de H. Herrfahrdt, Revolución y Ciencia del Derecho, Editorial Revista de Derecho Privado, Madrid, 1932.

- Trabajo de investigación: Guión para un estudio de la sociedad de un solo socio observada bajo el prisma del Derecho mercantil y el Derecho de la economía.

- Trabajo de investigación: Un dictamen de Derecho mercantil. Notas para un intento de construcción jurídica de la figura del comisario de la quiebra en Derecho español.

- Casos prácticos de Derecho mercantil.

- Derecho de las personas comerciantes. Hojas impresas. No se puede identificar revista o libro de origen.

- Das spanische Zivilrecht vor, durch und seit der Verfassung der spanichen Republik, Sonderabdruck us der Zeitschrift für auslandisches und internationals Privatrecht, 6. Jahrgang (1932), Nr. 4.

- Traducción de Konrad Kosack, Tratado de Derecho mercantil, 12. a edición alemana, Editorial Revista de Derecho Privado, Madrid, 1934.

Programas de Derecho mercantil de Antonio Polo:

- Universidad de Salamanca, Librería General "La Facultad”, Salamanca, 1933.

- Patronato Universitario, Imp. y Librería de Hernández, Salamanca, 1931.

- Patronato Universitario, Est. Tipográfico de Calatrava, Salamanca, 1932.

- El Derecho económico como nueva disciplina jurídica, Universidad de Salamanca, programa de cursos breves extraordinarios, 1932-33.

Artículos de Antonio Polo en la Revista de Derecho Privado:

- Traducción de R. Demogue, La responsabilidad civil de los accidentes de caza y las teorías modernas, 1931, núm. 216.

- Traducción de M. Rotondi, La venta de la Hacienda y la prohibición de concurrencia, 1931, núm. 210.

- Traducción de Ricardo Fubini, Contribución al estudio de los contratos complejos (llamados mixtos), 1931, núm. 208.

- Traducción de J. Champcomunal, Reseña crítica de la legislación, doctrina y jurisprudencia francesas en materia de derecho privado durante el año 1930, 1931, núm. 213. Idem (conclusión), 1931, núm. 214-215.

- Traducción de K. Wieland, La sociedad de responsabilidad limitada, 1932, núm. 228.

- Notas bibliográficas, Rheinstrom: Das neue Aktienrecht, 1932, núm. 230.

- Notas bibliográficas, Wieland: Handelsrecht, 1932, núm. 223.

- Notas bibliográficas, Wieland (Karl): La sede della societá commerciale, 1931, núm. 217.

- Notas bibliográficas, Ascarelli (Tulio): Appunti di Diritto Commerciale, 1931, núm. 218. 
- Notas bibliográficas, Lloréns (E.L.): ¿Qué es la tecnocracia?, 1933, núm. 241.

- Notas bibliográficas, Joaniquet (Aurelio): Los préstamos sobre mercancías en las leyes mercantiles, 1931, núm. 209.

- Don Lorenzo de Benito y Endara (1855-1932), 1932, núm. 231.

- Reseña de legislación, literatura y jurisprudencia en el Derecho privado italiano, 1934, núm. 248.

- Jurisprudencia del T.S., Mercantil: Derecho de las obligaciones mercantiles, 1934, núm. 246.

- Jurisprudencia del T.S., Mercantil, I. Derechos de las personas comerciantes, II. Derecho de las obligaciones mercantiles 1934, núm. 245.

- Jurisprudencia del T.S., Mercantil, I. Derechos de las cosas mercantiles, II. Derecho de las obligaciones mercantiles 1933, núm. 233.

- Las transformaciones del Derecho privado, por el Prof. Demófilo de Buen, 1934, núm. 254.

- El ejercicio del comercio por la mujer casada y el moderno Derecho constitucional español, 1933, núm. 232.

Uría retira sus trabajos el 16 de marzo de 1935.

Cabeza retira sus trabajos el 26 de febrero de 1935 .

\section{Signatura}

AGA 32/13520. Legajo 9137-3.

\section{Cátedra}

Derecho romano.

\section{Universidad}

Murcia y La Laguna.

\section{Anuncio}

3 de octubre, 1932. Gaceta del 6.

\section{Reglamento aplicable}

25 de junio, 1931.

\section{Fechas de la oposición}

Constitución del tribunal: 6 de septiembre, 1935.

Presentación de los opositores: mismo día que el anterior.

Votación: 8 de octubre, 1935. La propuesta el día siguiente. 


\section{Tribunal}

Presidente: Leopoldo García Alas García Argüelles.

Vocales: Felipe Clemente de Diego, José Castillejo, Miguel Traviesas.

Secretario: Laureano Sánchez Gallego.

\section{Opositores}

Ursicino Álvarez Suárez.

José Santa Cruz Teijeiro.

No comparecieron: Cándido Campo, Miguel Royo Martínez, Ignacio Serrano, Antonio Reverte.

\section{Votación}

Ursicino Álvarez fue propuesto por unanimidad para el primer lugar. Optó por la cátedra de Murcia.

José Santa Cruz fue propuesto por unanimidad para el segundo lugar. Aceptó la cátedra de La Laguna.

\section{Materiales}

- De tipo administrativo: actas, instancias presentadas por los aspirantes con acreditaciones de méritos.

- Cuestionario del tribunal (14 temas).

- Informes de los jueces sobre los trabajos de investigación presentados.

- Las actas recogen las evaluaciones de los jueces sobre los ejercicios de los opositores.

- Escritos del quinto ejercicio: "Papiniano, 17, 2, 81".

- Escritos del sexto ejercicio: "edictos de pretores y ediles".

No se conservan trabajos de los opositores.

\section{Signatura}

AGA 32/13477. Legajo 8588-2.

\section{Cátedra}

Derecho internacional público y privado.

\section{Universidad}

La Laguna.

\section{Anuncio}

Orden de 22 de febrero, 1933. Gaceta del 24. 


\section{Reglamento aplicable}

25 de junio, 1931.

\section{Fechas de la oposición}

Constitución del tribunal: 20 de febrero, 1934.

Presentación de los opositores: 22 de febrero, 1934.

Votación y propuesta: 30 de marzo, 1934.

\section{Tribunal}

Presidente: José Xirau.

Vocales: Camilo Barcia Trelles, Aniceto Sela, José Gascón Marín.

Secretario: Antonio Luna García.

\section{Opositores}

Adolfo Miaja de la Muela.

No comparecieron: Jesús Esperabé.

\section{Votación}

Adolfo Miaja fue propuesto por unanimidad.

\section{Materiales}

De tipo administrativo: actas, instancia de Esperabé con acreditación de méritos. Referentes a los ejercicios:

- Cuestionario elaborado por el tribunal (11 temas).

- Informes de los jueces sobre los trabajos de investigación presentados.

- Las actas recogen las evaluaciones de los jueces sobre los ejercicios de cada opositor.

- Escritos del ejercicio quinto: "Comentario al artículo 19 de Pacto de la Sociedad de Naciones".

- Escritos del ejercicio sexto. Dos temas: "Génesis de las teorías estatutarias"; "El problema de la seguridad internacional”.

Materiales de Adolfo Miaja:

- Programas: Derecho internacional público y Derecho internacional privado.

- Las ideas fundamentales del Derecho de gentes en la obra de Fray Serafín de Freitas, Asociación Francisco de Vitoria, Imp. La Rafa, Madrid, 1933.

- Internacionalistas españoles del siglo XVI. Fernando Vázquez de Menchaca (1512-1569), prólogo de Camilo Barcia Trelles, Talleres tipográficos Cuesta, Madrid, 1932.

- Trabajo de investigación: Los apátridas. Fechado en septiembre de 1928. 


\section{Signatura}

AGA 32/13524, 13525 y 13526. Legajo 9139.

\section{Cátedra}

Derecho civil.

\section{Universidad}

Murcia, Santiago y La Laguna.

\section{Anuncio}

Para Santiago y La Laguna 23 de mayo, 1933. Gaceta del 1 de junio.

Para Murcia 24 de junio, 1933. Gaceta del 29.

\section{Reglamento aplicable}

25 de junio, 1931.

\section{Fechas de la oposición}

Constitución del tribunal: 11 de enero, 1935.

Presentación de los opositores: 11 de enero, 1935.

Votación: 8 de marzo, 1935. La propuesta el día siguiente.

\section{Tribunal}

Presidente: Miguel Traviesas (por renuncia de Clemente de Diego).

Vocales: Felipe Sánchez-Román Gallifa, José Castán, Felipe Gil Casares.

Secretario: Ángel Viñas.

\section{Opositores}

Francisco Bonet Ramón.

Juan Ossorio Morales.

César Delgado González.

Manuel Batlle Vázquez.

Ignacio Serrano.

Todos pasan a la votación final.

No comparecieron: José Alguer Micó, Luis Donderis Tatay, Rosendo Ferrán Pérez.

\section{Votación}

Votación del primer lugar:

- Ossorio: tres votos (Traviesas, Sánchez-Román, Gil Casares). 
- Bonet: un voto (Viñas).

- Manuel Batlle: un voto (Castán).

La votación del segundo lugar fue ganada por Bonet por unanimidad.

La votación del tercer lugar fue ganada por Batlle. Obtuvo todos los votos menos el de Sánchez Román, quien votó a Serrano.

Ossorio optó por la cátedra de Murcia; Bonet por la de Santiago, Batlle aceptó la de La Laguna.

Fueron propuestos.

\section{Materiales}

De tipo administrativo: actas, instancias con acreditación de méritos.

De tipo académico o referentes a los ejercicios:

- Escritos del ejercicio práctico (ejercicio quinto).

- Ejercicio sexto: "La autonomía de la voluntad y el Código Civil".

Materiales de Juan Ossorio:

- Programa (157 lecciones).

- Memoria. Concepto, método, fuentes y programa. Datado en diciembre de 1934, Granada.

- Trabajo de investigación: Las servidumbres personales. Ensayo de sistematización, Datado en mayo de 1934, Granada.

- Trabajo de investigación: La pluralidad de tutores en el Derecho español. Contribución al estudio de la tutela, datado en diciembre de 1934, Granada.

- Traducción de G. del Vecchio, Los principios generales del Derecho, prólogo de Felipe Clemente de Diego, Librería Bosch, Barcelona, 1933.

- La doctrina de la "consideration" en el Derecho contractual inglés, Boletín de la Universidad de Granada, N. ${ }^{\circ}$ 19, 1932.

- Colectivismo, Individualismo (Conferencias de Doña María Martínez Sierra y D. Ángel Ossorio), Revista General de Legislación y Jurisprudencia, mayo 1933, Tomo 162, núm. V, p. 529.

Artículos de Juan Ossorio en la Revista de Derecho Privado:

- Sobre una interpretación del art. 1483 del Código Civil, Revista de Derecho Privado, mayo de 1929, núm. 188, p. 10.

- El cheque en la legislación inglesa, Revista de Derecho Privado, febrero de 1930, núm. 197, pp. 46.

- Publicaciones jurídicas de lengua inglesa, Revista de Derecho Privado, marzo de 1930, núm. 198, p. 89.

- Revista de revistas (en lengua inglesa), Revista de Derecho Privado, diciembre de 1930, núm. 207, pp. 390.

- Revista de revistas, Revista de Derecho Privado, febrero de 1932, núm. 221, p. 59. 
- Las servidumbres "in faciendo" en Derecho español, Revista de Derecho Privado, junio de 1933, núm. 249, pp. 177-192.

- Revista de revistas (en lengua inglesa), Revista de Derecho Privado, febrero de 1934, núm. 245, pp. 57-61.

- Notas bibliográficas, Renato Gaeta: Beni di familia a Patrimonio familiare, Revista de Derecho Privado, julio-agosto 1934, núms. 250 y 251.

Materiales de Bonet:

- Programa de Derecho civil español común y foral.

- Concepto, método, fuentes y programa del Derecho civil español común y foral.

- Trabajo de investigación: Jurisprudencia del T.S. civil.

- Trabajo de investigación: Contribución al estudio de la naturaleza del contrato de mandato.

- Trabajo de investigación: Principales adiciones al tomo IV de los comentarios al Código Civil de Manresa.

- Jurisprudencia del Tribunal Supremo. Impresiones grapadas de lo que parece ser una publicación en revista. Dos cuadernos.

- Lorenzo Padilla, historiador del Derecho castellano, Tesis doctoral, Tipografía de Archivos, Madrid, 1932.

- El anteproyecto de Código Civil argentino, Biblioteca de la Revista General de Legislación y Jurisprudencia, Reus, Madrid, 1933.

- Quintus Mucius Scaevola, Código Civil, continuado por José Castán Tobeñas con la cooperación de Francisco Bonet Ramón y Luis Batlle Vázquez, Tomo XXV, Reus, Madrid, 1933.

- Noticias bibliográficas, Revista General de Legislación y Jurisprudencia, febrero de 1934, Tomo 164, núm. II, p. 248.

Artículos de Bonet en la Revista de Derecho Privado:

- Con Castán: 1931, núm. 217; 1931, núm. 219; 1932, núm. 223; 1932, núm. 225; 1932, núms. 226-227; 1932, núm. 229; 1932, núm. 230; 1933, núm. 232;

- En solitario: 1933, núm. 236; 1933, núm. 237, 1933, núm. 238-239; 1933, núm. 240; 1933, núm. 241; 1933, núm. 243; 1934, núm. 247; 1934, núm. 249, 1934, núms. 250-251. 1934, núm. 254;

Materiales de Batlle:

- Programa de Derecho civil español (152 lecciones).

- Memoria sobre el concepto, método, fuentes y programa. Datado en 1935, Madrid.

- Quintus Mucius Scaevola, Código Civil, continuado por José Castán Tobeñas con la cooperación de Francisco Bonet Ramón y Luis Batlle Vázquez, Tomo XXV, Reus, Madrid, 1933.

- La propiedad de casas por pisos, prólogo de José Castán Tobeñas, Biblioteca de la Revista General de Legislación y Jurisprudencia, Reus, Madrid, 1933. 
- El derecho al nombre, Biblioteca de la Revista General de Legislación y Jurisprudencia, Reus, Madrid, 1931.

- Repercusiones de la Constitución en el Derecho privado, trabajo premiado el el concurso "Alcalá-Zamora" abierto por la Academia Nacional de Jurisprudencia y Legislación, Imprenta de Galo Sáez, Madrid, 1933.

- Notas bibliográficas, Mengual y Mengual (José María), Elementos de Derecho notarial, Revista de Derecho Privado, diciembre 1933, núm. 243, pp. 423-424.

Serrano retiró sus trabajos el 21 de mayo de 1935.

Delgado retiró sus trabajos. No consta fecha.

\section{Signatura}

AGA 32/13531. Legajo 9142-3 y legajo sin numerar.

\section{Cátedra}

Derecho político.

\section{Universidad}

La Laguna.

\section{Anuncio}

16 de junio, 1933. Gaceta del 17.

\section{Reglamento aplicable}

25 de junio, 1931.

\section{Fechas de la oposición}

Constitución del tribunal: 7 de diciembre, 1934.

Presentación de los opositores: 10 de diciembre, 1934.

Votación y propuesta: 5 de enero, 1935 .

\section{Tribunal}

Presidente: Adolfo G. Posada.

Vocales: Carlos Sanz Cid, Fernando de los Ríos, Teodoro González García.

Secretario: Nicolás Pérez Serrano.

\section{Opositores}

Francisco Ayala García-Duarte.

José Viani Caballero. Se retira el 27 de diciembre.

José Luis Santaló Rodríguez de Viguri. Se retira el 27 de diciembre.

No comparecieron: Epifanio Lorda, Gonzalo Cáceres. 


\section{Votación}

Ayala fue propuesto por unanimidad.

\section{Materiales}

De tipo administrativo: actas, instancias de los aspirantes con acreditación de méritos.

Correspondencia con motivo de la conformación del tribunal: cartas de Posada, Llorens, Martínez Pedroso, Gonzalo del Castillo.

Referentes a los ejercicios:

- Informes de los jueces sobre los trabajos de investigación presentados.

- Las actas recogen las evaluaciones de los jueces sobre los ejercicios de los opositores.

- Escrito del ejercicio quinto: "Comentario exegético y crítico del preámbulo de la constitución austriaca de 1934".

- Escrito del ejercicio sexto: "Análisis de la relación entre Estado y Derecho a partir del siglo XVIII".

Materiales de Ayala:

- Programa de Derecho político.

- Acerca del concepto, métodos, fuentes y programas de Derecho político.

- Trabajo de investigación: Los derechos individuales como garantía de la libertad.

- Trabajo de investigación: Los partidos políticos como órganos de gobierno en el Estado moderno.

- Sobre el punto de vista español ante la propuesta de una unión federal europea, de la Revista General de Legislación y Jurisprudencia de julio de 1931, Reus Madrid, 1931.

- Problemas jurídico-sociales del jornal mínimo. Con referencia especial a la labor de los Comités paritarios de Albañilería y Edificación (Comité Paritario de la Construcción) de Madrid, Imp. sobrinos de la Suc. De M. Minuesa de los Ríos, Madrid, 1931.

- Con Posada, El Derecho constitucional en España, Estratto dal I volumen de "La Constituzione degli Stati nell'Etá Moderna", Fratelli Treves Editori, Milano, 1933.

- Artículo de prensa (recortes): La reintegración nacional, El problema jurídico de la vivienda, La regulación constitucional, Unos comentarios.

Traducciones de Ayala:

- Carlos Kautsky, El programa de Erfurt, con una introducción de Julián Besteiro, Fundación Cesáreo del Cerro, Gráfica Socialista, Madrid, 1933.

- Juana Duprat, Las funciones sociales del Estado según el señor Posada, de la Revue Internationale de Sociologie, sep-oct 1930, Madrid, 1931. 
- Godehard J. Ebers, Derecho eclesiástico del Estado, Cuadernos de Política I, Revista de Occidente, Madrid, 1931.

- Carl Schmitt, Teoría de la Constitución, Editorial Revista de Derecho Privado, Madrid, 1934.

José Viani retiró sus materiales el 15 de noviembre de 1935.

Santaló retiró sus materiales el 12 de noviembre de 1935.

\section{Signatura}

AGA 32/13534 y 32/13535. Legajos 9144-1 y 9144-2.

\section{Cátedra}

Filosofía del Derecho.

\section{Universidad}

Murcia y La Laguna.

\section{Anuncio}

12 de agosto, 1933. Gaceta del 20.

\section{Reglamento aplicable}

25 de junio, 1931.

\section{Fechas de la oposición}

Constitución del tribunal: 7 de noviembre, 1934.

Presentación de los opositores: 8 de diciembre, 1934.

Votación: 22 de enero, 1935. La propuesta el día siguiente.

\section{Tribunal}

Presidente: Fernando de los Ríos.

Vocales: Miguel Sancho, Luis Recasens Siches, Blas Ramos.

Secretario: Antonio Luna.

\section{Opositores}

Felipe González Vicén.

José Corts Grau.

Luis Legaz Lacambra.

José R. Medina Echavarría.

No comparecieron: Epifanio Lorda, José Mingarro, José Viani. 


\section{Votación}

Echavarría fue propuesto para el primer lugar por unanimidad.

La votación del segundo lugar fue ganada por Lacambra por tres votos (Luna, Recasens, Sancho) contra dos de Vicén (Ramos y de los Ríos).

Echavarría optó por la cátedra de Murcia y Lacambra aceptó la de La Laguna. Fueron propuestos.

\section{Materiales}

Actas.

Referentes a los ejercicios.

- Informes de los jueces sobre los trabajos de investigación presentados.

- Las actas recogen las evaluaciones de los jueces sobre los ejercicios de cada opositor.

- Escritos del ejercicio quinto: "El sentido jurídico e histórico contenido en el párrafo I de la Intituta de Gayo y en las definiciones de lex, plebs y plebiscito".

- Escritos del ejercicio sexto: "El sentido óntico del Derecho en la escolástica jurídica y singular significación dentro de ella de la Contrareforma”.

Materiales de José R. Medina Echevarría.

- Programa.

- Concepto, método y fuentes.

- Trabajo de investigación: Introducción a la sociología contemporánea.

- La representación profesional en las asambleas legislativas, Anales de la Universidad de Valencia, 1926-1927, cuadernos 52 a 54.

Materiales de Luis Legaz Lacambra:

- Programa.

- Concepto, método y fuentes: Base y contornos de la Filosofía del Derecho.

- La théorie pure du Droit et l'idée du Droit Social (mecanografiado). Se indica que fue publicado en la Revue Internatinale de la Théorie du Droit.

- La primacía del espíritu en la construcción jurídica internacional. Extracto de otra fuente. No se puede identificar procedencia.

- En torno al eterno problema del Derecho natural. Comentarios sobre algunos aspectos de la más reciente Filosofía jurídica francesa, Universidad. Revista de Cultura y Vida Universitaria, Zaragoza, 1932.

- La filosofía jurídica del nacional-socialismo, Universidad. Revista de Cultura y Vida Universitaria, Zaragoza, 1934.

- El Estado de Derecho en la actualidad. Una aportación a la teoría de la juridicidad, Biblioteca de la Revista General de Legislación y Jurisprudencia, Reus, Madrid, 1934 .

- Die Hauprichtungen der Recht- , Staats-und Sozialphilosophie in Spanien, Archiv für Rechts-und Wirtschftsphilosophie, Oktober 1932, Heft 1, XXVI. Band. 
- Die Ontologische Grundlage der Reinen Rechtslehre, Zeitschrift für Öffentliches Recht, 1932, Heft 5, Band XII.

- Die Rechtphilosophie des Franciscus Suárez, Zeitschrift für Öffentliches Recht, 1934, Heft 3, Band XIV.

- Vorwort des Prof. Dr. Luis Legaz Lacambra zu der von ihm besorgten spanischen Ausgabe der "Rechts-uns Sozialphilosophie von Wilhelm Sauer", Zeitschrift für Öffentliches Recht, 1934, Heft 2, Band XXVII.

- Las garantías constitucionales del Derecho internacional, separado de la Revista de Derecho Público, núm.22, Madrid, 1933.

Traducciones de Legaz:

- Hans Kelsen, La teoría pura del Derecho. Método y conceptos fundamentales, Editorial Revista de Derecho Privado, Madrid, 1933.

- Hans Kelsen, Teoría General del Estado, Editorial Labor, Madrid-BarcelonaBuenos Aires, 1934.

- Wilhelm Sauer, Filosofía Juridica y Social, Editorial Labor, Madrid-BarcelonaBuenos Aires, 1933.

José Corts retiró sus materiales el 18 de mayo de 1935.

\section{Signatura}

AGA 32/13480 y 13481. Legajo 8590-1.

\section{Cátedra}

Derecho civil.

\section{Universidad}

Murcia.

\section{Anuncio}

4 de septiembre, 1933. Gaceta del 9.

\section{Reglamento aplicable}

25 de junio, 1931.

\section{Fechas de la oposición}

Constitución del tribunal: 15 de junio, 1934.

Presentación de los opositores: 16 de junio, 1934.

Votación y propuesta: 8 de julio, 1934. 


\section{Tribunal}

Presidente: Felipe Sánchez-Román Gallifa.

Vocales: José Castán, Blas Pérez, Vicente Guilarte.

Secretario: Ursicino Álvarez Suárez.

\section{Opositores}

José Alguer Micó.

Luis Donderis Tatay.

Francisco Bonet Ramón.

Juan Ossorio Morales.

César Delgado González.

Rosendo Ferrant Pérez.

No comparecieron: Manuel Batlle, Ignacio Serrano.

\section{Votación}

José Alguer fue propuesto por unanimidad.

\section{Materiales}

De tipo administrativo: actas, instancias con acreditación de méritos.

De tipo académico o referentes a los ejercicios:

- Cuestionario elaborado por el tribunal (20 temas).

- Escritos del ejercicio práctico (ejercicio quinto): cálculo de la legitima de cada hijo natural (resumen del enunciado).

- Ejercicio sexto: "Régimen de los derechos sobre cosas incorporales".

Materiales de José Alguer:

- Programa (187 lecciones).

- Memoria: Concepto y contenido. Método y procedimiento de enseñanza. Fuentes y medios de estudio.

- Tratado de la avería común. Según la historia, la teoría, el derecho positivo y las reglas de York y Amberes de 1924, con prólogo de Pedro Hors y Bau, Tipología de Santiago Vives, Barcelona, 1926.

- El concepto de la buena fe en la génesis y en la técnica del derecho privado, Imprenta Casanovas, Bercelona, 1928.

- La teoría de la avería común y las leyes marítimas escandinavas (Tesis doctoral), Imprenta hijo de Domingo Casanovas, Barcelona, 1928.

- Con Blas Pérez, traducción y edición de Ludwig Enneccerus, Derecho civil. Parte General, volumen primero, Librería Bosch, Barcelona, 1934.

- Con Blas Pérez, traducción y edición de Ludwig Enneccerus, Derecho de obligaciones, volumen primero, Librería Bosch, Barcelona, 1933.

- Trabajo de investigación: Ensayo sobre el concepto de derecho real. 
- Trabajo de investigación: Para la crítica del concepto de precontrato.

Materiales de Juan Ossorio:

- Programa (120 lecciones).

- Memoria. Concepto, método, fuentes y programa.

- Trabajo de investigación: Las servidumbres personales. Ensayo de sistematización, Datado en mayo de 1934, Granada.

- Traducción de G. del Vecchio, Los principios generales del Derecho, prólogo de Felipe Clemente de Diego, Librería Bosch, Barcelona, 1933.

- Publicaciones jurídicas de lengua inglesa, Revista de Derecho Privado, marzo de 1930, núm. 198, p. 89.

- Las servidumbres "in faciendo" en Derecho español, Revista de Derecho Privado, junio de 1933, núm. 249, pp. 177-192.

- Revista de revistas, Revista de Derecho Privado, febrero de 1932, núm. 221, p. 59.

- Revista de revistas (en lengua inglesa), Revista de Derecho Privado, febrero de 1934, núm. 245, pp. 57-61.

- La doctrina de la "consideration" en el Derecho contractual inglés, Boletín de la Universidad de Granada, N. ${ }^{\circ}$ 19, 1932.

Materiales de César Delgado:

- Programa de Derecho civil.

- Memoria. Concepto, método, fuentes y programa del Derecho civil.

- Trabajo de investigación: La garantía real y sus figuras afines.

- Tesi di laurea: L'odierna constituzione spagnola ed il diritto civile, Regia Universitá di Bologna, Relatore il chiarissimo Prof. A. Cicu.

\section{Signatura}

AGA 32/13540. Legajo 9148-1.

\section{Cátedra}

Derecho civil.

\section{Universidad}

Salamanca.

\section{Anuncio}

10 de enero, 1934. Gaceta del 14.

\section{Reglamento aplicable}

25 de junio, 1931. 


\section{Fechas de la oposición}

Constitución del tribunal: 14 de junio, 1935.

Presentación de los opositores: 15 de junio, 1935.

Votación y propuesta: 15 de julio, 1935.

\section{Tribunal}

Presidente: Demófilo de Buen.

Vocales: Esteban Madruga, Federico de Castro, Adolfo Pons.

Secretario: Vicente Guilarte.

\section{Opositores}

Ignacio Serrano Serrano.

César Delgado González.

Luis Donderis Tatay.

No comparecieron: Luis Portillo Pérez, Rosendo Ferrán Pérez, Juan Ossorio, Francisco Bonet, Manuel Batlle.

\section{Votación}

Ignacio Serrano fue propuesto por unanimidad.

\section{Materiales}

De tipo administrativo: actas, instancias de los aspirantes con acreditación de méritos.

De tipo académico o referentes a los ejercicios:

- Cuestionario del ejercicio sexto (42 temas).

- Escritos del caso práctico (ejercicio quinto).

- Escritos de ejercicio sexto: "Representación y mandato".

Materiales de Serrano:

- Programa.

- Memoria pedagógica.

- Trabajo de investigación: La autonomía de la voluntad. Fechado en 1935, Valladolid.

- Traducción del capítulo $1 .^{\circ}$ de la obra del doctor Franz Jenny: Der offentliche Glaube des Grundbuches nach dem Schweizerischem ZGB [sic].

- El registro de la propiedad en el Código civil suizo, con un prólogo de Jerónimo González, Talleres Tipográficos Cuesta, Valladolid, 1934.

- 11 ejemplares de la Revista Crítica de Derecho Inmobiliario con artículos de Serrano. Los siguientes números: 115 (1934); 116 (1934); 117 (1934); 118 (1934); 119 (1934); 120 (1934); 121 (1935); 122 (1935); 123 (1935); 124 (1935); 125 (1935). 


\section{Signatura}

AGA 32/13523. Legajo 9138-3.

\section{Cátedra}

Derecho internacional público y privado.

\section{Universidad}

Sevilla y La Laguna.

\section{Anuncio}

Para Sevilla 23 de enero, 1934. Gaceta del 29.

Para La Laguna 27 de octubre, 1934. Gaceta del 30.

\section{Reglamento aplicable}

25 de junio, 1931.

\section{Fechas de la oposición}

Constitución del tribunal: 23 de septiembre, 1935.

Presentación de los opositores: 10 de octubre, 1935.

Votación: 25 de noviembre, 1935. La propuesta el día siguiente.

\section{Tribunal}

Presidente: Camilo Barcia Trelles.

Vocales: Isidro Beato, Antonio Luna García, Luis Gestoso.

Secretario: Adolfo Miaja.

\section{Opositores}

José Luis Santaló.

José Quero Molares.

Fernando María Castiella Maíz.

Jesús Esperabé Arteaga.

Todos pasan a la votación final.

No comparecieron: Fernando Arias Parga.

\section{Votación}

Por unanimidad ganó el primer puesto José Quero y el segundo Fernando María Castiella. Queró optó por la cátedra de Sevilla y Castiella aceptó la de La Laguna. 


\section{Materiales}

De tipo administrativo: actas, instancia de los aspirantes con acreditación de méritos.

Referentes a los ejercicios:

- Informes de los jueces sobre los trabajos de investigación presentados.

- Las actas recogen las evaluaciones de los jueces sobre los ejercicios de cada opositor.

- Escritos del ejercicio quinto. Dos partes: “¿Qué influencia tiene en la aplicación de las sanciones colectivas previstas en el art. 16 del pacto de la Sociedad de Naciones, el principio Res inter alios acta?”; "Sucesión con elementos de derecho internacional privado" (resumen del enunciado).

- Escritos del ejercicio sexto. Dos temas: "El problema de la seguridad colectiva"; "El conflicto de leyes en la escuela anglo-americana contemporánea".

Materiales de Castiella:

- Memoria pedagógica.

- Concepto, método y fuentes del Derecho Internacional Privado.

- Trabajo de investigación: Origen, naturaleza, y alcance de los dictámenes del Tribunal Permanente de Justicia Internacional.

- Trabajo de investigación: La nationalité de la femme mariée. Aperçu général de la question et notes pour un article sur l'évolution du droit espagnol.

Materiales de José Quero:

- Programas: Derecho internacional público y Derecho internacional privado.

- Concepto, método y fuentes del Derecho internacional privado.

- Concepto, método y fuentes del Derecho internacional público.

- El principio de autonomía de la voluntad en el Derecho Internacional Privado, Tesis doctoral leída el 12 de mayo de 1930, publicada en la Revista Juridica de Catalunya en el número correspondiente a los meses de julio agosto y septiembre de 1932, G. Casacuberta, Barcelona, 1932.

- La adhesión de España al Código americano de Derecho internacional privado, Revista General de Legislación y Jurisprudencia, diciembre 1934, tomo 165, núm. VI, p. 695.

- El contrato de trabajo en el Derecho Internacional privado, Revista Social, firmado en noviembre 1929, p. 32.

- El contrato de trabajo en el Derecho Internacional privado, Revista Social, $p$. 257. Extracto de la revista. No puede identificarse año ni número.

- El contrato colectivo de trabajo, Revista Social, p.42. Extracto de la revista. No puede identificarse año ni número.

Esperabé retiró sus trabajos el 27 de noviembre, 1935.

Santaló retiró sus trabajos el 24 de enero, 1936. 


\section{Signatura}

AGA 32/13521. Legajo 9138-1.

\section{Cátedra}

Derecho administrativo.

\section{Universidad}

Santiago y Murcia.

\section{Anuncio}

Para Santiago 23 de enero, 1934. Gaceta del 29.

Para Murcia 12 de julio, 1934. Gaceta del 17.

\section{Reglamento aplicable}

25 de junio, 1931.

\section{Fechas de la oposición}

Constitución del tribunal: 4 de julio, 1935.

Presentación de los opositores: misma fecha que la anterior.

Votación: 20 de julio, 1935. La propuesta el día siguiente.

\section{Tribunal}

Presidente: José Gascón Marín.

Vocales: Eduardo Llorens, Joaquín García Labella, Nicolás Pérez Serrano.

Secretario: Sabino Álvarez Guendín.

\section{Opositores}

Segismundo Royo Fernández Cavada (profesor auxiliar de la Central).

Francisco Félix Montiel Giménez (auxiliar de Murcia). Se retiró el 20 de julio.

No comparecieron: Antonio Serra Piñar.

\section{Votación}

Segismundo Royo ganó por unanimidad la votación del primer lugar. Optó por la cátedra de Santiago y fue propuesto.

\section{Materiales}

De tipo administrativo: actas, instancias con acreditación de méritos.

- Notas de evaluación de los jueces sobre los trabajos de investigación y obras de los opositores. 
- Las actas recogen las evaluaciones de los jueces sobre los ejercicios.

- Escritos del quinto ejercicio (caso práctico): "El Gobierno publica un Decreto imponiendo limitaciones a la libertad industrial. ¿Qué recurso sería procedente conforme a la legislación vigente? ¿Quién podría interponerlo?”

- Escritos del ejercicio sexto "El concepto jurídico de la policía".

Materiales de Segismundo Royo:

- Programa (70 lecciones).

- Concepto, método, fuentes y programas de la disciplina.

- Trabajo de investigación: El Estado integral.

- Trabajo de investigación: El artículo 101 de la Constitución.

- La Responsabilidad de la Administración, Tipografía de Archivos, Madrid, 1933.

- El nuevo derecho municipal prusiano, Revista de Derecho Público, abril 1934, núm. 98, p. 108.

Montiel recibió sus materiales el 12 de agosto de 1935

\section{Signatura}

AGA 32/13522. Legajo 9138-2.

\section{Cátedra}

Filosofía del Derecho.

\section{Universidad}

Granada y Sevilla.

\section{Anuncio}

Para Granada 11 de abril, 1934. Gaceta del 26.

Para Sevilla 20 de febrero, 1934. Gaceta del 3 de marzo.

\section{Reglamento aplicable}

25 de junio, 1931.

\section{Fechas de la oposición}

Constitución del tribunal: 11 de junio, 1935.

Presentación de los opositores: 15 de junio, 1935.

Votación: 8 de julio, 1935. La propuesta el día siguiente.

\section{Tribunal}

Presidente: Manuel García Morente. 
Vocales: Miguel Sancho, Luis Recasens Siches, Gonzalo del Castillo.

Secretario: José Gaos.

\section{Opositores}

Felipe González Vicén (auxiliar de Valladolid).

José Corts Grau (auxiliar de Valencia).

José Mingarro San Martín. Se retiró el 4 de julio.

No comparecieron: Epifanio Lorda, Luis Legaz Lacambra, José María Semprún, José R. Medina, Manuel García Pelayo, Ramón Sancho, José Viani.

\section{Votación}

Por unanimidad González Vicén para el primer lugar y José Corts para el segundo. Vicén optó por la cátedra de Sevilla y Corts aceptó la de Granada.

\section{Materiales}

De tipo administrativo: actas, instancias de los aspirantes con acreditación de méritos.

Referentes a los ejercicios.

- Informes de los jueces sobre los trabajos de investigación presentados.

- Las actas recogen las evaluaciones de los jueces sobre los ejercicios de cada opositor. También trascriben el cuestionario (14 temas).

- Escritos del ejercicio quinto: textos de Suárez (Corts) y Grocio (Vicén). Sacados por sorteo de la siguiente lista: Platón, Aristóteles, Cicerón, Santo Tomás, Suárez, Grocio, Rousseau, Hegel. Consta la lista de obras consultadas.

- Escritos del ejercicio sexto: “¿Hay un fundamento ontológico en la distinción de lo justo y lo injusto?” (Corts); "La ontología de los social y sus consecuencias para la filosofía del derecho" (Vicén). Consta la lista del tribunal con los 17 temas. Materiales de Felipe González Vicén.

- Programa (40 lecciones).

- Trabajo de investigación: Kant y la filosofía del Estado. Fechado en Berlín, mayo de 1935 .

- Trabajo de investigación: En torno a la esencia y método de la Filosofía del Derecho. Fechado en Berlín, junio de 1935.

Materiales de José Corts Grau.

- Programa (55 lecciones).

- Concepto, método y fuentes de la Filosofía del Derecho.

- Ideario político de Balmes, Tesis doctoral, Madrid, 1934.

- Georges Renard y su doctrina de la institución, separado de la Revista de Derecho Público, abril de 1934, núm. 28, Imp. De Galo Sáez, Madrid, 1934.

- El sentido óntico y teológico del Derecho en la escolástica. La contrarreforma 
(Apuntes para un estudio), Revista General de Legislación y Jurisprudencia, mayo 1935, tomo 166, núm. V, p. 640.

\section{Signatura}

AGA 32/13531. Legajo 9142-1.

\section{Cátedra}

Historia del Derecho.

\section{Universidad}

Murcia.

\section{Anuncio}

18 de abril, 1934. Gaceta del 26.

\section{Reglamento aplicable}

25 de junio, 1931.

\section{Fechas de la oposición}

Constitución del tribunal: 11 de junio, 1935.

Presentación de los opositores: 15 de junio, 1935.

Votación y propuesta: 2 de julio, 1935.

\section{Tribunal}

Presidente: Claudio Sánchez Albornoz.

Vocales: Galo Sánchez, Manuel Torres López, José María Ramos Loscertales.

Secretario: José López Ortiz.

\section{Opositores}

Alfonso García Gallo.

No comparecieron: Juan Beneyto Pérez, Vicente Granell, Jaime M. Mans, Paulino Pedret.

\section{Votación}

Alfonso García Gallo fue propuesto por unanimidad.

\section{Materiales}

De tipo administrativo: actas, instancias de los aspirantes con acreditación de méritos. 
Referentes a los ejercicios:

- Informes de los jueces sobre los trabajos de investigación presentados.

- Las actas recogen las evaluaciones de los jueces sobre los ejercicios.

- Escrito del ejercicio quinto (caso práctico). Primera parte: "Trascripción y comentario del título tercero del libro I del Fuero Real". Segunda parte: "La centralización administrativa en Castilla en la baja edad media".

Materiales de Alfonso García Gallo:

- Textos de derecho castellano (mecanografiados).

- Avances de estudio sobre las Observancias aragonesas de Jacobo de Hospital (mecanografiado).

- Una colección de fazañas castellanas del siglo XII, Del Anuario de Historia del Derecho español, Tipografía de Archivos, Madrid, 1934.

- Textos de Historia del Derecho español para uso de las clases prácticas (mecanografiado).

- Introducción al estudio de la Historia del Derecho español. Concepto. Método. Fuentes. Programas. (mecanografiado).

- La aplicación de la doctrina española de la guerra. Datos para su estudio, Del Anuario de Historia del Derecho español, Tipografía de Archivos, Madrid, 1934. Constan tres números de la Revista de Derecho Público: el núm. 2 de 1932; el núm. 31 de 1934; el núm. 3 de 1932. Probablemente depositados en este legajo por error.

\section{Signatura}

AGA 32/13527 y 32/13528. Legajo 9140.

\section{Cátedra}

Derecho penal.

\section{Universidad}

La Laguna.

\section{Anuncio}

18 de julio, 1934, Gaceta del 30.

\section{Reglamento aplicable}

25 de junio, 1931.

\section{Fechas de la oposición}

Constitución del tribunal: 18 de julio, 1935. 
Presentación de los opositores: 19 de julio, 1935.

Votación y propuesta: 6 de agosto, 1935.

\section{Tribunal}

Presidente: Constancio Bernaldo de Quirós.

Vocales: Luis Jiménez de Asúa, Mariano Ruiz Funes, Pedro Sangro.

Secretario: Emilio González López.

\section{Opositores}

Manuel López-Rey.

No comparecieron: José Guallart.

\section{Votación}

Manuel López-Rey fue propuesto por unanimidad.

\section{Materiales}

De tipo administrativo: actas, instancias de los aspirantes con acreditación de méritos. Consta un cuadernillo con las publicaciones y méritos de Manuel López-Rey. Materiales de Manuel López-Rey:

- Programa (123 lecciones).

- Concepto, método, fuentes y programas de Derecho penal.

- Trabajo de investigación: Dolo eventual. Datado en Madrid, 1935.

- Un práctico castellano del siglo XVI. Antonio de la Peña, tesis doctoral, Tipografía de Archivos, Madrid, 1935. También consta la versión mecanografiada de septiembre de 1934 .

- Actes de la Conférence, V Conférence Internationale pour l'Unification du Droit Pénal. Madrid, 14-20 octobre 1934, sous la direction de Luis Jiménez de Asúa, avec le concour de Vespasien Pella, par Manuel López-Rey, Editions A. Pedone, Paris, 1935 .

- La reforma del Código Penal español. 5 de noviembre de 1932, Editorial Revista de Derecho Privado, Madrid.

- El valor procesal de la llamada tipicidad. Valor y contenido del auto de procesamiento, Editorial Revista de Derecho Privado, Madrid.

- Traducción con Constancio Bernaldo de Quirós de Luis Mattirolo, Tratado de Derecho judicial civil; quinta edición italiana, Tomo II, Reus, Madrid, 1933.

- Justicia, poder civil, Nueva Generación, Madrid, 1931.

- Con Félix Álvarez Valdés, El nuevo Código Penal, Editorial Revista de Derecho Privado, Madrid, 1933.

- Derecho penal. Obra ajustada al programa de 7 de junio de 1933 para las oposiciones a ingreso en la Escuela de Policía, Reus, Madrid, 1933. 
- Elementos de Derecho político y administrativo, nociones de Hacienda pública, contabilidad del Estado y Derecho penal. Obra ajustada al programa de 2 de enero de 1933 para los ejercicios de las oposiciones a ingreso en el Cuerpo Técnico de Correos, Madrid, 1933.

- ¿Tienen fuerza ejecutiva las certificaciones de los actos de conciliación?, Revista General de Legislación y Jurisprudencia, noviembre de 1931, Tomo 159, núm. V, p. 613 .

- ¿Nueva crisis del Derecho penal?, Revista General de Legislación y Jurisprudencia, febrero de 1934, Tomo 164, núm. II, p. 156.

- La jurisdicción común penal castellana en el siglo XVI. Un intento de construcción histórica, publicado en Revista General de Legislación y Jurisprudencia, abril de 1935, Reus, Madrid, 1935.

- El abandono de familia, publicado en Revista General de Legislación y Jurisprudencia, marzo de 1932, Reus, Madrid, 1932.

Artículos de Manuel López-Rey en la Revista de Derecho Público:

- Jurisprudencia del Tribunal Supremo, B) Notas sobre algunas sentencias de mayor interés, Revista de Derecho Público, febrero 1932, núm. 2.

- Jurisprudencia del Tribunal Supremo, A) Criminal, 2. ${ }^{\circ}$ Notas sobre algunas sentencias de mayor interés, Revista de Derecho Público, abril 1932, núm. 4.

- Notas bibliográficas, Cuello Calón (Eugenio): Cuestiones penales relativas al aborto, Revista de Derecho Público, junio 1933, núm. 6.

- Jurisprudencia del Tribunal Supremo, A) Criminal, 2. ${ }^{\circ}$ Nota sobre un caso de estafa. Sentencia de 17 de marzo de 1932, Revista de Derecho Público, julioagosto 1932, núms. 7 y 8.

- Jurisprudencia del Tribunal Supremo: Criminal: Nota sobre dos sentencias de interés, Revista de Derecho Público, octubre 1932, núm. 10.

- La reforma del Código Penal, Revista de Derecho Público, noviembre 1932, núm. 11.

- Rectificaciones a la reforma del Código Penal, Revista de Derecho Público, diciembre 1932, núm. 12.

- Notas bibliográficas, Fernández Pla (Francisco), La reforma penal en Cuba, y Tejera (Diego Vicente), Prontuario de jurisprudencia criminal, Revista de Derecho Público, enero 1933, núm. 13.

- Notas bibliográficas, Grispigni (Filippo), Corso di diritto penale, Revista de Derecho Público, marzi 1933, núm. 15.

- Notas bibliográficas, Manlio Taraschi, Il Codice penale commentato, Revista de Derecho Público, octubre 1934, núm. 34.

- Las causas de justificación en el Derecho penal castellano del siglo XVI, Revista de Derecho Público, noviembre 1934, núm. 35.

- Notas bibliográficas: Castro (Horacio de): Principios de Derecho soviético, y 
Galíndez Suárez (Jesús): La legislación penal en Vizcaya, Revista de Derecho Público, noviembre 1934, núm. 35.

- Las causas de justificación en el Derecho penal castellano del siglo XVI. Continuación, Revista de Derecho Público, diciembre 1934, núm. 36.

- Apostillas a una nota bibliográfica, Revista de Derecho Público, diciembre 1934, núm. 36.

- Notas bibliográficas, Bernaldo de Quirós y Ardila: El Bandolerismo, y Gómez Mesa (Antonio): Sobre el menor delincuente, Revista de Derecho Público, enero 1935, núm. 37.

- Notas bibliográficas, Cuello Calón (Eugenio): El Derecho penal de las dictaduras, Revista de Derecho Público, febrero 1935, núm. 38.

\section{Signatura}

AGA 32/13520. Legajo 9136-4.

\section{Cátedra}

Filosofía del Derecho.

\section{Universidad}

Central.

\section{Anuncio}

Orden de 6 de noviembre, 1934. Gaceta del 10.

\section{Reglamento aplicable}

25 de junio, 1931.

\section{Fechas de la oposición}

Constitución del tribunal: 22 de junio, 1935.

Presentación de los opositores: 25 de junio, 1935.

Votación y propuesta: 13 de julio, 1935.

\section{Tribunal}

Presidente: Miguel de Unamuno.

Vocales: Miguel Sancho, Luis Recasens Siches, Recaredo Fernández de Velasco.

Secretario: Nicolás Pérez Serrano.

\section{Opositores}

José Medina Echavarría (ayudante de filosofía del derecho de la Central). 
Alfonso García Valdecasas (catedrático de civil en Granada). José Mingarro San Martín se retiró.

No comparecieron: Blas Ramos, Enrique Luño, Epifanio Lorda, Francisco Marcos, José Corts, Luis Legaz Lacambra, José María Semprún, Jose R. Madina, Manuel Rey.

Manuel García Pelayo Alonso con instancia incompleta.

\section{Votación}

Se acordó por unanimidad la no provisión.

\section{Materiales}

De tipo administrativo: actas, instancias con acreditación de méritos.

Referentes a los ejercicios.

- Informes de los jueces sobre los trabajos de investigación presentados.

- Las actas recogen las evaluaciones de los jueces sobre los ejercicios de cada opositor. También trascriben el cuestionario (14 temas).

- Escritos del ejercicio quinto: Dante. Tema sacado en sorteo de la siguiente lista: Platón, Aristóteles, Dante, Suárez, Vitoria, Hobbes, Montesquieu, Rousseau, Kant, Hegel, Goethe.

- Escritos del ejercicio sexto: “¿Qué importancia ha tenido para la Filosofía Jurídica la transformación del concepto de ley natural en el Renacimiento?

\section{Signatura}

AGA 32/13531. Legajo 9142-2.

\section{Cátedra}

Historia del Derecho.

\section{Universidad}

La Laguna.

\section{Anuncio}

30 de abril, 1935. Gaceta del 18 de mayo.

\section{Reglamento aplicable}

25 de junio, 1931.

\section{Fechas de la oposición}

Constitución del tribunal: 7 de enero, 1936. 
Presentación de los opositores: 17 de enero, 1936.

Votación y propuesta: 6 de marzo, 1936.

\section{Tribunal}

Presidente: José María Ots.

Vocales: José López Ortiz, José Manuel Segura Soriano, Ramón Prieto, José Antonio Rubio.

Secretario: Alfonso García Gallo.

\section{Opositores}

Juan Beneyto Pérez.

Vicente Granell. Se retira el 6 de marzo.

No comparecieron: José Peraza, Jaime M. Mans, Paulino Pedret, Juan Manzano.

\section{Votación}

Todos votaron por la provisión menos Ots, quien votó a Beneyto. La provisión se declaró desierta.

\section{Materiales}

De tipo administrativo: actas, instancias de los aspirantes con acreditación de méritos.

Referentes a los ejercicios:

- Informes de los jueces sobre los trabajos de investigación presentados.

- Las actas recogen las evaluaciones de los jueces sobre los ejercicios de los opositores.

- Escrito del ejercicio quinto (caso práctico). Primera parte: "Trascripción y comentario de un diploma en latín del siglo XII". Segunda parte: "Trascripción y comentario del fuero de Cuenca XXXII, 7".

- Escritos del sexto ejercicio. Primera parte, dos grupos: "El derecho local en la Reconquista española"; "Influencia de la organización del ejército en la organización del Estado a través de las diferentes épocas". Segunda parte: "Relaciones de la agricultura y la ganadería en las Cortes castellanas de la baja edad media”. Las actas trascriben el cuestionario con los 15 y 16 temas (grupos primero y segundo) para la primera parte y los 10 para la segunda. 


\section{Signatura}

AGA 32/13538 y 32/13539. Legajo 9146.

\section{Cátedra}

Economía política y Hacienda pública.

\section{Universidad}

Murcia y Santiago.

\section{Anuncio}

Orden de 8 de mayo, 1935. Gaceta del 13.

Hubo una convocatoria para la cátedra de Murcia el 25 de enero de 1934. Declarada nula por Orden de 1 de marzo de 1934.

\section{Reglamento aplicable}

25 de junio, 1931.

\section{Fechas de la oposición}

Constitución del tribunal: 10 de diciembre, 1935.

Presentación de los opositores: mismo día que al anterior.

Votación: 20 de marzo, 1936. La propuesta el día siguiente.

\section{Tribunal}

Presidente: José Gascón Marín.

Vocales: Antonio Flores de Lemus, José Álvarez Cienfuegos.

Secretario: Enrique Rodríguez Mata (tras el abandono de Eulogio Alonso-Villaverde Moris el 7 de enero).

\section{Opositores}

Francisco Oriol Catena.

Jesús Prados Arrarte.

Manuel Sánchez Sarto.

Julio Tejero Nieve.

Pedro Antonio Muñoz Casayús.

No comparecieron: Enrique Martín Guzmán, Antonio Bermúdez Cañete, Mariano Sebastián Herrador.

\section{Votación}

Votación del primer lugar:

- Jesús Prados: dos votos (Cienfuegos, Flores). 
- Julio Tejero: un voto (Gascón).

- Manuel Sánchez Sorto: un voto (Mata).

En la segunda votación Prados obtuvo todos los votos menos el de Gascón, quién votó a Tejero.

En la votación del segundo lugar Julio Tejero obtuvo todos los votos menos el de Cienfuegos, quien votó a Oriol.

Prados optó por la cátedra de Santiago y Tejero aceptó la de Murcia. Fueron propuestos.

\section{Materiales}

De tipo administrativo: actas, instancias con acreditación de méritos.

De tipo académico o referentes a los ejercicios:

- Escritos del ejercicio práctico (ejercicio quinto).

- Escritos de ejercicio sexto.

Materiales de Jesús Prados:

- Programa.

- La reforma monetaria de Roosvelt. El plan de Fisher para compensar el dólar, Publicaciones de la Unión Económica, Madrid, 1934.

- Artículos en la revista Economía Española: Bibliografía, Paul Einzig, Los fundamentos económicos del fascismo (1934); R.F. Harrod, International Economics; Weltwirtschaftliches Archiv (1935); Banco de Portugal: Servico de Estadística e Estudios Económicos, Boletín número 4, enero a junio de 1934 (1934); Franklin D. Roosevelt: sur la bonne voie (1934), J. D. Janson, Foreing Trade in the U.S.S.R., y Weltwirtschaftliches Archiv (1935), Weltwirtschaftliches Archiv: Zeitschrift des Instituts für Weltwirtscht (1935), Weltwirtschaftliches Archiv, septiembre de 1934 y Eduardo Ibarra Rodríguez, Plan para organizar los estudios de la Historia de la Economía social en Aragón (1935).

- Artículos de prensa.

Materiales de Julio Tejero:

- Programas.

- Concepto y metodología de las Ciencias Económicas.

- Artículos en la revista Economía Española: Bibliografía, Francesco Vito, La concezione biológica dell'Economia (1934); Rivista Internazionale di Scienze Sociali; L’Economie dirigée. Conferences organisées par la Societé des anciens élèves et élèves de l'École de Sciences politiques (1935); Miglioli (Guido), La collectivisation des campagnes sovietiques (1934); Martín (Garmain), Sommesnous sur la bonne route? Problémes financiers du temps présent (1934), Rivista Internazionale di Scienze Sociali, enero de 1935 (1935).

Materiales de Sánchez Sorto.

- Programas. 
- Trabajo de investigación: Anteproyecto de una Ley de Cooperativas.

- Trabajo de investigación: Los Consejos de Fábrica en Alemania: trascendencia internacional de esta institución.

- Les banques publiques en Espagne jusqu'a 1815, reprint from History of the Principal Banks, The Hague, Martinus Nijhoff.

- Die amtliche Statistik in Spanien. Extracto. No se puede identificar procedencia.

- Anexo 1: conferencias (carpeta).

- Anexo 3: recensiones, artículos, conferencias (carpeta).

Traducciones de Sánchez Sorto:

- C. J. Fuchs, Economía política, tercera edición, Labor, Barcelona-Buenos Aires, 1932.

- J. Ramsay Macdonald, Socialismo, segunda edición, Labor, Barcelona-Buenos Aires, 1928.

- Roberto Michels, Organización del comercio exterior, Labor, Barcelona-Buenos Aires, 1930.

- Sigmund Schott, Estadística, Labor, Barcelona-Buenos Aires, 1928.

- Con Rafael Luego Tapia, Ludwig Heyde, Compendio de política social, segunda edición, Labor, Barcelona-Buenos Aires, 1931.

- Adolf Weber, La economía mundial al alcance de todos, con un prefacio de Oskar von Miller, Labor, Madrid-Barcelona-Buenos Aires, 1933.

- Ernst Wageman, Estructura y ritmo de la economía mundial, Labor, MadridBarcelona-Buenos Aires, 1933.

\section{Signatura}

AGA 32/13536 y 32/13537. Legajo 9145.

\section{Cátedra}

Derecho civil.

\section{Universidad}

Santiago y La Laguna.

\section{Anuncio}

Para La Laguna Orden de 18 de mayo, 1935. Gaceta del 28.

Para Santiago Orden de 15 de junio, 1935. Gaceta del 21.

\section{Reglamento aplicable}

25 de junio, 1931. 


\section{Fechas de la oposición}

Constitución del tribunal: 3 de enero, 1936.

Presentación de los opositores: 4 de enero, 1936.

Votación: 26 de febrero, 1936. La propuesta el día siguiente.

\section{Tribunal}

Presidente: Clemente de Diego.

Vocales: Francisco Bonet, Manuel Batlle.

Secretario: Ignacio Serrano.

Se excusaron: Valdecasas, Valverde, Dualde, Gil Casares, Ossorio.

\section{Opositores}

Manuel Antonio Romero Vieitez. Recurrió el acuerdo de su no admisión.

Alfonso de Cossío Corral.

Miguel Royo Martínez.

Luis Portillo Pérez. Se retiró el 24 de febrero.

César Delgado González.

Pasaron a la votación final Romero, Cossío, Delgado y Royo.

No comparecieron: Luis Donderis Tatay, Rosendo Ferrán Pérez, Francisco García-Revillo, Enrique Rajoy.

\section{Votación}

En la votación del primer lugar Manuel Antonio Romero obtuvo todos los votos menos el de Serrano, quien votó a Royo.

La votación del segundo lugar fue ganada por Cossío por unanimidad.

Romero optó por la cátedra de Santiago, Cossío aceptó la de La Laguna.

Fueron propuestos.

\section{Materiales}

De tipo administrativo: actas, instancias de los aspirantes con acreditación de méritos. Cartas y telegramas sobre conformación del tribunal.

Recurso de Romero contra el acuerdo del tribunal de no admitirlo, de 7 de enero, 1936.

De tipo académico o referentes a los ejercicios:

- Escritos del ejercicio práctico (ejercicio quinto): "El Sr. A ha contraído matrimonio tres veces..." (Inicio del enunciado).

- Escritos de ejercicio sexto: "La hipoteca de seguridad".

Materiales de Romero: programas.

Materiales de Cossio:

- Programa de Derecho civil español común y foral. 
- Concepto, métodos, plan y fuentes Derecho civil español común y foral.

- Trabajo de investigación: Algunas observaciones en torno a la teoría general del patrimonio, con especial consideración del llamado patrimonio del ausente.

- Introducción a la teoría del patrimonio en Roma: res mancipi y nec mancipi, Anales de la Universidad de Valladolid, julio-septiembre 1934, núm. 20.

- Idem (Conclusión), Anales de la Universidad de Valladolid, octubre-diciembre 1934, núm. 21.

- El usufructo de acciones del artículo 486 de nuestro Código civil, Revista Crítica de Derecho Inmobiliario, diciembre 1933, núm. 108.

Materiales de Royo:

- Memoria y programa.

- Una innovación necesaria en la carrera de Derecho, Revista General de Legislación y Jurisprudencia, diciembre 1932, Tomo 161, Núm. IV

- Aportaciones al estudio de la hipoteca sobre bienes muebles, Tesis doctoral leída ante el claustro de la Universidad de Bolonia el 30 de junio de 1930, Imp. de "El Correo de Andalucía”, Sevilla, 1933.

- Artículos de la Revista Crítica de Derecho Inmobiliario: Notas sobre la consideración jurídica del gusano de seda (1931); Notas acerca de la naturaleza contractual del matrimonio (mayo 1932 y junio 1932).

Materiales de Portillo: Notas y boceto para una memoria pedagógica.

Materiales de Delgado: Programa.

\section{Signatura}

AGA 32/13533. Legajo 9143.

\section{Cátedra}

Derecho mercantil.

\section{Universidad}

La Laguna.

\section{Anuncio}

O. de 31 de mayo, 1935. Gacetas del 6 de junio.

\section{Fechas de la oposición}

1936, 11 de enero: constitución del tribunal.

1936, 13 de enero: presentación de los opositores.

1936, 29 de abril: votación y propuesta. 


\section{Tribunal}

Presidente: Ricardo López Barroso.

Vocales: Álvaro Calvo, Francisco Hernández Borondo.

Secretario: Antonio Polo.

Se excusaron Boix, Candil y Martínez Moya. Éste último por figurar como candidato en las próximas elecciones generales.

\section{Opositores}

Joaquín Rodríguez Rodríguez.

Elías Ros Pallares. Se retira el 24 de abril.

Miguel Cabeza Anide. Se retira el 24 de abril.

Rodrigo Uría.

No comparecieron: Enrique Martín Guzmán, Manuel Pascual.

Todos menos Uría pasan al último ejercicio.

\section{Votación y propuesta}

Joaquín Rodríguez fue propuesto por unanimidad.

\section{Materiales}

De tipo administrativo: actas, instancias de los aspirantes con acreditación de méritos.

De tipo académico o referentes a los ejercicios:

- Escritos del quinto ejercicio.

- Escritos del sexto ejercicio. Las actas recogen el cuestionario (25 temas).

Materiales de Joaquín Rodríguez:

- Concepto de los agentes de comercio con especial consideración del Derecho español, Tipografía de Archivos, Madrid, 1935.

- Notas bibliográficas, Hirsch (Ernst E.), Praktische Fälle aus dem Handels-und Wirtschaftsrecht mit Lösungen, Revista de Derecho Privado, septiembre 1933, núm. 240.

- Notas bibliográficas, Mutz (Richard), La vente a Prix uniques, Revista de Derecho Privado, febrero 1935, núm. 257.

Trabajos de investigación de Joaquín Rodríguez:

- Contabilidad mercantil. Teoría general.

- Proyecto de comentario a los arts. 886-898 del Código de Comercio español.

- Datos para el estudio de las adquisiciones de un no titular según el Derecho mercantil español.

- Tesis doctoral: El regreso por no aceptación en Derecho español y comparado. Materiales de Ros Pallares:

- Programa. 
- Trabajo de investigación: Trabajo en preparación sobre Notas biográficas del jurisconsulto Bartolomé de Albornoz y doctrina jurídico-mercantil contenida en su libro "El arte de los contratos".

- El seguro de vida y la muerte presunta, Revista General de Legislación y Jurisprudencia, mayo 1934, Tomo 164, núm. V.

- Artículos en la revista Vida Corporativa, órgano del Colegio Oficial de Agentes comerciales: Índice de cosas que pueden ser término objetivo en la relación jurídico-mercantil, 1935, núm. 98; idem (continuación), 1935, núm. 102; ídem, 1935, núm. 103; ídem, 1935, núm. 104; ídem (conclusión), 1935, núm. 105.

Materiales de Cabeza:

- Trabajo de investigación: El derecho de separación del socio en las sociedades mercantiles.

Trabajo de investigación. No se indica autor: Guión para la discusión en el seminario de Derecho mercantil del proyecto de ley unitaria publicado en la Gaceta del día 20 de octubre de 1932. Datos para la redacción del texto español. Copia del original fechado en Madrid, a noviembre de 1932.

Se conservan ejemplares de la Revista de Derecho Privado, sin artículos de ningún opositor. También un ejemplar de la Revista de Sanidad de Guerra (1937).

Uría retira sus trabajos el 23 de abril de 1936.

Cabeza retira sus trabajos el 28 de abril de 1936.

\section{Signatura}

AGA 32/13561. Legajo 9576-4.

\section{Cátedra}

Derecho político.

\section{Universidad}

La Laguna.

\section{Anuncio}

Orden de 8 de agosto, 1935. Gaceta del 20.

Se anunció a traslación el 27 de mayo, 1935. Gaceta del 30.

\section{Reglamento aplicable}

25 de junio, 1931.

\section{Fechas de la oposición}

No consta que la oposición se celebrara. 
El oficio del negociado indica que la fecha de comienzo de los ejercicios era el 25 de junio, 1936.

\section{Tribunal}

Presidente: Antonio Royo Villanova.

Vocales: Fernando de los Ríos, Gonzalo del Castillo, Francisco Ayala, Eduardo Llorens.

Suplentes: Arias de Velasco, Pérez Serrano, Elorrieta, Martínez Pedroso.

\section{Opositores}

Constan instancias de los siguientes:

Francisco Javier Conde García.

Gonzalo Cáceres Crosa.

Epifanio Lorda Roig.

José Viani Caballero.

Ramón Sancho Brased.

Materiales

Oficios del negociado e instancias de los aspirantes, con acreditación de méritos.

\section{Signatura}

AGA 32/13561. Legajo 9576-12.

\section{Cátedra}

Derecho canónico.

\section{Universidad}

Santiago.

\section{Anuncio}

10 de septiembre, 1935. Gaceta del 19.

Se declaró desierta la provisión por traslación.

\section{Reglamento aplicable}

25 de junio, 1931.

\section{Fechas de la oposición}

No consta que la oposición se celebrara.

El oficio del negociado indica que los ejercicios comenzarían el 25 de junio de 1936. 


\section{Tribunal}

Presidente: Juan Moneva.

Vocales: Manuel Cabrera, Jesús Mérida, José María Campos, Manuel Jiménez Fernández.

Suplentes: Francisco Gómez del Campillo, José Escobedo, Teodoro Andrés, Armando Álvarez Rodríguez.

\section{Opositores}

El oficio recoge como aspirantes a los siguientes:

Heraclio Sánchez Rodríguez.

José María Rego Machinéa.

Paulino Pedret Casado.

Epifanio Lorda Roig.

Cándido Campos García Valenzuela.

José Bernal Montero.

\section{Materiales}

Oficios del negociado e instancias de los aspirantes, con acreditación de méritos. Trabajo de investigación sin indicación de su autor: Importancia que tiene el Derecho romano como elemento primordial de una formación jurídica completa. $Y$ cual tiene para los juristas españoles (mecanografiado, 42 pp.).

\section{Signatura}

AGA 32/13561. Legajo 9576-8.

\section{Cátedra}

Derecho administrativo.

\section{Universidad}

Murcia.

\section{Anuncio}

11 de septiembre, 1935. Gaceta del 20.

Se anunció a traslación el 2 de agosto, 1935. Gaceta del 6.

\section{Reglamento aplicable}

25 de junio, 1931. 


\section{Fechas de la oposición}

No consta que la oposición se celebrara.

El oficio del negociado indica que la fecha de comienzo de los ejercicios era el 25 de junio, 1936.

\section{Tribunal}

Presidente: Adolfo G. Posada.

Vocales: Antonio Royo Villanova, Segismundo Royo, Jesús Sánchez Biedma, Sabino Álvarez Guendín.

Suplentes: Gascón Marín, Valenzuela, García Oviedo, Gil-Robles Quiñones (se admite su renuncia por Orden de 27 de noviembre, 1935).

\section{Opositores}

Constan instancias de los siguientes:

Antonio Mesa Segura.

José Luis Santaló Rodríguez de Viguri.

Juan Galván Escutia.

Francisco Félix Montiel Jiménez.

José Viani Caballero.

\section{Materiales}

Oficios del negociado e instancias de los aspirantes, con acreditación de méritos.

\section{Signatura}

AGA 32/13561. Legajo 9576-11.

\section{Cátedra}

Estudios superiores de Derecho privado.

\section{Universidad}

Central.

\section{Anuncio}

R.O. de 25 de agosto, 1930. Gaceta del 28.

En suspenso por Orden de 12 de abril, 1932.

Anunciada nuevamente el 25 de octubre, 1935.

\section{Reglamento aplicable}

No consta. 


\section{Fechas de la oposición}

No consta que la oposición se celebrara.

\section{Tribunal}

Consta como presidente Felipe Clemente de Diego.

\section{Opositores}

Constan instancias de los siguientes:

Federico de Castro.

Alfonso García Valdecasas.

Demófilo de Buen.

Manuel Miguel Traviesas.

José Benito Mampel.

Enrique R. Ramos.

Joaquín de Dalmases.

Ignacio de Casso.

Antonio Sacristán Colás.

\section{Materiales}

Oficios del negociado e instancias de los aspirantes, con acreditación de méritos.

\section{Signatura}

AGA 32/13561. Legajo 9576-9.

\section{Cátedra}

Derecho procesal.

\section{Universidad}

Santiago.

\section{Anuncio}

2 de diciembre, 1935. Gaceta del 12.

Se anunció a traslación el 10 de abril, 1935. Gaceta del 15.

\section{Reglamento aplicable}

25 de junio, 1931.

\section{Fechas de la oposición}

No consta que la oposición se celebrara. 
El oficio del negociado indica que la fecha de comienzo de los ejercicios era el 1 de julio, 1936.

\section{Tribunal}

Presidente: Francisco Beceña.

Vocales: Gabriel Bonilla, Niceto Alcalá-Zamora del Castillo, Francisco Marcos, Leonardo Prieto.

Suplentes: José Xiráu, Emilio Gómez Orbaneja, Matías Domínguez Ballarín, José Serrano.

\section{Opositores}

Constan instancias de los siguientes:

Agustín Iscar Alonso.

Ángel Enciso Calvo.

Antonio Cases Casañ.

\section{Materiales}

Oficios del negociado e instancias de los aspirantes, con acreditación de méritos.

\section{Signatura}

AGA 32/13561. Legajo 9576-2.

\section{Cátedra}

Economía política y Hacienda pública.

\section{Universidad}

Sevilla.

\section{Anuncio}

31 de enero, 1936. Gaceta del 6 de febrero.

\section{Reglamento aplicable}

25 de junio, 1931.

\section{Fechas de la oposición}

No consta que la oposición se celebrara.

\section{Tribunal}

El oficio del negociado recoge dos nombres: 
- Agustín Viñuales (propuesto por Sevilla).

- Ramón Carande (propuesto por Sevilla).

\section{Opositores}

El oficio del negociado recoge dos nombres:

Manuel Sánchez Sarto.

Francisco Oriol Catena.

Jesús Prados Arrarte.

Julio Tejero Nieves.

Mariano Sebastián Herrador.

Pedro Antonio Muñoz Casajús.

José Castañeda Thornet.

\section{Materiales}

Oficios del negociado e instancias de los aspirantes, con acreditación de méritos.

\section{Signatura}

AGA 32/13565. Legajo 9578.

\section{Cátedra}

Derecho civil.

\section{Universidad}

Salamanca y Oviedo.

\section{Anuncio}

11 de junio, 1940. BOE del 25 .

\section{Reglamento aplicable}

25 de junio, 1931.

\section{Fechas de la oposición}

Constitución del tribunal: 30 de septiembre, 1940.

Presentación de los opositores: 3 de octubre, 1940.

Votación: 15 de noviembre, 1940. La propuesta el día siguiente.

\section{Tribunal}

Presidente: Felipe Clemente de Diego.

Vocales: Felipe Gil Casares, Ignacio de Casso, Blas Pérez.

Secretario: Juan Ossorio Morales. 


\section{Opositores}

José Beltrán de Heredia Castaño.

César Delgado González.

Luis Donderis Tatay.

José Fernández Santa Eulalia.

Todos pasan al quinto ejercicio. Delgado, Donderis y Santa Eulalia se retiran el 14 de noviembre. Continúa Beltrán.

\section{Votación}

José Beltrán fue propuesto por unanimidad. Realiza la siguiente opción: por la cátedra de Salamanca en caso de que el concurso de traslado sea resuelto a favor de Ignacio Serrano. En caso contrario, por la de Oviedo. Fue propuesto en tal sentido.

\section{Materiales}

De tipo administrativo: actas, instancias de los aspirantes con acreditación de méritos.

Protesta del aspirante César Delgado contra su inadmisión, de 17 de septiembre de 1940. Se indica que figura como excluido "por no haber justificado con documento bastante mi adhesión al nuevo Estado". Acompaña certificados al efecto: certificado de la Jefatura de Falange y de la Comisaría de Investigación y Vigilancia de Valladolid.

De tipo académico o referentes a los ejercicios:

- Escritos del caso práctico (ejercicio quinto). Consta la copia del enunciado.

- Escrito de ejercicio sexto: "Obligaciones pecuniarias".

Materiales de Beltrán:

- Proyecto de un curso de Derecho civil en forma de programa.

- Concepto, método y fuentes del Derecho civil.

- Trabajo de investigación: Elemento constitutivo de la posesión. Sistematización doctrinal.

- Trabajo de investigación: Usucapión de la cosa común por un copropietario. Legislación italiana.

- Trabajo de investigación: Concepto de posesión en la legislación y jurisprudencia italianas.

- Trabajo de investigación: Usufructo sobre usufructo en la legislación española. Teoría negativa.

- Trabajo de investigación, con Alfonso Bellón Renolaves y Antonio Hernández Gil: Concepciones jurídicas de Luis Vives.

Materiales de Santa-Eulalia: Memoria expositiva sobre el concepto, método, fuentes y programa. 
Materiales de Donderis:

- Programa.

- Del concepto, método y fuentes del Derecho civil español, común y foral.

- Trabajo de investigación: El negocio jurídico fiduciario. Fechado en Valencia, 1940.

- La copropiedad. Teorías. Derecho español, con un prólogo de José Castán Tobeñas, Reus, Madrid, 1933.

Materiales de Delgado: Estudio sobre el concepto, método, fuentes y programa. Retiró el resto de materiales (nota de 16 de noviembre de 1940).

\section{Signatura}

AGA 32/13568. Legajo 9580.

\section{Cátedra}

Historia del Derecho.

\section{Universidad}

Salamanca, Sevilla y Murcia.

\section{Anuncio}

Para Granada y Sevilla, Orden del 11 de junio, 1940. BOE del 25.

Posteriormente Granada se desagrega.

Salamanca se agrega por Orden de 20 de agosto, 1940. BOE del 29.

Murcia se agrega por Orden de 6 de agosto, 1940. BOE del 19 de septiembre.

\section{Reglamento aplicable}

25 de junio, 1931.

\section{Fechas de la oposición}

Constitución del tribunal: 30 de septiembre, 1940.

Presentación de los opositores: 3 de octubre, 1940.

Votación: 22 de octubre, 1940. La propuesta el día siguiente.

\section{Tribunal}

Presidente: Salvador Minguijón.

Vocales: Manuel Torres López, Carmelo Viñas, Luis García Valdeavellano.

Secretario: José Santa Cruz. 


\section{Opositores}

Juan Beneyto Pérez.

Juan Manzano Manzano.

Consta instancia de Jaime M. Mans Puigarnau, pero no aparece en la lista de aspirantes del negociado.

\section{Votación}

Por unanimidad Beneyto obtuvo el primer lugar y Manzano el segundo. Beneyto optó por la cátedra de Salamanca y Manzano por la de Sevilla. Fueron propuestos. La provisión de la cátedra de Murcia fue declarada desierta.

\section{Materiales}

Actas.

De tipo académico o referentes a los ejercicios:

- Escritos del caso práctico (ejercicio quinto): Traducción y comentario de un texto del fuero de Logroño de 1095.

- Escritos de ejercicio sexto. Dos partes: "El elemento germánico en la época visigótica y en los fueros municipales”; “Aportaciones económicas a la sociedad conyugal”. Las actas recogen la lista de temas acordados por el tribunal.

Materiales de Beneyto:

- Memoria sobre el concepto, el método, las fuentes y el programa de la asignatura.

- Trabajo de investigación: 300 textos para el estudio del sistema político medieval.

- Trabajo de investigación: Notae super foris regni valentiae.

- Trabajo de investigación: Sobre las glosas al Código de Valencia.

- Separatas sobre temas de Historia del Derecho Valenciano.

Es un tomo que contiene los siguientes artículos: Regulación del trabajo en la Valencia del 50o, del Anuario de Historia del Derecho español, Madrid, 1931; Expropiación y ensanche en la Valencia del 500, Cultura Valenciana, Quadern II, Març-abril 1931; Sobre la territorialización del Código de Valencia, Boletín de la Sociedad Castellonense de Cultura, 1931; Significato Storico dell' "Empriu". Contributo allo studio degli "Ademprivia”, RSDI, 1932; Il diritto catalano in Italia, 1933; Per un index d'escriptors "super foris regni valentiae", Valencia, 1935; Un opúsculo jurídico de Jaffer, Boletín de la Sociedad Castellonense de Cultura, 1936; Arnaldi Joannis opusculum, Boletín de la Sociedad Castellonense de Cultura, 1936; Sobre tres formularios valencianos, Boletín de la Sociedad Castellonense de Cultura, 1936.

Materiales de Manzano:

- Un compilador indiano. Manuel José de Ayala, Del Boletín del Instituto de In- 
vestigaciones Históricas, año XIII, t. XVIII, pp.152-240, Buenos Aires, julio de 1934-marzo de 1935.

- Un documento inédito a "Cómo funcionaba el Consejo de Indias", contributed with an introduction by Juan Manzano, The Hispanic American Historical Review, August 1935, No. 3, vol. XV.

- Introducción al estudio de la Historia del Derecho español. (Concepto. Método. Fuentes. Programas).

- Las "Notas" a las Leyes de Indias, de Manuel José de Ayala, Publicaciones del Instituto de Derecho Comparado Hispano-Portugués-Americano, C. Bermejo Impresor, Madrid, 1935.

- El nuevo código de leyes de las Indias. Proyecto de Juan Crisóstomo de Ansotegui, de la Revista de Ciencias Jurídicas y Sociales, año XVIII, núms. 73 y 74.

- Los trabajos recopiladores de Diego de Zorrilla y Rodrigo de Aguiar, tirada aparte de la Colección de Estudios Históricos, Jurídicos, Pedagógicos y Literarios, Homenaje a D. Rafael Altamira, Madrid, 1936.

- Algunas aclaraciones a las últimas "Observaciones" sobre Manuel José de Ayala y sus obras. No se puede identificar la procedencia. Madrid, 15 de julio de 1939

\section{Signatura}

AGA 32/13569 y 32/13570. Legajo 9581.

\section{Cátedra}

Derecho procesal.

\section{Universidad}

Barcelona y Murcia.

\section{Anuncio}

11 de junio, 1940. BOE del 25.

\section{Reglamento aplicable}

25 de junio, 1931.

\section{Fechas de la oposición}

Constitución del tribunal: 30 de septiembre, 1940.

Presentación de los opositores: 3 de octubre, 1940.

Votación: 18 de noviembre, 1940. La propuesta el día siguiente. 


\section{Tribunal}

Presidente: Blas Pérez González.

Vocales: Mauro Miguel Romero, José Serrano Suárez, Eduardo Dívar Martín.

Secretario: Leonardo Prieto Castro.

\section{Opositores}

Jaime Guasp Delgado.

Valentín Silva Melero.

Antonio Martínez Bernal.

Ángel Enciso Calvo.

\section{Votación}

Jaime Guasp Delgado obtuvo el primer lugar por unanimidad.

La votación del segundo lugar fue ganada por Valentín Silva por tres votos (Prieto, Serrano y Miguel Romero) contra dos de Ángel Enciso (Dívar y Pérez). Guasp optó por la cátedra de Barcelona y Silva aceptó la de Murcia. Fueron propuestos.

\section{Materiales}

Actas.

De tipo académico o referentes a los ejercicios:

- Escritos del caso práctico (ejercicio quinto). El enunciado se recoge en el acta.

- Escritos de ejercicio sexto: "El control jurisdiccional que se efectúa en la instancia provincial contencioso-administrativa española y procedimiento para efectuarlo".

Materiales de Guasp:

- Concepto, método, fuentes y programa de la asignatura.

- Juez y hechos den el proceso civil. Una crítica del derecho de disposición de las partes sobre el material de hecho del proceso, tesis doctoral. Fechada en junio de 1940.

Materiales de Silva:

- Trabajo de investigación: Contribución al estudio del negocio jurídico ilícito den Derecho civil.

- Traducción: Fritz Mang, El obrero alemán en el nacional-socialismo, Ediciones Nueva España, Ávila, 1939.

- Artículos en el Revista General de Legislación y Jurisprudencia: Contribución al estudio de la relación jurídica procesal (1930), Las sentencias constitutivas (1931); El compromiso (1932); Notas para el estudio de la confesión en el proceso civil (1933); Notas para el estudio del concepto de Derecho procesal (1934); La cosa juzgada en el proceso civil (1936).

Materiales de Antonio Martínez: Programa. 
Constan algunos materiales sin indicación de su autor:

- Estudio sobre el concepto del Derecho procesal.

- Fuentes y medios necesarios para el estudio del Derecho procesal.

- Método de enseñanza.

- Programa de Derecho procesal civil.

\section{Signatura}

AGA 32/13570 y 32/13571. Legajo 9582.

\section{Cátedra}

Derecho penal.

\section{Universidad}

Valladolid, Oviedo y Murcia.

\section{Anuncio}

Para Santiago y Valladolid por Orden de 11 de junio, 1940. BOE del 25.

Posteriormente Santiago se desagrega.

Oviedo se agrega por Orden de 13 de agosto, 1940. BOE del 8 de septiembre.

Murcia se agrega por Orden de 18 de septiembre, 1940. BOE del 23.

\section{Reglamento aplicable}

25 de junio, 1931.

\section{Fechas de la oposición}

Constitución del tribunal: 3 de octubre, 1940.

Presentación de los opositores: misma fecha que la anterior.

Votación: 31 de octubre, 1940. La propuesta el día siguiente.

\section{Tribunal}

Presidente: Inocencio Jiménez Vicente.

Vocales: Eugenio Cuello, Juan Brey, Romualdo Hernández.

Secretario: Isaías Sánchez Sánchez Tejerina.

\section{Opositores}

Juan del Rosal Fernández.

Octavio Pérez Vitoria.

Antonio Ferrer Sama.

José Guallart López de Goicoechea.

Antonio Peláez de las Heras. 


\section{Votación}

José Guallart obtuvo el primer puesto por unanimidad.

Ferrer ganó la votación del segundo lugar por cuatro votos (Romualdo, Sánchez, Cuello y Jiménez) contra uno de del Rosal (Brey).

Octavio Pérez ganó la votación del tercer lugar por cuatro votos (Romualdo, Sánchez, Cuello y Jiménez) contra uno de Ferrer (Brey).

Guallart optó por la cátedra de Valladolid, Ferrer por la de Murcia y Pérez aceptó la de Oviedo.

Fueron propuestos y nombrados por O.O. de 19 de noviembre (BOE del 2 de diciembre).

\section{Materiales}

Actas. Incluyen las evaluaciones de los ejercicios y trabajos presentados.

Instancias de los aspirantes.

Materiales de Guallart:

- Programa.

- Concepto, método, fuentes y programa.

- Trabajo de investigación: El método estadístico. Estadística de las actuaciones de los tribunales tutelares de menores.

- La antijuridicidad como elemento del delito, Universidad. Revista de Cultura y Vida Universitaria, Tip. “La Académica”, Zaragoza, 1931.

- El Derecho penal de los menores. Los tribunales para niños, Tip. "La Académica", Zaragoza, 1925.

- Literaturbricht, Aurelio F. Concheso, La Unión Internacional del Derecho penal no ha muerto, Zeitschrift für die gesamte Strafrechtwissenschaft, 1930, Band 51 , Heft 2.

- Rapport, Congrés Pénal et Pénitentiaire International de Berlin, 1935.

- Los tribunales de menores en Italia, Tribunales Tutelares de Menores, Publicaciones del Consejo Superior de Protección a la infancia, Folleto II, Madrid, 1930.

- Programa de lecciones de metodología jurídica, Universidad de Zaragoza, curso 1924-25.

- Le Nouveau code pénal espagnol, Bulletin de l'Institut Intermédiaire International, La Haye, octubre, 1929.

- Colaboración en Estadísticas, Tribunales Tutelares de Menores, Zaragoza, 1921-1931.

Artículos de Guallart en Universidad. Revista de Cultura y Vida Universitaria: Las naves-asilos en el tratamiento italiano de la juventud abandonada o delincuente (1924); La reforma de la instrucción pública en Italia (1925); La pedagogía correccional (1928); El nuevo Código penal español (1929); El X Congreso Penal y Penitenciario Internacional (1930). 
Materiales de Ferrer:

- Programa.

- Concepto, método, fuentes y programa.

- Trabajo de investigación: El error en el Derecho penal.

- Trabajo de investigación: La tentativa como especial tipo de lo injusto.

Materiales de Octavio Pérez:

- Memoria sobre el concepto, método, fuentes del Derecho penal.

- Nuevos tribunales de menores en Italia, Revista General de Legislación y Jurisprudencia, marzo de 1936, Tomo 168, núm. III.

- Necrologio, In memoria di Quintiliano Saldaña, Rivista di Diritto Penitenziario, 1940, anno IX, n. I.

- La nueva legislación italiana sobre tribunales de menores, Arxius de Psicologia i Psiquiatria infantil, Barcelona, 1935.

- Trabajos de investigación: El centro de reeducación de menores de Roma; El "Asistenziario" para libertos de Nápoles; El reformatorio de menores de la isla de Nisida, EL museo criminal de Roma.

- La minoría penal, Bosch, Barcelona.

- El discernimiento como fundamento de la responsabilidad criminal de los menores, Anales de la Universidad de Barcelona, curso 1939-1940.

\section{Signatura}

AGA 32/13580. Legajo 9587-2.

Expediente digitalizado.

\section{Cátedra}

Filosofía del Derecho.

\section{Universidad}

Oviedo y Sevilla.

\section{Anuncio}

11 de junio, 1940. BOE del 25.

\section{Reglamento aplicable}

25 de junio, 1931.

\section{Fechas de la oposición}

Constitución del tribunal: 30 de septiembre, 1940.

Presentación de los opositores: 3 de octubre, 1940.

Votación: 29 de octubre, 1940. La propuesta el día siguiente. 


\section{Tribunal}

Presidente: Eduardo Callejo de la Cuesta.

Vocales: Mariano Puigdollers, Luis Legaz Lacambra, Manuel Marina.

Secretario: José Corts.

\section{Opositores}

Ramón Pérez Blesa.

Francisco Elías de Tejada Spínola.

José Luis Santaló.

Enrique Gómez Arboleya.

\section{Votación}

Gómez Arboleya obtuvo el primer puesto por unanimidad.

Ramón Pérez Blesa ganó la votación del segundo lugar por tres votos (Corts, Legaz, y Callejo) contra dos de Elías de Tejada (Marina y Puigdollers).

Gómez Arboleya optó por la cátedra de Sevilla y Pérez Blesa aceptó la de Oviedo. Fueron propuestos y nombrados por O.O. de 14 de noviembre de 1940 (BOE del 25).

\section{Materiales}

Actas. Incluyen las evaluaciones del tribunal de los ejercicios y trabajos presentados.

Instancias de los aspirantes.

De tipo académico o referentes a los ejercicios:

- Escritos del caso práctico (ejercicio quinto). Comentario de texto: "Institutionis, Lib. I, Tit. II, p. $1 .^{0}$ ".

- Escritos de ejercicio sexto: "Naturaleza y función de los principios generales del Derecho y su problemática". Sacado por sorteo de la lista de 10 temas aprobada, que aparece en las actas.

Materiales de Ramón Pérez Blesa:

- Concepto, método, fuentes y programa de filosofía del Derecho.

- Trabajo de investigación: La ontología de la ley en la escolástica española.

Materiales de Gómez Arboleya:

- Herman Heller, Boletín de la Universidad de Granada, abril 1940, año XII, Núm. 58. 


\section{Signatura}

AGA 32/13581. Legajo 9587-3.

\section{Cátedra}

Derecho mercantil.

\section{Universidad}

Oviedo y Salamanca.

\section{Anuncio}

11 de junio, 1940. BOE del 25.

\section{Reglamento aplicable}

25 de junio, 1931.

\section{Fechas de la oposición}

Constitución del tribunal: 2 de octubre, 1940.

Presentación de los opositores: 3 de octubre, 1940.

\section{Tribunal}

Presidente: Felipe Clemente de Diego.

Vocales: Ricardo Mur, José Viñas, Joaquín Garrigues.

Secretario: Juan Ossorio.

\section{Opositores}

Elías Ros Pallarés. Se retiró el 25 de octubre, antes de comenzar el sexto ejercicio. No comparecieron: Rodrigo Uría, Agustín Vicente Gella.

Constan instancias de aspirantes no admitidos: Miguel Cabeza, Manuel Pascual. La provisión fue declarada desierta.

\section{Materiales}

Actas. Incluyen las evaluaciones del tribunal de los ejercicios y trabajos presentados.

Instancias de los aspirantes, con acreditación de méritos.

De tipo académico o referentes a los ejercicios:

- Escrito del caso práctico (ejercicio quinto). Dos partes: "Un comerciante aceptó una letra de cambio de 50.000 pts. (comienzo)"; "Comentario del artículo $287 \mathrm{del}$ Código de comercio". Materiales de Elías Ros:

- Programa. 
- Estudio acerca del concepto, método, fuentes y programa de Derecho mercantil.

- El delito de estafa y el de apropiación indebida. Estudio sobre Derecho penal, Tesis doctoral, Imp. de Francisco Alcocer, Valencia.

- Trabajo de investigación: Notas biográficas del jurisconsulto Bartolomé de Albornoz y doctrina jurídico-mercantil contenida en su libro "Arte de los contratos". - Trabajo de investigación: Índice de cosas que pueden ser término objetivo en la relación jurídico-mercantil.

- El seguro de vida y la muerte presunta, Revista General de Legislación y Jurisprudencia, mayo 1934, Tomo 164, núm. V.

\section{Signatura}

AGA 32/13583. Legajo 9588.

\section{Cátedra}

Derecho administrativo.

\section{Universidad}

Santiago y Murcia.

\section{Anuncio}

11 de junio, 1940. BOE del 25.

\section{Reglamento aplicable}

25 de junio, 1931.

\section{Fechas de la oposición}

Constitución del tribunal: 30 de septiembre, 1940.

Presentación de los opositores: 3 de octubre, 1940.

Votación: 25 de octubre, 1940. La propuesta el día siguiente.

\section{Tribunal}

Presidente: Carlos García Oviedo.

Vocales: Sabino Álvarez Guendín, Luis Jordana de Pozas, Recaredo Fernández de Velasco.

Secretario: Alfonso de Hoyos.

\section{Opositores}

Eugenio Pérez Botija. 
Antonio Mesa Segura.

José María Pi Suñer.

Juan Galvañ Escutia.

Pi Suñer y Eugenio Pérez Botija pasan a la votación final.

\section{Votación}

Por unanimidad Pi Suñer obtuvo el primer puesto y Eugenio Pérez Botija el segundo.

Pi Suñer optó por la cátedra de Santiago y Eugenio Pérez Botija aceptó la de Murcia.

Fueron propuestos. Nombrados por O.O. de 7 de noviembre de 1940 (BOE del 17).

\section{Materiales}

Actas. Incluyen las evaluaciones del tribunal de los ejercicios y trabajos presentados.

Instancias de los aspirantes.

De tipo académico o referentes a los ejercicios:

- Escritos del caso práctico (ejercicio quinto).

- Escritos de ejercicio sexto: "Concepto de dominio público".

- Constan unas Notas referentes al primer ejercicio, por Pi Suñer.

Materiales de Eugenio Pérez:

- Memoria sobre el concepto, método, fuentes y programa de la disciplina.

- Índice resumen y comentario de disposiciones aparecidas en el $B O E$ durante el mes de julio de 1940. Mecanografiado.

- Con María Palancar, La prevención de los accidentes del trabajo (por los modernos medios psicológicos, gráficos y mecánicos; eficacia comparativa de unos y otros desde los puntos de vista humanitario y económico), Imp. Suc. de Minuesa, Madrid, 1934.

- Sobre modalidades de la potestad reglamentaria, Revista de Derecho Público, Núm. 53 .

Materiales de Pi Suñer:

- Memoria sobre el concepto, método, fuentes y programa de la asignatura Derecho administrativo.

- Programas: Derecho administrativo, Escuela de Administración Pública, Curso 1937-38; Derecho municipal y provincial, Escuela de Administración Pública, Derecho internacional público; Procedimientos administrativos, Diputación provincial de Barcelona, 1918; cursos 1934-35 de la Facultad de Derecho y Ciencias Económicas y Sociales de la Universidad de Barcelona.

- Estudio crítico de la organización de la beneficencia provincial e España, memoria para el grado de doctor, 1912. 
- Trabajo de investigación: Cuartillas para el estudio de la Ley Municipal española de 1935.

- Estudio sobre la eficacia legal del recurso de alzada contra los acuerdos de los ayuntamientos. Mecanografiado. Publicado en la Revista Jurídica del Colegio de Abogados de Barcelona (1920).

- Procedimientos administrativos, Edición del programa, memoria y esquema de un libro sobre la materia con las notas del autor anteriores a 1923, El Municipio español, Barcelona, 1930.

- Lo contencioso administrativo, Versión taquigráfica, revisada, completada y anotada bibliográficamente, del curso profesado sobre la materia de la Facultad de Derecho de la Universidad de Barcelona, prólogo de Claudio Omar y Barrera, Centro de Administración Municipal, Barcelona.

Trabajos relacionados con ponencias y congresos:

- Comunicaciones del ayuntamiento de Barcelona a los Congresos Internacionales de Ayuntamientos, de Sevilla y París. Mecanografiados.

- Ponencia para el Congreso de Municipios Españoles de Gijón. Mecanografiado.

- Ponencia, IV Congreso Internacional de Ciudades y Organismo Locales (1929), IV. Documentos y deliberaciones, Ponentes adicionales, Bruxelles, Union Internationale de Villes.

- Tema para el Congreso Nacional Municipalista de Madrid. Estudio de las bases para la constitución de la Unión de Ciudades Españolas.

Artículos (debido a su abundancia, se hace mera indicación de las revistas que publican sus artículos y su número):

- Artículos publicados en El Municipio español. Núms: 21, 24, 33, 44, 46, 47, 51, $54,59,56,57,68,60,61-62,63,76$.

- Artículos publicados en La Administración Pública, 1920, cuaderno primero, 1931, cuadernos segundo y quinto.

- Artículos publicados en Revista Moderna de Administración Local. Núms: 268, 270, 277, 289.

- Artículos publicados en Revista Jurídica de Cataluña: febrero 1919, enero 1921.

- Artículos publicados en Pequeña Gaceta del Régimen Local. Núms: 83, 90.

- Colaboraciones en Publicaciones de la Unión de Municipios Españoles: 1927, 1928, 1930.

- Otros artículos: Revista de la Facultad de Derecho de Madrid (1940), Vida Local (1935), Revista de Trabajo (1940).

- Artículos de prensa. 


\section{Signatura}

AGA 32/13591. Legajo 9592-3.

\section{Cátedra}

Derecho romano.

\section{Universidad}

Santiago y La Laguna.

\section{Anuncio}

Por orden del 11 de junio de 1940, BOE del 25, se anunciaron a oposición libre las cátedras de Salamanca y Murcia. Cubiertas ambas por concurso previo de traslado, se declararon vacantes las de Santiago y La Laguna.

\section{Reglamento aplicable}

25 de junio, 1931.

\section{Fechas de la oposición}

Constitución del tribunal: 30 de septiembre, 1940.

Presentación de los opositores: 3 de octubre, 1940.

Votación: 21 de octubre, 1940. La propuesta el día siguiente.

\section{Tribunal}

Presidente: Manuel Torres López.

Vocales: Eusebio Díaz González, José Fernández González, Carlos Sánchez Peguero.

Secretario: José Santa Cruz Teijeiro.

\section{Opositores}

Isidoro Martín Martínez.

\section{Votación}

Isidoro Martín Martínez obtuvo el primer puesto por unanimidad. Optó por la cátedra de Santiago y fue propuesto. La provisión de la cátedra de La Laguna fue declarada desierta (orden de 30 de octubre de 1940, BOE del 9 de noviembre).

\section{Materiales}

Actas. Incluyen las evaluaciones del tribunal de los ejercicios y trabajos presentados. 
De tipo académico o referentes a los ejercicios:

- Escritos del caso práctico (ejercicio quinto). Traducción, interpretación y comentario de "D. 13, 7, 9, 1".

- Escritos de ejercicio sexto: "Constitución política de la época republicana". Sacado por sorteo de la lista de 10 temas aprobada, que aparece en las actas.

Materiales de Isidoro Martín Martínez:

- Traducción del Manual de Derecho romano de Pacchioni.

- Traducción del Perspectivas Romanísticas de Biondi.

\section{Signatura}

AGA 32/13591. Legajo 9592-2.

\section{Cátedra}

Derecho canónico.

\section{Universidad}

Valencia y Santiago.

Los ejercicios de ambas provisiones fueron independientes. Constan actas diferentes para cada uno.

\section{Anuncio}

11 de junio, 1940. BOE del 25.

Orden de 30 de septiembre de 1940 segrega la provisión de la cátedra de Granada y agrega la de Santiago, $B O E$ del 4 de octubre.

\section{Reglamento aplicable}

25 de junio, 1931.

\section{Fechas de la oposición}

Constitución del tribunal: 3 de octubre, 1940.

Presentación de los opositores: 4 de octubre, 1940.

Votación: 5 de noviembre, 1940.

\section{Tribunal}

Presidente: Leopoldo Eijo Garay, obispo de Madrid-Alcalá.

Vocales: Juan Moneva, Eloy Montero, Nicolás Santos de Otto.

Secretario: Jesús Mérida. 


\section{Opositores}

Paulino Pedret Casado.

José Bernal Montero.

Pedro Ramón Lamas Lourido.

José Maldonado Fernández del Torco.

Todos pasaron a la votación final.

No comparecieron: Heraclio Sánchez Rodríguez, Miguel Hernandez Ascó.

\section{Votación}

Por unanimidad se acuerda no haber lugar a la provisión.

\section{Materiales}

Oficios del negociado y sobre conformación del tribunal.

Actas. Incluyen las evaluaciones del tribunal de los ejercicios y trabajos presentados.

Instancias de los aspirantes.

De tipo académico o referentes a los ejercicios:

- Escritos del caso práctico (ejercicio quinto).

- Escritos de ejercicio sexto. Para Santiago: "La dote del beneficio eclesiástico según el Canon 1410 y según el Corpus Juris”. Para Valencia: “Modificaciones introducidas por los Cánones 97 y 1077 en la disciplina del Corpus Juris, habida cuenta del Derecho anterior y posterior al Concilio Lateranense.

No constan Materiales de los opositores. Se unen a las actas las listas de los que fueron presentados.

\section{Signatura}

AGA 32/13567. Legajo 9579.

\section{Cátedra}

Derecho internacional público y privado.

\section{Universidad}

Sevilla y La Laguna.

\section{Anuncio}

11 de junio, 1940. BOE del 25.

La cátedra de La Laguna fue agregada por Orden de 3 de octubre, 1940. BOE del 7. 


\section{Reglamento aplicable}

25 de junio, 1931.

\section{Fechas de la oposición}

Constitución del tribunal: 28 de octubre, 1940.

Presentación de los opositores: 30 de octubre, 1940.

Votación: 30 de noviembre, 1940. La propuesta el día siguiente.

\section{Tribunal}

Presidente: Eduardo Callejo de la Cuesta.

Vocales: José María Trías de Bes, Luis Gestoso, Antonio de Luna.

Secretario: Fernando María Castiella.

\section{Opositores}

Pedro Cortina Mauri.

Eduardo Pérez Griffo. Se retira el 29 de noviembre.

Juan Manuel Castro Rial.

Jesús Esperabé de Arteaga González.

Eusebio Díaz Morera.

\section{Votación}

Por unanimidad Pedro Cortina obtuvo el primer lugar y Juan Manuel Castro el segundo. Cortina optó por la cátedra de Sevilla y Castro aceptó la de La Laguna. Fueron propuestos.

\section{Materiales}

De tipo administrativo: actas, instancias de los aspirantes con acreditación de méritos.

De tipo académico o referentes a los ejercicios:

- Escritos del caso práctico (ejercicio quinto). El enunciado aparece en el acta:

"A, súbdito español, contrae matrimonio canónico en Paris... (comienzo)".

- Escrito de ejercicio sexto. Dos partes: "El bloqueo"; "Asistencia jurídica internacional". Consta la copia del temario (10 temas y 10 temas).

- Evaluaciones del tribunal de los ejercicios.

Materiales de Cortina:

- Memoria sobre el tema de concepto, método y fuentes del Derecho internacional público. Fechado en septiembre, 1940.

- Memoria sobre el tema de concepto, método y fuentes del Derecho internacional privado. Fechado en septiembre, 1940.

- Doce informes, núms. 1, 2, 3, 4, 6, 7, 8, 11, 12, 14, 16, 18. Dictámenes de la Asesoría Jurídica del Ministerio de Asuntos Exteriores. 
Materiales de Castro:

- Trabajo de investigación: Represalias.

- Trabajo de investigación: Ideas sobre el nuevo Derecho alemán. Fechado en julio, 1940 .

- Trabajo de investigación: Generalidades sobre la guerra total.

- Memoria de Derecho internacional público.

- Memoria de Derecho internacional privado.

\section{Signatura}

AGA 32/13673. Legajo 9763.

AGA 32/13674. Legajo 9763.

AGA 32/13675. Legajo 9764.

AGA 32/13676. Legajo 9764

\section{Cátedra}

Derecho político.

\section{Universidad}

Oviedo y Sevilla.

\section{Anuncio}

Orden del 30 de julio de 1940, BOE del 25 de agosto de 1940, anuncia al turno de oposición libre la cátedra de Oviedo (está vinculada a la orden del 11 de junio de 1940, Gaceta del 25).

Se agrega la provisión de la de Sevilla por Orden de 21 de junio, 1941. BOE del 2 de julio.

\section{Reglamento aplicable}

25 de junio, 1931.

\section{Fechas de la oposición}

Constitución del tribunal: 19 de noviembre, 1941.

Presentación de los opositores: 21 de noviembre, 1941.

Votación: 3 de febrero, 1942. La propuesta el día siguiente.

\section{Tribunal}

Presidente: Carlos Ruiz del Castillo.

Vocales: Alfonso García Valdecasas, Gonzalo del Castillo Alonso, Recaredo Fernández de Velasco.

Secretario: Alfonso de Hoyos Sánchez. 


\section{Opositores}

Juan Misol Matilla.

Ignacio María Lojendio Irure.

Francisco Javier Conde García.

Francisco Elías de Tejada Spínola.

Luis Sánchez Agesta.

Nicolás Ramiro Rico.

Eugenio Vegas Latapié.

Lojendio, Conde, Elías de Tejada y Vegas Latapié pasan a la votación final.

No comparecieron: Guillermo Estrada Acebal, Antonio Poch Gutiérrez de Caviedes, Salvador Lissarrague Novoa.

\section{Votación}

Votación del primer puesto:

- Lojendio: tres votos (Hoyos, Velasco y Castillo Alonso).

- Vegas: un voto (Valdecasas).

- Conde: un voto (Ruiz del Castillo).

Primera votación del segundo puesto:

- Sánchez Agesta: dos votos (Ruiz del Castillo y Velasco).

- Vegas: dos votos (Hoyos, Valdecasas).

- Elías de Tejada: un voto (Castillo Alonso).

Segunda votación del segundo puesto: Sánchez Agesta por unanimidad.

Lojendio optó por la cátedra de Sevilla y Agesta por la de Oviedo.

Nombrados por Orden de 12 de noviembre de 1942.

\section{Materiales}

De tipo administrativo:

- Actas. Incluyen las evaluaciones del tribunal de los ejercicios y trabajos presentados.

- Instancias de los opositores con acreditación de requisitos.

- Expediente de censura de El nuevo Estado nacionalsindicalista, de Elías de Tejada. Prohibida su publicación. Fecha de salida: 24 de octubre de 1938.

De tipo académico o referentes a los ejercicios:

- Escritos del caso práctico (ejercicio quinto): "Suárez: de Legibus, Lib. III, Cap. IV".

- Escrito de ejercicio sexto. Tema 3: "Concepto de la Política. Doctrinas contemporáneas acerca de las relaciones entre la Política, la Sociología y la Ética”. Lista de 16 temas recogida en las actas.

Materiales de Lojendio:

- Memoria sobre el concepto, método, fuentes y programas del Derecho político. 
- Trabajos de investigación: El mito político; Las fuentes intelectuales de las declaraciones de derecho y especialmente de la francesa de 1789.

- Régimen político del Estado español. Consta una versión mecanografiada en dos tomos y otra impresa: Bosch, Barcelona.

- El derecho de revolución, Editorial Revista de Derecho Privado, Madrid, 1941. Materiales de Sánchez Agesta:

- Trabajos de investigación: La teoría del sistema. Historia del sistema de la ciencia del Derecho privado; Concepto histórico-político de nación.

- Consta un oficio del negociado de cátedras fechado el 26 de enero de 1944. Ordena la entrega a Luis Sánchez Agesta de la memoria que presentó para tomar parte en las oposiciones.

Materiales de Eugenio Vegas:

- Concepto, método, fuentes y programa del Derecho político.

- Trabajo de investigación: Catolicismo y república. Un episodio de la historia de Francia, Gráfica Universal, Madrid, 1932.

Materiales de Nicolás Ramiro:

- Programa.

- Memoria pedagógica.

- Trabajos de investigación: Lengua y política (Mecanografiado); La verdad política y la idea de la tradición, tesis doctoral, 1941; El fundamento antropológico de la Política.

Materiales de Misol:

- Concepto, método, fuentes y programa del Derecho político.

- Trabajos de investigación: Fin de la comunidad civil (Estado).

Materiales de Javier Conde: Dos libros de Carl Schmitt. Impreso. No indica procedencia.

\section{Signatura}

AGA 32/13647. Legajo 9625.

AGA 32/13648. Legajo 9625 .

\section{Cátedra}

Derecho romano.

\section{Universidad}

Central.

\section{Anuncio}

28 de agosto, 1940. BOE del 13 de septiembre. 


\section{Reglamento aplicable}

25 de junio, 1931.

\section{Fechas de la oposición}

Constitución del tribunal: 4 de noviembre, 1941.

Presentación de los opositores: 5 de noviembre, 1941.

Votación y propuesta: 28 de noviembre, 1941.

\section{Tribunal}

Presidente: Felipe Clemente de Diego.

Vocales: Eusebio Díaz González, José Castán Tobeñas, Manuel Torres López.

Secretario: José López Ortiz.

\section{Opositores}

Ursicino Álvarez Suárez (catedrático de Derecho romano, desempeñando con carácter interino la cátedra de la Central).

Carlos Sánchez Peguero (auxiliar de la Central). Abandona el 17 de noviembre (consta carta).

No comparecieron: Francisco de Pelsmaeker Ivañez.

\section{Votación}

Ursicino Álvarez fue propuesto por unanimidad.

\section{Materiales}

De tipo administrativo:

- Actas. Incluyen las evaluaciones del tribunal de los ejercicios y trabajos presentados.

- Instancias de los opositores con acreditación de requisitos.

De tipo académico o referentes a los ejercicios:

- Escrito del caso práctico (ejercicio quinto): "Dig. 28, 8, 7".

- Escrito de ejercicio sexto: "El principado de Augusto; tesis propuestas para definirlo y crítica de las mismas. Interpretación de la Constitución Augustea”. Lista de 9 temas recogida en las actas.

Materiales de Ursicino Álvarez:

- Programas: I, Derecho romano; II, Progresión histórica del derecho privado romano; III, Derecho público romano (comprendido penal y municipal); IV, Derecho de pandectas, como introducción al Derecho civil.

- Memoria pedagógica. Concepto, método, fuentes y enseñanza del Derecho romano. Tres tomos. Editorial Revista de Derecho Privado, Madrid, 1940.

- Derecho romano. Apuntes tomados de las explicaciones dadas por el Profesor 
Ursicino Álvarez Suárez en la Universidad Central, segunda edición, Editados por la Delegación de Derecho del SEU, Madrid, 1940.

- Bibliografía, De Zulueta: The new fragments of Gaius (PSI 1182); Anuario de Historia del Derecho español, Tomo XI, Madrid, 1934, p.540.

- Schulz (F.), Prinzipen des Römischen Rechst, München und Leipzig, 1934; idem, p.558.

- El Congreso Internacional de Derecho romano celebrado en Bolonia y Roma del 17 al 27 de abril de 1933, idem, p.586.

- Contribución al estudio de las donaciones, "mortis causa”, entre cónyuges, Publicaciones de la Revista "Estudios Jurídicos”, Imp. Samarán, Madrid, 1941.

Trabajos mecanografiados de Ursicino:

- Naturaleza jurídica del Ser Colectivo con especial referencia al Derecho romano; el problema de su responsabilidad penal, tesis doctoral, curso 1932-33.

- Esquema de dos lecciones sobre el nacimiento de las obligaciones por acto voluntario.

- Casos prácticos de Derecho romano.

- Sobre un caso de aplicación del Derecho romano en Mallorca.

- La "abdicatio liberis" en relación con la patria potestad romana.

Artículos o traducciones de Ursicino en la Revista de Derecho Privado (debido a su abundancia se hace mera indicación de número y año): 218 (1931);219 (1931); 237 (1933);241 (1933); 248 (1934); 249 (1934); 273 (1936); 279 (1940); 285 (1940); 288 (1941), 294 (1941).

Materiales de Sánchez Peguero:

- Artículos en la Revista de Derecho Privado: 188 (1929), 295 (1941).

\section{Signatura}

AGA 32/13650. Legajo 9651-2.

\section{Cátedra}

Derecho mercantil.

\section{Universidad}

Zaragoza.

\section{Anuncio}

10 de enero, 1941. BOE del 15.

\section{Reglamento aplicable}

25 de junio, 1931. 


\section{Fechas de la oposición}

Constitución del tribunal: 26 de noviembre, 1941.

Presentación de los opositores: misma fecha que la anterior.

Votación y propuesta: 15 de diciembre, 1941.

\section{Tribunal}

Presidente: José María Zumalacárregui.

Vocales: Joaquín Garrigues, Francisco Candil, Juan Moneva.

Secretario: José Viñas.

\section{Opositores}

Agustín Vicente Gella.

No comparecieron: Rodrigo Uría González.

\section{Votación}

Agustín Vicente Gella fue propuesto por unanimidad.

Nombrado por Orden de 23 de diciembre, 1941.

\section{Materiales}

De tipo administrativo:

- Actas. Incluyen las evaluaciones del tribunal de los ejercicios y trabajos presentados.

- Instancias de los opositores con acreditación de requisitos.

De tipo académico o referentes a los ejercicios:

- Escrito del caso práctico (ejercicio quinto). Parte primera: "El comerciante A era deudor al Banco B... (comienzo del enunciado). Segunda parte: "Comentario del artículo 487 del Código de Comercio".

- Escrito de ejercicio sexto. Dos temas: "Libranza, vales, pagarés a la orden y cartas de crédito"; "El concepto de naviero y el Estado armador". Sacados a la suerte del cuestionario del tribunal (59 temas).

Materiales de Agustín Vicente Gella:

- Memoria sobre el contenido, método, fuentes, etc. del Derecho mercantil.

- "Incorporated Trading Companies" (Las sociedades de capitales en el derecho británico), Universidad. Revista de Cultura y Vida Universitaria, Tip. "La Académica”, Zaragoza, 1933.

- Las resoluciones de la asamblea general de una sociedad anónima, Tip. "La Académica", Zaragoza, 1932.

- Karl Heinsheimer, Derecho mercantil, tercera edición efectuada por Karl Geiler, traducido y anotado con especial referencia a la legislación española por Agustín Vicente Gella, Labor, Barcelona-Madrid-Buenos Aires, 1933. 
- Introducción al Derecho mercantil, segunda edición, Labor, Barcelona-Madrid-Buenos Aires, 1934.

- A. Morando, El contrato de cuenta corriente, traducida por Agustín Vicente Gella, Editorial Revista de Derecho Privado, Madrid, 1933.

- L. Quesnot, Administración financiera. Métodos contables y balances, traducción de la cuarta edición francesa y notas sobre la legislación española y extranjera por Agustín Vicente Gella, Labor, Barcelona-Madrid-Buenos Aires, 1936.

- Leon Batardon, Tratado práctico de sociedades mercantiles, traducción de la sexta edición francesa adaptada a la legislación española y práctica mercantil españolas por Agustín Vicente Gella, Labor, Barcelona-Madrid-Buenos Aires-Río de Janeiro, 1935.

\section{Signatura}

AGA 32/13661. Legajo 9757.

AGA 32/13662. Legajo 9757.

\section{Cátedra}

Derecho romano.

\section{Universidad}

Granada y Oviedo.

\section{Anuncio}

Para Oviedo por 28 de marzo, 1941. BOE del 7 de abril.

La de Granada se agregó por Orden de 29 de octubre de 1941. BOE del 6 de noviembre.

\section{Reglamento aplicable}

25 de junio, 1931.

\section{Fechas de la oposición}

Constitución del tribunal: 19 de junio, 1942.

Presentación de los opositores: misma fecha que la anterior.

Votación: 7 de julio, 1942. La propuesta el día siguiente.

\section{Tribunal}

Presidente: Manuel Torres López.

Vocales: Eusebio Díaz González, Ursicino Álvarez, José Ferrández.

Secretario: Isidoro Martín Martínez. 


\section{Opositores}

Juan Iglesias Santos.

Faustino Gutiérrez Alviz.

Benjamín Ortiz Román.

Antonio Reverte Moreno.

Iglesias y Reverte pasan a la votación final.

No comparecieron: Emilio Viñals Sagrera.

\section{Votación}

Por unanimidad Juan Iglesias fue propuesto para el primer lugar y Antonio Reverte para el segundo.

Juan Iglesias optó por la cátedra de Oviedo y Antonio Reverte aceptó la de Granada.

Nombrados por Orden de 9 de julio de 1942.

\section{Materiales}

De tipo administrativo:

- Actas. Incluyen las evaluaciones del tribunal de los ejercicios y trabajos presentados.

- Instancias de los opositores con acreditación de requisitos.

De tipo académico o referentes a los ejercicios:

- Escritos del caso práctico (ejercicio quinto): "Dig. 13, 6, 5, 12".

- Escrito de ejercicio sexto. Tema 11: "Polémica sobre la posibilidad de aplicar al Derecho romano la dogmática moderna". Lista de 20 temas recogida en las actas. Materiales de Juan Iglesias:

- Memoria pedagógica.

- Trabajo de investigación: Dig. 2, 14 de pactis. Por error se encuentra entre los materiales de la oposición de Derecho canónico, 32/13659 (9756-1).

Materiales de Antonio Reverte:

- Memoria pedagógica.

- Traducción de Pacchioni, Manual de Derecho romano. Pruebas de imprenta.

- Trabajo de investigación: Tres trabajos sobre el Derecho romano antiguo.

- Trabajo de investigación: Modos de adquirir la propiedad y sus clasificaciones. Materiales de Benjamín Ortiz:

- Programa.

- Estudio sobre el concepto, método, fuentes y programas del Derecho romano.

- Trabajo de investigación: Revisión de tratados internacionales.

- Las ideas cristianas y el Derecho romano, tesis presentada para obtener el título de doctor, Universidad de Oviedo, Est. Tip. "La Cruz”, Oviedo, 1941.

Materiales de Faustino Gutiérrez: 
- Memoria pedagógica.

- Los bienes de los difuntos en el Derecho indiano, Anales de la Universidad Hispalense, 1941, n. ${ }^{\circ}$ III, y 1942, n. ${ }^{\circ}$ I.

- Trabajo de investigación: Los bienes de los difuntos en el Derecho indiano. Mecanografiado.

- Trabajo de investigación: La usucapión originaria y los requisitos "bona fides" y "iusta causa".

\section{Signatura}

AGA 32/13632. Legajo 9617-1.

AGA 32/13633. Legajo 9618.

AGA 32/13634. Legajo 9618.

\section{Cátedra}

Derecho procesal.

\section{Universidad}

Valencia, Granada y Santiago.

\section{Anuncio}

28 de marzo, 1941. BOE del 7 de abril.

Se agrega la provisión de la cátedra de Granada por Orden de 10 de julio, 1941. $B O E$ del 28.

\section{Reglamento aplicable}

25 de junio, 1931.

\section{Fechas de la oposición}

Constitución del tribunal: 18 de octubre, 1941.

Presentación de los opositores: 20 de octubre, 1941.

Votación: 8 de diciembre, 1941. La propuesta el día siguiente.

\section{Tribunal}

Presidente: José Viñas.

Vocales: Mauro Miguel Romero, José Serrano Suárez, Manrique Mariscal de Gante.

Secretario: Leonardo Prieto Castro. 


\section{Opositores}

Antonio Martínez Bernal.

Ángel Enciso Calvo.

Miguel Fenech Navarro.

\section{Votación}

La votación del primer puesto fue ganada por Ángel Enciso con todos los votos menos el de Prieto, quien votó a Miguel Fenech.

La votación del segundo puesto fue ganada por Fenech con tres votos contra dos por la no provisión (Serrano y Viñas).

En la votación del tercer puesto Antonio Martínez Bernal obtuvo dos votos (Prieto y Mariscal) contra tres por la no provisión.

Enciso optó por la cátedra de Valencia y Fenech aceptó la de Granada. Fueron propuestos. Nombrados por Orden de 23 de diciembre, 1941.

La cátedra de Santiago se declaró desierta.

\section{Materiales}

De tipo administrativo:

- Actas. Incluyen las evaluaciones del tribunal de los ejercicios y trabajos presentados.

- Instancias de los aspirantes son acreditación de requisitos.

- Oficios del negociado.

De tipo académico o referentes a los ejercicios:

- Relación de obras consultadas en el cuarto ejercicio.

- Escritos del caso práctico (ejercicio quinto): "Falleció A bajo testamento (comienzo del enunciado)".

- Escritos de ejercicio sexto: "La prueba". Tema a sorteo. Lista de 36 temas recogida en actas.

Materiales de Enciso:

- Memoria que sobre el concepto, método, fuentes y programas presenta al opositor. Fechado en octubre de 1941.

- Acción y personalidad. Contribución al estudio de las excepciones dilatorias de los números 2 y 4 del artículo 533 de la Ley de Enjuiciamiento Civil, tesis doctoral, Imp. de Galo Sáez, Madrid, 1940.

- Prólogo a la Teoría General del Derecho de Francesco Carnelutti, Editorial Revista de Derecho Privado, Madrid, 1941.

- Con M. Perales, Notas de Derecho procesal civil, Litografía E. Nieto, Madrid, 1932.

- Artículos en la Revista de Derecho Privado. Los siguientes números (entre 1935 
y 1941): 262-263, p.273; 269, p.62 (traducción); 271, p.133; 284, p.230; 288, pp. 24-29; 290, p.168; 294, p.365.

Materiales de Miguel Fenech Navarro:

- Memoria que sobre el concepto, método y fuentes y del Derecho procesal.

- Trabajos realizados por los alumnos en el Seminario de Derecho procesal (primer curso) bajo la dirección del profesor ayudante Miguel Fenech Navarro.

- Traducción de Ernst Beling, Derecho procesal penal. Mecanografiado.

- Trabajo de investigación: El Derecho penal en la Rusia soviética.

- Trabajo de investigación: El Real Tribunal de la Acordada. Siglo XVIII. Contribución al estudio de la historia de las instituciones procesales de la América española.

- Nuevas orientaciones del Derecho procesal penal, Revista General de Legislación y Jurisprudencia, julio-agosto 1941.

- Jurisprudencia penal, idem.

- Jurisprudencia procesal penal, idem.

- Jurisprudencia procesal penal, Revista General de Legislación y Jurisprudencia, sección doctrinal, 1941, Tomo I (169 de la colección).

- Código de Justicia Militar, anotado y concordado por Nicasio Pou Ribas, redactado por Miguel Fenech Navarro, Manuales Reus, Madrid.

- La posición del juez en el Nuevo Estado. Ensayo de sistematización de las directrices actuales, prólogo del Dr. Jaime Guasp, Espasa-Calpe, Madrid, 1941.

- Consta una traducción de Friedrich Stein, Das private Wissen des Richters, prólogo fechado en Leipzig, mayo de 1893. Mecanografiado y sin indicación del autor.

\section{Signatura}

AGA 32/13644. Legajo 9623-2.

Cátedra

Filosofía del Derecho.

\section{Universidad}

Murcia.

\section{Anuncio}

28 de marzo, 1941. BOE del 7 de abril.

\section{Reglamento aplicable}

25 de junio, 1931. 


\section{Fechas de la oposición}

Constitución del tribunal: 8 de julio, 1941.

Presentación de los opositores: 8 de julio, 1941.

Votación: 23 de julio, 1941.

\section{Tribunal}

Presidente: Wenceslao González Oliveros.

Vocales: Mariano Puigdollers, Miguel Sancho, Jesús Mérida.

Secretario: Luis Izaga.

\section{Opositores}

Francisco Elías de Tejada Spínola.

\section{Votación}

Francisco Elías de Tejada fue propuesto por unanimidad.

\section{Materiales}

Actas. Incluyen los juicios del tribunal sobre los ejercicios y trabajos presentados. De tipo académico o referentes a los ejercicios:

- Consta que el ejercicio cuarto fue la lección 16: "Otras corrientes del neokantismo. La filosofía de los valores y la obra de Lask. El relativismo. Kelsen. La fenomenología”. Diez bolas extraídas de cuarenta. El tribunal eligió la tal lección. - Escritos del caso práctico (ejercicio quinto).

- Escrito de ejercicio sexto. Comentario de un texto de Erasmo: "Bellum inter Christianos non bellum, sed seditio". Se unen el resto textos propuestos.

No se conservan materiales del opositor. Consta que fueron retirados el 25 de julio, 1941.

Según las actas presentó los siguientes:

- Memoria.

- Ideas políticas de Ángel Ganivet.

- Notas para una Teoría del Estado.

- La figura del Caudillo. Contribución al Derecho público nacional- sindicalista.

- Gerónimo Castillo de Bobadilla.

- Puntos de vista para una Filosofía de la Historia del Derecho. 


\section{Signatura}

AGA 32/13645. Legajo 9623-4.

\section{Cátedra}

Historia del Derecho.

\section{Universidad}

Santiago.

\section{Anuncio}

7 de abril, 1941. BOE del 20.

\section{Reglamento aplicable}

25 de junio, 1931.

\section{Fechas de la oposición}

Constitución del tribunal: 10 de julio, 1941.

Presentación de los opositores: misma fecha que la anterior.

Votación: 24 de julio, 1941.

\section{Tribunal}

Presidente: Manuel Torres López.

Vocales: Galo Sánchez Sánchez, José López Ortiz, Alfonso García Gallo.

Secretario: Juan Beneyto Pérez.

\section{Opositores}

José Maldonado Fernández del Torco.

\section{Votación}

José Maldonado fue propuesto por unanimidad.

\section{Materiales}

Actas. Incluyen los juicios del tribunal sobre los ejercicios y trabajos presentados. De tipo académico o referentes a los ejercicios:

- Escrito del caso práctico (ejercicio quinto). Diplomas de la Cat. de Zamora: A 132, C 120 y C 126. Se refieren respectivamente a la concesión de molinos, carta de población y concesión de tierras con sus regalías. Sale a suerte el primero.

- Escrito de ejercicio sexto: "El comienzo de la capacidad jurídica en el Derecho romano y en el germánico español." 
Materiales del opositor.

- Concepto, método, fuentes y programa de Historia del Derecho español.

- Trabajo de investigación: Indicación del contenido canónico del "Teatro Eclesiástico de las Indias Occidentales” del Gil González Dávila (Iglesias de Méjico, Puebla de los Ángeles, Mechoacán, Verapaz, Guadalajara y Chiapa). Fechado en 1940.

- Trabajo de investigación: Influencia de las Decretales en las Partidas, en Derecho matrimonial.

- Trabajo de investigación: Las relaciones entre el Derecho canónico y el Derecho secular en los concilios españoles del siglo XI. Fechado en 1941.

- Román Riaza, Revista de la Facultad de Derecho de Madrid, enero- marzo 1940, p. 47

- Sobre la construcción jurídica de la teoría de las relaciones entre la Iglesia y el Estado, idem, p. 70.

\section{Signatura}

AGA 32/13661 y 13662. Legajo 9756-1.

\section{Cátedra}

Derecho canónico.

\section{Universidad}

Valencia y Santiago.

\section{Anuncio}

20 de mayo, 1941. BOE del 31.

La Orden de 30 de junio de 1941 agrega la provisión de la cátedra de Valencia, $B O E$ del 5 julio.

\section{Reglamento aplicable}

25 de junio, 1931.

\section{Fechas de la oposición}

Constitución del tribunal: 11 de febrero, 1942.

Presentación de los opositores: 11 de febrero, 1942.

Votación: 22 de abril, 1942. La propuesta el día siguiente.

\section{Tribunal}

Presidente: Juan Moneva 
Vocales: Pedro Montero, Nicolás Santos de Otto, Jesús Mérida.

Secretario: José López Ortiz.

\section{Opositores}

Paulino Pedret Casado.

José Bernal Montero.

Pedro Ramón Lamas Lourido.

Miguel Hernández Ascó.

Todos pasaron a la votación final.

No comparecieron: José María Rego Machinea, José Maldonado Fernández del Torco.

\section{Votación}

Primera votación del primer lugar:

- Paulino Pedret: un voto (López Ortiz).

- Pedro Ramón Lamas: dos votos (Mérida y Otto).

- Miguel Hernandez Ascó: dos votos (Montero y Moneva)

Segunda votación del primer lugar: Pedro Ramón Lamas ganó por unanimidad.

Primera votación del segundo lugar:

- Paulino Pedret: dos votos (López Ortiz y Moneva).

- Miguel Hernandez Ascó: dos votos (Montero y Mérida).

- Bernal: un voto (Otto).

Segunda votación del segundo lugar:

- Paulino Pedret: tres votos (Otto, López Ortiz y Moneva).

- Miguel Hernandez Ascó: dos votos (Montero y Mérida).

Lamas optó por la cátedra de Valencia y Pedret aceptó la de Santiago.

\section{Materiales}

De tipo administrativo:

- Cartas sobre conformación del tribunal.

- Actas. Incluyen las evaluaciones del tribunal de los ejercicios y trabajos presentados.

- Instancias de los aspirantes.

De tipo académico o referentes a los ejercicios:

- Escritos del caso práctico (ejercicio quinto). Dos partes: "Decretales de Gregorio IX, c. XIX, Lib. II, Tit. I"; "Domingo Quilez y Babina Martín parecían tener propósito de contraer entre sí matrimonio" (comienzo de enunciado).

- Escritos de ejercicio sexto: "Abades".

Materiales de Lamas:

- Programa. 
Trabajos de investigación mecanografiados.

- Contribución del Derecho eclesiástico al concepto de "Jus ad Rem".

- El clero y el ejercicio de la medicina.

- El temor reverencial, vicio del consentimiento matrimonial.

- La jurisdicción eclesiástica castrense en España.

- Estudio histórico-doctrinal del matrimonio canónico en cuanto negocio jurídico formal, tesis doctoral, Universidad Central.

Materiales de Pedret:

- Exposición del concepto, método, fuentes y programa.

- Contribuzón ao estudo da historia de Galiza, sobre os "Capitula Martini". No se puede identificar procedencia.

- Un informe sobre Galicia de José Andrés Cornide y Saavedra, Asociación Española para el progreso de las Ciencias, XIV Congreso, C. Bermejo Impresor, Madrid, 1935.

- Don Ángel Amor Rubial, publicado en Faro de Vigo, núm. 19.351.

- El amor en la familia cristiana, publicada en El Compostelano, núms. 57785795 .

Trabajos de investigación mecanografiados de Pedret.

- Consideraciones acerca del Convenio de España con la Santa Seda de 7 de junio de 1941.

- Nuestro señor Jesucristo ante el priscilianismo.

- En el aniversario del maestro.

Consta por error un texto de Juan Iglesias: Dig. 2, 14 de pactis.

\section{Signatura}

AGA 32/13631. Legajo 9616-3.

\section{Cátedra}

Derecho administrativo.

\section{Universidad}

Santiago.

\section{Anuncio}

22 de mayo, 1941. BOE del 1 de junio.

\section{Reglamento aplicable}

25 de junio, 1931. 


\section{Fechas de la oposición}

Constitución del tribunal: 15 de septiembre, 1941.

Presentación de los opositores: 16 de septiembre, 1941.

Votación y propuesta: 26 de septiembre, 1941.

\section{Tribunal}

Presidente: José Gascón Marín.

Vocales: Alberto Martín Artajo (somo suplente de Sabino Álvarez Guendín), Luis Jordana de Pozas, Recaredo Fernández de Velasco.

Secretario: Segismundo Royo.

\section{Opositores}

Antonio Mesa Segura.

\section{Votación}

Todos votan a Antonio Mesa menos Artajo, quien no designa opositor. Fue propuesto.

\section{Materiales}

Actas. Incluyen las evaluaciones del tribunal de los ejercicios y trabajos presentados.

De tipo académico o referentes a los ejercicios:

- Escrito del caso práctico (ejercicio quinto): "Un particular es concesionario de un salto de X metros cúbico por segundo en el río Segura (comienzo del enunciado)".

- Escrito de ejercicio sexto: "Jerarquía de las fuentes del Derecho administrativo". Tema a sorteo de entre una lista de cuatro, transcrita en las actas.

Materiales de Antonio Mesa Segura:

- Concepto, método, fuentes y programa.

- Trabajo de investigación: Naturaleza de la relación que el Estado establece con las cosas que le son necesarias. Fechado en 1936.

- Partecipazione degli amministrati nell'opera dell'Amministrazione, tesi di laurea, Regia Universitá di Bologna, relatore il Chiar.mo Prof. Umberto Borsi. 


\section{Signatura}

AGA 32/13651. Legajo 9752.

AGA 32/13652. Legajo 9753.

\section{Cátedra}

Economía política y Hacienda pública.

\section{Universidad}

Oviedo, Valencia y Zaragoza.

\section{Anuncio}

11 de junio, 1940. BOE del 25. Al comienzo se anunció para proveer la cátedra de Sevilla.

Por Orden de 19 de agosto de 1940 se suspende y se anuncia para Oviedo y Zaragoza, $B O E$ del 19.

Se agrega Valencia por Orden de 11 de febrero de 1941, BOE del 17.

Se abre nuevo plazo por Orden de 7 de noviembre de 1941.

\section{Reglamento aplicable}

25 de junio, 1931.

\section{Fechas de la oposición}

Constitución del tribunal: 8 de junio, 1942.

Presentación de los opositores: 10 de junio, 1942.

Votación: 8 de julio, 1942. La propuesta el día siguiente.

\section{Tribunal}

Presidente: José María Zumalacárregui.

Vocales: Vicente Gay, Miguel Sancho, Luis Oloriaga.

Secretario: José María Areilza Martínez-Roda.

\section{Opositores}

Valentín Andrés Álvarez Álvarez.

José Castañeda Chornet.

Manuel de Torres Martínez.

Pedro Antonio Muñoz Casayús.

Juan Sardá Dexeus.

Miguel Paredes Marcos.

No comparecieron: Antonio Gómez Orbaneja, Mariano Sebastián Herrador. 


\section{Votación}

Por unanimidad Valentín Andrés Álvarez Álvarez fue propuesto para el primer lugar y Manuel de Torres Martínez para el segundo.

Miguel Paredes ganó la votación del tercer lugar por tres votos (Areilza, Oloriaga, Gay) contra un voto de Casajús (Sancho) y otro de Castañeda (Zumalacárregui). Álvarez optó por la cátedra de Oviedo, Torres por la de Valencia y Paredes aceptó la de Zaragoza.

\section{Materiales}

De tipo administrativo:

- Actas. Incluyen las evaluaciones del tribunal de los ejercicios y trabajos presentados.

- Instancias de los opositores con acreditación de requisitos.

De tipo académico o referentes a los ejercicios:

- Escrito del caso práctico (ejercicio quinto): "Se desea saber qué disposiciones concretas monetarias y complementarias deben adoptarse para financiar sin inflación...(comienzo del enunciado)".

- Escrito de ejercicio sexto. Dos temas de economía y uno de hacienda: "El crédito. [etc.]"; "Salario justo. Salario mínimo. Salario Familiar"; "La preparación económica de la guerra actual y du diferencia con la preparación clásica. La guerra total". Sacados a la suerte del cuestionario del tribunal (53 temas de economía y 39 de hacienda).

Materiales de Valentín Andrés Álvarez:

- Programas.

- Memoria: Objeto, método y fuentes.

- Trabajo de investigación: Nuevo análisis de la repercusiones e incidencias de un gravamen.

- La economía como ciencia y como arte, publicado en la Revista de Estudios Políticos, año I, núm. 2, abril, 1941.

- Manual de Hacienda pública, Ballesteros (Pío), Revista de Estudios Políticos, año I, núm. 3, julio, 1941.

- Política económica, Weber (Adolfo), idem.

- Nuevos conceptos de la teoría económica del valor, Revista de Estudios Políticos, año I, núm. 4, octubre, 1941.

- El indicador del mercado, publicado en la Anales de Economía, núm. 1, marzo, 1941.

- Las valoraciones del comercio exterior de España. Historia y crítica, tesis doctoral. Mecanografiada.

Materiales de Miguel Paredes:

- Programas. 
- Memoria: Objeto y métodos de la Economía política y Hacienda pública.

- Las ideas económicas de Juan Güell y Ferrer.

- Notas para un estudio de las formas de mercado.

Materiales de Juan Sardá:

- Notas para la Historia monetaria española

Materiales de Manuel de Torres.

- Memoria: Concepto, método y fuentes.

- La agricultura valenciana y la solidaridad económica nacional, conferencia pronunciada en el la Cámara de Comercio de Madrid el 16 de marzo de 1934, Gráfica Administrativa, Madrid, 1934. No aparece procedencia.

- La fertilidad de la tierra, la ley del mínimo y la ley del rendimiento decreciente.

- Cursillo de conferencias sobre el problema arrocero, organizado por el C.E.E.V. en el Ateneo Mercantil, Centro de Estudios Económicos Valencianos. 
Acosta Inglott, Rafael

Alcalá-Zamora Castillo, Niceto

Algarra Postius, Jaime

Alguer Micó, José

Alonso-Villaverde Morís, Eulogio

Altamira Crevea, Rafael

Álvarez Álvarez, Valentín Andrés

Álvarez Blanco Guendín, Sabino

Álvarez Buylla, Adolfo

Álvarez de Cienfuegos, José

Álvarez de los Corrales, Diego

Álvarez del Manzano Álvarez de Rivera, Faustino*

Álvarez González, Melquíades

Álvarez Rodríguez, Armando

Álvarez Suárez, Ursicino*

Andrés Marcos, Teodoro

Antón del Olmed Oneca, José

Aragón García, Miguel

Aramburu Zuloaga, Félix Pío

Arias Ramos, José

Arribas Baraya, Julián

Ayala García- Duarte, Francisco

Azcárate Flórez, Pablo de

Azcárate Menéndez, Gumersindo

Barcia Trelles, Camilo

Barrio Mier, Matías*

Batlle Vázquez, Manuel

Beato Méndez, Hilario

Beato Sala, Isidro

Beceña González, Francisco

Bedmar Escudero, Manuel

Beltrán de Heredia Castaño, José

Beneyto Pérez, Juan

Benito de la Llave, Enrique de 
Benito Endara, Lorenzo

Benito Mampel, José de

Bernabé Herrero, Juan Antonio

Bernis Carrasco, Francisco

Blanco Constans, Francisco

Boix Raspall, José María

Bonet Ramón, Francisco

Bonilla San Martín, Adolfo

Brañas Menéndez, Alfredo

Brualla Alicar, Manuel

Buen Lozano, Demófilo de

Burón García, Gregorio

Cabeza León, Salvador

Cabrera Warleta, Manuel

Calabuig Larra, Vicente

Callejo de la Cuesta, Eduardo

Calvo Alfageme, Álvaro

Calvo Madroño, Ismael

Campos Pulido, José María

Canales Ibañez, Nicolás

Candil Calvo, Francisco*

Carande Thobar, Ramón

Carreras Arañó, Juan

Casabó, José

Casajús Gómez, Roberto

Casso Romero, Ignacio

Castán Tobeñas, José

Castejón Martínez, Federico

Castiella Maíz, Fernando María

Castillejo Duarte, José

Castillo Alonso, Gonzalo del

Castro Bravo, Federico de *

Castro Rial, Juan Manuel

Checa Salamanca, Ricardo de

Clemente de Diego, Felipe *

Comas Arqués, Augusto

Comín Moya, Francisco 
Correa Torrejón, José

Cortina Mauri, Pedro

Corts Grau, José

Cossío Corral, Alfonso de

Crespo Salazar, José

Cruz Teijeiro, José Santa

Cuello Calón, Eugenio *

Cueva Palacio, Francisco

Díaz Domínguez, Antonio

Díaz Ordoñez, Víctor

Díez de Tejada, José

Díez-Canseco Berjón, Laureano*

Dios Trías Jiró, Juan de

Dios Vico Bravo, Juan de

Domínguez Ballarín, Matías

Dualde Gómez, Joaquín

Durán Bas, Manuel

Elías de Tejada Spínola, Francisco

Elorrieta Artaza, Tomás Juan

Eloycegui Ituarte, Miguel

Enciso Calvo, Ángel

Escobedo González Alberú, José

Estanyol Colón, José

Estrada Villaverde, Guillermo

Fábrega Cortés, Magín

Falcón Ozcoidi, Modesto

Fenech Navarro, Miguel

Fernández de Córdoba, Gonzalo

Fernández de Velasco, Recaredo

Fernández González, José

Fernández Prida, Joaquín

Ferrán Rivas, Ignacio

Ferrer Sama, Antonio

Figuera Lezcano, Antonio de la

Flaquer Fraisse, José

Flores de Lemus, Antonio *

Franco López, Gabriel 
Gadea Orozco, José María

Gadea Orozco, Vicente

García Amado, Eladio

García de Valdeavellano Arcimis, Luis

García Dorado, Pedro

García Gallo, Alfonso

García Labella, Joaquín

García Oviedo, Carlos

García Valdecasas Páez, Guillermo

García Valdecasas, Alfonso

García-Alas García-Argüelles, Leopoldo

García-Alas Ureña, Leopoldo

Garriga Folch, Pedro

Garrigues Díaz- Cañabate, Joaquín

Gascón Marín, José*

Gay Forner, Vicente

Gestoso Alarcón, Luis

Gestoso Tudela, Luis

Gil Casares, Felipe

Gil Gil, Gil

Gil Robles Quiñones, José María

Gil Robles, Enrique

Giménez Baena, Rafael

Giménez Fernández, Manuel

Giner de los Ríos, Francisco

Girón Arcas, Joaquín

Gómez Arboleya, Enrique

Gómez del Castillo, Francisco

Gómez González, Mariano

Gómez Orbaneja, Emilio

Gómez Piñán, Tomás

González de Echavarri Vivancos, José María

González García, Teodoro

González López, Emilio

González Oliveros, Wenceslao

González Vicén, Felipe

González-Posada Biesca, Adolfo 
Guallart López de Goicoechea, José

Guardia Corencia, Miguel de la

Guasp Delgado, Jaime

Guilarte González, Vicente

Gutiérrez Cañas, Demetrio

Hernández Boronde, Francisco

Hinojosa Menjoulet, José

Iglesias Santos, Juan

Isaac Rovira, Pedro

Jardón Santa Eulalia, José Alberto

Jiménez de Asúa, Luis

Jiménez de la Flor, Esteban

Jiménez Vicente, Inocencio

Jordana de Pozas, Luis

Lamas Lourido, Pedro Ramón

Langle Rubio, Emilio

Laraña Ramírez, Manuel

Lasala Llanas, Manuel de

Lasera Samsón, Ricardo

Laso Medina, José

Legaz Lacambra, Luis

Llopis Domínguez, José

Llorens Lariana, Eduardo Luis

Lojendio Irure, Ignacio María

López Ortiz, José

López Rey Arrojo, Manuel

López Sánchez, Pedro*

López Vigo, Vicente

Luna García, Antonio *

Luño Peña, Enrique

Madruga Jiménez, Esteban

Maldonado Fernández del Torco, José

Manjón Manjón, Andrés

Mantilla Ortiz, César

Manzano Manzano, Juan

Maranges Diago, José María Rafael

Marcos Pelayo, Francisco 
María Herrero, Celestino

Martí Jara, Enrique

Martín Martínez, Isidoro

Martínez Pedroso, Manuel

Martínez-Moya Crespo, Salvador

Medina Echavarría, José Ramón

Mellado Leguez, Fernando (tercer puesto)

Mendizábal Martín, Luis

Mendizábal Villalba, Alfredo

Mendoza Castaño, Vicente de

Mérida Pérez, Jesús

Mesa Moles, Antonio*

Miaja de la Muela, Adolfo

Michelena García de Paredes, Leopoldo de

Miguel Romero, Mauro

Miguel Traviesas, Manuel

Millet Alhambra, José María

Minguijón Adrián, Juan Salvador

Miralles Salabert, Luis

Misol Martín, Arsenio

Moneva Pujol, Juan

Montejo Rica, Tomás

Montero Gutiérrez, Eloy

Montero Ríos, Eugenio

Morales Alonso, Juan Pedro

Moreno Nieto, José

Moret Prendergast, Segismundo

Moris Fernández-Vallín, Adolfo

Mur Sancho, Ricardo

Núñez Forcelledo, Benito

Olariaga Pujana, Luis

Orodea Ibarra, Eduardo

Ossorio Morales, Juan

Otero Carracedo, José

Ots Capdequí, José María

Otto Escudero, Nicolás Santos de

Pedret Casado, Paulino 
Pelsmaeker Ibañez, Francisco

Peña Entrala, Pablo de

Pereda Ugarte, Gregorio de

Pérez Alonso, Miguel

Pérez Blesa, Ramón

Pérez Botija, Eugenio

Pérez Bueno, Fernando

Pérez González, Blas

Pérez Serrano, Nicolás

Pérez Vitoria, Octavio

Pi Suñer, José María

Piernas Hurtado, José Manuel* (no nombrado en una de las provisiones)

Pina Milán, Rafael de

Polo Díez, Antonio

Pou de Foxá, José

Prada Fernández, Lorenzo de*

Prados Arrarte, Jesús

Prieto Castro, Leonardo

Puigdollers Oliver, Mariano

Quero Molares, José

Ramos Sobrino, Blas

Recasens Siches, Luis*

Requejo Alonso, Prudencio

Reverte Moreno, Antonio

Riaza Martínez-Ossorio, Román

Rico Valarino, Ángel

Ríos Urruti, Fernando de los (o del Río)

Ripollés Baranda, Mariano

Roces Suárez, Wenceslao

Rodríguez Aniceto, Nicolás

Rodríguez de Cepeda, Rafael

Rodríguez Mata, Enrique

Rodríguez Muñoz, Arturo

Rodríguez Rodríguez, Joaquín

Romero Vieitez, Manuel Antonio

Ros Eusebio Díaz, Joaquín

Royo Fernández-Cavada, Segismundo 
Royo Villanova, Antonio (segundo puesto)

Rubio Sacristán, José Antonio

Rueda Neira, Ramón Ramiro

Ruiz del Castillo, Carlos

Ruiz-Funes García, Mariano

Sacristán Colás, Antonio

Sala Bonán, Juan (fallecido ante de ser nombrado)

Saldaña García, Quintiliano*

Salom Antequera, Salvador

Samsó Rivera, José

Sánchez Agesta, Luis

Sánchez de Castro, Manuel

Sánchez Diezma, Jesús

Sánchez Gallego, Laureano

Sánchez Román, Felipe

Sánchez Rubio, Ángel

Sánchez Sánchez, Galo *

Sánchez Sánchez-Tejerina, Isaías

Sánchez Sarto, Manuel

Sánchez-Román Gallifa, Felipe

Sancho Izquierdo, Miguel

Sancho Seral, Martín Luis

Santamaría de Paredes, Vicente

Santiago Portero, Juan

Sanz Cid, Carlos

Segura Soriano, José Manuel

Sela Sampil, Aniceto

Sela Sampil, Luis*

Serrano Branat, Eduardo

Serrano Serrano, Ignacio

Serrano Suárez, José

Silva Melero, Valentín

Soler Pérez, Eduardo

Tarrasa Román, Manuel Bartolomé

Tejero Nieve, Julio

Toledano Hernansaiz, Eustaquio

Tormo Monzó, Elías 
Torres Aguilar, Salvador

Torres Campos, Manuel

Torres López, Manuel

Torres Martínez, Manuel de

Torres Sánchez, Lino

Trías de Bes, José María

Ureña Smenjaud, Rafael

Valenzuela Soler, José

Valle Pascual, Luis del

Valverde Valverde, Calixto

Ventura Payás, José María

Vicente Gella, Agustín

Vida Vilches, Jerónimo

Villanueva Gómez, Justo

Viñas Mey, José

Viñuales Pardo, Agustín

Xiráu Palou, José

Yanguas Messía, José María de*

Zumalacárregui Prat, José María

${ }^{*}$ Con asterisco los propuestos en dos oposiciones 



\section{ÍNDICE DE CÁTEDRAS}

Ampliación del Derecho civil y Códigos españoles

Derecho administrativo

Derecho canónico

Derecho civil

Derecho civil español, común y foral

Derecho internacional privado

Derecho internacional público

Derecho internacional público y privado

Derecho mercantil

Derecho mercantil de España y de las principales nacionales de Europa y América

Derecho mercantil y penal

Derecho municipal comparado

Derecho natural

Derecho penal

Derecho político

Derecho político de los principales Estados y Derecho mercantil y Legislación de aduanas de los pueblos con los que España tiene más frecuentes relaciones comerciales

Derecho político español comparado con el extranjero

Derecho político y administrativo

Derecho procesal

Derecho procesal civil, penal, canónico y administrativo, y Teoría y práctica de redacción de Instrumentos públicos

Derecho romano

Disciplina general de la Iglesia y particular de España

Economía política

Economía política y Estadística

Economía política y Estadística y Hacienda pública

Economía política y elementos de Hacienda pública

Economía política y Hacienda pública

Elementos de Derecho mercantil y penal

Elementos de Derecho natural

Elementos de Derecho político y administrativo español

Elementos de Economía política y Estadística 
Estudios superiores de Ciencia política y Derecho político

Estudios superiores de Derecho penal y Antropología criminal

Estudios superiores de Derecho privado

Filosofía del Derecho

Filosofía del Derecho y Derecho internacional (doctorado)

Historia general del Derecho español

Historia y elementos de Derecho civil español, común y foral

Historia y elementos de Derecho romano

Historia y examen crítico de los principales tratados de España con otras potencias

Instituciones de Derecho canónico

Instituciones de Derecho romano

Instituciones de Hacienda pública de España

Introducción al estudio del Derecho, Principios de Derecho natural, Historia y elementos del Derecho romano

Legislación comparada

Nociones de Derecho civil, mercantil y penal de España (Escuela del Notariado de Valladolid)

Política social y Legislación comparada del trabajo

Procedimientos judiciales, práctica forense y redacción de instrumentos públicos

Procedimientos judiciales y práctica forense

Teoría y práctica de redacción de instrumentos públicos y actuaciones judiciales

Redacción de instrumentos públicos y actuaciones judiciales (Escuela del Notariado de Madrid).

Teoría y práctica de los procedimientos judiciales y práctica forense 


\section{PROGRAMA HISTORIA DE LAS UNIVERSIDADES \\ PUBLICACIONES \\ ISSN: $1886-0710$}

1. Estado de la Universidad de Alcalá (1805), estudio preliminar de José Luis Peset, edición de Diego Navarro, Madrid 1999, 120 pp.

http://hdl.handle.net/10016/7875

2. La investigación en la universidad, edición de Carmen Merino, Madrid 1999, $217 \mathrm{pp}$.

http://hdl.handle.net/10016/7876

3. Aurora Rivière Gómez, Orientalismo y nacionalismo español. Estudios árabes y hebreos en la Universidad de Madrid (1843-1868), Madrid 2000, 143 pp.

http://hdl.handle.net/10016/7905

4. Manuel Martínez Neira, El estudio del derecho. Libros de texto y planes de estudio en la universidad contemporánea, Madrid 2001,318 pp.

http://hdl.handle.net/10016/7877

5. Daniel Comas Caraballo, Autonomía y reformas en la Universidad de Valencia (1900-1922), Madrid 2001, 334 pp.

http://hdl.handle.net/10016/7878

6. Carolina Rodríguez López, La Universidad de Madrid en el primer franquismo: ruptura y continuidad (1939-1951), Madrid 2002, 490 pp.

http://hdl.handle.net/10016/7879

7. Ramon Aznar i Garcia, Cánones y leyes en la universidad de Alcalá durante el reinado de Carlos III, Madrid 2002, 349 pp.

http://hdl.handle.net/10016/7880

8. Enrique Villalba Pérez, Consecuencias educativas de la expulsión de los jesuitas de América, Madrid 2003, 246 pp.

http://hdl.handle.net/10016/7881

9. Archivos universitarios e historia de las universidades, edición de José Ramón

Cruz Mundet, Madrid 2003, 345 pp.

http://hdl.handle.net/10016/7882

10. La enseñanza del derecho en el siglo XX. Homenaje a Mariano Peset, edición de Adela Mora Cañada, Madrid 2004, 578 pp.

http://hdl.handle.net/10016/7883 
11. Manuel Martínez Neira / José M. ${ }^{a}$ Puyol Montero / Carolina Rodríguez López, La universidad española 1889-1939. Repertorio de legislación, Madrid 2004, 389 pp. http://hdl.handle.net/10016/7884

12. Hacia un modelo universitario: la Universidad Carlos III de Madrid, edición de Adela Mora Cañada y Carolina Rodríguez López, Madrid 2004, 365 pp. http://hdl.handle.net/10016/7885

13. Manuales y textos de enseñanza en la universidad liberal, edición de Manuel Ángel Bermejo Castrillo, Madrid 2004, 750 pp.

http://hdl.handle.net/10016/7886

14. Susana Guijarro González, Maestros, escuelas y libros. El universo cultural de las catedrales en la Castilla medieval, Madrid 2004, CD + 349 pp.

http://hdl.handle.net/10016/7887

15. Filosofía para la universidad, filosofía contra la universidad, edición de Faustino Oncina Coves, Madrid 2008, 360 pp.

http://hdl.handle.net/10016/3506

16. Manuel Martínez Neira / José María Puyol Montero, El doctorado en derecho. 1930-1956, Madrid 2008, 340 pp.

http://hdl.handle.net/10016/3386

17. Germán Perales Birlanga, El estudiante liberal. Sociología y vida de la comunidad escolar universitaria de Valencia. 1875-1939, Madrid 2009, 326 pp.

http://hdl.handle.net/10016/4376

18. Alfons Aragoneses, Un jurista del Modernismo. Raymond Saleilles y los orígenes del derecho comparado, Madrid 2009, 259 pp.

http://hdl.handle.net/10016/5778

19. Antonio López Vega, Biobibliografía de Gregorio Marañón, Madrid 2009, 187 pp. http://hdl.handle.net/10016/6178

20. Pio Caroni, La soledad del historiador del derecho. Apuntes sobre la conveniencia de una disciplina diferente, Madrid 2010, 225 pp.

http://hdl.handle.net/10016/6560

21. Francisco Crosas López, De enanos y gigantes. Tradición clásica en la cultura medieval hispánica, Madrid 2010, 169 pp.

http://hdl.handle.net/10016/8346

22. Manuel Martínez Neira / Natividad Araque Hontangas, El marqués de Morante y la Universidad de Madrid, Madrid 2011, 277 pp.

http://hdl.handle.net/10016/10578 
23. Antonio Planas Rosselló / Rafael Ramis Barceló, La facultad de leyes y cánones de la Universidad Luliana y Literaria de Mallorca, Madrid 2011, 186 pp. http://hdl.handle.net/10016/11325

24. Francisco Ayala / Eduardo L. Llorens / Nicolás Pérez Serrano, El derecho político de la Segunda República, estudio preliminar, edición y notas de Sebastián Martín, Madrid 2011, CLXXXIX + 396 pp.

http://hdl.handle.net/10016/11365

25. Pablo Campos Calvo-Sotelo, La evolución histórica del espacio físico de la universidad. Impulsos conceptuales, paradigmas arquitectónicos, estrategias institucionales y propuestas recientes de innovación, Madrid 2011, 236 pp.

http://hdl.handle.net/10016/12017

26. Andry Matilla Correa, Los primeros pasos de la ciencia del Derecho Administrativo en Cuba. José María Morilla y el Breve tratado de Derecho Administrativo (1847), Madrid 2011, 329 pp.

http://hdl.handle.net/10016/12033

27. José María Puyol Montero, La autonomía universitaria en Madrid (1919-1922), Madrid 2011, 545 pp.

http://hdl.handle.net/10016/12289

28. Manuel Cachón Cadenas, Historias de procesalistas, universidades y una guerra civil (1900-1950), Madrid 2012, 681 pp.

http://hdl.handle.net/10016/14588

29. María Paz Alonso Romero, Salamanca, escuela de juristas. Estudios sobre la enseñanza del derecho en el Antiguo Régimen, Madrid 2012, 722 pp.

http://hdl.handle.net/10016/15129

30. Carlos Nieto Sánchez, San Clemente de Bolonia (1788-1889): el fin del Antiguo Régimen en el último colegio mayor español, Madrid 2012, 480 pp.

http://hdl.handle.net/10016/15708

31. Natividad Araque Hontangas, Manuel José Quintana y la Instrucción pública, prólogo de Jean-Louis Guereña, Madrid 2013, 427 pp.

http://hdl.handle.net/10016/17196

32. La Universidad Central durante la Segunda República: Las Ciencias Humanas y Sociales y la vida universitaria, edición de Eduardo González Calleja y Álvaro Ribagorda, Madrid 2013, 376 pp.

http://hdl.handle.net/10016/17394

33. Manuel Martínez Neira, La creación del cuerpo de catedráticos de universidad (1812-1857). Estudio histórico-jurídico, Madrid 2013, 358 pp.

http://hdl.handle.net/10016/18077 
34. Luis Enrique Otero Carvajal (dir.), La Universidad nacionalcatólica. La reacción antimoderna, Madrid 2014, 1098 pp.

http://hdl.handle.net/10016/18911

35. Manuel Martínez Neira, La regulación de las oposiciones a cátedras universitarias: $1845-1931$, Madrid 2014, $146 \mathrm{pp}$.

http://hdl.handle.net/10016/19338

36. Aulas modernas. Nuevas perspectivas sobre las reformas de la enseñanza secundaria en la época de la JAE (1907-1939), edición de Leoncio López-Ocón, Madrid 2014, $364 \mathrm{pp}$.

http://hdl.handle.net/10016/19883

37. María Ángeles Longás Lacasa, Historia de la Biblioteca de la Universidad de Mallorca (1767-1829), Madrid 2015, 437 pp.

http://hdl.handle.net/10016/21552

38. Fernando Liendo Tagle, Pablo de Olavide y la nueva planta de los estudios, Madrid 2016, 176 pp.

http://hdl.handle.net/10016/23895

39. Rafael Ramis Barceló, Doctores hispanos en leyes y cánones por la Universidad de La Sapienza de Roma (1549-1774), Madrid 2017, 274 pp.

http://hdl.handle.net/10016/24015

40. Julián Gómez de Maya, De Al-Ricotí al rector Sabater: estudios históricos sobre la Universidad de Murcia y sus antecedentes, Madrid 2017, 388 pp.

http://hdl.handle.net/10016/24848

41. Luigiaurelio Pomante, A Great Research Lab on University History and Higher Education in Spain: Instituto Antonio de Nebrija de Estudios sobre la Universidad (1997-2009), Madrid 2017, 253 pp.

http://hdl.handle.net/10016/25309

42. Pablo Campos Calvo-Sotelo / Laura Luceño Casals, Las formas de la educación. Vínculos entre dimensión docente y dimensión arquitectónica en disciplinas creativas, como expresión de innovación universitaria, Madrid 2018, 169 pp.

http://hdl.handle.net/10016/26594

43. Rafael Ramis Barceló / Pedro Ramis Serra, Los primeros grados de la Universidad de Baeza (1549-1580), Madrid 2018, 234 pp.

http://hdl.handle.net/10016/27079

44. Víctor Guijarro Mora, Artefactos y acción educativa. La cultura del objeto científico en la enseñanza secundaria en España (1845-1930), Madrid 2018, 273 pp.

http://hdl.handle.net/10016/27200 
45. Javier Carlos Díaz Rico (ed.), Oposiciones a cátedras de derecho (1847-1943), Madrid 2018, 486 pp.

http://hdl.handle.net/10016/27454 